\title{
Breech presentation vaginal or abdominal delivery? : a prospective longitudinal study
}

Citation for published version (APA):

de Leeuw, J. P. (1989). Breech presentation vaginal or abdominal delivery? : a prospective longitudinal study. [Doctoral Thesis, Maastricht University]. Groeneveldt. https://doi.org/10.26481/dis.19890407jl

Document status and date:

Published: 01/01/1989

DOI:

10.26481/dis.19890407jl

Document Version:

Publisher's PDF, also known as Version of record

\section{Please check the document version of this publication:}

- A submitted manuscript is the version of the article upon submission and before peer-review. There can be important differences between the submitted version and the official published version of record.

People interested in the research are advised to contact the author for the final version of the publication, or visit the DOI to the publisher's website.

- The final author version and the galley proof are versions of the publication after peer review.

- The final published version features the final layout of the paper including the volume, issue and page numbers.

Link to publication

\footnotetext{
General rights rights.

- You may freely distribute the URL identifying the publication in the public portal. please follow below link for the End User Agreement:

www.umlib.nl/taverne-license

Take down policy

If you believe that this document breaches copyright please contact us at:

repository@maastrichtuniversity.nl

providing details and we will investigate your claim.
}

Copyright and moral rights for the publications made accessible in the public portal are retained by the authors and/or other copyright owners and it is a condition of accessing publications that users recognise and abide by the legal requirements associated with these

- Users may download and print one copy of any publication from the public portal for the purpose of private study or research.

- You may not further distribute the material or use it for any profit-making activity or commercial gain

If the publication is distributed under the terms of Article $25 \mathrm{fa}$ of the Dutch Copyright Act, indicated by the "Taverne" license above, 
BREECH PRESENTATION

VAGINAL OR ABDOMINAL DELIVERY ?

a prospective longitudinal study 
Cover illustration reproduced from Eucharius Roesslin

'Den Roseghaert' van den bevruchten vrouwen, 1516

CIP-DATA Koninklijke Bibliotheek, Den Haag

Leeuw Johannes Philippus de

Breech presentation vaginal or abdominal delivery? : a prospective longitudinal study / Johannes Philippus de Leeuw. - [S.I. : s.n.] (Landgraaf : Groenevelt) Proefschrift Maastricht. - Met lit. opg.

ISBN 90-9002722-X

SISO 605.5 UDC $618.4(043.3)$

Trefw.: stuitbevallingen / verloskunde.

Publication of this thesis was made possible by the Concerted Action Project no. I.1.1 of Third Programme in the Field of Medical and Public Health of the EEC, de Stichting het Scholten-Cordes Fonds and het Researchfonds Bronovo.

The Belgian part of the study was aided by grant no: 3.0077 .85 of the Fund for Medical Scientific Research. 


\title{
Breech Presentation Vaginal or Abdominal Delivery? \\ a prospective longitudinal study
}

\author{
Proefschrift
}

ter verkrijging van de graad van doctor aan de Rijksuniversiteit Limburg te Maastricht, op gezag van de Rector Magnificus, Prof. Dr F.I.M. Bonke, volgens het besluit van het College van Dekanen, in het openbaar te verdedigen op vrijdag, 7 april 1989 om 14.00 uur

door

Johannes Philippus de Leeuw

geboren te Amsterdam in 1951 
Promotores:

Co-promotores:

Beoordelingsconmissie: Prof. Dr C.E. Blanco (voorzitter)

Dr P. Buekens, Université Libre de Bruxelles (België)

Prof. Dr T.K.A.B. Eskes, Katholieke Universiteit

Nijmegen

Prof. Dr J.M.A. van Engelshoven

Dr N.P. Patel, Ninewells Hospital, The University Dundee (Scotland) 
Ter nagedachtenis aan Prof. Dr J.J. Veltkamp Aan mijn vader mijn moeder

Voor Catherine en Sarah 
[The] test of a capable obstetrician [...] is the manner in which a psysician evaluates as well as conducts a breech labor' (O'Leary, 1979), 


\section{Contents}

Voorwoord

Abbreviations

\section{CHAPTER 1}

General introduction 15

$\begin{array}{ll}1.1 \text { Introduction } & 15\end{array}$

$\begin{array}{ll}1.2 & \text { Aims of the study } \\ 1.3 & 16\end{array}$

$\begin{array}{lll}1.3 & \text { Other studies } & 17\end{array}$

CHAPTER 2

Review of the literature

2.1 Increasing incidence of cesarean section in breech presentation 19

$\begin{array}{lll}2.2 & \text { Term breech } & 21\end{array}$

1 Mortality and morbidity 21

2 Follow-up $\quad 23$

2.3 Preterm breech 26

1 Mortality and morbidity 26

2 Follow-up $\quad 30$

2.4 Indications for cesarean section in breech presentation 31

1 Parity 31

2 Type of breech 32

3 Hyperextension of the fetal head 33

$4 X$-ray pelvimetry 33

$\begin{array}{lll}2.5 & \text { Birth trauma in breech delivery } & 34\end{array}$

\section{CHAPTER 3}

Patients and methods

$\begin{array}{lll}3.1 & \text { Patients } & 37\end{array}$

$\begin{array}{lll}3.2 & \text { Collection of perinatal data } & 38\end{array}$

$\begin{array}{ll}3.3 \text { Obstetrical management } & 38\end{array}$

$\begin{array}{lll}3.4 & \text { Definitions } & 39\end{array}$

1 Maternal data 39

2 Pregnancy data $\quad 39$

3 Delivery data 41

4 Newborn data 44

5 Puerperal data 48 
6. Data analysis $\quad 49$

7 Statistical methods $\quad 50$

3.5 Study population Gent-Maastricht $\quad 50$

1 Maternal characteristics of the study population 51

2. Characteristics of neonates presenting in breech at birth 52

3 Prenatal care $\quad 53$

4 Course of pregnancies 54

5 Management of labor 55

6 Mode of delivery $\quad 56$

3.6 Study population: differences between vaginally and abdominally delivered patients $\quad 58$

1 Maternal characteristics of the study population $\quad 58$

2. Characteristics of neonates presenting in breech at birth 59

3 Prenatal care $\quad 60$

4 Course of pregnancies 61

5 Management of labor 63

6 Mode of delivery 64

\section{CHAPTER 4}

Results

4.1 Neonatal condition $\quad 67$

1 Apgar scores $\quad 67$

2 Umbilical cord blood gas analysis 68

3 Ventilation after birth, correction of the acid base balance with sodium bicarbonate and transfer to the neonatal unit 71

4 Congenital malformations, birth trauma, seizures neonatal infections, sepsis, RDS and duration of hospital stay

$\begin{array}{ll}5 \text { Intracranial hemorrhage } & 76\end{array}$

6 Mortality $\quad 78$

4.2 Maternal morbidity and mortality $\quad 85$

\section{CHAPTER 5}

Factors studied in relation to neonatal outcome

5.1 Neonatal outcome analyzed by parity and breech type 89

5.2 Use of oxytocine during labor and its influence on the neonatal outcome 


\section{CHAPTER 6}

Complicating factors during delivery and neonatal outcome

6.1 Birth weight and mode of delivery in the weight category of $2500 \mathrm{~g}$ or more

6.2 BPD and the mode of delivery

6.3 Cord prolapse

6.4 Hyperextension of the fetal head

6.5 Umbilicus-to-delivery time

6.6 Duration of the second stage of labor

CHAPTER 7

Results of neurological examinations after birth

CHAPTER 8

Follow-up

\section{CHAPTER 9}

Breech deliveries and CTG patterns.

9.1 Introduction

9.2 Material and Methods

9.3 Results

9.4 Conclusions

CHAPTER 10

Discussion

Summary

Samenvatting

References

Addenda

Curriculum vitae 



\section{Voorwoord}

Dit proefschrift kwam tot stand in nauwe samenwerking tussen de Universiteit van Gent en de Universiteit van Maastricht.

Van allen die hebben bijgedragen aan de voltooiing van dit onderzoek wil ik allereerst Prof. dr J. de Haan bedanken. Hij gaf mij een gedegen opleiding tot vrouwenarts en maakte al in een vroeg stadium duidelijk, dat promoveren bij een universitaire opleiding vanzelfsprekend was. Voor zijn bemoeienissen met mijn proefschrift ben ik hem zeer erkentelijk.

Dr J. Stoot wil ik danken voor de operatieve vaardigheden, die hij mij tijdens mijn opleidingsjaar in Heerlen heeft bijgebracht.

Prof. Dr G.G.M. Essed, beste Gerard, van jou heb ik niet alleen de verloskunde geleerd, maar ook de verloskunst. Jouw kennis en ervaring hebben mijn proefschrift verrijkt.

Dr H. Hoogland, beste Henk, zonder jouw spontane hulp was ik niet ver gekomen. Het was een bijzondere eer om van gedachten te kunnen wisselen met Prof. M. Thiery en Prof. R. Derom over de vele boeiende aspecten van de verloskunde. Vooral op internationale congressen waren zij een geweldige steun en hebben zij mij ook in deze wereld de weg gewezen.

De nauwgezette beoordeling van het manuscript door de beoordelingscommissie bestaande uit Prof. Dr C.E. Blanco, Dr P. Buekens, Prof. Dr T.K.A.B. Eskes, prof. Dr J.M.A. van Engelshoven en Dr N.P. Patel heeft geleid tot een inhoudelijke verbetering.

Guy Martens en Georges van Maele hebben respectievelijk als informaticus en statisticus vele problemen opgelost, vol energie en altijd met een goed humeur. $\mathrm{Er}$ is een prima basis gelegd voor verder onderzoek in de toekomst.

Een goede samenwerking met de afdeling kindergeneeskunde was essentieel. Dr J.W. Gerver was voor mij als een rots in de branding.

Dr J.S.H. Vles vond ondanks zijn eigen promotieperikelen toch nog tijd voor het neurologisch onderzoek en deskundig advies.

Dankzij Resy van Bilsen-Ubachs konden de vele gegevens betreffende alle pasgeborenen zo nauwkeurig en compleet mogelijk verzameld worden.

Door de inspanningen van Dr P. Vanhaesebrouck en Mw A. Verheylezoon in Gent en de polikliniek-assistentes van de afdeling kindergeneeskunde in Maastricht was een optimale opkomst bij het follow-up onderzoek mogelijk.

Dr M. Afschrift, Drs B.R.J. Walstra en Dr R.O. de Jong waren behulpzaam bij het interpreteren van de echografiën van de schedel.

De afdeling medische fotografie van het Academisch ziekenhuis in Maastricht verzorgde de foto's. 
Jan Klerkx corrigeerde de engelse tekst.

Marcel Aldenhuizen loste de conversieproblemen met de Apple computer op.

De inventarisatie van alle CTG's nam Mirjam van Rozendaal geheel voor haar rekening, waarmee ze hopenlijk een belangrijke stap heeft gezet op weg naar een verloskundige carrière.

Manon Gordijn en Nathalie Deforche waren als secretaressen altijd even behulpzaam.

De zeer prettige verstandhouding tussen assistenten in opleiding onderling en hun begrip voor mijn situatie hebben veel bijgedragen tot de uiteindelijk toch snelle afronding van dit proefschrift.

De goede en prettige sfeer binnen de gynaecologenmaatschap in Dordrecht maakte het mogelijk dat er ondanks de drukte van de praktijk ruimte en tijd was om de laatste zaken rond de promotie af te werken.

Tenlotte wil ik ook de ouders van de kinderen, die bij dit onderzoek betrokken waren, danken voor hun medewerking.

Last but not least mijn lieve Catherine en Sarah; zij kennen mij alleen als man en vader, die maar aan één ding denkt: Promoveren. Ik ben mij ervan bewust, dat ik veel heb in te halen. Het geweldige medeleven en de steun van onze ouders zal ik niet gauw vergeten.

Ik ben $U$ allen zeer erkentlijk. 


\section{Abbreviations}

\begin{tabular}{|c|c|}
\hline $\mathrm{BPD}$ & $=$ Biparietal diameter \\
\hline $\mathrm{CS}$ & $=$ cesarean section \\
\hline CPAP & $=$ continuous positive airway pressure \\
\hline CTG & $=$ cardiotocography \\
\hline FHR & $=$ fetal heart rate \\
\hline FIGO & = Fédération Internationale de Gynécologie et d'obstétrie \\
\hline $\mathrm{ICH}$ & = intracranial hemorrhage \\
\hline IUGR & $=$ intra uterine grow retardation \\
\hline HELPP & $=$ Hemolysis Elevated Liver function tests Low Platelet counts \\
\hline LBW & $=$ low birth weight \\
\hline NS & $=$ not significant \\
\hline PROM & $=$ premature rupture of membranes \\
\hline RDS & $=$ respiratory distress syndrome \\
\hline $\mathrm{SD}$ & $=$ standard deviation \\
\hline SID & $=$ sudden infant death \\
\hline VD & $=$ vaginal delivery \\
\hline VLBW & $=$ very low birth weight \\
\hline WHO & $=$ World Health organisation \\
\hline
\end{tabular}





\section{Chapter 1}

\section{General introduction}

\subsection{Introduction}

Management of the breech presentation has remained a controversial subject in contemporary obstetrics and the proper handling of the breech-presenting baby is one of the most hotly contested areas in obstetric management (Perkins, 1987; Flanagan et al., 1987; Myers and Gleicher, 1987; Döring and de Sousa Gerbert, 1988). Vaginal delivery for fetuses in breech presentation is supposed to be associated with considerably higher rates of perinatal mortality and morbidity when compared to cephallic presentation, even when prematurity and congenital anomalies are excluded (Fisher-Rasmussen and Trolle, 1967; Rovinsky et al., 1973; NIH Publication, 1981; Seeds and Cefalo, 1982). This is supposed to be due to an increased risk of birth trauma and/or hypoxaemia during labor with either overt cord prolapse or occult umbilical cord compression (Warenski, 1980).

It is generally assumed that these risks are increased and of a different nature in preterm compared to term breech deliveries.

Moreover, differences in outcome are suggested between frank and non-frank breech presentation, between vaginal breech deliveries in primiparous and multiparous women and between fetuses presenting in breech presentation with or without a hyperextended head.

Vaginal delivery of breech presentation remained the preferred way of delivery until the late 1950's. At that time, cesarean section began to be recommended on a routine basis to minimize perinatal morbidity and mortality (Wright, 1959). Recently, a number of obstetricians have recommended that all children in breech presentation be delivered by cesarean section (Kubli et all, 1976; Smale et al., 1976) or advised wide indications for elective cesarean section in breech presentation for the same reasons. As a result of these recommendations, there was a substantial increase in the rate of cesarean section in breech presentation all over Europe and the United States. This increase was probably also caused partly by the introduction of $\mathrm{X}$-ray pelwimetry especially in case of breech presentation (Collea et al., 1978 and 1980), as well as by the application of electronic fetal monitoring in obstetrics. Although the increase in cesarean section frequency in breech presentation was intended to decrease the perinatal and maternal mortality and morbidity, in the last decade it became doubtful to what extent the effects aimed at were being realised by such management.

Follow-up by means of neurological and general examination of breech born neonates suggested that late morbidity was probably more influenced by general 
obstetrical and neonatal factors than the mode of delivery itself (Faber-Nijholt, 1981; Faber-Nijholt et al., 1983)

In addition, a remarkable variance was found to exist in the incidence of cesarean sections in breech presentations between countries and between centers.

\subsection{Aims of the study}

Concerm about the rising cesarean section frequency in general and in breech presentation especially, as well as doubt concerning the improvement in neonatal and maternal morbidity and mortality by increasing the cesarean section rate in breeches led to this study. Moreover, this concern was underlined by the fact that the cesarean section frequency in breeches varies strongly between institutes as well as between countries with comparable obstetrical populations and obstetrical results. Although the increase in cesarean section frequency in breech presentation was intended to decrease the perinatal and maternal mortality and morbidity, these goals in general do not seem to be achieved. Therefore a number of questions were formulated:

- Does the increase of the cesarean section frequency in breech presentation have a positive or a negative effect on the neonatal and maternal mortality and morbidity ?

- Which factors play a role in the decision to deliver a breech vaginally or by cesarean section ? In order to answer this question, parity, type of breech, prematurity as well as hyperextension of the head were examined in more detail in relation to neonatal and maternal mortality and morbidity.

- Which fetal heart rate patterns can be found during the late dilatation period and the second stage, and to what extent do these phenomena determine in the route of delivery in breech presentation?

- Is there a difference in neonatal and maternal mortality and short and long term morbidity between the vaginally and abdominally delivered neonates, if the basic management procedure of a breech presentation is regarded as not different from a vertex presentation?

To investigate these questions a prospective longitudinal descriptive study was started regarding the management of breech presentation in two University hospitals: the Department of Obstetrics and Gynecology at the University of Gent (Belgium) and the Department of Obstetrics and Gynecology of the University of Limburg, Maastricht (The Netherlands).

The cooperation between these two departments was initiated in order to increase the number of cases in the different birth weight categories. 


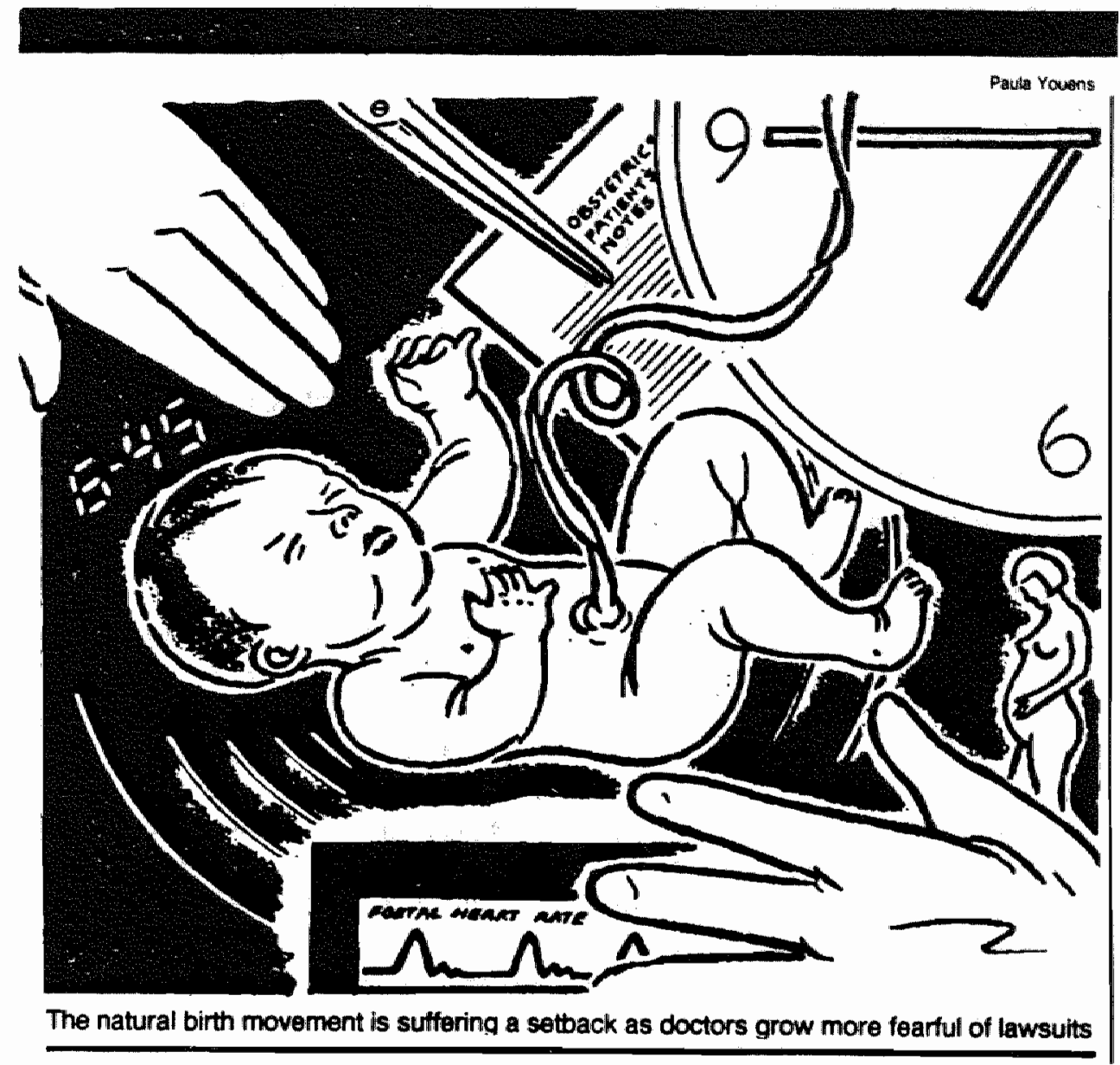

\subsection{Other studies}

There have been quite a number of studies about the management of the term and preterm breech, as shown in the following chapters. However the vast majority of the studies are retrospective, without a prospectively written protocol, and have dealt solely with perinatal mortality and Apgar scores, excluding other information such as umbilical artery $\mathrm{pH}$, neonatal, physical and neurological examination, early neonatal injuries, long term neurological follow-up and maternal morbidity (Lewis and Seneviratne, 1979).

Other studies did not compare different types of management at the same time in the same institution, but merely report how changes in practice affected breech outcome in different periods of time (Ingemarsson et al., 1978; Green et al., 1982; Svenningsen et al., 1985; Stephenson, 1986; Doering and de Sousa Gerbert, 1988). 
Therefore it is frequently not possible to analyse reliably the conditions regarding the determining factors for the route of delivery and/or the indications for cesarean section.

Also, the reasons for admission and exclusion of cases from the studies often heavily influence the final results.

In the preterm group, particularly the group with a birth weight less than $1500 \mathrm{~g}$, the number of infants is small, and the numbers in the groups with which they are compared are also often different. Infants with a birth weight lower than $1000 \mathrm{~g}$ are not included in some studies (Karp et al., 1979; DeCrespigny and Pepperell, 1979), whereas in other studies the lower limit is 2000 or 2500 grams. This makes comparison of the data difficult or even impossible. Some of the studies deal only with neonatal data from intensive care units, instead of studying the data of all patients in the group, including those which have not been transported to the neonatal intensive care unit (Cox et al., 1982; Main et al., 1983; Yu et al., 1984). Compared with an obstetric population, intrapartum death is often not included in studies which deal only with neonatal intensive care unit clients (Westgren and Paul, 1985).

Nonrandomized retrospective studies of perinatal mortality and morbidity may be misleading for three reasons (Newton et al., 1986):

- The misperception of viability will worsen vaginal delivery statistics;

- The combination of perinatal complications may seriously bias center-based mortality studies;

- The effect of the method of delivery on morbidity has been incompletely studied. No randomized prospective data have been published regarding delivery of the preterm breech. According to some authors there still seems to be a need for a prospective randomized collaborative study. These authors believe it would be ethically justified to perform such a study (Westgren et al., 1985; Terry and Lloyd, 1986; Grant, 1986; Treffers, 1987). 


\section{Chapter 2}

\section{Review of the literature}

\subsection{Increasing incidence of cesarean section in breech presentation}

A number of reasons have been proposed for the recent rapid increase in the general cesarean section rate. The main part of this increase in cesarean sections is attributed to failure in progress of labor, previous cesarean section, fetal distress and last but no least the breech presentation (Philipson and Rosen, 1985).

In addition there are some countries, like the USA, with a legally minded society, where legall factors play an important role. The risk of litigation if vaginal delivery is allowed, even without any predicted or actual complication, is of particular relevance. The persistently higher rates of cesarean sections among private as compared to public health insured patients is also a factor of importance (Porreco et al., 1985; Ahram, 1985). Financial as well as emotional factors may play a role in this situation.

Also, the woman may ask for a cesarean section, which is not medically indicated. A laboring woman has the obvious right to give or withhold consent, but she also has the right to expect that her obstetrician will not exploit her natural fears, concerns, and discomfort in order to perform an operation for which there is no good medical indication, when the mother and baby will do best if labor is allowed to continue (Hall, 1987).

In the USA, the proportion of breech presentations delivered by cesarean section rose from $11.6 \%$ in 1970 to $60.1 \%$ in 1978, accounting for about 10 to $15 \%$ of the rise in cesarean section rate in the USA over those years (NIH publication, 1981). Further support for a high section rate is given in the authoritative textbook William's Obstetrics, where the editors Pritchard and Mac Donald (1980) record that in their own unit in Dallas the abdominal delivery rate for breech presentation is $75 \%$. In many institutions in North America the relatively recent policy of performing cesarean section in all term breeches accounts for approximately $40 \%$ of the increase in cesarean section rate over the last 10 years. For example, in the Royal Victoria hospital in Montreal there was a dramatic rise in the cesarean section rate for breech presentation from 22\% in the decade 1963-1973 to $94 \%$ in 1978 and 1979 (Green et al.,1982). According to these authors, this rate approached $100 \%$ in 1982. All hospitals which are members of the Commission on Professional and Hospital Activities in the United States showed a sharp increase in the proportion of cesarean sections performed because of breech presentation, from $11.6 \%$ in 1970 to $79.8 \%$ in 1984. (Shiono et al., 1987). 
In most of the West-European countries, cesarean delivery rates in breech presentation have also risen steadily over the past decade. In Britain the proportion of cesarean sections performed because of breech presentation has increased about fourfold over the past decade, to about $40 \%$, and in some centres the proportion is much higher (Russell, 1982).

In Scotland the cesarean section rate varies from $35 \%$ to $94 \%$ in various units (Patel, 1987).

In Heidelberg the cesarean section delivery rate for breech presentation increased from $55 \%$ in 1973 to almost $90 \%$ ten years later, and according to the data of the Bavarian perinatal studies, this trend is spreading all over West Germany (Kubli, 1985).

In one of the University clinics in Paris the rate of cesarean section for breech presentation in 1981 reached $87.1 \%$ and $61.5 \%$ for primiparas and multiparas, respectively (Poisson-Salomon et al., 1986).

In The Netherlands, too, there was a general increase in the cesarean section rate in breech presentation from $8 \%$ in 1969 to $14 \%$ in 1976 and to $28 \%$ in 1983 (Meuwissen and Reynders, 1985). In 57.819 computer registered singleton pregnancies in The Netherlands the cesarean section rate was $26.5 \%$ in the breech group, compared to $6.8 \% 0$ in the vertex group. The cesarean section rate did not decline with increasing gestational age (Schutte et al., 1985). From the same 5-year nationwide registration (1982-1986) it was noted that the cesarean section rate in all breeches had increased from $27.1 \%$ in 1983 to $30.5 \%$ in 1986 . The cesarean section rate in primiparous women sectioned for breech presentations was $36.5 \%$ (LVR, 1987).

A high degree of inter-hospital variation in the management of breech presentations was reported by Ekker (1979). In 1976 the rate of cesarean section in case of breech presentation varied from 0 to $50 \%$ or more in 133 hospitals in the Netherlands, without differences in perinatal mortality.

The mean frequency of vaginally delivered breeches in the eight Dutch University hospitals was $58.3 \%$ in 1982 and $62.4 \%$ in 1983 . However, the rates in these eight tertiary centers ranged from 39.7 to $83.7 \%$ in 1982 and from 49.0 to $80.4 \%$ in 1983 (de Haan, 1987).

For Belgium no reliable general data about the cesarean section rate for breech presentation are available. In a recent report of cesarean section rates in 19 industrialized countries of Europe, North America and the Pacific, the cesarean section rate for breech presentation was found to vary from $93 \%$ in Sweden to $39 \%$ in Hungary ( Notzon et al., 1987). 


\subsection{Term breech}

\subsubsection{Mortality and morbidity}

A review of the literature reveals several studies comparing vaginally born breech infants with infants in breech presentation born by cesarean section. However, most of the studies reported since 1975 have been retrospective (Bingham and Lilford,1987). Moreover, information about infant morbidity and development in these studies is scanty, and the studies showed inherent study design problems including non-randomized reasons for the choice of birth route.

In a retrospective study of 365 breech presentations weighing more than $2500 \mathrm{~g}$ at birth, Fischer-Rasmussen and Trolle (1967) showed that the mortality in the group exspected to be delivered vaginally was 5.5 times higher than that in the corresponding group in cephalic presentation. Three hundred and nineteen neonates were delivered vaginally, while a cesarean section during labor was performed in 46 neonates. There were 8 deaths in the vaginal group mostly caused by well-known obstetrical complications. There was no death in the elective cesarean section group.

Their conclusion was that the preferred route of delivery in breech presentation was the cesarean section.

In the New York City data (NIH publication, 1981) breech-presenting infants delivered by cesarean section showed a fivefold lower neonatall mortality rate than those delivered vaginally, while there had been no overall decrease in mortality over a 10-year period (1967-1977) for the total group of breech presentations (vaginal and cesarean combined). From this apparent contradiction it becomes clear that there is a shift of the better risk breech birth from the vaginal delivery group to the cesarean birth category.

In a recent retrospective study of Petitti and Golditch (1984), neither intrapartum mortality nor neonatal mortality in term breech infants who survived to labor showed significant differences between breech infants delivered vaginally and those delivered by cesarean section. The cesarean section rate in this study was high( $73 \%$ ) and morbidity in relation to the method of delivery was not examined.

From a retrospective study of 2,145 cases of term singleton breech presentations Rovinsky et al. (1973) concluded that, in retrospect, 24 perinatal deaths were due to asphyxia and trauma at vaginal delivery, while the deaths of 17 infants $(1 \%)$ could possible have been prevented by cesarean birth. Despite this fact, routine elective cesarean section for this indication alone is not yet considered acceptable by these authors. A study by Muth et al. (1976) showed no differences in perinatal mortality, Apgar scores or $\mathrm{pH}$ between the vaginal method of delivery and cesarean section. Hence they concluded that further widening of the indications for cesarean section should not be recommended.

In a retrospective analysis of 213 singleton infants born in breech presentation and weighing more than 2500g, Lyons and Papsin (1978) found a corrected (congenital malformations incompatible with life excluded) perinatal mortality of zero for both 
vaginal and abdominal delivery, although perinatal morbidity including five-minute Apgar score of less than 7, traumatic morbidity and neurological problems were greater for vaginal delivery. From a retrospective study of 507 cases of term breeches, Bilodeau and Marier (1978) concluded that vaginal breech delivery will not be the cause of increased mortality and morbidity after careful surveillance before and during labor. In this study the only case of perinatal death occurred in the cesarean section group because of abruptio placentae associated with prolapse of the cord. However, the neurological condition and further development of the children were however not examined, in this study, as was the case in the most other studies cited.

In a retrospective study of 480 term breeches of all types, DeCrespigny and Pepperell (1979) could find no difference in mortality or morbidity between those delivered vaginally and abdominally. They concluded that "more than $60 \%$ of [term] breech infants can be satisfactorily delivered vaginally, and breech presentation alone is no sufficient indication for elective cesarean section." In a retrospective review of 334 breech deliveries, Mann and Gallant(1979) failed to find a significant improvement in neonatal mortality and morbidity (only Apgar score) rates for those delivered by cesarean section versus vaginal delivery in fetuses weighing more than $2000 \mathrm{~g}$. The cesarean section rate in this study was $37 \%$. In a randomized prospective study of 208 term frank breeches, Collea et al.(1980) demonstrated that 52 out of 115 patients randomized to a vaginal delivery, indeed delivered vaginally. The perinatal mortality was zero in both the vaginal and cesarean group and there was one significant case of fetal morbidity due to a lethal congenital anomaly. In this study, X-ray pelvimetry played an important role in the final decision for the route of delivery. Therefore more than $50 \%$ of the originally planned vaginal deliveries ended in a cesarean section. Moreover, a number of other indications were used as exclusion criteria for certain patients. In a retrospective study, comparing two periods, Green et al.(1982) showed no significant improvement in the rate of birth asphyxia, trauma and perinatal death after an increase in cesarean section rate for term breech deliveries from $22 \%$ to $94 \%$.

Other authors (O'Leary, 1979; Gimovsky et al., 1980; Watson et al., 1984; Barlöv and Larsson, 1986) showed safe vaginal delivery in the majority of patients with breech presentation using a selective management protocol, in wich X-ray pelvimetry and estimated fetal weight usually played an important role.

Gimovsky et al. (1980) were able to deliver $43 \%$ of all term breech presentations vaginally. The only death attributable to breech presentation occurred in a fetus delivered outside the study protocol. Regarding morbidity, there was one transient case of Erb's palsy and four patients with Apgar scores of less than 4 to 6 at 5 minutes.

Using a protocol based on X-ray pelvimetry measurements and estimated fetal weight, a study by Watson et al. (1984) resulted in a cesarean section rate of $36 \%$ in the frank-breech presentation, while the corrected perinatal mortality was 0 . Apgar scores were not significantly different for infants delivered vaginally or 
abdominally and no infant showed any sign of birth trauma.

In a prospective study of 150 term breech deliveries (O'Leary, 1979) 81 women were managed according a protocol in which parity, gestational age, estimated fetal weight, previous breech, some aspects during delivery (Zatuchni-Andros Breech Score, 1965) and X-ray pelvimetry were determinant factors. Sixty nine women qualified for the control group. Two deaths were reported as the result of a breech extraction, as well as 8 cases with low Apgar scores and 4 birth injuries in the control group, compared with no death, one low Apgar score and one birth injury in the study group. The cesarean section rate was $14 / 69(20.2 \%)$ in the control group and $33 / 81(40 \%)$ in the study group.

Barloev and Larsson (1986) performed a prospective study, using the so called Westin's scoring system, mainly based on factors derived from X-ray pelvimetry, with a study group of 226 neonates. No corrected neonatal mortality and a very low frequency $(0.8 \%)$ of persistent morbidity in the cesarean section group was found. However, there was a smaller proportion of Apgar scores $>7$ at one minute in the vaginal group $(70.6 \%)$. After 5 minutes the frequency of low Apgar scores was the same in the vaginal and abdominal group. Immediate traumatic morbidity occurred in $6.9 \%$ of the vaginal deliveries and in $0.8 \%$ of the abdominal deliveries. Immediate abnormal cerebral signs were evident in $2.9 \%$ of vaginal deliveries and in 0.9 $\%$ at cesarean section. However there was no persistent morbidity in the vaginal group. The cesarean section rate in this study was $54.9 \%$.

In a recent retrospective study (Tatum et al., 1985), it was found that vaginal deliv* ery at or near term of selected breech infants over 2000 grams, selected by means of routinely used clinical criteria such as parity, estimated fetal weight, $\mathrm{X}$-ray pelvimetry etc, was not associated with an increased neonatal morbidity and mortality compared with cesarean section.

In a retrospective analysis of breech deliveries of 36 weeks gestation or over, Bingham et al., (1987) found no serious fetal morbidity or mortality in the group with intention to deliver vaginally compared with planned cesarean section. However, vaginal delivery was attempted in only 149 women, and 223 of the 313 patients (71\%) were finally delivered by cesarean section. In this studly Bingham et al. criticized the comparison of cesarean section with vaginal delivery, because this comparison does not account for the primary decision regarding the mode of delivery and does not distinguish between elective and secundary cesarean section.

\subsubsection{Follow-up}

Conflicting data regarding the immediate and long term outcome of children vaginally born at term in breech presentation are found in the literature.

This is partly due to the fact that some authors rely only on Apgar scores, others on the umbilical cord acid-base balance, whether or not combined with Apgar scores, while still others also perform general and neurological examinations directly 
after birth and/or after a varying numbers of years. Moreover most of the available studies are retrospective and do not account for the effect of concomitant variables like the mode of delivery, gestational age or birth weight on direct fetal outcome and late morbidity.

It has been suggested that there is a negative influence on fetal oxygenation in the vaginally managed breech delivery ( Serreyn et al., 1973;Derom, 1978).

Most of the studies which relate direct neonatal condition with the umbilical cord acid-base balance show a lower arterial umbilical $\mathrm{pH}$ in vaginal breech deliveries than in vertex delivery, probably due to the frequency of cord compression in the second stage of labor, as reported by Kubli et al.(1975).

Hill et al.(1976) found a significant drop in fetal $\mathrm{pH}$ taken from foot or buttock during the second stage in breech birth by the time the breech reaches the perineum. Recent studies showed no difference in umbilical cord $\mathrm{pH}$ values between the breech and vertex groups, but showed a lower arterial $\mathrm{pH}$ value in neonates delivered vaginally compared to those delivered by cesarean section (Luterkort and Marsal, 1987; Mecke et al., 1988). However, in these studies the mean umbilical artery $\mathrm{pH}$ values for both groups are within the range which is generally considered as normal in obstetrics. Moreover, it is still unknown which mean umbilical artery $\mathrm{pH}$ has consequences for the for the long term development of the child in the various groups under study.

Various studies have been reported comparing breech-born children with a control group of vertex-born children as regards long term morbidity. Many of these studies have serious shortcomings: they are either retrospective or based on a small number cases, or the follow-up interpretatons are performed only once directly after birth (Manzke 1978).

In a prospective study in which the children were examined psychologically and neurologically at an age of 8 and 12 months, Berendes (1965) found no differences between breech-born children with a birth weight over 2500 grams and vertex-born children in the same weight category.

Sadowski and Staemmler (1974) concluded from a study of mailed questionaires (only $50 \%$ of which could be used) that vaginal delivery in breech presentation is connected with a definitely increased risk of cerebral lesion.

Fianu and Joelsson (1979) published data on long term morbidity pertaining only to children with near or above average intelligence, obtained by means of questionaires sent to parents and teachers. They found a 7 -fold increase in the incidence of hyperkinesia and learning disability in breech children compared to the vertex-born group.

These investigators found hyperkinetic syndromes and learning disabilities in $15.4 \%$ of the breech-borns delivered vaginally and in $1 \%$ of the breech-borns delivered by cesarean section. The study suggests that, in addition to other factors, trauma and possibly even periods of asphyxia during delivery play a significant role in the occurrence of the disturbances. This study has practically all the serious drawbacks mentioned by Manzke (1978), and therefore the results can hardly be considered reliable. 
In a case controlled study, Faber-Nijholt et al.(1983) found no differences between breech-born children and vertex-born children as regards serious neurological dysfunctions. Minimal dysfunctions were found significantly more often among breech-born children. These minimal dysfunctions, however, were probably more influenced by the pregnancy-related complications than by the question whether the child was born in breech presentation. In this study the cesarean section frequency was $20 \%$ and the children were examined at an age of 18 months and at ages varying between 3 and 10 years.

In a 4-year prospective longitudinal study of infants presenting in breech at term ( 37 weeks or over) compared to a normal group of neonates born in vertex presentation, O'Connell and Keane (1984) found more immature patterns of motor development relating to the lower limbs in the term breech deliveries.

Analysis showed further that the section breeches were later in motor development than the vaginal breeches.

In a psychological assesment at 4 years of age, lower IQ scores were noted, with the exception of the elective cesarean section subjects in the breech group, which are not different from the control group in terms of IQ.

However, in a group of males born in breech presentation Nilsen and Bergsjo (1985) found no statistical differences in general intelligence level 18 years after birth, compared with all Norwegian conscripts of the same birth cohort.

Luterkort et al.(1986) evaluated the outcome of breech deliveries by a neurological score and a follow-up examination at 18 months of age, comparing the results with vertex-born children in the same study group selected in the 33 rd gestational week. They found no difference in neurological score or in general development between the breech group as a whole and the vertex group.

There have also been a few studies which have compared the outcome of children in breech presentation born vaginally with the outcme of those born by cesarean section.

Hochuli et al. (1977) and Hochuli and Kaech (1981) examined prospectively the difference in late morbidity between vaginally born and abdominally born breeches in the period 1972-1975. The children were examined at an age of 6 months and at ages over four years.

Late morbidity, consisting of psychomotoric retardation, cerebral palsy and behavioural abnormalities, was found with the same frequency in the vaginal and abdominal group, at a cesarean section rate of $34.3 \%$. The authors concluded that it is safe to do cesarean sections in breech presentations on an individual basis.

However, in this study $14 \%$ of the children were not available for the follow-up examinations.

Mantzke (1978), in a prospective controlled study, concluded that the prognosis of vaginally breech-born children was marginally less favorably than that of infants delivered by cesarean section.

Bistoletti et al.(1981), comparing vaginally and abdominally delivered breeches, found two persisting brachial palsies and one case of late psychomotor development 
in the vaginal group. But only infants with acute birth asphyxia and infants suffering traumatic injury at birth were examined.

A study by Huchcroft et al. (1981) indicated that the subsequent health and development of children is similar whether the infant in breech presentation is delivered vaginally or by cesarean section.

In monitoring morbidity over 2 years of life and examining individually every braindamaged infant. Rosen et al. (1985) showed no differences in outcome for the breech presentation delivered by cesarean section as compared with the breech presentation delivered vaginally for all birth weights above $2000 \mathrm{~g}$.

Krause et al.(1984) found significantly less late morbidity (disturbances in motor function and concentration) of children at the ages of 5 to 6 year in the group of term breeches delivered by cesarean section. The authors attributed this cerebral dysfunction to disturbances in the cerebral blood circulation caused by vaginal delivery of breeches.

Svenningsen et al.(1985) compared the long term outcome of 709 breech born infants born within two different time spans (1971-1977 and 1974-1977), with a significant difference in cesarean section frequency $(16.1 \%$ versus $37.1 \%$ ).

At a follow-up at 2 years of age in both periods, neurodevelopmental sequelae was found to occur significantly more often in the vaginally born infants $(5.7 \%$ and $2.0 \%$ ), compared with the abdominal group ( $0 \%$ and $0.7 \%$ ).

But in a majority of the cases, i.e. in 14 out of 18 vaginally delivered patients, obstetric complications were present besides the fact that the breech was born vaginally. Differences within one period (1974-1977) between vaginally and abdominally born breeches and vaginally vertex-born children were also studied. In this period the incidence of neurodevelopmental sequelae at the 4-year follow-up did not differ between the three groups.

Kouam et al.(1986) did a follow-up study in 57 children presented in breech and delivered by primary cesarean section. The children were examined between $11 / 4$ and 6 years of age. Seven of these children showed either speech disturbances or slight motor disturbancies $(12 \%)$. The original study group, however, consisted of 172 cases of primary cesarean section born breeches.

Bingham and Lilford (1987) concluded from a review of 7 follow-up studies that there was an overall relationship between subsequent cerebral palsy and vaginal breech delivery.

\subsection{Preterm breech}

\subsubsection{Mortality and morbidity}

The same controversy as that over the management of term breech presentation also exists over the premature breech (Cruikshank and Pitkin, 1977; Anonymous 1979; 
Russell, 1982; Lieberman and Chiswick, 1982; Anonymous, 1983; Anderson and Strong, 1988).

Breech delivery in preterm birth is generally considered to offer a greater risk to the infant compared with term born children, both because of the vulnerability of the infant and because of the discrepancy between head circumference and body size in premature children. Due to this last fact, entrapment of the relatively large head by the partially dilated cervix is supposed to present a serious threat. The same danger, however, is present in a cesarean section in early pregnancy, and probably even more pronounced, due to the difficult anatomical conditions in the small pelvis in early pregnancy: the lower uterine segment is not well established and the uterine wall is thick.

In cases involving premature breech fetuses, the choice of delivery methods in respect to direct and long term neonatal outcome is complicated by the risks of prematurity itself, including respiratory distress and intraventricular hemorrhage (Silber, 1987).

Mortality and/or morbidity in preterm breeches born vaginally is supposed to be increased compared to infants born premature vaginally in cephalic presentation (Kauppila et al., 1981). From a critical examination of eleven papers published between 1975 and 1979 about the cesarean section debate in premature breech delivery, Crowley and Hawkins (1980) concluded that for infants weighing 1500-2500 $\mathrm{g}$ the survival rate is independent of the mode of delivery. In these eleven papers with exception of one study (Ingemarsson et al., 1978) always weight criteria has been used. Studies by Ingemarsson et al.(1978); Duenhoelter et al.(1979); De Crespigny and Pepperell (1979); Geirsson et al.(1982); v Eyk and Huisjes (1983) and Granati et al.(1984) suggested that cesarean delivery would significantly lower the number of cleaths in premature infants presenting in breech. The limits for the definition of prematurity also vary considerably in these studies: 37 weeks amenorrhoea, less than 2500 gram, low birth weight. In addition, the studies did not always analyse the different birth weight categories separately.

As regards morbidity, Duenholter et al.(1979) have reported a retrospective casecontrolled study of 88 singleton fetuses weighing between 1000-2499 g (only nine pairs were $<1500 \mathrm{~g}$ in birth weight) and presenting in breech. Asphyxia was more frequent in the vaginally than in the abdominally delivered group, and vaginal delivery was more commonly associated with birth trauma and intracranial hemorrhage. In a retrospective study of 88 preterm infants, V Eyk and Huisjes (1983) showed that entrapment of the fetal head and cord prolapse in vaginal delivery was correlated with neonatal morbidity and concluded that their results undoubtedly would have been better if a policy of routine cesarean section had been followed in premature breeches.

Granati et al. (1984) showed a significantly greater incidence of asphyxia, neonatal mortality and sequelae for the vaginally delivered group in comparison to the group delivered by cesarean section in 68 infants of less than 36 weeks gestation. 
Other reports concluded, however, that in preterm breech presentation in the weight category of 1500-2500 grams there is no evidence that a policy of routine cesarean delivery is more advantageous than vaginal delivery. (Karp et al.,1979; Kauppila et al., 1981; Nisell et al., 1981; Bodmer et al., 1986).

Karp et al. (1979) concluded that only footling breeches, especially those in the lower weight ranges, should be delivered by cesarean section. For the birth weight category of $1500-2500 \mathrm{~g}$, they conclude that vaginal delivery can be safely undertaken when the presentation is either full or frank breech.

In spite of the increase in cesarean section rate from $12.2 \%$ in the period 1967-1971 to $44.7 \%$ in the period 1972-1.976 during the study by Kauppila et al(1981), the apgar scores for infants weighing 1500-2500 $\mathrm{g}$ did not differ between those in breech presentation delivered by the vaginal route and those born by cesarean section. Bodmer et al.(1986) also found no difference in outcome between vaginally born preterm breeches and an abdominally born group at 29-36 weeks amenorrhoea.

Of particular interest is the question whether cesarean section benefits the very premature breech fetus, weighing less than 1500 grams.

On the one hand, these fetuses are subject to the risks of head entrapment. On the other hand, they may have such high morbidity and mortality rates resulting from prematurity itself, that the benefits of cesarean section are marginal (Silber, 1987). The results of most studies regarding very premature breech fetuses appear inconclusive.

Some studies limited to the very low birth weight category (lower than $1500 \mathrm{~g}$ ) detected a significant increase in survival rate with cesarean birth (Bowes et al., 1979; Crowley and Hawkins, 1980; Main et al., 1983 ), whereas others suggested that the recent decrease in neonatal mortality of very low birth weight infant in breech presentation is largely unrelated to the increased use of cesarean birth (Effer et al., 1983; Olshan et al., 1984; Yu et al., 1984; Rosen and Chik, 1984; Newton et al., 1986).

In a study by Bowes et al. (1979) there were 39 deaths among the 57 infants delivered vaginally $(68 \%)$, while three deaths occurred among the 12 neonates delivered by cesarean section (25\%). This statistically significant difference might however have been influenced by differences in birth weight and changes in the perinatal management during the period 1970-1977, in which the study was performed.

From a review of eleven papers published since 1975, Crowley and Hawkins (1980) concluded that for the infant weighing between 1000 and $1500 \mathrm{~g}$, operative delivery appears to be advantageous, but that operative delivery is much more difficult to justify for babies weighing less than $1000 \mathrm{~g}$. However these eleven studies analyzed retrospectively data published between 1975 and 1979.

In the study by Main et al.(1983), 93 breech infants weighing 750-1499 g were delivered by cesarean section and 123 were delivered vaginally. The former group's mortality was 29 per cent, compared to 58 percent for the latter, a statistically significant difference. Morbidity as reflected by low Apgar scores and intracranial 
hemorrhage was not found to be affected by abdominal delivery in this study. Effer et al.(1983) presented a retrospectively analyzed series of very low birth weight breech deliveries over the period 1973-1980, and showed that the neonatal mortality rate for this group was not significantly different in the infants delivered vaginally, when compared to those delivered by cesarean section.

Neither did Olshan et al. (1984) find any statistically significant difference between the mortality rates of those delivered vaginally and those delivered by cesarean section in the weight range of $700-1500 \mathrm{~g}$. However, death due to intrapartum stillbirth for the two groups was not discussed. From a group of 1338 neonates with a gestational age of less than 32 weeks and/or a birth weight of less than $1500 \mathrm{~g}$ in the Netherlands, Verloove-Vanhorick and Verwey (1987) concluded that there was a significantly increased mortality risk in vaginally born breech infants. Since other factors also influence the mode of delivery of very premature infants in breech, the results of this analysis should be interpreted with care.

Westgren et al. (1985) reported a retrospective study of 136 infants in breech presentation, weighing less than $1500 \mathrm{~g}$, born between $1977-1981$, with a cesarean rate of $73 \%$. No difference in mortality with respect to the mode of delivery could be detected for any of the three birth weight categories $(750$ to $999 \mathrm{~g}, 1000$ to $1249 \mathrm{~g}, 1250$ to $₫ 499 \mathrm{~g}$ ).

In a retrospective study of breech singleton infants with birth weights lower than $2500 \mathrm{~g}$, comparing 2 study periods (1973-1974 and 1979-1980), Cox et al.(1982) reported that the increasing cesarean section rate $(19.1 \%$ to $42.2 \%)$ resulted in a decrease in the number of stillbirths ( 24.7 to $11.1 \%$ ), as well as in corrected neonatal mortality $(23.9 \%$ to $8.7 \%)$ and in an increase in the number of surviving infants $(66.2 \%$ to $82.1 \%)$.

Yu et al. (1984) reported on a large series of 322 live births weighing less than 1500 g. The cesarean rate for singleton births with breech presentation in this study was $44 \%$. They found that the survival rate after cesarean section was significantly higher than after vaginal delivery in breech infants weighing 1001 to $1500 \mathrm{~g}$ (41 neonates), but failed to demonstrate any difference in the 501 to $1000 \mathrm{~g}$ range ( $31 \mathrm{ne}$ onates). However, this group had a significantly lower cesarean rate $(10 \%)$ and a lower survival rate (45\%) than the category $1001-1500 \mathrm{~g}$, in which the cesarean section frequency was $71 \%$ and the survival rate was $88 \%$.

With regard to the morbidity in this very low birth category, conflicting results are again presented in the literature comparing vaginally and abdominally born children. This is largerly due to several confounding factors connected with prematurity itself. In an effort to minimize the influence of these confounding variables the morbidity was determined by Westgren et al. (1985) in a group of 22 matched pairs of vaginal/cesarean section breech deliveries without fetal and maternal ante partum complications. The incidence of low Apgar scores (less than 7 at one and five minutes) was similar in the two groups ( 82 and $55 \%$ in the vaginal group and 86 and $50 \%$ in the cesarean section group respectively).

Rosen and Chik (1984) studied mortality and morbidity in the neonatal period and 
examined every brain-damaged infant for all birth weights in $500 \mathrm{~g}$ increments beginning at $500 \mathrm{~g}$. There were no differences in outcome for the breech presentation delivered by cesarean section as compared with the breech presentation delivered vaginally, as long as the fetus was alive on admission and had no major congenital abnormalities.

Although they found no significant differences in morbidity data and mortality between the newborn infants after vaginal and abdominal delivery, Von Weisbach et al.(1986) advised a liberal use of cesarean section, based on the brief period of assisted ventilation after abdominal delivery compared with vaginal delivery in the very low birth category $(\leqslant 1500 \mathrm{~g})$.

\subsubsection{Follow-up}

Long term follow-up assessment of infants born in breech presentation, comparing cesarean with vaginal births, has been reported in various studies (Ingemarsson et al., 1978; Woods et al., 1979; Effer et al., 1983; Cox et al., 1982), and some studies have suggested that cesarean delivery would significantly lower long term morbidity in the premature infant presenting in breech (Ingemarsson et al., 1978; Nisell et al., 1981; Cox et al., 1982; Frenzel et al., 1984).

A study by Ingemarsson et al.(1978) included a follow-up at 1-5 year of age, in which it was found that $24 \%$ of the vaginally delivered infants and $2.5 \%$ of those delivered by cesarean section showed developmental or neurological abnormalities. In all children, signs of long-term sequelae appeared within the first year.

This study comprised all infants delivered in one clinic before the 37 th week of gestation, and compared two periods with different obstetrical management.

In a group of 126 neonates, Frenzel et al. (1984) found no increase in serious neurological handicaps, but only more minimal psychomotor deviations in vaginally born infants compared to infants born by primary cesarean section.

However, the differences between the two groups were not statistically significant in the birth weight category of $1500-2499 \mathrm{~g}$. In the birth weight category lower than $1500 \mathrm{~g}$ no correlation with mode of delivery was found.

Nisell et al.(1981) studied over a 6-year period 21 children with a low Apgar score, of which 2 infants in the vaginal group and one in the cesarean section group showed persistent developmental or neurological sequelae. The cesarean section rate was 31 per cent.

In a follow-up study by Woods (1979) of 38 out of 60 surviving neonates ( 30 weighing 1500-2499 g and 8 weighing $1000-1499 \mathrm{~g}$ ) only one infant in the cesarean section group showed a retarded motor and mental development. The number of vaginally born survivors was not known, but all had a normal development. In this study only $63 \%$ of the survivors were followed up. In a retrospective study, Effer et al. (1983) reported no significant difference in the data regarding handicap rate both at 2 years and 3 years of age between the vaginal group and the abdominal group in the very 
low birth weight category (lower than $1500 \mathrm{~g}$ ). In this study handicaps related to ordinary activities and skills of daily living were analyzed.

In a retrospective study of breech singleton infants of birth weight lower than 2500 g, comparing 2 study periods (1973-1974 and 1979-1980), Cox et al.(1982) reported an increased incidence of neurological sequelae in survivors $(4.7 \%$ in the first period, $21.9 \%$ in the second period). Moreover, the neurological handicap rate was greater in those delivered by cesarean section $(25.8 \%)$ than in the vaginally delivered group (12.1\%). This study, however did not take into account the development and improvement in neonatal care, nor did it differentiate between the different birth weight categories.

In a 2 year follow-up study including clinical and neurodevelopmental examination, Yu et al.(1984) found no significant difference between cesarean and vaginal birth in the ocurrence of disability in the very low birth weight survivors presenting by breech. Disability was defined as cerebral palsy, developmental delay, sensory deficits, hydrocephalus or epilepsy

\subsection{Indications for cesarean section in breech presentation}

\subsubsection{Parity}

Parity is considered to be a major factor in the management of breech delivery. This is shown particularly in the frequent exclusion of the primiparous mother with a breech infant from a trial of vaginal labor because of the lack of a "proven adequate pelvis" for vaginall delivery.

Older papers report an increase in the perinatal mortality rate in primiparae with breech presentation compared to all term vaginal deliveries (Varner, 1962).

Also, the risk of death following vaginal delivery among primiparae was reported to be higher than in abdominal delivery (Fortney et al., 1986).

Paradoxically, other authors have found that perinatal morbidity and mortality were actually increased in multiparous patients (Fischer-Rasmussen and Trolle, 1967; Brenner et al., 1974; Rovinsky et al., 1973; Gimovsky et al., 1980; Tatum et al., 1985). In the study by Gimovsky et al.(1980) a higher incidence of low $5 \mathrm{~min}$ Apgar scores was noted in multipara, although the difference was not statistically significant.

Andermann et al.(1984) and Clinch and Matthews (1984) found no difference in immediate neonatal outcome between the vaginal delivery of breeches and cesarean sections after a trial of vaginal delivery in primigravidae. They concluded that properly selected primigravidae with a breech presentation could be delivered vaginally with immediate outcomes comparable to those found after cesarean section. In a recent retrospective study over a 7 year period by Tatum et all (1985), vaginal delivery was achieved in $37 \%$ of multiparous patients, while primiparous women were delivered vaginally in $22 \%$ of the cases with neonates over 2000 grams. This 
difference was statistically significant. The study by Clinch and Matthews (1984) also showed more multiparous women $(60 \%)$ to be delivered vaginally compared with primiparous women $(37 \%)$.

\subsubsection{Type of breech}

In general, three types are distinguished: frank breech, complete breech and incomplete breech (single and double footling presentation). Because some complete breeches convert into an incomplete breech as labor progresses, as reported by Cruikshank (1986), these two types of breech presentation together were often defined as non-frank breeches. In addition, the type of breech presentation is sometimes difficult to assess by clinical means prior to labor (Barloev and Larsson, 1986). The relation between the type of breech and the risk of cord prolapse is supposed to be one important reason why the type of breech should be a factor in the management of breech presentation. In addition, the birth canal will probably be more dilated in a frank breech than in a non-frank presentation, which offers a better condition for the aftercoming head. Moreover, in the case of a non-frank breech, the risk of aspiration is increased due to external stimuli, which especially presents a greater danger in case of meconium-stained amniotic fluid.

The incidence of prolapse of the umbilical cord for all breech presentations is reported as $1.4 \%-6 \%$, compared with $0.5 \%$ in vertex presentations (Rovinsky et al., 1973).

Frank breech presentation is associated with a cord prolapse incidence of $0.4 \%$, whereas in complete breech presentation this incidence is $4 \%-5 \%$ and in footling breech presentation 15\% (Tatum et al., 1985). In a study by Gimovsky (1980) of 208 patients with breech presentation delivered vaginally, prolapse of the umbilical cord was observed in as many as $10.5 \%$ of complete breech presentations and in $28.5 \%$ of single footling breeches. None of the fetuses who presented in breech with cord prolapse and were delivered vaginally had any neonatal morbidity. According to other studies, cord prolapse-related neonatal morbidity problems are more frequent. These authors therefore allow vaginal delivery only in selected frank breeches (Editorial comment Survey, 1981).

In a later randomized prospective study by Gimovsky et al in 1983, 70 patients with complete or incomplete breech presentations were selected for a trial of labor and potential vaginal delivery. Thirty-one $(44 \%)$ of the seventy patients were finally delivered vaginally. The conclusion of this study was that carefully selected non-frank breeches can also be delivered vaginally, despite the fact that in this study one fullterm infant was lost following vaginal delivery as a result of intrapartum hypoxia, probably due to pressure on the umbilical cord in combination with general anaesthesia because of extraction. Prolapse of the cord is not always a serious complication in a breech presentation, but it can be lethal. For this reason some authors plan only selected frank breeches for vaginal delivery and recommend that nom- 
frank term breeches should be delivered electively $5-7$ days before term by cesarean section (Editorial comment Survey 1981 and 1984). In a series of 2.145 cases of term singleton breech presentation, Rovinsky et al. (1973) found a two-fold increase in perinatal mortality in non-frank over frank breech presentation, again suggesting a greater danger of cord prolapse in non-frank breech presentation. In this study overt cord prolapse and fetal distress were twice as frequent in the non-frank in the frank presentations.

In 1987, cesarean section was still recommended for non-frank breech presentation (Myers and Gleicher, 1987).

\subsubsection{Hyperextension of the fetal head}

Hyperextension of the fetal head in breech presentation shortly before labor starts is considered an extra risk factor in vaginal breech deliveries, due to the increased risk of entrapment and/or excessive flexion of the fetal head.

Consequently, hyperextension has been associated with neonatal death (Caterini et al., 1975) and severe neonatal complications such as injuries of the spinal cord, supraspinal area and brain stem in cases of vaginal delivery (Weinstein et al., 1983). In order to prevent these complications elective cesarean section is recommended in these conditions as the management of choice (Abrams et al., 1973; Caterini et al., 1975; Ballas et al., 1978; Westgren et al., 1981).

Weinstein et al. (1983), however, described that in some cases these complications cannot be prevented by cesarean section. According to these authors, this is probably due to rotation or flexion of the fetal head in the intrapartum period prior to cesarean section. Recently, spinal cord injury was described in a breech-presenting, cesarean section-delivered, preterm infant, and the authors warned against application of traction or any stretching forces in the delivery of a breech-presenting fetus (Ilagan et al., 1987).

A striking feature of the literature about this intra-uterine fetal condition is the differences in incidence reported by various authors. Caterini et al.(1975) reported a frequency of $5.1 \%$, Ballas et al. (1978) $0.8 \%$, Westgren et al. (1981) $7.4 \%$ and Tatum et al. (1985) $7 \%$.

In all of these studies $\mathrm{X}$-ray was used in diagnosing this fetal condition. The different frequencies of this condition reported in the various studies probably reflect the different criteria for classification of the $\mathrm{X}$-ray films, rather than a real difference in the occurrence of hyperextension of the fetal head.

\subsubsection{X-ray pelvimetry}

Opinions differ widely regarding the value of antenatal radiography in the management of breech deliveries (Ridley et al, 1982). Particularly the role of X-ray pelvime- 
try for breech presentation is still controversial (Varner et al,1980, Alder et al, 1987), because normal measurements in vaginal delivery of breeches at term do not guarantee an easy vaginal delivery (Rovinsky et all, 1973). Apart from its value with regard to pelvimetry, antenatal radiography may also be helpful in diagnosing and determining the type of breech and the hyperextension of the fetal head, in confirming fetal maturity and in detecting fetal abnormalities (Ridley et al.,1982).

While in some countries (e.g in the Netherlands) X-ray pelvimetry is not used at all in the management of a breech delivery, it is considered almost obligatory (Collea et al, 1980; Federle et al, 1982; Tatum et al, 1985) in other countries (Canada, USA). Recently, CT pelvimetry in evaluation of the fetus in breech presentation has been proposed (Federle et al., 1982; Kopelman et al., 1986).

Several sets of normal values for $\mathrm{X}$-ray pelvimetry are can be found in the literature, resulting in different breech scoring systems (Westin, 1977; Zatuchni and Andros, 1965). This is either due to disagreement as to what constitutes normal pelvic measurements, or to racial differences.

\subsection{Birth trauma in breech delivery}

Birth trauma in breech-born children occurs more frequently in vaginally born children than in abdominally born children. These traumata can be divided into two categories: a) those generally without long-term consequences (clavicula fracture, humerus fracture, plexus lesions) and b) serious injuries with possible implications for future health (intracranial hemorrhage, tentorial tears, fracture dislocation of the cervical spine, rupture of the liver or spleen) (Anonymous, 1978).

Traumatic birth injury contributes significantly to the increased perinatal morbidity and mortality rates related to vaginal breech delivery (Tatum et al., 1985)

However, injuries also occurred in infants delivered by cesarean section and they cannot be avoided completely even by cesarean section (Hochuli and Kaech, 1981; Gimovsky and Paul 1982; Tatum et al., 1985; Baerlov and Larsson 1986; Cruikshank, 1986; Perkins, 1987; Alexander et al., 1987).

The procedure of breech extraction by cesarean section, and especially if performed by the smallest possible Phannenstiel incision, or in premature breech by the lower uterine segment, which is incompletely developed, carries a risk comparable to that of a vaginal delivery.

In the low birth weight category, fractures and palsies have also been found to occur after both vaginal and cesarean birth (Bodmer et al., 1986).

Intracranial hemorrhage is the most common and serious cause of neurological morbidity and mortality in the newborn infant (Volpe, 1981; Baerts, 1986). A correlation between intracranial hemorrhage and vaginal breech delivery is often assumed (Bejar et al., 1982) and many causal factors, such as neonatal skull trauma, have been implicated in the etiology of subarachnoid, intracerebral and subdural hemor- 
rhage (Painter and Bergman, 1982). An example is injury to occipital bone during breech delivery, causing subdural hemorrhage in the posterior cranial fossa (Wigglesworth and Husemeyer, 1977). Tears of the tentorium cerebelli have been found with great frequency in dead fetuses delivered in breech presentation (Holland, 1922). The role of the mode of delivery in the etiology of intracranial hemorrhage is still controversial especially in premature infants (Mc Donald et al., 1984; Low et al., 1986; Morales and Koerten, 1986). Tejani et al. (1987) found less early intracranial hemorrhage in breech-delivered neonates with low birth weight $(\leqslant 2000$ g) if delivered by cesarean section.

Cerebral hemorrhage was also seen in some abdominal deliveries in breech presentation (Kauppila et al., 1981).

In a recent study, no significant reduction was found in the risk of intracranial hemorrhage neonates with birth weight $\leqslant 1500 \mathrm{~g}$ in cesarean section delivery (Bada et al., 1984). 



\section{Chapter 3}

\section{Patients and Methods}

\subsection{Patients}

Of the 2706 infants weighing 500 grams or more which were delivered in Maastricht between January 1984 and June 1986, 211 (7.7\%) were born in breech presentation. Corresponding figures for Gent during the same period were 138 breech delivered infants out of $2140(6.4 \%$ ) (Table 3.1 ).

Table 3.1 Selection of cases $(\%)$

\begin{tabular}{lrrrrr}
\hline & Gent & \multicolumn{2}{c}{ Maastricht } \\
\hline No. of Births $(\geqslant 500 \mathrm{~g})$ & 2140 & & 2706 & \\
No. of Breeches & 138 & $(6.4)$ & & 211 & $(7.7)$ \\
\hline $\begin{array}{l}\text { Number of cases excluded } \\
\quad \text { Multiple births (neonates) }\end{array}$ & 44 & $(31.8)$ & 37 & $(17.5)$ \\
$\quad$ Lethal malformations & & & & & 31 \\
$\quad$ Antepartum fetal death & & 2 & & 3 \\
\hline Number of remaining cases & & 11 & & & 3 \\
\hline
\end{tabular}

A substantial part of the perinatal mortality in breeches is due to fetal death prior to the onset of labor (Brenner et al., 1974) and to the presence of abnormalities incompatible with life (Neilson, 1970).

Therefore, fetal death before labor and congenital malformations incompatible with live were excluded from the study, since its principal aim was to compare the results of those vaginally and abdominally born breeches alive or able to survive at the beginning of the labor process. In addition, multiple pregnancies were excluded, since the obstetrical management is seriously influenced by general obstetrical factors as well as by mechanical factors during delivery.

All other deliveries, resulting in a birth weight over or equal to 500 grams were included in the study, irrespective of other maternal/fetal diseases. Consequently, all breeches in both hospitals fullfilling the criteria mentioned were consecutively admitted to the study.

After exclusion of 31 multiple pregnancies, 11 antepartum fetal deaths and 2 lethal malformations, 94 cases were retained for analysis in Gent. 
In Maastricht the study group consisted of 174 cases remaining after exclusion of 31 multiple births, 3 antepartum fetal deaths and 3 lethal malformations (Table 3.1). Of the total study group of 268,92 fetuses $(34 \%)$ were delivered by cesarean section and $176(66 \%)$ were born vaginally.

\subsection{Collection of perinatal data}

As stated in the last paragraph, the study comprised all consecutive breech deliveries resulting in a birth weight over or equal to 500 grams from January 1984 to June 1986 in both university hospitals .

In addition, the study was continued from July 1986 until January 1987 for preterm breech deliveries ( gestational age $<37$ weeks and/or birth weight lower than 2500 grams), resulting in 18 extra cases in the lower birth weight categories.

All obstetrical and neonatal data were collected prospectively according to a standardized protocol (Addendum 3.1), which was originally developed by the EEC concerted Action Project on Perinatal monitoring (Derom, 1983; Duisterhout et al., 1983 ). This protocol was modified for breech deliveries after a pilot study ( Derom et al., 1984). The standardized data collection enabled the comparison of the patients from the two hospitals and also offered the possibility of analysing the data of all the cases.

The main characteristics of this protocol were:

(1) accurately defined items, no time-related data or crude data instead of diagnoses;

(2) availability of a substantial number of data related to essential aspects regarding mother, pregnancy, delivery, puerperium and newborn;

(3) qualitative items answered by yes/no/unknown or by the relevant qualification; quantitative items by a figure;

(4) addition of specific items related to breech presentation i.e type of breech presentation and mode of delivery, hyperextension of the fetal head, prolapse of the umbilical cord and umbilicus-to-delivery time.

\subsection{Obstetrical management}

The general policy agreed upon in both hospitals was to start with a trial of labor, intending a vaginal delivery, except in the presence of clear-cut contraindications such as placenta praevia, overt contracted pelvis and some cases of an uterine scar etc.

The patient underwent routine physical examination and assessment of the maternal pelvis by vaginal examination. No routine $\mathrm{X}$-ray pelvimetry was performed before labor. In Gent, X-ray pelvimetry during labor was only performed if there was no progress of labor. No formal prognostic breech scoring indices were used. In both hospitals the usual parameters for assessing the diagnosis no progress of labor 
and/or fetal distress were applied which meant that no extra items other than the ones already used, such as uterine activity, dilatation, engagement of the presenting part, judgement of the fetal heart rate pattern and fetal blood sampling were scored. Only in Gent a partogram was used. An experienced obstetrician and a neonatologist were always present during delivery in both hospitals. The decision to perform a primary cesarean section was made by a senior obstetrician.

To assess fetal weight, fundal height, Leopold manoeuvres and ultrasonography were used in both hospitals, if necessary. All neonates over or equal to 500 grams were included in the study irrespective of the estimated fetal weight during pregnan$c y$, which is sometimes used to determine the obstetrical management as regards the route of delivery, and irrespective of the direct neonatal treatment. Cesarean delivery was not withheld for fetal indications when the fetal weight was estimated at over or equal to 500 grams and gestational age was more than 26 weeks.

At delivery, the policy was to resuscitate all infants unless they were judged to be too immature or too seriously malformed to merit the continuation of treatment.

\subsection{Definitions}

\subsubsection{Maternal data (see Addendum 3.1):}

Age: in completed years.

Height: measured without footwear.

Number of pregnancies: the total number of pregnancies, including the pregnancy at issue.

Parity: the total number of pregnancies that lasted longer than 16 weeks and resulted in a neonate weighing 500 grams or more, including the pregnancy at issue.

Diabetes mellitus: classification according to Priscilla White (1974).

\subsubsection{Pregnancy data (see Addendum 3.1):}

Duration of pregnancy: the number of completed weeks at the first prenatal visit to one of the hospitals, or in non-booked cases (no ante partum care in one of the two hospitalsy at the time of admission to one of the hospitals. The first prenatal examination in one of the two hospitals was reported, since a number of intrauterine transfers from other hospitals to the two university centers were present in the study population. 
Prenatal care: in cases where more than one person checked the patient during the prenatal visits, the person who was in charge of the largest number of prenatal examinations was coded: midwife, family physician, resident or obstetrician.

Number of prenatal visits: the number of prenatal visits included all prenatal visits during the pregnancy at issue, whether performed by the obstetrician, the resident, the midwife or the family physician.

Diastolic blood pressure: maximal diastolic blood pressure during the first 20 weeks. and after the first 20 weeks of amenorrhoea.

Hypertension: defined as a diastolic blood pressure of either

(a) $110 \mathrm{mmHg}$ or more on one occasion during prenatal care

(b) $90 \mathrm{mmHg}$ or more on two consecutive occasions during prenatal care

(c) The use of antihypertensive drugs before pregnancy.

Protein excretion: classified as urinary protein excretion $>0.3 \mathrm{~g} / 1$.

The hypertensive disorders were classified into:

A. Gestational hypertension.

B. Chronic hypertension and Chronic Renal Disease.

C. Unclassified hypertension.

(Davey and MacGillivray, 1985)

Smoking habits: daily consumption of cigarettes at the time of the first prenatal visit. More than 10 cigarettes per day was considered abnormal.

Third trimester vaginal bleeding: defined as vaginal blood loss after 24 completed weeks of amenorrhoea.

Ante partum hospital admittance: the total number of days spent by the patient in one of the two hospitals for pregnancy-related events complicating the pregnancy at issue.

Duration of pregnancy at the time of delivery: the number of completed weeks at the time of delivery. The number of completed weeks was taken either as certain or as best estimate, depending on available data regarding menstrual cycle, last menstrual period, basal body temperature, ovulation induction etc. and/or pregnancy test, fundal heights and ultrasonographic data.

Biparietal diameter: the distance between the parietal bones measured at last ultrasonic examination before delivery.

Congenital malformations: determined during pregnancy by sonography. 
Hyperextended head: Hyperextension was determined by measuring the angle between the cervical vertebrae and the tangient plane of the occipital bone, in degrees. The value obtained at the last ultrasound examination was noted. Hyperextension was defined as an angle of less than 90 degrees.

\subsubsection{Delivery data (see Addendum 3.1):}

Induction of labor: labor induced with the aid of pharmaceutical agents and/or by artificial rupture of membranes.

Augmentation: stimulation of uterine activity by oxytocin, prostaglandines or similar drugs during spontaneous labor.

General anaesthesia: general anaesthesia during labor.

Epidural anaesthesia: epidural anaesthesia during labor.

Regional anaesthesia includes anaesthesia of the perineum, pudendal block and paracervical block.

Analgetics-sedatives: administration of analgetics or sedatives during labor and/or delivery excluding general, regional and epidural anaesthesia.

Rupture of membranes: the diagnosis of ruptured membranes was clinically assessed. Time and mode of rupture of the membranes were marked. Prolonged rupture of the membranes was defined as a period of more than 24 hours between rupture of membranes and birth.

Term (more than 37 completed weeks of amenorrhoea) and preterm (less than 37 completed weeks of amenorrhoea) rupture of membranes were distinguished (WHO definition, 1977 accepted by FIGO, 1976 and 1982).

Type of breech presentation: in this study the breech presentation was defined as either frank or non-frank presentation.

A frank breech presentation is diagnosed when the lower extremities are flexed at the hips and extended at the knees, with the feet positioned in close proximity to the head. A non-frank breech is defined as complete and incomplete breech presentations, thus including double footling and single footling (William's Obstetrics, 1985).

Electronic fetal monitoring: recording of the fetal heart rate by means of a fetal monitor, either by ultrasound or electrocardiogram. Uterine activity recorded either 
externally or by means of an intra uterine catheter.

The intrapartum heart rate tracings of fetuses in breech presentation were recorded and analysed. Tracings were recorded at a paper speed of $3 \mathrm{~cm} / \mathrm{min}$ in Maastricht and $1 \mathrm{~cm} / \mathrm{min}$ in Gent by means of the usual fetal heart rate monitors.

Uterine activity was recorded externally from the maternal abdomen or internally after rupture of the membranes. The tracings were analyzed from one hour before the patient started pushing actively until one hour after this moment, or as long as the second stage lasted. In case of a secondary cesarean section the tracing was analyzed from one hour before the cesarean section was performed. Heart rate patterns were related to Apgar scores and umbilical cord blood gases in order to evaluate their importance for the immediate neonatal outcome.

Prolapse of the umbilical cord: presence of umbilical cord by vaginal examination.

Second stage: the period between the start of active pushing and the birth of the neonate in minutes.

Umbilicus-10-delivery time: the time between the delivery of the umbilical cord and the delivery of the head. Whenever possible the umbilicus to delivery time was measured in seconds for each infant delivered vaginally. This time was assessed by means of a clock, equiped with a seconds hand which was available in the delivery room.

\section{Mode of delivery:}

Spontaneous delivery: Bracht's manoeuvre (see below).

Assisted breech extraction: initially spontaneous delivery but birth of the child finally completed either by manoeuvres according to de Snoo,Mauriceau-Veit-Smellie, Lovset, van Deventer, Müller or others. Forcipal extraction to deliver the aftercoming head was coded separately.

Total breech extraction: birth of the child by total extraction.

The following definitions apply to the spontaneous, the assisted and total breech extraction.

Bracht's manoeuvre: keeping together the legs and body of the child and rotating around the symphysis, with spontaneous delivery of arms, while an assistant supports the delivery by a light external fundal pressure.

(Bracht, 1938)

Müller manoeuvre: initial delivery of the anterior arm by extracting the trunk as far as possible and subsequently the freeing of the posterior arm by lifting the child to the opposite side.

(Mueller, 1921; Hoogeveen, 1956; Liem Siong Kian,1962) 
van Deventer manoeuvre: delivery of the posterior arm first, by lifting the neonate's body and pulling it to one side, after which the anterior arm is brought down by lowering the body and pulling it firmly to the other side.In case the latter fails, the baby is rotated around its longitudinal axis, so that the anterior arm becomes posterior and can be delivered in a similar manner.

(van Deventer, 1701; Hoogeveen, 1956; Liem Siong Kian, 1962)

de Snoo manoeuvre: the neck is fixed in a fork-grasp with the left hand, thereby supporting the body of the neonate on the left forearm. The right hand is placed first above the symphysis and then, with simultaneous traction on the shoulders with the left hand and pressure on the head with the right hand, the neonate is delivered. (De Snoo, 1949)

Mauriceau manoeuvre: while an assistant pulls at the child's feet, one puts one or two fingers of the left hand into the baby's mouth in order to deliver the chin first. This was orginally described by Mauriceau in 1668 in Paris as a method for the delivery of the aftercoming head in difficult cases.

(Mauriceau, 1668; Hoogeveen, 1956; Liem Siong Kian, 1962)

Smellie manoeuvre: a hand is inserted into the vagina and two fingers are passed until they rest on each canine fossa, the body of the child lying on the forearm. The head is kept well flexed. The other hand is placed over the shoulders and pulls the baby downwards. This modification of Mauriceau technique was published by Smellie (1752). In Germany Veit (1836) made this technic more popular. The procedure is recognized nowadays as the method of Mauriceau-Veit-Smellie.

(Smellie, 1752; Hoogeveen, 1956; Liem Siong Kian, 1962)

Martin-Wiegand-Winckel: One hand exerts pressure above the symphysis at the side of the occiput, in cooperation with the internal hand, which presses two fingers against the upper jaw.

(Wiegand, 1822)

Lovset manoeuvre: The fetal body is rotated over approximately 180 degrees, in such a way that the posterior shoulder appears under the symphysis, whereby the original posterior arm delivers almost spontaneously. Rotation to the orginal position will then simplify the delivery of the other arm (Lovset,1936; v Waes v.d. Velde and $\mathrm{v}$ Waes, 1954)

Medio-lateral episiotomy was routinely used in all vaginal deliveries.

Primary cesarean section: a cesarean section performed electively before the start of labor: e.g a primary cesarean section at a moment when the fetal membranes are still intact and uterine contractions have not yet started. 
Secondary cesarean section: a section performed during labor or after rupture of membranes with no uterine activity.

The indications for cesarean section were subdivided into:

(1) fetal indications: a) fetal distress as diagnosed by abnormal fetal heart-rate pattern; b) fetal acidosis as diagnosed by fetal blood sampling; c) clinically assumed fetal hypoxaemia; d) prevention of possible fetal complications.

(2) dystocia: feto-pelvic disproportion or failure of progress of labor.

(3) maternal indications: severe maternal illness or scarred uterus.

(4) placental indications: abruptio placentae, placenta previa

Indications for cesarean section were described as precisely as possible and all cases were analysed for this purpose by one senior obstetrician.

In both Gent and Maastricht, cesarean section was performed using a low transverse uterine incision.

\subsubsection{Newborn data (Addendum 3.1):}

Birth: Live birth is the complete expulsion or extraction from its mother of a product of conception, irrespective of the duration of pregnancy, which after such a separation breathes or shows any other evidence of life, such as beating of the heart, pulsation of the umbilical cord, or the definite movement of voluntary muscles, whether or not the umbilical cord has been cut or the placenta is attached; each product of such a birth is considered live born (WHO,1977-Approved by FIGO, 1976 and 1982)

Birth weight (grams): the first weight of the newborn obtained after birth. This weight should be measured preferably within the first hour of life, before significant postnatal weight loss has occurred (WHO,1977-Approved by FIGO,1976 and 1982).

Low birth weight: weight between $1500-2499$ gram (up to and including $2499 \mathrm{~g}$ )

Very low birth weight: weight between 500-1499 gram (up to and including $1499 \mathrm{~g}$ )

Preterm birth: birth at a gestational age less than 37 completed weeks (less than 259 completed days).

(WHO, 1977-Approved by FIGO, 1976 and 1982) 
Small for gestational age: birth weight below to the 10 th percentile corrected for sex and parity according the Amsterdam growth table (Kloosterman, 1970).

Apgar score: Apgar scores were recorded at 1 and 5 minutes after birth (Apgar, 1953; Apgar and James, 1962). A score of less than 7 was chosen as the critical value.

Umbilical artery and vein pH: The cord was clamped immediately after birth with 3 clamps, isolating a piece of $10-15 \mathrm{~cm}$, from which a blood sample was withdrawn. Blood gas analysis was carried out immediately after obtaining the sample.

Blood was either collected in a syringe and transferred to a glass capillary (Maastricht) or directly collected in glass capillairies (Gent) right after birth from the umbilical artery and vein for $\mathrm{pH}$-determination.

Comparison of measurements made in Gent and Maastricht by means of buffer solution showed no statistical differences.

The study included both venous and arterial samples, thus eliminating errors in identifying the source of the sample as venous or arterial when determinations were similar in both samples.

Transferral to the neonatal unit: any transportation to or stay in the neonatal unit of the child.

Artificial ventilation: any ventilation with or without intubation (mask and bag) within 24 hours of delivery.

Correction of neonatal acidosis: correction of acidosis by means of sodium bicarbonate within 24 hours of delivery:

Neonatal morbidity: estimated by intracranial hemorrhage, seizures, respiratory distress syndrome (RDS), neonatal infection, congenital malformation, birth trauma, duration of hospital stay or general and neurological examination within 24 hours following birth and at an age of one year. Bronchopulmonary dysplasia and retinopathy of prematurity (RDP) as late complications of RDS were also scored.

Intracranial hemorrhage: the diagnosis of intracranial hemorrhage was made by ultrasound, CT-scan and/or autopsy.

Ultrasound examination was performed in Maastricht using a Technicare realtime section scanner with a $5 \mathrm{MHZ}$ probe; $\mathrm{CT}$ scan examination was performed with a Philips Tomoscan 350 . In Gent a Krantzbühler type $4000 \mathrm{~S} / \mathrm{L}$ realtime sector scanner with a $5 \mathrm{MHZ}$ probe was used.

A standard intracranial ultrasound examination consisted of three sagittal sections (left, median and right parasagittal sections) and 3 coronal sections (antero-cerebral, mid-cerebral and postero-cerebral). Neonatal intracranial hemorrhage was recorded on a standardized protocol sheet with a specific grading system for intracerebral 
hemorrhage according to Papile et al, 1978 (Addendum 3.2).

In Maastricht uitrasonography of intracranial structures was done routinely postpartum within 48 hours after birth, regardless of wheter neonates were symptomatic or not, except in a small number of cases at the start of the project. In Gent this examination of the brain by $C T$ scan or ultrasound was not regularly used.

Revision of all ultrasound examinations was performed by two experienced radiologists after six months. The original diagnosis was unknown to these two examinators.

Seizures: those seizures for which medication was required.

Respiratory Distress Syndrome: the requirement of continuous positive airway pressure (CPAP) or artificial ventillation during more than 24 hours in all infants, excluding cases of primary pneumonia. In case of neonatal death within 24 hours, followed by autopsy, this diagnosis was also accepted when the typical microscopic changes for this disease were present.

Antenatal corticosteroid therapy to accelerate fetal lung maturity was not used.

Neonatal infection: neonatal infections were classified as bacterial sepsis and/or meningitis, localized infections(pneumonia) and intrauterine infections (cytomegalovirus, herpes genitalis, Listeria monocytogenes, rubella, syphilis, toxoplasmosis).

Sepsis was accepted as a diagnostic feature when clinical evidence was present without doubt about the diagnosis. In all cases of suspected sepsis bacteriological data were collected. The diagnosis of meningitis was made by examination and/or culture of spinal fluid.

Congenital malformation: congenital malformations determined during pregnancy or post partum by general examination and coded according the classification of organ systems (BPA Classification, 1979). Groups and subgroups of congenital anomalies classified according to the ICD 9th revision code.

Smaller anomalies such as congenital dislocation of the hip, inguinal hernia and congenital hydrocele, undescended testicle, hypospadia and epispadia were not recorded.

Birth trauma: all palsies, fractures, significant visceral traumata, and other traumata, which possibly were caused by the delivery.

Hospital stay of the newborn: number of days between birth and discharge of the child from the neonatal unit or any hospital where the child was admitted continuously following birth. This was noted only for the surviving infants. Infants who died during the initial hospital stay were described separately. 


\section{Neurological examination:}

All neonates underwent a general and neurological examination within 48 hours after birth.

The neonatal neurological examination was carried out according to the method described by Precht1 (1977). Standardisation of examination and diagnosis was obtained by using a special sheet which was developed to score the neurological data and diagnosis (see Addenda 3.3,3.4 and 3.5).

No neonatal neurological optimality score was used. The examination was performed in principle within 48 hours after birth. In cases where this was not possible the infant was examined before discharge from the hospital.

Neurological examination was performed by an experienced paediatrician or paediatric neurologist.

\section{Date and time of neonatal death:}

Fetal death was considered ante partum if evidence of demise was present before the onset of labor or if fetal heart activity could not be detected before the onset of labor.

Fetal death was considered intrapartum if any fetal heart activity was present during labor, but the infant was stillborn.

Perinatal mortality is defined in this study as fetal deaths plus deaths occurring less than 7 completed days after birth, in babies weighing $500 \mathrm{~g}$ or more (Chiswick, 1986).

Antepartum fetal death was excluded in our study.

Perinatal mortality (FIGO) is defined as stillborn infants plus death occurring less than 7 completed days after birth in infants weighing $1000 \mathrm{~g}$ or more.

Neonatal death was defined as death of a liveborn infant before 28 completed days of life.

Early neonatal death was defined as death within 7 completed days after delivery of newborns of $500 \mathrm{~g}$ or more.

Late neonatal death was defined as death after 7 completed days but before $28 \mathrm{com}$ pleted days of life following birth.

(WHO,1977-Approved by FIGO,1976 and 1982, with the modification of "completed days").

Postneonatal death is death after 28 days but before discharge of the child from the hospital. 
Autopsy: in case of death, permission for autopsy was asked in all cases.

Follow-up: A general and neurological examination of all children at the age of one year (corrected for prematurity) was performed using a standardized protocol (Addendum 3.6). These examinations were performed by an experienced paediatrician or paediatric neurologist.

The parents were requested by letter to take part in a single examination of their child. The children were examined according to year of birth. Therefore the children were practically of the same age at the moment of the follow-up examination. If there were grave objections to examination at the hospital, the child was examined at home.

\subsubsection{Puerperal data (Addendum 3.1):}

Maternal fever: temperature of $38.0 \mathrm{C}$ or higher on any two consecutive days of the first 10 days post partum or a temperature of $39.0 \mathrm{C}$ or higher on any of the first 10 days excluding the first 24 hours. The temperature was measured orally at least 4 times daily by a standard technique, for as long as the patient remained in hospital.

Patients with a temperature of more than $38.0 \mathrm{C}$ before delivery were excluded. In no cases were prophylactic antibiotics given and antibiotics were administered onlly when true signs of infections were present postoperatively.

Wound infection: presence of purulent drainage from the incision with induration and tenderness with or without fever.

Urinary tract infection: a positive urinary culture obtained from a midstream urine specimen with a significant bacteriuria $(>100.000$ organisms $/ \mathrm{ml})$.

Blood transfusion: the number of units of blood transfused. A unit of blood is defined as $500 \mathrm{ml}$ of blood or $250 \mathrm{ml}$ of packed cells. Blood transfusions during pregnancy were not scored.

Hospitalisation of the mother: the number of days in the hospital post partum.

Maternal death: the death was defined as the death of any woman while pregnant or within 42 completed days of delivery, irrespective of the duration and the site of the pregnancy, from any cause related to or aggravated by the pregnancy or its management, but not from accidental or incidental causes (WHO, 1977-Approved by FIGO, 1976 and 1982). 


\subsubsection{Data analysis}

All the data were recorded on data sheets. In each hospital one person checked the completeness and accuracy of the patient records. These sheets were sent for correction, validation and processing to the departement of medical informatics of the University of Gent.In order to get an overview of the total activities of both departments, a limited number of general data were retrieved from the annual reports of the relevant periods (Tables 3.A and 3.B).

Table 3.A- Overwiew of total mumber of births (birth weight $\geqslant 500 \mathrm{~g}$ ) in Gent.

\begin{tabular}{|c|c|c|c|}
\hline & 1984 & 1985 & 1986 \\
\hline Number of patients & 873 & 822 & 834 \\
\hline \multicolumn{4}{|l|}{ Breech presentation } \\
\hline Number & 62 & 51 & 47 \\
\hline Percentage & 7.1 & 6.2 & 5.6 \\
\hline Multiple births (children) & 44 & 29 & 49 \\
\hline \multicolumn{4}{|l|}{ Single births } \\
\hline$\geqslant 2500 \mathrm{~g}$ & 769 & 739 & 724 \\
\hline$<2500 \mathrm{~g}$ & 64 & 58 & 71 \\
\hline \multicolumn{4}{|l|}{ Cesarean section } \\
\hline Number & 76 & 58 & 51 \\
\hline Percentage & 8.7 & 7.0 & 6.1 \\
\hline \multicolumn{4}{|l|}{ Perinatal mortality (Figo) } \\
\hline Number & 15 & 18 & 17 \\
\hline Percentage & 1.8 & 2.2 & 2.0 \\
\hline \multicolumn{4}{|l|}{ Primiparous } \\
\hline Number & 421 & 344 & 374 \\
\hline Percentage & 48 & 41 & 45 \\
\hline
\end{tabular}

Table 3.8- Overview of total number of births (birth weight $\geqslant 500 \mathrm{~g}$ ) in Maastricht.

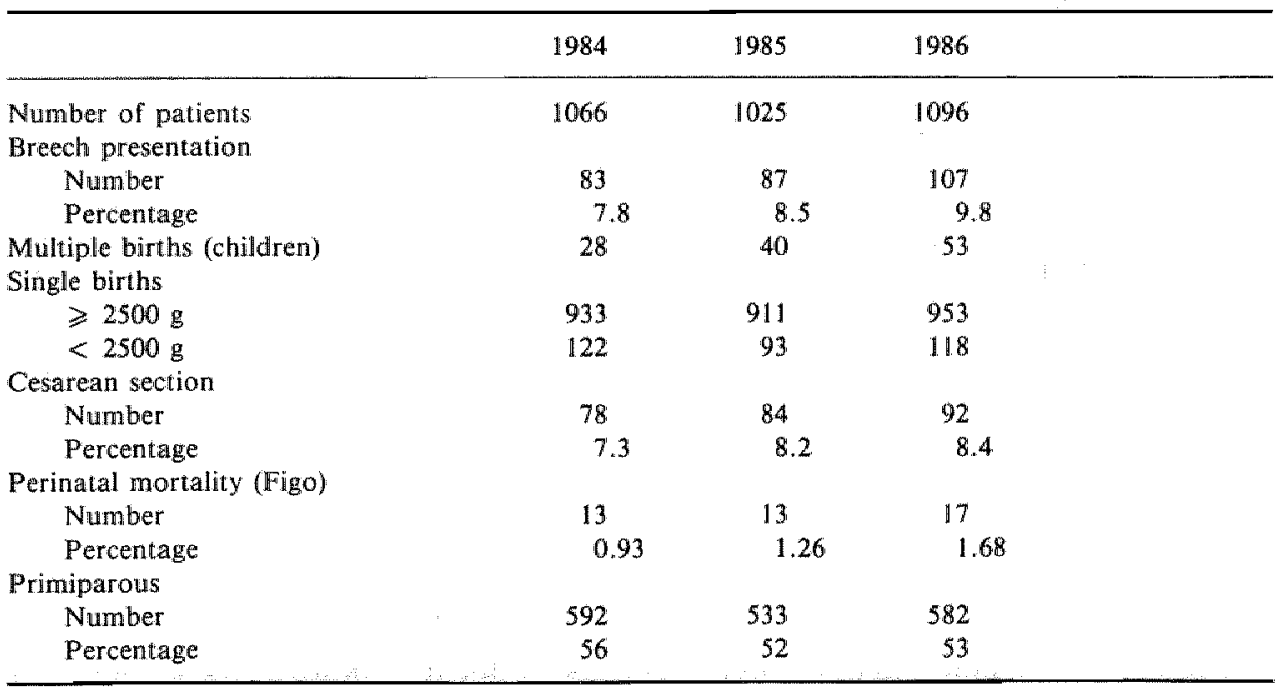


The results of vaginally and abdominally delivered breeches were compared as to neonatal, and maternal outcome and comparisons were made between the two hospitals. The outcome was evaluated in three birth weight categories: $500-1499 \mathrm{~g}$, $1500-2499 \mathrm{~g}$ and $2500 \mathrm{~g}$ or more, because many problems regarding the neonatal outcome will be due to prematurity itself rather than to the mode of delivery. Birth weight, rather than gestational age, was used as the index of maturity. In all three groups, outcome in relation to type of breech presentation and parity was evaluated.

\subsubsection{Statistical methods}

Data were summarized by sample size and descriptive parameters (mean, standard deviation, etc) and often visualized by graphical presentations (histogram, pie-chart, etc.).

Categorical data, expressed as frequencies, were compared by the Chi-square test. In those situations were the expected frequencies are below the constraints, Fisher's exact probability test was used. The evidence of associations for the different subgroups was combined and tested by the Mantel-Haenszel's summary high square test. On the other hand inferential statistics on continuous data were analysed by the use of an appropriate test, preferring non-parametric methods, in view of the non-normal distribution form of most of the study variables.

Comparisons between two non-related groups (the two clinics for example) were performed by the Mann-Whitney U-test, whereas in the case of paired samples the Wilcoxon matched-pairs rank-sum test was used.

Testing the null hypothesis of any linear relationship between two study variables was expressed by the Spearman rank correlation coefficient ' ${ }^{\mathrm{s}}$.

Comparison tests were always supplemented by a number of values and a range of descriptive parameters. (e.g. median, range).

Correlations between two study variables are visualized by a scatter plot of the data. Statistically significant differences required a significance level of 0.05 . Higher significance levels are given if appropriate (e.g. $\mathrm{P}<0.001$ ).

\subsection{Study population Gent-Maastricht}

Table 3.1 depicts a number of data regarding the study populations in the two hospitals.

The number of multiple births was 31 in Gent and 31 in Maastricht.

In Gent two congenital malformations incompatible with life were found, against three in Maastricht.

The latter concerned two cases of hydrocephaly and one case of a cardiac tumor (neurofibroma). The two cases in Gent were one case of Potter's syndrome and one case of congenital pulmonary hypoplasia probably due to rupture of the membranes 
at 20 weeks of amenorrhoe (probably earlier) and birth at 28 weeks. At autopsy the lungs weigheds $19 \mathrm{~g}$.

Eleven cases of antepartum fetal death occurred in Gent, compared to three cases in Maastricht. Some data for these patients are listed in Table 3.1a.

Table 3.1a Ante partum fetal death.

\begin{tabular}{llllllll}
\hline $\begin{array}{l}\text { Patient } \\
\text { No. }\end{array}$ & $\begin{array}{l}\text { birth } \\
\text { weight }\end{array}$ & sex & booked & age & parity & weeks & cause of death \\
\hline $84 / 120$ & 550 & F & no & 26 & 2 & 30 & unknown \\
$84 / 526$ & 820 & M & no & 19 & 1 & 20 & unknown \\
$84 / 653$ & 680 & M & yes & 25 & 1 & 24 & unknown \\
$84 / 829$ & 590 & F & yes & 27 & 1 & 22 & unknown \\
$85 / 285$ & 2010 & F & no & 39 & 3 & 36 & unknown \\
$85 / 605$ & 2180 & F & no & 25 & 1 & 36 & unknown \\
$85 / 400$ & 578 & F & no & 27 & 2 & 22 & anencephaly \\
$85 / 512$ & 710 & F & no & 26 & 1 & 22 & Potter's syndiome \\
$85 / 751$ & 660 & F & no & 30 & 3 & 28 & unknown \\
$85 / 783$ & 730 & F & no & 26 & 1 & 28 & placental insufficiency \\
$86 / 122$ & 520 & F & no & 26 & 1 & 27 & chronic hypoxacmia \\
$84 / 998$ & 670 & F & yes & 26 & 3 & 26 & unknown \\
$84 / 1070$ & 920 & M & yes & 18 & 1 & 29 & pre-eclampsia \\
$85 / 877$ & 1560 & F & yes & 32 & 1 & 33 & abruptio placentae \\
\hline
\end{tabular}

\subsubsection{Maternal characteristics of the study population}

The characteristics of the populations are shown in Table 3.2 .

The mean age of the mothers was $27 \pm 4$ years in Gent and $28 \pm 5$ years in Maastricht. The mean height of the patients was $163 \pm 6 \mathrm{~cm}$ in Gent and $165 \pm 6 \mathrm{~cm}$ in Maastricht.

Table 3.2 Maternal characteristics of the study population in both hospitals.

\begin{tabular}{|c|c|c|c|}
\hline $\begin{array}{l}\text { Characteristics } \\
\text { of patients }\end{array}$ & $\begin{array}{l}\text { Gient } \\
(n=94)\end{array}$ & $\begin{array}{l}\text { Manstricht } \\
(n=174)\end{array}$ & $\begin{array}{l}\text { Sigmificance } \\
\text { level }\end{array}$ \\
\hline $\begin{array}{l}\text { Ape (mean } \pm \mathrm{SD} \text { ) } \\
\text { Height (mean } \pm \mathrm{SD} \text { ) } \\
\text { Primiparae }\end{array}$ & $\begin{array}{l}27 \pm 4 \\
163 \pm 6 \\
54(5796)\end{array}$ & $\begin{array}{l}28 \pm 5 \\
165 \pm 6 \\
105(60 \%)\end{array}$ & $\begin{array}{l}\mathrm{NS}^{*} \\
\mathbb{P}<0.01 * \\
\mathrm{NS}^{* *}\end{array}$ \\
\hline \multicolumn{4}{|l|}{ Gestational age (weeks) } \\
\hline$<28$ & $7(70)$ & $10(60 \%)$ & \\
\hline 28-37 & $32(35 \%)$ & $51(29 \%)$ & $\mathrm{NS}^{*}$ \\
\hline $37-42$ & $53(56 \%)$ & $105(60 \%)$ & \\
\hline$\geqslant 42$ & $2(2 \%)$ & $8(50 \%)$ & \\
\hline
\end{tabular}

* Mann-Whitney U test

* Chimsquare test 
In Gent there were $54(57 \%)$ primiparous patients and in Maastricht $105(60 \%)$. Of the Gent patients, $7(7 \%)$ had a gestational age less than 28 weeks; of the Maastricht patients $10(6 \%)$. The Maastricht population included 8 cases $(5 \%)$ with a gestational age of 42 completed weeks or more, the Gent population 2 cases ( $2 \%$ ). With the exception of their mean height, no statistical differences were found between the populations in the two hospitals (Table 3.2).

\subsubsection{Characteristics of neonates presenting in breech at birth}

Table 3.3 depicts the birth weight distribution of neonates in the two hospitals. Birth weight of $2500 \mathrm{~g}$ or more were found in 63 of the Gent neonates $(67 \%)$ and in 126 of the Maastricht neonates $(72 \%)$.

Fifteen neonates (16\%) weighed between 1500-2499 gram in Gent, against 28 (16\%) in Maastricht.

A birth weight below $1500 \mathrm{~g}$ was found in 20 neonates (12\%) in Maastricht and in 16 neonates $(17 \%)$ in Gent.

Tuble 3.3 Birth weight distribution in both hospitals.

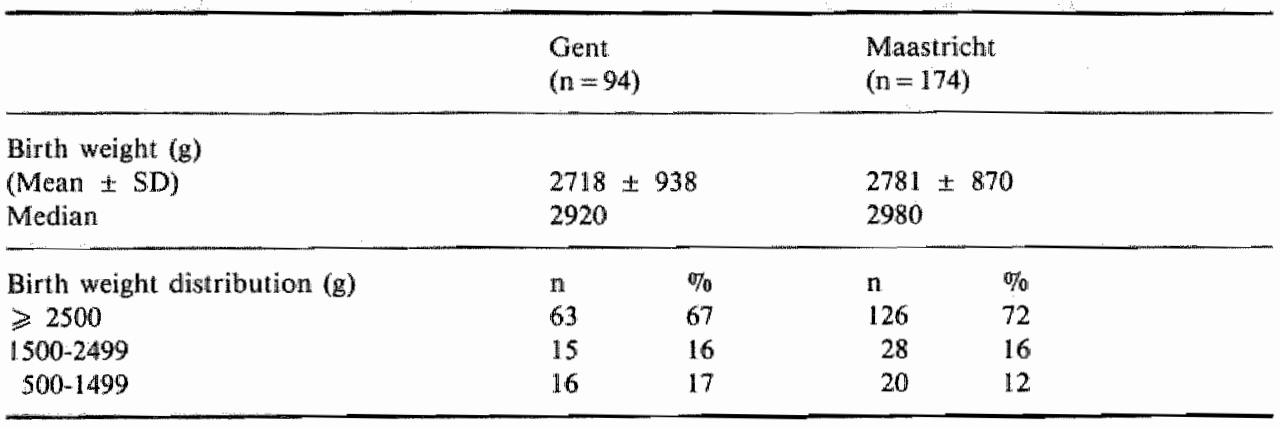

Mamn-Whitney U test: NS

Table 3.4 Characteristics of neonates presemting in breech at birth.

\begin{tabular}{|c|c|c|c|c|c|}
\hline \multirow{4}{*}{$\begin{array}{l}\text { Type of Breech } \\
\text { Frank } \\
\text { non- Frank }\end{array}$} & \multicolumn{2}{|c|}{$\begin{array}{l}\text { Gent } \\
(n=94)\end{array}$} & \multicolumn{2}{|c|}{$\begin{array}{l}\text { Maastricht } \\
(\mathrm{n}=174)\end{array}$} & \multirow[t]{2}{*}{$\begin{array}{l}\text { Chi-square } \\
\text { test }\end{array}$} \\
\hline & n & $\% \%$ & $\mathrm{n}$ & $0 \%$ & \\
\hline & 68 & 72 & 125 & 72 & NS \\
\hline & 26 & 28 & 49 & 28 & NS \\
\hline \multicolumn{6}{|l|}{ Inlants'sex } \\
\hline Male & 39 & 41 & 88 & 51 & NS \\
\hline Female & 55 & 59 & 86 & 49 & NS \\
\hline Sex ratio & 70.9 & & 102.3 & & \\
\hline
\end{tabular}


No significant differences in fetal weight were found between the two hospitals in the study population.

As for the type of breech presentation, a frank breech presentation was the prevalent type in both hospitals: $68(72 \%)$ in Gent and $125(72 \%)$ in Maastricht (Table 3.4). The percentages of frank and non-frank breeches were also similar in both hospitals.

Table 3.4 also shows the classification according to sex in the two hospitals. No statistical differences were found between the two study groups.

\subsubsection{Prenatal care}

In Gent 86 women $(91 \%)$ presented at the outpatient clinic of the university hospital for prenatal care supervised by a gynecologist and/or resident, compared with 84 $(48 \%)$ of the patients in Maastricht. In Maastricht $89(51 \%)$ of the patients were managed ante partum either by midwifes or general practitioners and referred to the hospital during the last weeks of pregnancy, when the breech presentation was persistent. In Gent 5 patients $(5 \%)$ were managed ante partum only by familly practioners (table 3.5).

Table 3.5 Prenatal care.

\begin{tabular}{lcrrr}
\hline & \multicolumn{2}{c}{ Gent $(\mathrm{n}=94)$} & \multicolumn{2}{c}{ Maastricht $(\mathrm{n}=174)$} \\
& $\mathrm{n}$ & $\%$ & $\mathrm{n}$ & $\mathrm{0}_{0}$ \\
\hline Midwife & 0 & 0 & 84 & 48 \\
Family Physician & 5 & 5 & 5 & 3 \\
Resident & 34 & 36 & 30 & 17 \\
Obstetrician & 52 & 55 & 54 & 31 \\
No prenatal controls or unknown & 3 & 4 & 1 & 0.5 \\
\hline
\end{tabular}

The number of intra-uterine transports from other hospitals was 24 in Maastricht (13.707), while in Gent no intra-uterine transport from other hospitals took place. However, the number of non-booked patients in Gent was however 11. Eight of these non-booked cases were referred by a gynecologist outside the university hospital, two by a family physician and one patient appeared to have had no antenatal care at all. In addition, there were 9 referrals from other hospitals to the Gent university hospital for induction of labor after intra-uterine death, since in this area prostaglandine induction was possible in the university hospital.

The numbers of prenatal visits to the two hospitals are listed in Table 3.5a. 
Table 3.5a Number of prenotal visits.

\begin{tabular}{lcccc}
\hline & \multicolumn{2}{c}{$\begin{array}{c}\text { Gent }(\mathrm{n}=94) \\
\mathrm{n}\end{array}$} & \multicolumn{2}{c}{$\begin{array}{c}\text { Maasticht } \\
\mathrm{n}\end{array}$} \\
\hline $0-4$ & 9 & 10 & 10 & 6 \\
$5-9$ & 34 & 36 & 44 & 25 \\
$10-14$ & 34 & 36 & 92 & 53 \\
315 & 10 & 11 & 24 & 14 \\
unknown & 7 & 7 & 4 & 2 \\
\hline
\end{tabular}

Chi-square test: NS

\subsubsection{Course of pregnancies}

In $7(7 \%)$ pregnancies in Gent and in $4(2 \%)$ pregnancies in Maastricht chronic hypertension was diagnosed. Gestational hypertension was diagnosed in 11 cases $(12 \%)$ in Gent, against 24 cases $(14 \%)$ in Maastricht. No statistical differences were found between the two hospitals (Table 3.6).

Table 3.6 Hypertension disorders in both hospirals according to the ciassification by Davey and McGillivray.

\begin{tabular}{lrrrrl}
\hline & \multicolumn{2}{c}{$\begin{array}{c}\text { Gent }(\mathrm{n}=94) \\
\mathrm{n}\end{array}$} & $\begin{array}{l}\text { Maastricht }(\mathrm{n}=174) \\
0\end{array}$ & $\mathrm{n}$ & $\begin{array}{l}\text { Chi-square } \\
\text { test }\end{array}$ \\
\hline Chronic hypertension & 7 & 7 & 4 & 2 & NS \\
Gestational hypertension & 11 & 12 & 24 & 14 & NS \\
Unclassified hypertension & 2 & 2 & 1 & 0.5 & NS \\
\hline
\end{tabular}

Diabetes mellitus was not diagnosed in Gent. In Maastricht diabetes mellitus was present in 3 mothers (Table 3.7 ).

There were no statistically significant differences between the two hospitals. In 6 cases $(6 \%)$ in Gent and in $16(9 \%)$ cases in Maastricht, vaginal blood loss occurred in the second half of pregnancy.

Table 3.7 Frequency of complicating moternal factors.

\begin{tabular}{|c|c|c|c|c|c|}
\hline \multirow[t]{2}{*}{ Maternal factors } & \multicolumn{2}{|c|}{ Gent $(n=94)$} & \multicolumn{2}{|c|}{ Maastricht $(\mathrm{n}=174)$} & \multirow{2}{*}{$\begin{array}{l}\text { Chi-square } \\
\text { test }\end{array}$} \\
\hline & $\mathrm{n}$ & $\%$ & $\mathrm{n}$ & $\%$ & \\
\hline Diabetes mellitus & 0 & 0 & 3 & 2 & $\mathrm{NS}$ \\
\hline Third trimester vaginal bleeding & 6 & 6 & 16 & 9 & NS \\
\hline Ciguretite smoking & 10 & 11 & 36 & $2 \|$ & $p \leqslant 0.05$ \\
\hline Prolonged rupture of membranes & 9 & 10 & 17 & 10 & NS \\
\hline Admission to hospital & 64 & 68 & 66 & 38 & $p<0.001$ \\
\hline
\end{tabular}


In Gent, 10 of the gravidae (11\%) were smokers, compared with $36(21 \%)$ in Maastricht. This difference is statistically significant.

Prolonged rupture of the membranes occurred in 9 cases (10\%) in Gent and in 17 cases $(10 \%)$ in Maastricht.

Hospital admission occurred in 64 cases $(68 \%)$ in Gent and in 66 cases $(38 \%)$ in Maastricht. This difference is statistically significant.

\subsubsection{Management of labor}

The final management during labor in both hospitals is summarized in Table 3.8 . As is shown in this table, there were certain differences in the pattern of care during labor, but the general policy of management in both departments is the same. Differences in policy between the two hospitals include induction and augmentation of labor, use of anaesthetics and narcotic drugs and artificial rupture of the membranes. These reached the level of statistical significance only for epidural and regional anaesthesia.

Table 3.8 Management of labor.

\begin{tabular}{|c|c|c|c|c|c|}
\hline & \multicolumn{2}{|c|}{ Gent $(n=94)$} & \multicolumn{2}{|c|}{ Maastricht $(n=174)$} & \multirow{2}{*}{$\begin{array}{l}\text { Chi-square } \\
\text { test }\end{array}$} \\
\hline & $n$ & $\%$ & $\mathbf{n}$ & $\%$ & \\
\hline Induction of Labor & 8 & 9 & 5 & 3 & $\mathbb{N S}$ \\
\hline Augmentation & 36 & 38 & 67 & 39 & NS \\
\hline General anesthesia & 33 & 35 & 52 & 30 & NS \\
\hline Epidural anesthesia & $22(5)$ & $23(14)$ & $7(4)$ & $4(7)$ & $\mathrm{p}<0.001$ \\
\hline Regional analgesia & 32 & 34 & 104 & 60 & $p<0.001$ \\
\hline Sedatives & 4 & 4 & 5 & 3 & NS \\
\hline Artificial rupture of membranes & 20 & 21 & 22 & 13 & NS \\
\hline
\end{tabular}

Epidural anesthesia during cesarean section in parenthesis and expressed as percentage regarding total number of cesarean sections (NS; chi-square test)

Intravenous oxytocin or prostaglandins were used to start uterine contractions or to increase dysfunctional labor in 67 cases $(39 \%)$ in Maastricht and in 36 cases $(38 \%)$ in Gent. Induction of labor occurred in 5 cases $(3 \%)$ in Maastricht and in 8 cases $(9 \%)$ in Gent. Local, pudendal or paracervical anaesthesia was used in 104 cases $(60 \%)$ in Maastricht and in 32 cases $(34 \%)$ in Gent. This difference was statistically significant.

Epidural anaesthesia was performed in 7 cases (4\%) in Maastricht and in 22 cases $(23 \%)$ in Gent. Epidural anaesthesia during cesaerean section was not excluded and is noted in parenthesis.

Anesthesia for the 36 patients delivered by cesarean section in Gent consisted of a general procedure in 31 cases (33\%) and of epidural anesthesia in 5 cases(14\%). In two cases general anesthesia was used during vaginal delivery. 
In Maastricht $52(30 \%)$ received general anesthesia, while 4 patients $(7 \%)$ received epidural anesthesia.

Analgesics and/or sedatives were rarely used in either hospital.

The membranes were artificially ruptured in 20 cases (21\%) in Gent and in 22 cases $(13 \%)$ in Maastricht.

In 54 cases $(58 \%)$ in Gent and in 131 cases $(75 \%)$ in Maastricht rupture of membranes occurred spontaneously.

\subsubsection{Mode of delivery}

Of the 94 neonates in Gent $36(38 \%)$ were delivered by cesarean section and 58 $(62 \%)$ were delivered vaginally. Of the 174 neonates in Maastricht $118(68 \%)$ were clelivered vaginally, while $56(32 \%)$ were born abdominally (Tablle 3.9 ).

Table 3.9 Mode of Delivery.

\begin{tabular}{|c|c|c|c|}
\hline & $\begin{array}{l}\text { Gent } \\
(n=94)\end{array}$ & $\begin{array}{l}\text { Maastricht } \\
(n=174)\end{array}$ & $\begin{array}{l}\text { Chi-square } \\
\text { test }\end{array}$ \\
\hline $\begin{array}{r}\text { Cesarean Section } \\
\text { before labor }\end{array}$ & $\begin{array}{l}36(38 \%) \\
19(20 \%)\end{array}$ & $\begin{array}{l}56(32 \%) \\
10(6 \%)\end{array}$ & $\begin{array}{l}\mathbb{N S} \\
\mathrm{p}<0.001\end{array}$ \\
\hline Vaginal Delivery & $58(62 \%)$ & $1.18(68 \%)$ & $\mathrm{NS}$ \\
\hline Unassisted Breech (Bracht Manoeuwre) & $34(59 \%)$ & $67(57 \% 0)$ & NS \\
\hline Assisted Breech & $22(38 \%)$ & $49(42 \%)$ & NS \\
\hline Breech Extraction & $2(3 \%)$ & $2(2070)$ & NS \\
\hline
\end{tabular}

The incidence of cesarean section in the breech population of the two hospitals was $38 \%$ in Gent and 32\% in Maastricht. This means there was no statistically significant difference between the two hospitals regarding the mode of delivery.

Nineteen primary cesarean sections (20\%) were carried out in Gent and 10 in Maastricht $(6 \%)$. This difference is statistically significant. The reasons for primary cesarean section in Gent included a supposed cephalopelvic disproportion in 3 cases and signs of intra-uterine asphyxia before labor started in 5. In 10 cases primary cesarean sections were performed for maternal indications, five of which were performed on the indication of repeat section only.

In the one remaining case the indication was a placental factor.

In Maastricht 6 cases with a manifest cephalopelvic disproportion and 4 with signs of intra-uterine asphyxia before labor formed the indications for primary cesarean section.

The most frequent indication for cesarean section in Maastricht and Gent was no progress of labor or absence of engagement ( $50 \%$ and $31 \%$ respectively). In Gent maternal factors accounted for a section indication (28\%) more frequently than in Maastricht $(0 \%)$, and this difference was statistically significant. Fetal indications 
were the reason for cesarean section in 11 cases $(31 \%)$ in Gent and in $27(48 \%)$ cases in Maastricht (Table 3.10).

Table 3.10 Indications for cesarean section.

\begin{tabular}{|c|c|c|c|c|c|}
\hline & \multicolumn{2}{|c|}{ Gertt $(n=36)$} & \multicolumn{2}{|c|}{ Matastricht $(\mathrm{n}=56)$} & \multirow{2}{*}{$\begin{array}{l}\text { Chi-square } \\
\text { test }\end{array}$} \\
\hline & $\mathrm{n}$ & 啭 & in & \% & \\
\hline Fetal & 11 & $3 i 1$ & 27 & 48 & NS \\
\hline Dystocia & 11 & 31 & 28 & 50 & NS \\
\hline Placental & 4 & 11 & 1 & 2 & NS \\
\hline Maternall & 10 & 28 & 0 & 0 & $p<0.001$ \\
\hline
\end{tabular}

Placental factors (Placenta praevia, solutio placentae) rarely constituted the reason for cesarean section in both hospitals ( 4 cases in Gent and one case in Maastricht). Of all vaginal deliveries in Gent $59 \%(\mathrm{n}=34)$ occurred spontaneously using the Bracht manoeuvre, while $38 \%(n=22)$ were performed by assisted breech extraction. In 2 cases $(3 \%$ ) total breech extraction was necessary, mainly due to signs of deteriorating intra-uterine condition as estimated by fetal heart rate monitoring ( $\mathrm{Ta}$ ble 3.9).

In Maastricht $57 \%(\mathrm{n}=67)$ of the deliveries occurred spontaneously using the Bracht manoeuvre, while $42 \%(n=49)$ were performed by assisted breech extraction. Total breech extraction was performed In 2 cases $(2 \%)$ in Maastricht because of signs of fetal hypoxaemia. (Table 3.9).

As for the assisted breech deliveries in Gent, a Van Deventer or Müller manoeuvre was applied once, a De Snoo or Mauriceau manoeuvre 3 times and a Lóvset procedure 15 times. In two cases a Mauriceau manoeuvre was combined with a Lovset manoeuvre and in one case a forcipal extraction was used to deliver the aftercoming head (tablle 3.10a).

Table 3.10a Assisted breech manoewwres in the fwo hospitals.

\begin{tabular}{|c|c|c|c|c|}
\hline & \multicolumn{2}{|c|}{ Gent $(n=22)$} & \multicolumn{2}{|c|}{ Maastricht $(n=49)$} \\
\hline & $n$ & 80 & $\mathrm{n}$ & of \\
\hline V Deventer/Müller & 1 & 5 & 20 & 57 \\
\hline De Snoo/Mauriceau & 3 & 14 & 11 & 22 \\
\hline Lörset & 15 & 68 & 1 & 2 \\
\hline De Snoo/Mauriceau-Lowset & 2 & 9 & 1 & 2 \\
\hline $\begin{array}{l}\text { Van Deventer/Müller- } \\
\text { De Snoo/Mauriceau }\end{array}$ & 0 & 0 & 15 & 31 \\
\hline Forcipal extraction & 1 & 5 & 1 & 22 \\
\hline
\end{tabular}

In Maastricht a Van Deventer or Müller manoeuvre was applied in 20 cases, a Mauriceau manoeuvre or de Snoo's manoeuvre in 11 cases and a Løvset procedure in one case. 
In Maastricht a Van Deventer or Müller manoeuvre was often combined with an initial Bracht manoeuvre for the development of the head ( 20 cases).

In 15 cases De Snoo or Mauriceau manoeuvres were used in combination with a Van Deventer or Müller manoeuvre. In one case a De Snoo manoeuvre was used, in combination with a Lovset procedure and in one case forcipal extraction was used to deliver the aftercoming head (Table 3.10a).

In view of the fact that the management of breech presentation did not seriously differ for the two hospitals, it is justified to consider both populations as one study group.

\subsection{Study population: differences between vaginally and abdominally delivered patients.}

After exclusion of multiple pregnancies $(n=62)$, ante partum fetal deaths $(n=14)$ and lethal malformation $(n=5), 268$ cases were left for analysis: 36 cases with a birth weight of 500-1499 grams, 43 cases with a birth weight of 1500-2499 grams and 189 neonates weighing more than $2500 \mathrm{~g}$ (Tables 3.11 and 3.13).

Of the total study group of 268 cases, $92(34 \%)$ neonates were delivered by cesarean section and $176(66 \%)$ were born vaginally.

Table 3.11 Selection of the study populations (\%).

\begin{tabular}{|c|c|c|}
\hline \multicolumn{3}{|c|}{ Gent/Maastricht } \\
\hline No. of Births $(\geqslant 500 \mathrm{~g})$ & 4846 & \\
\hline No. of Breeches & 349 & $(7.2)$ \\
\hline Number of cases excluded & 81 & $(23.2)$ \\
\hline Multiple births (neonates) & \multicolumn{2}{|c|}{62} \\
\hline Lethal malformations. & \multicolumn{2}{|c|}{5} \\
\hline Antepartum fetal deaths & \multicolumn{2}{|c|}{14} \\
\hline Number of remaining cases & 268 & (5.5) \\
\hline
\end{tabular}

\subsubsection{Maternal characteristics of the study population}

The differences between the vaginally delivered group and the abdominally delivered group are described in Table 3.12 .

There were 101 primigravidas $(57 \%)$ and 75 multigravidas $(43 \%)$ in the vaginal group and 58 primigravidas $(63 \%)$ and 34 multigravidas $(37 \%)$ in the cesarean section group.

With exception for the mean height, no statistically significant differences were found between the vaginal and abdominal group (Table 3.12). 
Table 3.12 Moternal characteristics of the stady popalorion the the groups.

\begin{tabular}{|c|c|c|c|}
\hline $\begin{array}{l}\text { Characteristics } \\
\text { of patients }\end{array}$ & $\begin{array}{l}\text { Vaginal Dellwery } \\
(n=176)\end{array}$ & $\begin{array}{l}\text { Cesarean Section } \\
(\mathrm{n}=92)\end{array}$ & $\begin{array}{l}\text { Significance } \\
\text { lewel }\end{array}$ \\
\hline Age mean \pm SD & $27 \pm 4$ & $26 \pm 5$ & NS* \\
\hline Height (mean 1 SD) & $166 \pm 5$ & $164 \pm 6$ & $p<0.0 *^{*}$ \\
\hline Primiparae & $101(5)$ & $58(630 \%)$ & $\mathrm{NS}^{* * *}$ \\
\hline \multicolumn{4}{|l|}{ Gestational age (weeks) } \\
\hline$<28$ & $14(8 \%)$ & $3(3 \%)$ & \multirow{4}{*}{ NS* } \\
\hline $28-37$ & $46(260)$ & $37(40 \%)$ & \\
\hline $37-42$ & $11)(63 \%)$ & $47(51 \%)$ & \\
\hline$\geqslant 42$ & $5(3 \%)$ & $5(5 \%)$ & \\
\hline
\end{tabular}

* Mann-Whiney U test

* Chisquare test.

\subsubsection{Characteristics of neonates presenting in breech at birth}

Birth weight of $2500 \mathrm{~g}$ or more was found in 132 neonates $(75 \%)$ in the vaginal group and in 57 neonates $(62 \%)$ in the abdominal group; 26 neonates (15\%) in the vaginal group and 17 neonates $(18 \%)$ in the abdominal group weighed between $1500-2499 \mathrm{~g}$.

A birth weight below $1500 \mathrm{~g}$ was found in 18 neonates $(10 \%)$ in the vaginal group and in 18 neonates $(20 \%)$ in the abdominal group.

Differences in fetal weight were not found between vaginally and abdominally delivered neonates in the total study group.

Sixteen of the infants weighing more than 2500 grams at birth were premature ( $<$ 37 weeks of gestational age). All other infants weighing more than $2500 \mathrm{~g}$ were more than 37 weeks gestational age. No neonates were small for their gestational age.

Table 3.13 Birth weight distribution for the two groups.

\begin{tabular}{|c|c|c|c|c|}
\hline \multirow{3}{*}{$\begin{array}{l}\text { Birth weight }(\mathrm{g}) \\
\text { (Mean } \pm \mathrm{SD}) \\
\text { Median }\end{array}$} & \multicolumn{2}{|c|}{$\begin{array}{l}\text { Vaginal Delivery } \\
(n=176)\end{array}$} & \multicolumn{2}{|c|}{$\begin{array}{l}\text { Cesarean Section } \\
(\mathrm{n}=92)\end{array}$} \\
\hline & \multicolumn{2}{|c|}{$2811 \pm 793$} & \multicolumn{2}{|c|}{$2660 \pm 1062$} \\
\hline & \multicolumn{2}{|c|}{2945} & \multicolumn{2}{|c|}{2980} \\
\hline Birthweight distribution (g) & $\mathrm{n}$ & $\%$ & $\mathrm{n}$ & $0_{\text {柏 }}$ \\
\hline$\geqslant 2500$ & 132 & 75 & 57 & 62 \\
\hline $1500-2499$ & 26 & 15 & 17 & 18 \\
\hline $500-1499$ & 18 & 10 & 18 & 20 \\
\hline
\end{tabular}

Mann-Whitney U test: NS 
In the birth weight category of $1500-2499$ grams 5 neonates in the cesarean section group and 12 neonates in the vaginal group were small for their gestational age. Of the group weighing between 500 and 1499 grams 10 neonates in the cesarean section group and one neonate in the vaginal group were small for gestational age. Statistically significant differences in the incidence of being small for gestational age between the vaginally delivered neonates and the abdominally delivered neonates were found only in the birth weight category of $500-1499 \mathrm{~g}$ $(\mathrm{p}<0.005$, chi-square test).

As regards the type of breech presentation, the prevalent type in both groups was frank breech presentation. The percentages of frank and non-frank breeches were similar in both groups (Table 3.14).

Table 3.14 Characteristics: of neonates presenting in breech at birth.

\begin{tabular}{|c|c|c|c|c|c|}
\hline & \multicolumn{2}{|c|}{$\begin{array}{l}\text { Vaginal Delivery } \\
(n=176)\end{array}$} & \multicolumn{2}{|c|}{$\begin{array}{l}\text { Cesarean Section } \\
(n=92)\end{array}$} & \multirow[t]{2}{*}{$\begin{array}{l}\text { Chi-square } \\
\text { test }\end{array}$} \\
\hline Typle of Breech & $n$ & $\%$ & n & $q_{0}$ & \\
\hline Frank & 131 & 74 & 62 & 67 & $\mathrm{NS}$ \\
\hline non- Frank & 45 & 26 & 30 & 33 & $\mathrm{NS}$ \\
\hline \multicolumn{6}{|l|}{ Infant" sex } \\
\hline Male & 82 & 47 & 45 & 49 & NS \\
\hline female & 94 & 53 & 47 & 51 & NS \\
\hline Sex ratio & 87.2 & & 95.7 & & \\
\hline
\end{tabular}

Chi-square test: NS

The distribution of male and female infants and the calculated sex ratios in the two groups are also shown in Table 3.14. Of the 176 cases in the vaginal group, $82(47 \%)$ neonates were male and $94(53 \%)$ were female. The sex ratio, i.e the number of males per 100 females, was 87.2.

Of the 92 cases in the cesarean section group, 45 neonates (49\%) were male and 47 $(51 \%)$ were female. The sex ratio was 95.7 .

No statistical differences were found between the two groups (Table 3.14).

\subsubsection{Prenatal care}

Of the women in the abdominal group $67(73 \%)$ had presented at the outpatient clinic of the university hospitals, for prenatal care supervised by a gynacologist or resident. In the vaginal group, this number was $103(59 \%)$. Twenty five $(27 \%)$ of the patients in the abdominal group and 69 patients $(39 \%)$ in the vaginal group had been managed by midwives or a family doctor ante partum and had been referred to the hospital during the last weeks of pregnancy, when the breech presentation was persistent (Table 3.15). In this table the figures regarding the prenatal care are also given for the three weight categories. 
Table 3.15 Prematal care $(\%)$

\begin{tabular}{lccccccccc}
\hline & \multicolumn{3}{c}{ Total group } & \multicolumn{2}{c}{$\geqslant 2500 \mathrm{~g}$} & \multicolumn{2}{c}{$1500-2499 \mathrm{~g}$} & \multicolumn{2}{c}{$5001499 \mathrm{~g}$} \\
& $\mathrm{VD}$ & $\mathrm{CS}$ & $\mathrm{VD}$ & $\mathrm{CS}$ & $\mathrm{VD}$ & $\mathrm{CS}$ & $\mathrm{VD}$ & $\mathrm{CS}$ \\
\hline Midwife & $63(36)$ & $21(23)$ & $50(38)$ & $15(26)$ & $11(42)$ & $3(18)$ & $2(11)$ & $3(17)$ \\
Family physician & $6(3)$ & $4(4)$ & $3(2)$ & $1(2)$ & $3(12)$ & $0(0)$ & $0(0)$ & $3(17)$ \\
Resident & $44(25)$ & $20(22)$ & $30(23)$ & $11(19)$ & $8(31)$ & $5(29)$ & $6(33)$ & $4(22)$ \\
Obstetrician & $59(34)$ & $47(51)$ & $48(36)$ & $30(53)$ & $3(12)$ & $9(53)$ & $8(44)$ & $8(44)$ \\
No prenatal controls & $4(2)$ & $0(0)$ & $1(1)$ & $0(0)$ & $1(3)$ & $0(0)$ & $2(12)$ & $0(0)$ \\
or unknown & & & & & & & & & \\
\hline Total & 176 & 92 & 132 & 57 & 26 & 17 & 18 & 18 \\
\hline
\end{tabular}

Table 3.16 Number of prenatal wisits (\%).

\begin{tabular}{lccccccccc}
\hline & \multicolumn{2}{c}{ Total group } & \multicolumn{2}{c}{$\geqslant 2500 \mathrm{~g}$} & \multicolumn{2}{c}{$1500-2499 \mathrm{~g}$} & \multicolumn{2}{c}{$500-1499 \mathrm{~g}$} \\
& VD & $\mathrm{CS}$ & $\mathrm{VD}$ & $\mathrm{CS}$ & $\mathrm{VD}$ & $\mathrm{CS}$ & $\mathrm{VD}$ & $\mathrm{CS}$ \\
\hline $0-5$ & $11(6)$ & $8(9)$ & $3(2)$ & $1(2)$ & $3(12)$ & $4(27)$ & $5(36)$ & $3(20)$ \\
$5-10$ & $44(26)$ & $34(37)$ & $27(21)$ & $15(26)$ & $9(36)$ & $8(53)$ & $8(57)$ & $11(73)$ \\
$10-15$ & $92(52)$ & $34(37)$ & $79(60)$ & $31(54)$ & $12(48)$ & $2(13)$ & $1(7)$ & $1(7)$ \\
$<15$ & $23(13)$ & $11(12)$ & $22(17)$ & $10(17)$ & $1(4)$ & $\mathbb{1}(7)$ & $0(0)$ & $0(0)$ \\
unknown & $6(3)$ & $5(5)$ & $1(0.5)$ & $0(0)$ & $1(4)$ & $2(12)$ & $4(22)$ & $3(17)$ \\
\hline Total & 176 & 92 & 132 & 57 & 26 & 17 & 18 & 18 \\
\hline
\end{tabular}

Chi-square test: NS

The number of intra-uterine transportations or non-booked patients was not statistically different for the vaginal group and the abdominal group

The form of prenatal care and the number of prenatal visits according to the three birth weight categories are listed in Tables 3.15 and 3.16. No statistically significant differences were found between the vaginal and abdominal groups.

\subsubsection{Course of pregnancies}

In the abdominal group four (4\%) pregnancies presented with chronic hypertension. In the vaginally delivered group, chronic hypertension was diagnosed in $7(5 \%)$ pathents.

There were no statistical differences between the two groups (Table 3.17).

However, gestational hypertension was more frequent in the cesarean section group: $18 \%$ (17 cases) against $10 \%$ (18 cases) in the vaginal group. This difference is not significant.

Diabetes mellitus was diagnosed in 3 patients, none of whom belonged to the vaginal group (Table 3.18).

In 6 cases in the vaginal group and in 16 cases in the abdominal group vaginal blood 
Table 3.17 Hypertensian disorders in the two groups according to the classification by Davey and Mcoillivray.

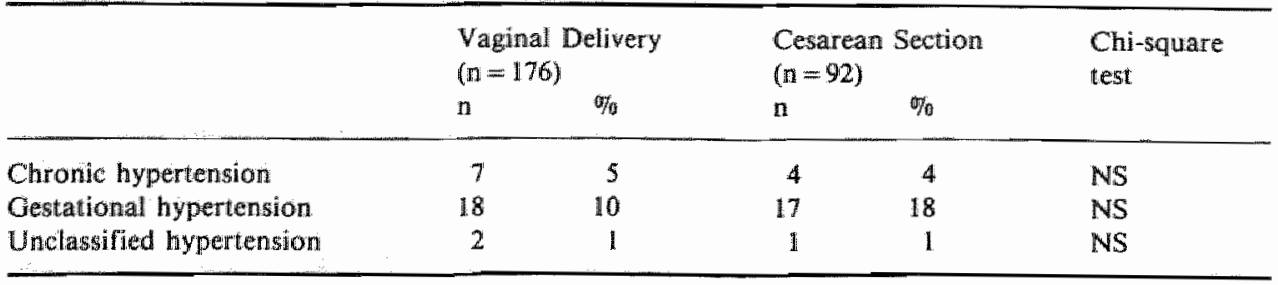

Table 3.18 Frequency of maternal complicating factors in the both groups.

\begin{tabular}{lcll}
\hline Maternal factors $(\%)$ & $\begin{array}{l}\text { Vaginal Deliwery } \\
(\mathrm{n}=176)\end{array}$ & $\begin{array}{l}\text { Cesarean Section } \\
(\mathrm{n}=92)\end{array}$ & $\begin{array}{l}\text { Chi-square } \\
\text { test }\end{array}$ \\
\hline Diabetes mellitus & $0(0)$ & $3(3)$ & $\mathrm{NS}$ \\
Third trimester vaginal bleeding & $6(3)$ & $16(17)$ & $\mathrm{p}<0.001$ \\
Cigarette smoking & $33(19)$ & $13(14)$ & $\mathrm{NS}$ \\
Prolonged rupture of membranes & $15(9)$ & $11(12)$ & $\mathrm{NS}$ \\
Admission to hospital & $74(42)$ & $56(61)$ & $\mathrm{p}<0.01$ \\
\hline
\end{tabular}

loss occurred during the second half of pregnancy. This difference is significant. In the vaginal group, 33 patients were smokers, compared with 13 patients in the abdominal group. This difference is not significant.

Prolonged rupture of the membranes occurred in 15 cases in the total vaginal group and in 11 cases in the cesarean section group. This difference is not significant. In the vaginal group 74 patients $(42 \%)$ required prenatal admission, against 56 patients $(61 \%)$ in the cesarean section group. This difference is significant.

Table 3.19 shows the distribution of the admissions over the three weight categories. There were significantly different numbers of admissions for the two groups in the three birth weight categories.

Table 3.19 Frequency of admissions in the three weight calegories.

\begin{tabular}{|c|c|c|c|c|c|}
\hline \multirow[t]{2}{*}{ Mode of Dellwery } & \multicolumn{2}{|c|}{ Vaginal Delivery } & \multicolumn{2}{|c|}{ Cesarean Section } & \multirow{2}{*}{$\begin{array}{l}\text { Chi-square } \\
\text { test }\end{array}$} \\
\hline & $\mathrm{n}$ & $\%$ & $\mathrm{n}$ & $\%$ & \\
\hline \multicolumn{6}{|l|}{ Birth weight (g) } \\
\hline$\geqslant 2500$ & 43 & 33 & 25 & 44 & $\mathrm{NS}^{*}$ \\
\hline $1500-2499$ & 17 & 65 & 15 & 88 & NS* \\
\hline $500-1499$ & 14 & 78 & 16 & 89 & NS* \\
\hline Total & 74 & 42 & 56 & 61 & $p<0.01$ \\
\hline
\end{tabular}

* $p<0.05$ (Mantel-Haenszel"s test) 


\subsubsection{Management of labor}

Management of labor in both groups is summarized in Table 3.20 and 3.20a. Intravenous oxytocin or prostaglandins to start uterine activity or to increase dysfunctional labor were used in 79 cases (45\%) in the vaginal group and in 24 cases $(26 \%)$ in the abdominal group. Induction of labor occurred in 1 case in the abdominal group and in 12 cases in the vaginal group.

Table 3.20 Management of Labor (\%).

\begin{tabular}{lccc}
\hline Total Group & VD & CS & Chi-square \\
& $n=176$ & $n=92$ & test \\
\hline Induction of Labor & $12(7)$ & $1(1)$ & $\mathrm{p}<0.05$ \\
Augmentation & $79(45)$ & $24(26)$ & $\mathrm{p}<0.01$ \\
General anesthesia & $2(1)$ & $83(90)$ & $\mathrm{p}<0.001$ \\
Epidural anesthesia & $20(11)$ & $9(10)$ & $\mathrm{NS}$ \\
Regional analgesia & $131(74)$ & $5(5)$ & $\mathrm{NS}$ \\
Sedatives & $6(3)$ & $3(3)$ & $\mathrm{p}<0.001$ \\
Artificial rupture of & $38(22)$ & $4(4)$ & \\
membrames & & &
\end{tabular}

In 185 cases rupture of membranes occurred spontaneously. The membranes were artifically ruptured in 4 cases in the abdominal group and in 38 cases in the vaginal group. In the remaining 41 cases membranes were ruptured during cesarean section. Analgesics and/or sedatives were rarely used in either of the groups.

In the birth weight category of 2500 grams or more, 132 cases were delivered vaginally, 103 deliveries $(78 \%$ ) were performed under regional anesthesia, (including anaesthesia for episiotomies ) and 17 deliveries (13\%) under epidural anesthesia. One patient $(1 \%)$ received general anesthesia for delivery of the aftercoming head, and 11 patients $(8 \%)$ required no anesthesia.

Table 3.20a Management of Labor (\%).

\begin{tabular}{lccccccc}
\hline & \multicolumn{2}{c}{$\geqslant 2500 \mathrm{~g}$} & \multicolumn{2}{c}{$1500-2499 \mathrm{~g}$} & \multicolumn{2}{c}{$500-1499 \mathrm{~g}$} \\
& $\mathrm{VD}$ & $\mathrm{CS}$ & $\mathrm{VD}$ & $\mathrm{CS}$ & $\mathrm{VD}$ & $\mathrm{CS}$ \\
& $\mathrm{n}=132$ & $\mathrm{n}=57$ & $\mathrm{n}=26$ & $\mathrm{n}=17$ & $\mathrm{n}=18$ & $\mathrm{n}=18$ \\
& $10(8)$ & $0(0)$ & $2(8)$ & $1(6)$ & $0(0)$ & $0(0)$ \\
& $71(54)$ & $23(40)$ & $5(19)$ & $1(6)$ & $3(17)$ & $0(0)$ \\
Induction of Labor & $1(1)$ & $51(89)$ & $0(0)$ & $16(94)$ & $1(6)$ & $16(89)$ \\
Augmentation* & $17(13)$ & $6(1 \mathrm{l})$ & $2(8)$ & $1(6)$ & $1(6)$ & $2(6)$ \\
General anesthesia** & $103(78)$ & $5(9)$ & $21(81)$ & $0(0)$ & $7(39)$ & $0(0)$ \\
Epidural anesthesia & $3(2)$ & $1(2)$ & $0(0)$ & $1(6)$ & $3(17)$ & $1(6)$ \\
Regional analgesia** & $27(20)$ & $3(5)$ & $7(30)$ & $0(0)$ & $4(22)$ & $1(6)$ \\
Sedatives & & & & & & \\
Artificial rupture** & & & & & & &
\end{tabular}

Mantel-Haenszel's test: * $p<0.05$

* $p<0.001$ 
Anesthesia for the 57 patients delivered by cesarean section was took the form of general anesthesia in 51 cases $(89 \%)$ and of epidural anesthesia in 6 cases $(11 \%)$ (Table $3.20 \mathrm{a}$ ).

There were certain statistically significant differences in policy between the two groups and between the three birth weight categories, including induction and augmentation of labor, use of anaesthetics and narcotic drugs and artificial rupture of the membranes.

\subsubsection{Mode of delivery}

Of the 268 neonates in the studygroup, $176(66 \%)$ were delivered vaginally and 92 $(34 \%)$ were delivered by cesarean section (Table 3.21 ).

Table 3.21 Mode of Delivery.

\begin{tabular}{lcccc}
\hline & $\begin{array}{c}\text { Total group } \\
(\mathrm{n}=268)\end{array}$ & $\begin{array}{c}\geqslant 2500 \mathrm{~g} \\
(\mathrm{n}=189)\end{array}$ & $\begin{array}{c}1500-2499 \mathrm{~g} \\
(\mathrm{n}=43)\end{array}$ & $\begin{array}{c}500-1499 \mathrm{~g} \\
(\mathrm{n}=36)\end{array}$ \\
\hline $\begin{array}{l}\text { Cesarean Section } \\
\text { before labor }\end{array}$ & $29(34 \%)$ & $57(30 \%)$ & $17(40 \%)$ & $18(50 \%)$ \\
\hline $\begin{array}{l}\text { Vaginal Delivery } \\
\text { Unassisted Breech (Bracht Manoeuvre) }\end{array}$ & $176(66 \%)$ & $19(33 \%)$ & $4(24 \%)$ & $6(34 \%)$ \\
Assisted Breech & $101(57 \%)$ & $77(58 \%)$ & $12(46 \%)$ & $12(67 \%)$ \\
Breech Exiraction & $71(40 \%)$ & $52(40 \%)$ & $14(54 \%)$ & $5(28 \%)$ \\
\hline
\end{tabular}

The highest percentage of cesarean sections occurred in the 500-1500 gram category $(50 \%)$.

The indications for cesarean section are listed in Table 3.22.

The most frequent indication for cesarean section was dystocia (42\%). Maternal factors accounted for a cesarean section indication in 10 cases $(11 \%$ ).

Signs of distress or hypoxaemia were a reason for cesarean section in 38 cases $(41 \%)$.

Placental factors (placenta praevia, solutio placentae) was rarely a reason for cesarean section (Table 3.22)

Table 3.22 Indicarions for cesarean section.

\begin{tabular}{|c|c|c|c|c|c|c|c|c|}
\hline & \multicolumn{2}{|c|}{ Total group } & \multicolumn{2}{|c|}{$\geqslant 2500 \mathrm{~g}$} & \multicolumn{2}{|c|}{$1500-2499 \mathrm{~g}$} & \multicolumn{2}{|c|}{$500-2499 \mathrm{~g}$} \\
\hline & $\mathrm{n}$ & $0 \%$ & $\mathrm{n}$ & $\%$ & $\mathrm{n}$ & $0 \%$ & $n$ & $\%_{0}$ \\
\hline Fetal & 38 & 41 & 12 & 21 & 11 & 65 & 15 & 83 \\
\hline Dystocia & 39 & 42 & 37 & 65 & 2 & 12 & 0 & 0 \\
\hline Placental & 5 & 5 & 1 & 2 & 3 & 17 & 1 & 6 \\
\hline Maternal & 10 & 11 & 7 & 12 & 1 & 6 & 2 & $\mathbb{1}$ \\
\hline Total & 92 & 99 & 57 & 100 & 17 & 100 & 18 & 100 \\
\hline
\end{tabular}


Twenty nine primary cesarean sections (11\%) were carried out (Table 3.21). Of these, 9 were carried out because of signs of intra-uterine asphyxia.

In 9 patients a manifest cephalo-pelvic dysproportion was the indication for a primary cesarean section; in 10 cases a maternal factor accounted for a cesarean section indication, and in one case there was a placental factor which constituted the reason for the cesarean section.

Of the 268 patients in the studygroup, $176(66 \%)$ were delivered vaginally. Fifty seven percent of the vaginal deliveries occurred spontaneously using the Bracht manoeuvre, while $40 \%$ of the vaginal deliveries were performed by assisted breech extraction. In the vaginally delivered group, 4 cases $(2 \%)$ required total breech extraction due to signs of deteriorating intra-uterine condition as estimated by fetal heart rate monitoring (Table 3.21).

As regards the assisted breech, a Van Deventer or Müller manoeuvre was applied 21 times, a Mauriceau manoeuvre 11 times, a De Snoo manoeuvre 3 times and a Løvset procedure 16 times. A combination of two manoeuvres was used in 18 cases. In two cases forcipal extraction was used to deliver the aftercoming head (see also Table 3.10a).

In the birth weight category of $2500 \mathrm{~g}$ or more, a Bracht manoeuvre was performed in 77 patients $(58 \%)$. Assisted breech was the method of delivery for 52 of the 132 patients $(40 \%)$ in the vaginally delivered group.

In 3 cases $(2 \%)$ total breech extraction had to be carried out due to signs of fetal hypoxaemia as estimated by fetal heart rate monitoring.

In the group of $1500-2499 \mathrm{~g}, 46 \%$ of the deliveries occurred spontaneously using the Bracht manoeuvre, while $54 \%$ of the deliveries were performed by assisted breech extraction.

In the very low birth weight category (500-1499 g) the Bracht manoeuvre was performed in 12 cases $(67 \%)$, assisted breech was the method of delivery for 5 patients $(28 \%)$, and in one case $(6 \%)$ a total breech extraction was necessary (Table 3.21 ). 



\section{Chapter 4}

\section{Results}

\subsection{Neonatal condition.}

\subsubsection{Apgar scores}

The numbers of Apgar scores lower than 7 at one minute $(1 \mathrm{~min})$ and five minutes ( $5 \mathrm{~min}$ ) after birth, grouped by method of delivery, are shown in Table 4.1 . There were no missing values for the total group.

Low $1 \mathrm{~min}$ Apgar scores were recorded in $51(29 \%)$ neonates of the vaginally delivered group and in $41(45 \%)$ neonates delivered by cesarean section. This difference is statistically significant. After five minutes these figures were $14(8 \%)$ and $9(10 \%)$. This difference is not significant (Table 4.1).

Table 4.1 Apgar score according to mode of delivery in the total study group (\%).

\begin{tabular}{|c|c|c|c|}
\hline Mode of Delivery & $\begin{array}{l}\text { Vaginal } \\
\text { Delivery } \\
(n=176)\end{array}$ & $\begin{array}{l}\text { Cesarean Section } \\
(\mathrm{n}=92)\end{array}$ & Chi-square test \\
\hline $1^{\prime}$ Apgar $<7$ & $51 \quad(29)$ & $41 \quad(45)$ & $\mathrm{p}<0.02$ \\
\hline $5^{\prime}$ Apgar $<7$ & $14 \quad(8)$ & $9 \quad(10)$ & NS \\
\hline
\end{tabular}

In the birth weight category of $2500 \mathrm{~g}$ or more, a low 1 min Apgar score was recorded in 27 neonates $(20 \%)$ of the vaginally delivered group and in 17 neonates (30\%) of the abdominally delivered group; after five minutes these figures were five (4\%) and two $(4 \%)$ respectively (Table $4.1 \mathrm{a})$.

Table 4. la Birth weight-specific Apgar score according to made of detwery (\%).

\begin{tabular}{lllllll}
\hline Birth weight category $(\mathrm{g})$ & $\geqslant 2500$ & \multicolumn{3}{c}{$1500-2499$} & \multicolumn{3}{c}{$500 \times 1499$} \\
\hline Mode of Delivery & VD & CS & VD & CS & VD & CS \\
No. of Breeches & 132 & 57 & 26 & 17 & 18 & 18 \\
\hline $1 \cdot$ Apgar $<7$ & $27(20)$ & $17(30)$ & $7(27)$ & $10(59)$ & $17(94)$ & $14(78)$ \\
5 & $5(4)$ & $2(4)$ & $1(4)$ & $2(12)$ & $8(44)$ & $5(28)$ \\
\hline
\end{tabular}

Chi-square test: NS 
These differences in the incidence of low Apgar scores at one and five minutes between the vaginal and abdominal group in this weight category are not statistically significant.

In the birth weight category of $1500-2499 \mathrm{~g}$, a low 1 min Apgar score was recorded in 7 neonates (27\%) of the vaginal group and in 10 neonates $(59 \%)$ of the abdominal group; after five minutes, these figures were one $(4 \%)$ and two $(12 \%)$.

A higher incidence of 1 and 5 min Apgar scores below 7 was found in cesarean section born neonates. However, no statistically significant differences in the 1 and 5 min Apgar scores could be demonstrated between the two groups (vaginal versus abdominal delivery) in the 1500-2499 gram birth weight category.

In the group of newborns with a birth weight between 500 and $1499 \mathrm{~g}$, low 1 min Apgar scores were found in 17 cases $(94 \%)$ in the vaginally delivered group and in 14 cases $(78 \%)$ in the abdominally delivered group; after 5 minutes these figures were $8(44 \%)$ and $5(28 \%)$ respectively. So in this birth weight category there was a greater proportion of lower Apgar scores at one and five minutes for vaginal delivery.

However, these differences in the 1 and 5 min Apgar scores between the vaginal and abdominal group are not statistically significant.

\subsubsection{Umbilical cord blood gas analysis}

Tables 4.2, 4.2a and 4.3,4.3a present the results of umbilical cord blood gas analysis of all patients for the various birth weight categories, in relation to the mode of delivery.

The mean umbilical arterial and venous blood $\mathrm{pH}$ values and the distribution of these values are shown. The umbilical blood gas analysis could not be performed in 10 cases; 5 in the vaginal group and 5 in the cesarean section group.

The mean umbilical arterial $\mathrm{pH}$ was 7.22 in the vaginally delivered group and 7.23 in the abdominally delivered group (Table 4.2).

Tuble 4.2 Relation between umbilical artery $p H$ and mode of delivery in the total study group (\%).

\begin{tabular}{|c|c|c|}
\hline $\begin{array}{l}\text { Mode of Delivery } \\
\text { No. of Breeches }\end{array}$ & $\begin{array}{l}\text { Vaginal Delivery } \\
171\end{array}$ & $\begin{array}{l}\text { Cesarean Section } \\
87\end{array}$ \\
\hline Mean umbillical artery $\mathrm{pH}$ & 7.22 & 7.23 \\
\hline SD & 0.09 & 0.10 \\
\hline$\leqslant 7.10$ & $17(10)$ & $8(9)$ \\
\hline $7.11-7.20$ & $50 \quad(29)$ & $15(17)$ \\
\hline$\geqslant 7.20$ & $104(61)$ & $64 \quad(74)$ \\
\hline
\end{tabular}

Mann-Whitney U-test: NS 
The mean umbilical venous $\mathrm{pH}$ was 7.31 in the vaginally delivered group and 7.28 in the abdominally delivered group (Table 4.3).

In the vaginally delivered group with a birth weight of $2500 \mathrm{~g}$ or more, the umbilical cord blood gas analysis was available in 131 cases; one sample was missing.

In the cesarean section group with a birth weight of $2500 \mathrm{~g}$ or more the umbilical cord blood gas analysis was incomplete in one case. In this case the umbilical artery blood gas analysis was absent, while the umbilical venous blood gas analysis was present.

In the cesarean section group of newborns weighing $2500 \mathrm{~g}$ or more 4 neonates $(7 \%)$ showed an arterial umbillical $\mathrm{pH}$ value equal to or lower than 7.10 , compared with 10 neonates $(8 \%)$ in the vaginal group (Table $4.2 \mathrm{a}$ ). An arterial pH value of 7.11-7.20 was determined in 4 neonates $(7 \%)$ of the cesarean section group, compared with 43 neonates ( $33 \%$ ) of the vaginal group.

Table 4.2a Relation between umbilical artery $p H$ and mode of delivery in the three different weight categories (\%).

\begin{tabular}{|c|c|c|c|c|c|c|}
\hline Birth weight category (g) & \multicolumn{2}{|l|}{$\geqslant 2500$} & \multicolumn{2}{|c|}{$1500-2499$} & \multicolumn{2}{|c|}{$500-1499$} \\
\hline Mode of Delivery & VD & $\mathrm{CS}$ & VD & $\mathrm{CS}$ & VD & $\mathrm{CS}$ \\
\hline No. of Breeches & $13 \Perp$ & 56 & 25 & 15 & 15 & 116 \\
\hline Mean umbilical artery pH & 7.22 & 7.25 & 7.24 & 7.19 & 7.21 & 7.20 \\
\hline $\mathrm{SD}$ & 0.08 & 0.08 & 0.09 & 0.15 & 0.13 & 0.09 \\
\hline$\leqslant 7.10$ & $10(8)$ & $4(7)$ & $2(8)$ & $2(13)$ & $5(33)$ & $2(12)$ \\
\hline $7.11-7.20$ & $43(33)$ & $4(7)$ & $6(24)$ & $5(33)$ & $1(7)$ & $6(38)$ \\
\hline$\geqslant 7.20$ & $78(60)$ & $48(86)$ & $17(68)$ & $8(53)$ & $9(60)$ & $8(50)$ \\
\hline
\end{tabular}

The vaginally delivered neonates showed a slightly lower mean umbilical artery $\mathrm{pH}$ value than the abdominally delivered children $(7.22$ versus 7.25$)$ in the weight category of 2500 grams or more. This difference is statistically significant, but the mean umbilical artery $\mathrm{pH}$ in both groups is over 7.20 (Table $4.2 \mathrm{a}$ ).

The mean venous umbilical $\mathrm{pH}$ was 7.32 in the vaginally delivered group and 7.30 in the abdominally delivered group in the birth weight category of $2500 \mathrm{~g}$ or more. The $\mathrm{pH}$ values in the venous umbilical cord blood are shown in Table $4.3 \mathrm{a}$ for three $\mathrm{pH}$ categories.

In the cesarean section group 3 neonates $(5 \%)$ had a venous umbilical pH value equal to or lower than 7.10 , compared with one neonate $(1 \%)$ in the vaginal group (Table 4.3a). A venous pH value between $7.11-7.20$ was found in 2 neonates (4\%) of the cesarean section group, against 6 newborns $(5 \%)$ of the vaginal group in the birth weight category of $2500 \mathrm{~g}$ or more.

In the vaginal group of the $1500-2499 \mathrm{~g}$ birth weight category the arterial umbillical cord $\mathrm{pH}$ was determined in 25 cases and the venous umbilical $\mathrm{pH}$ in 26 cases. One value was missing in the arterial samples. 
Table 4.3 Relation between umbilicat venous $p H$ and mode of delivery in the lotal study group (\%oj.

\begin{tabular}{|c|c|c|}
\hline $\begin{array}{l}\text { Wode of Delivery } \\
\text { No. of Breeches }\end{array}$ & $\begin{array}{l}\text { Vaginal Delivery } \\
173\end{array}$ & $\begin{array}{l}\text { Cesarean Siection } \\
90\end{array}$ \\
\hline Mean umbilical venous $\mathrm{pH}$ & 7.31 & 7.28 \\
\hline $\mathrm{SD}$ & 0.07 & 0.09 \\
\hline$\leqslant 7.10$ & $3(2)$ & $6(7)$ \\
\hline 7.11 .7 .20 & $11(6)$ & 8 (9) \\
\hline$\geqslant 7.20$ & $159 \quad(92)$ & $76(84)$ \\
\hline
\end{tabular}

Mann-Whitney U-test NS

In the abdominal group 15 arterial and 16 venous umbilical cord $\mathrm{pH}$ values were measured for analysis; 2 arterial samples were missing. One venous sample was absent.

An arterial pH value equal to or lower than 7.10 was found in 2 neonates (13\%) of the cesarean section group of newborns weighing 1500-2499 $\mathrm{g}$, compared with 2 neonates $(8 \%)$ of the vaginal group.

An arterial $\mathrm{pH}$ value of $7.11-7.20$ was found in 5 neonates (33\%) of the cesarean section group, against 6 neonates (24\%) of the vaginal group in the this birth weight category (Table $4.2 a$ ).

There was no statistically significant difference in the mean umbilical artery pH (7.19 versus 7.24 ) between the vaginally delivered and abdominally delivered neomates in this weight category (Table $4.2 \mathrm{a}$ ).

In the cesarean section group one neonate $(6 \%)$ had a venous umbilical pH value equal to or lower than 7.10 , compared to none in the vaginal group. A venous $\mathrm{pH}$ value between $7.11-7.20$ was found in 4 neonates $(25 \%)$ of the cesarean section group, compared with one neonate $(4 \%)$ of the vaginal group in the same birth weight category (Table 4.3a).

The mean venous umbilical pH was 7.23 in the abdominal group and 7.33 in the vaginal group. This difference in umbilical venous $\mathrm{pH}$ between the two groups is significant.

Trible 4.3a Relation between umbilical venous $p H$ and mode of delivery in the three different weight categomies (o\%).

\begin{tabular}{|c|c|c|c|c|c|c|}
\hline \multirow{3}{*}{$\begin{array}{l}\text { Birth weight category (g) } \\
\text { Mode of Deliwery } \\
\text { No. of Breeches }\end{array}$} & \multicolumn{2}{|l|}{$\geqslant 2500$} & \multicolumn{2}{|c|}{$1500-2499$} & \multicolumn{2}{|c|}{$500-1499$} \\
\hline & VD & $\mathrm{CS}$ & $\mathrm{VD}$ & $\mathrm{CS}$ & VD & $\mathrm{CS}$ \\
\hline & 131 & 57 & 26 & 16 & 16 & 17 \\
\hline Mean umbilical venous pH & 7.32 & 7.30 & 7.33 & 7.23 & 7.26 & 7.25 \\
\hline $\mathrm{SD}$ & 0.07 & 0.07 & 0.07 & 0.13 & 0.13 & 0.110 \\
\hline$\leqslant 7.10$ & $1(1)$ & $3(5)$ & $0(0)$ & $1(6)$ & $2(12)$ & $2(12)$ \\
\hline $7.11-7.20$ & $6(5)$ & $2(4)$ & $1(4)$ & $4(25)$ & $4(25)$ & $2(12)$ \\
\hline$\geqslant 7.20$ & $124(94)$ & $52(91)$ & $25(96)$ & $11(69)$ & $10(63)$ & $13(76)$ \\
\hline
\end{tabular}


Finally the arterial and venous umbilical values in the $500-1499 \mathrm{~g}$ birth weight category are presented.

In the vaginally delivered group the umbilical cord blood gas analysis was available in 15 cases ( 3 values were missing), while in the cesarean section group the umbilicalcord blood-gas analysis was available in 16 cases ( 2 values were missing). In one case in the cesarean section group and in one case in the vaginally delivered group the umbilical artery $\mathrm{pH}$ was absent, while the umbilical venous $\mathrm{pH}$ was available.

Arterial $\mathrm{pH}$ values equal to or lower than 7.10 were noted in 2 neonates $(12 \%)$ of the cesarean section group, compared with 5 neonates $(33 \%)$ of the vaginal group. An arterial $\mathrm{pH}$ value between 7.11-7.20 was found in 6 neonates (38\%) of the cesarean section group, compared with one neonate $(7 \%)$ of the vaginal group in the same birth weight category (Table $4.2 \mathrm{a}$ ).

The mean arterial pH was 7.20 in the abdominally delivered group, against 7.21 in the vaginally delivered group.

No statistically significant difference was found between the two groups.

Two neonates $(12 \%)$ in the abdominal group and 2 neonates $(12 \%)$ in the vaginal group had a venous $\mathrm{pH}$ value below 7.10 (Table 4.3a). A venous $\mathrm{pH}$ value between 7.11-7.20 was found in 2 neonates (12\%) of the cesarean section group, compared with 4 neonates $(25 \%)$ of the vaginal group in the same birth weight category (Table 4.3a).

The mean venous umbilical $\mathrm{pH}$ was 7.26 in the vaginal group and 7.25 in the abdominal group.

No statistically significant differences were found between the two groups.

\subsubsection{Ventilation after birth, correction of the acid base balance with sodium bicarbonate and transfer to the neonatal unit.}

Cases in which artificial ventilation, correction of the acid base balance with sodium bicarbonate and/or transfer to the neonatal unit were required are listed in Tables 4.4 and $4.4 \mathrm{a}$. One case in the group of neonates weighing $2500 \mathrm{~g}$ or more was excluded from this evaluation because of intrapartum death.

Ventilation without intubation was required in 15 cases in the vaginal group (9\%), compared with 10 cases in the abdominal group $(11 \%)$, while ventilation with intubation had to be applied in 18 cases in the vaginal group (10\%) and in 25 cases in the abdominal group (27\%), a statistically significant difference.

Twelve of the neonates $(13 \%)$ in the abdominally delivered group received sodium bicarbonate during the first 24 hours after birth to correct acidosis, while in the vaginally delivered group acidosis was corrected in 10 neonates $(6 \%$ ).

As regards the transport to the neonatal unit, 73 neonates $(79 \%)$ were transferred to the neonatal unit after cesarean section, against $74(42 \%)$ after vaginall birth. This means there was a significant difference in favour of the vaginal group as far as this aspect was concerned. 
Table 4.4 Ventilation after birth, correction with sodium bicarbonate and transfer to the neomatal unit in relation to mode of delivery (ow).

\begin{tabular}{|c|c|c|c|}
\hline $\begin{array}{l}\text { Mode of delivery } \\
\text { No. of Breeches }\end{array}$ & $\begin{array}{l}\text { Waginal } \\
\text { Deliwery } \\
(n=175)\end{array}$ & $\begin{array}{l}\text { Cesarean } \\
\text { Section } \\
(\mathrm{n}=92)\end{array}$ & $\begin{array}{l}\text { Chi-square } \\
\text { test }\end{array}$ \\
\hline $\begin{array}{l}\text { Ventilation without } \\
\text { intubation }\end{array}$ & is (9) & $10 \quad(11)$ & NS \\
\hline Ventilation with intubation & $18(10)$ & $25(27)$ & $\mathrm{p}<0.001$ \\
\hline $\begin{array}{l}\text { Correction of acid } \\
\text { base ballance }\end{array}$ & $10 \quad(6)$ & $12 \quad(13)$ & NS \\
\hline Transfer to neonatal unit & $74 \quad(42)$ & $73 \quad(79)$ & $\mathrm{p}<0.001$ \\
\hline
\end{tabular}

As regards two other aspects, ventilation without intubation and correction of acid base balance, no statistically significant difference could be demonstrated between the two groups as a whole.

In the $2500 \mathrm{~g}$ or more birth weight category, ventilation without intubation was required in 8 cases of the vaginal group (6\%), compared with 7 cases of the abdominal group $(12 \%)$, while ventilation with intubation had to be applied in 3 cases in the vaginal group $(2 \%)$ and in 2 cases of the abdominal group $(4 \%)$. There was no statistically significant difference between the two groups in the rate of artificial ventilation.

Two of the neonates ( $2 \%$ ) in the vaginally delivered group received sodium bicarbonate within the first 24 hours after birth to correct acidosis, while acidosis was corrected in one neonate ( $2 \%$ ) in the abdominally delivered group. No statistically significant difference could be demonstrated between the two groups.

After cesarean section, neonates were more frequently transferred to the neonatal unit than after a vaginal birth: $40(70 \%)$ in the abdominal group and $35(27 \%)$ in the vaginal group. This was statistically significant.

In the 1500-2499 $\mathrm{g}$ birth weight category, artificial ventilation without intubation was required in 5 cases in the vaginal group (19\%), compared with 2 cases in the abdominal group (12\%), while ventilation with intubation had to be applied in 4 cases in the vaginal group (15\%) and in 9 cases in the abdominal group (53\%). So artificial ventilation with intubation occurred more frequently in the cesarean section group, and this difference is statistically significant.

Three of the neonates $(12 \%)$ in the vaginally delivered group received sodium bicarbonate within the first 24 hours after birth to correct acidosis, while acidosis was corrected in 5 neonates $(29 \%)$ in the abdominal group. However, no statistically significant difference could be demonstrated between the two groups in this regard. As regards transfer to the neonatal unit, this was necessary for 16 neonates $(94 \%)$ after cesaerean section and for 25 neonates $(96 \%)$ after vaginal birth. Once again, this difference is not significant. 
Table 4.4a Ventilation after birth, correction with sodium bicarbonate and transfer to the neonatal amin in relation to mode of delivery $(\%)$.

\begin{tabular}{|c|c|c|c|c|c|c|}
\hline \multirow{3}{*}{$\begin{array}{l}\text { Birth weight category }(\mathrm{g}) \\
\text { Mode of Delivery } \\
\text { No. of Breeches }\end{array}$} & \multicolumn{2}{|l|}{$\geqslant 2500$} & \multicolumn{2}{|c|}{$1500-2499$} & \multicolumn{2}{|c|}{$500-1499$} \\
\hline & VD & $\mathrm{CS}$ & VD & $\operatorname{Cs}$ & VD & CS \\
\hline & 131 & 57 & 26 & 17 & 1.8 & 18 \\
\hline $\begin{array}{l}\text { Ventilation } \\
\text { without intubation }\end{array}$ & $8(6)$ & $7(12)$ & $5(19)$ & $2(12)$ & $2(11)$ & $1(6)$ \\
\hline Ventilation with intubation & $3(2)$ & $2(4)$ & $4(15)$ & $9(53)^{*}$ & $11(61)$ & $14(78)$ \\
\hline $\begin{array}{l}\text { Correction of acid } \\
\text { base balance }\end{array}$ & $2(2)$ & $1(2)$ & $3(12)$ & $5(29)$ & $5(28)$ & 6. (33) \\
\hline Transfer to neonatal unit & $35(27)$ & $40(70)^{* * *}$ & $25(96)$ & $16(94)$ & $14(78)$ & $17(94)$ \\
\hline
\end{tabular}

Chi-square test $\begin{aligned} * p & <0.02 \\ * * \mathrm{p} & <0.001\end{aligned}$

The results in the very low birth weight (500-1499 g) category are also listed in Table 4.4a.

Artificial ventilation without intubation was applied in one neonate in the cesarean section group $(6 \%)$ and in 2 neonates in the vaginally delivered group (11\%). Artificial ventilation with intubation was applied in 14 neonates in the cesarean section group (78\%) and in 11 neonates in the vaginally delivered group $(61 \%)$.

Correction of acidosis with sodium bicarbonate was required in 5 neonates (28\%) in the vaginally delivered group and in 6 neonates $(33 \%)$ in the cesarean section group.

The percentage of infants requiring admission to the intensive care unit showed no statistically significant difference; 17 neonates in the cesarean section group $(94 \%)$ and 14 meonates in the vaginal group (78\%).

Five neonates died directly after birth, before transfer to the intensive care unit was possible.

\subsubsection{Congenital malformations, birth trauma, seizures, neonatal infections, sepsis, RDS and duration of hospital stay.}

In this chapter the neonatal morbidity with regard to the items mentioned in the title is described. These items were checked until the moment the child was discharged from the hospital (Table 4.5).

Congenital malformations were recorded in 4 cases (2\%) in the vaginal group and in 5 cases $(5 \%)$ in the abdominal group.

Birth trauma occurred in 5 vaginally delivered neonates $(3 \%)$ and in one neonate delivered by cesarean section $(1 \%)$.

In the vaginal group 2 neonates $(1 \%)$ had seizures, against $4(4 \%)$ in the abdominal group.

Neonatal infection was diagnosed in 10 neonates $(6 \%)$ in the vaginal group. In 7 of these cases $(4 \%)$ septicaemia was found. In the abdominal group 20 neonates 
Table 4.5 Neonatal morbidity in relation to mode of delivery in the cotal study group (om,

\begin{tabular}{|c|c|c|c|c|}
\hline $\begin{array}{l}\text { Mode of Dellivery } \\
\text { No. of Brechs }\end{array}$ & $\begin{array}{l}\text { waginal } \\
\text { delivery } \\
(n=176)\end{array}$ & $\begin{array}{l}\text { cesarean } \\
\text { section } \\
(n=92)\end{array}$ & $\begin{array}{l}\text { Chi-square } \\
\text { test }\end{array}$ & $\begin{array}{l}\text { Monn-Whithey } \\
\text { U test }\end{array}$ \\
\hline Malformations & $4 \quad(2)$ & $5(5)$ & NS & \\
\hline Birth trauma & $5 \quad(3)$ & 1 (1) & NS & \\
\hline Seizures & 2 (1) & 4 (4) & NS & \\
\hline Neonatal infections & $10 \quad(6)$ & $20 \quad(22)$ & $p<0.001$ & \\
\hline Sepsis: & $7 \quad(4)$ & $11 \quad(12)$ & $p<0.02$ & \\
\hline RDS & $13 \quad(7)$ & $15 \quad(16)$ & $p>0.05$ & \\
\hline $\begin{array}{l}\text { Postpartum hospital days } \\
\text { (mean } \pm \text { SD) }\end{array}$ & $8.8 \pm 23.4$ & $17.9 \pm 28.0$ & & $p<0.001$ \\
\hline
\end{tabular}

* This item includtes only the surviving neonates.

$(22 \%)$ had an infection; septicaemia was present in 11 cases $(12 \%)$. Neonatal infection and sepsis were significantly higher in the cesarean section group (Table 4.5). RDS occurred in 15 cases $(16 \%)$ in the abdominal group and in 13 cases $(7 \%)$ in the vaginal group, and this difference was also statistically significant.

The surviving infants in the vaginal group were discharged home after an initial hospital stay of $8.8 \pm 23.4$ days. In the abdominal group the mean duration of hospitalisation was $17.9 \pm 28.0$ days (Table 4.5). This difference was statistically significant.

In the group with a birth weight of $2500 \mathrm{~g}$ or more, three infants were born with congenital anomalies. One occurred in the cesarean group (2\%) and two in the vaginally delivered group (2\%).

In the vaginal group one child suffered from syndactylie, while another showed chondroplasia. The child in the cesarean section group suffered from a congenital heart defect, transposition of the large vessels.

In the vaginal group trauma related morbidity was encountered in 3 cases $(2 \%)$. One infant sustained a brachial plexus injury, which resolved completely within one year, and one child had a clavicle fracture. "The third case resulted in the death of the neonate (see mortality, 4.1.6).

Seizures occurred in one case in the abdominal group ( $2 \%$ ).

In the same case there were also perinatal problems. The child was born by cesarean section with Apgar scores 1 and 2 and was admitted to the neonatal ward with asphyxia.

Neonatal infection occurred in 3 neonates $(5 \%)$ in the abdominal group, compared with one in the vaginal group $(1 \%)$. Sepsis and RDS were not diagnosed in either group for this birth weight category.

The surviving infants in the vaginal group were discharged after a hospital stay of $1.3 \pm 3.1$ days in the vaginal group and $3.2 \pm 5.1$ days in the abdominal group. This difference was statistically significant (Table 4.5a). 
Table 4.5a Neonatal morbidity in retation to mode of delivery (40).

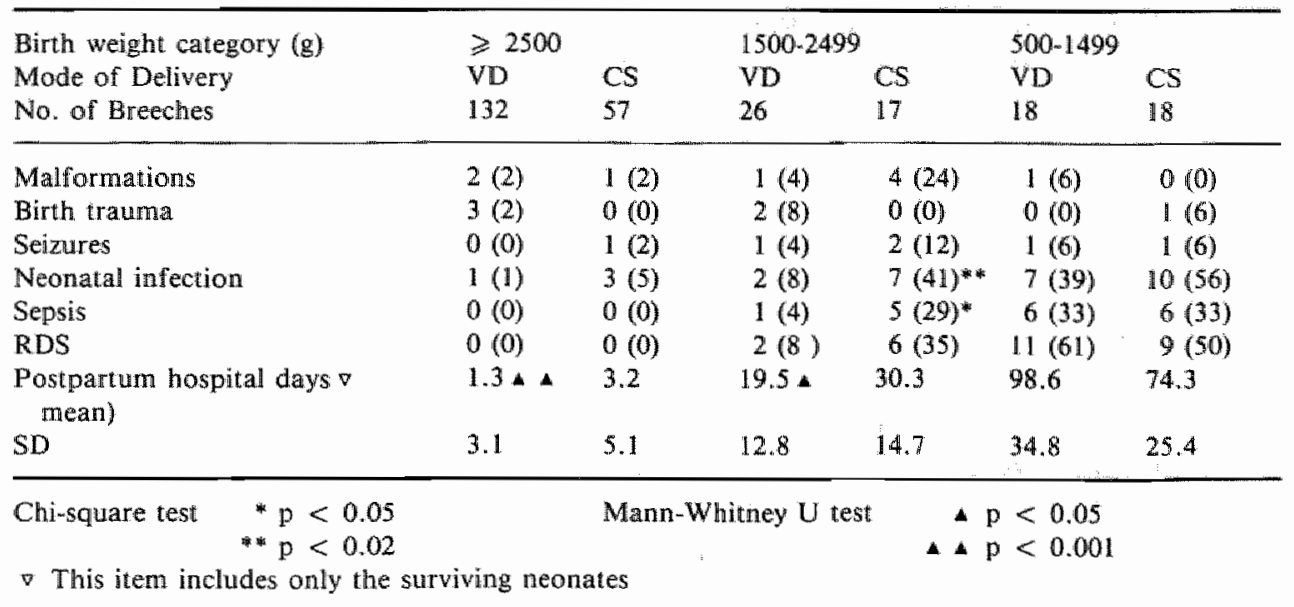

Neonatal morbidity in the group of newborns weighing $1500-2499 \mathrm{~g}$ is listed in Table 4.5a.

Congenital malformations were found in 4 abdominally delivered neonates $(24 \%)$ and in one vaginally delivered neonate $(4 \%)$. One infant in the abdominal group suffered from a congenital heart defect: transposition of the large vessels.

Another infant had a cheiloschisis, one infant had polycystic kidneys and one infant suffered from congenital gastroschisis.

The malformation in the vaginal group was a case of micrognathia with median palatoschisis.

Birth trauma in the vaginal group in this weight category occurred in 2 cases $(8 \%$ ). As regards birth trauma in this weight category, the following injuries were diagnosed: one infant in this group sustained a brachial plexus injury, which resolved completely within one year of age.

Another child in the vaginal group suffered from multiple hematomata after a difficult breech extraction and died soon after delivery. This birth trauma occurred after an intra-uterine transportation of over $45 \mathrm{~km}$ (see mortality, 4.1.6). In the abdominal group there was no birth trauma in this weight category.

Seizures occurred in two cases $(12 \%)$ delivered by cesarean section and in one case $(4 \%)$ delivered vaginally.

The presence of neonatal infection was significantly different in the two groups: 7 neonates $(41 \%)$ among the abdominally delivered infants compared with two neonates $(8 \%)$ in the vaginally delivered group. Five of the neonates $(29 \%)$ in the cesarean section group with neonatal infection had septicemia, compared with one neonate $(4 \%)$ in the vaginal group, a difference which was significantly different. As regards RDS there was an increased incidence of respiratory distress syndrome in the abdominally delivered group: 6 neonates ( $35 \%$ ), compared with 2 neonates $(8 \%)$ in the vaginal group. The difference in this incidence of respiratory distress syndrome is not significant. 
The surviving infants in the vaginal group were discharged after an initial stay of $19.5 \pm 12.8$ days. In the abdominal group the mean duration of hospitalisation was $30.3 \pm 14.7$ days. This difference was statistically significant.

In the very low birth weight category (500-1499 g) congenital malformations were found in one $(6 \%)$ neonate in the vaginally delivered group.

This child suffered from femur-fibula-ulna-hypoplasia ( FFU complex).

No trauma-related morbidity was encountered in the vaginally delivered group. In the cesarean section group there was one case of mortality, which may be attributed to a difficult breech extraction at cesarean section (see mortality 4.1.6).

Seizures occurred in one case delivered by cesarean section and in one case delivered vaginally (both 6\%).

Neonatal infection occurred in $56 \%$ (10 cases) of the cesarean section group and in $39 \%$ ( 7 cases) of the vaginal group. Both groups showed 6 cases (33\%) with septicemia (Table 4.5a).

The incidence of idiopathic respiratory distress syndrome did not differ significantly between the two groups ( $61 \%$ versus $50 \%$ ).

The surviving infants in the vaginal group were discharged after an initial hospital stay of $98.6 \pm 34.8$ days. In the abdominal group the mean duration of hospitalisation was $74.3 \pm 25.4$ days.

\subsubsection{Intracranial hemorrhage}

In Gent ultrasound examination was only performed if there was clinical suspician of the diagnosis of intracranial hemorrhage.

In Gent a clinical diagnosis of intracranial hemorrhage $(\mathrm{ICH})$ was made by the atm tending paediatrician in 4 cases ( $4 \%$ ) (Table 4.6a).

Table 4.69 Incidence and classification of intracramial hemorhage in birh weight categories in Gent.

\begin{tabular}{|c|c|c|c|c|c|c|c|c|c|}
\hline $\begin{array}{l}\text { Birth weight } \\
\text { (grams) }\end{array}$ & $\begin{array}{l}\text { Num } \\
\text { of in } \\
\text { in } \mathrm{O}\end{array}$ & $\begin{array}{l}\text { ef of } \\
\text { ints } \\
\text { it }\end{array}$ & $\begin{array}{l}\mathrm{ICH} \\
\mathrm{n}\end{array}$ & $\%$ & $\begin{array}{l}\text { classific } \\
\text { grade } \\
1\end{array}$ & $\begin{array}{l}\text { ation of } \\
\text { grade } \\
2\end{array}$ & $\begin{array}{l}\text { ICH }(n) \\
\text { grade } \\
3\end{array}$ & $\begin{array}{l}\text { grade } \\
4\end{array}$ & others \\
\hline$\geqslant 2500$ & $\begin{array}{l}\mathrm{YD} \\
\mathrm{CS}\end{array}$ & $\begin{array}{l}42 \\
21\end{array}$ & $\begin{array}{l}1(1) \\
0(0)\end{array}$ & $\begin{array}{l}\text { 2. (2) } \\
\text { of (0) }\end{array}$ & & & & & 1 \\
\hline $1500-2499$ & $\begin{array}{l}\text { VD } \\
\mathrm{CS}\end{array}$ & $\begin{array}{l}8 \\
7\end{array}$ & $\begin{array}{l}1(1) \\
0(0)\end{array}$ & $\begin{array}{c}13(13) \\
0(0)\end{array}$ & 1 & & & & \\
\hline $500-1499$ & $\begin{array}{l}\text { VD } \\
\text { CS }\end{array}$ & $\begin{array}{l}8 \\
8\end{array}$ & $\begin{array}{l}1(1) \\
1(1)\end{array}$ & $\begin{array}{l}13(13) \\
13(13)\end{array}$ & & 1 & & & 1 \\
\hline Total & $\begin{array}{l}\text { VD } \\
\text { CS }\end{array}$ & $\begin{array}{l}58 \\
36\end{array}$ & $\begin{array}{l}3(3) \\
1(1)\end{array}$ & $\begin{array}{l}5(5) \\
3(3)\end{array}$ & 1 & 1 & & & 2 \\
\hline
\end{tabular}

()$=$ number/percentage after revision by two independent radiologists

Chinsquare test: NS 
In the birth weight category of $2500 \mathrm{~g}$ or more one neonate showed a subarachnoidal hemorrhage. Ultrasound examination of the brain 48 hours post partum was normal. This diagnosis was confirmed by computurized tomography.

In the 1500-2499 g birth weight category one neonate in the vaginal group suffered from grade $\mathbb{1}$ intracranial hemorrhage. The diagnosis was confirmed by ultrasound examination of the brain.

In the 500-1499 $\mathrm{g}$ birth weight category one neonate in the cesarean section group suffered from grade 2 intracranial hemorrhage, which diagnosis was made by ultrasound examination. In the vaginal group a parenchymatous bleeding occurred. This was a clinical diagnosis without ultrasound or computerized tomography examination. Autopsy was refused by the parents.

Revision of all the sonograms did not change the final results.

In Maastricht ultrasonography of intracranial structures was done routinely, except in 18 cases. In most of these 18 cases the neonates were already discharged from the hospital before ultrasound examination could be performed.

Intracranial hemorrhage occurred neither in the abdominal nor in the waginally delivered group in the neonates weighing $2500 \mathrm{~g}$ or more.

In the 1500-2499 g birth weight category intracranial hemorrhage occurred in 2 neonates $(11 \%)$ of the vaginal group and in 2 neonates $(8 \%)$ of the abdominal group. One infant in the vaginal group suffered from an extensive subdural hemorrhage diagnosed after autopsy, but not seen on ultrasound examination. One neonate in the cesarean section group had a subependymal and intraventricular hemorrhage as diagnosed by autopsy. No ultrasound examination could be performed in this neonate after birth because of severe morbidity.

Table 4.6b Incidence and classification of intracranial hemorrhage in birth weight categories in Mastricht.

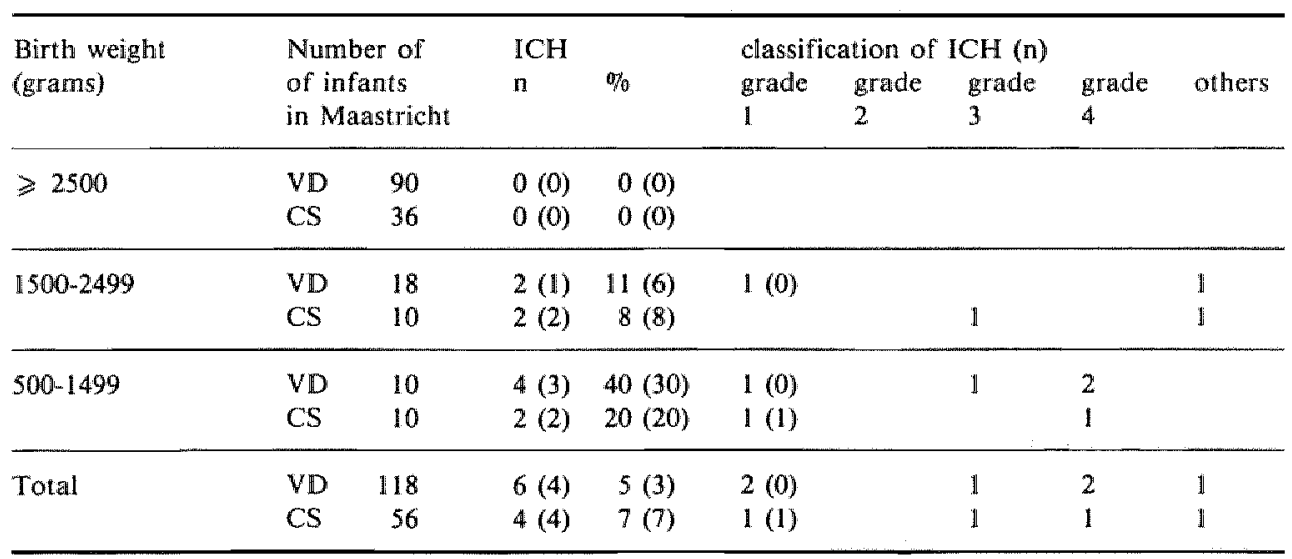

() $)$ number/percentage after revision by two independent radiologists

Chî-square test: NS 
A grade 3 intracranial hemorrhage occurred in one neonate in the cesarean section group. The grade 1 intracranial hemorrhage in the vaginal group was not diagnosed after revision (see Table $4.6 \mathrm{~b}$ ).

In the $500-1499 \mathrm{~g}$ birth weight category intracranial hemorrhage was diagnosed in 2 neonates $(20 \%)$ in the abdominal group and in 4 neonates $(40 \%)$ in the vaginal group. In the vaginal group 2 neonates suffered from grade 4 intraparenchymal hemorrhage and one child from a grade 3 intracranial hemorrhage. In the abdominal group one neonate suffered from grade 4 intracranial hemorrhage.

After revision of the sonograms by two experienced radiologists one grade 1 intracranial hemorrhage in the vaginal group was considered to be normal (Table 4.6b).

In the total study group a diagnosis of intracranial hemorrhage was recorded in 9 cases $(5 \%)$ of the vaginal group and in 5 cases $(5 \%)$ of the cesarean section group. The incidence of intracranial hemorrhage in the total study group did not differ significantly, nor was any statistically significant difference observed between the vaginally delivered neonates and the abdominally delivered neonates in the three birth weight categories.

Table 4.6c Incidence and classification of intracranial hemorrhage in birth weight categories in the total study group.

\begin{tabular}{|c|c|c|c|c|c|c|c|c|c|}
\hline \multirow{3}{*}{$\begin{array}{l}\text { Birth weight } \\
\text { (grams) } \\
\geqslant 2500\end{array}$} & \multicolumn{2}{|c|}{$\begin{array}{l}\text { Number of } \\
\text { infants in } \\
\text { total group }\end{array}$} & \multirow{2}{*}{$\begin{array}{l}\text { ICH } \\
\text { In } \\
1(1)\end{array}$} & \multirow{2}{*}{$\frac{\%}{1(1)}$} & \multirow[t]{3}{*}{$\begin{array}{l}\text { classifi } \\
\text { grade } \\
1\end{array}$} & \multirow[t]{3}{*}{$\begin{array}{l}\text { tion of } \\
\text { grade } \\
2\end{array}$} & \multirow[t]{3}{*}{$\begin{array}{l}\mathrm{ICH}(\mathrm{n}) \\
\text { grade } \\
3\end{array}$} & \multirow[t]{3}{*}{$\begin{array}{l}\text { gradle } \\
4\end{array}$} & \multirow{3}{*}{$\begin{array}{l}\text { others } \\
1\end{array}$} \\
\hline & VD & 132 & & & & & & & \\
\hline & $\mathrm{CS}$ & 57 & $0(0)$ & $0(0)$ & & & & & \\
\hline \multirow[t]{2}{*}{$1500-2499$} & VD & 26 & $3(2)$ & $12(8)$ & $2(1)$ & & & & 1 \\
\hline & $\mathrm{CS}$ & 17 & $2(2)$ & $12(12)$ & & & 1 & & 1 \\
\hline \multirow[t]{2}{*}{$500 \cdot 1499$} & VD & 18 & $5(4)$ & $28(22)$ & $1(0)$ & & 1 & 2 & 1 \\
\hline & $\mathrm{CS}$ & 18 & $3(3)$ & $17(17)$ & 1 & 1 & & 1 & \\
\hline \multirow[t]{2}{*}{ Total } & VD & 176 & $9(7)$ & $5(3)$ & $3(1)$ & & 1 & 2 & 3 \\
\hline & $\mathrm{CS}$ & 92 & $5(5)$ & $5(8)$ & $1(1)$ & 1 & 1 & 1 & $\mathbb{1}$ \\
\hline
\end{tabular}

( ) = number/percentage after rewision by two independent radiologists

Chi-square test: NS

\subsubsection{Mortality}

In the total group 13 deaths occurred in the vaginal group and 10 deaths in the abdominal group (4.7).

The single case of mortality in the birth weight category of $2500 \mathrm{~g}$ or more occurred during labor and was caused by puncturing of the prolapsed umbilical cord by a fetal scalp electrode. This fatal error occurred during the unjustified replacement of 
Table 4.7 Birth weight-specific mortality according to mode of delivery.

\begin{tabular}{lrrrrrrrrr}
\hline Birth weight (g) & \multicolumn{3}{c}{ Total group } & \multicolumn{2}{c}{$\geqslant 2500$} & \multicolumn{2}{c}{$1500-2499$} & \multicolumn{2}{c}{$500-1499$} \\
Mode of Delivery & VD & CS & VD & CS & VD & CS & \multicolumn{2}{c}{ VD } & CS \\
\hline No. of Breeches & 176 & 92 & 132 & 57 & 26 & 17 & 18 & 18 \\
Intrapartum fetal death & 1 & 0 & 1 & 0 & 0 & 0 & 0 & 0 \\
Early neonatal mortality & 10 & 8 & 0 & 0 & 2 & 2 & 8 & 6 \\
Late neonatal mortality & 0 & 0 & 0 & 0 & 0 & 0 & 0 & 0 \\
Post neonatal mortality & 2 & 2 & 0 & 0 & 0 & 2 & 2 & 0 \\
\hline
\end{tabular}

an electrode which became detached just before the diagnosis of cord prolapse was made; an exotic trauma, which with competent management should have been avoided. Post mortem examination was performed and no congenital malformations were detected in this case. Laceration of the vessels of the umbilical cord was found at $7 \mathrm{~cm}$ distance from its abdominal insertion.

There was no late or post-neonatal mortality in either of the groups in the two hospitals.

In the group with a birth weight between 1500-2499 $\mathrm{g}$ six deaths occurred: two deaths in the vaginal group and four deaths in the abdominal group (Table 4.7) In the vaginal group one death was due to respiratory distress syndrome and neonatal infection (streptococcus pneumonia) after premature rupture of the membranes (85.740, Table 4.8).

The other death was due to intracranial hemorrhage and bleeding of the abdominal organs after a difficult vaginal breech delivery with head entrapment (85.869, Table 4.8). This patient was transferred by emergency transport from another hospital over a distance of $45 \mathrm{~km}$ in the area and arrived on the delivery floor with $7 \mathrm{~cm}$ dilatation and a severe bradycardia of unknown duration at a gestational age of 30 weeks. Breech extraction was performed immediately, but the infant died 14 hours after birth. Post mortem examination was performed and revealed intra- and extracerebral hemorrhage and intraperitoneal bleeding in most of the abdominal organs (liver,kidneys etc.), suggesting at least severe intra-uterine asphyxia.

One perinatal death in the abdominal group in this weight category was due to sepsis and RDS (84.664, Table 4.8).

Another neonate died from a congenital heart disease with complete transposition of the pulmonary artery and aorta (86.221, Table 4.8). At the same time severe immaturity of the lungs and RDS with intracranial hemorrhage was diagnosed.

Two cases of late neonatal mortality were recorded in this birth weight category, and these occurred in the abdominal group. One infant died 2 months after birth due to cerebral bleeding grade 3 and hyaline membrane disease $(84.630$, Table 4.8$)$. Post-mortem examination was refused by the parents.

The other infant had a congenital gastroschisis and intestinal obstruction (86.285, Table 4.8). After an attempt at operative correction of this anomaly, the neonate 


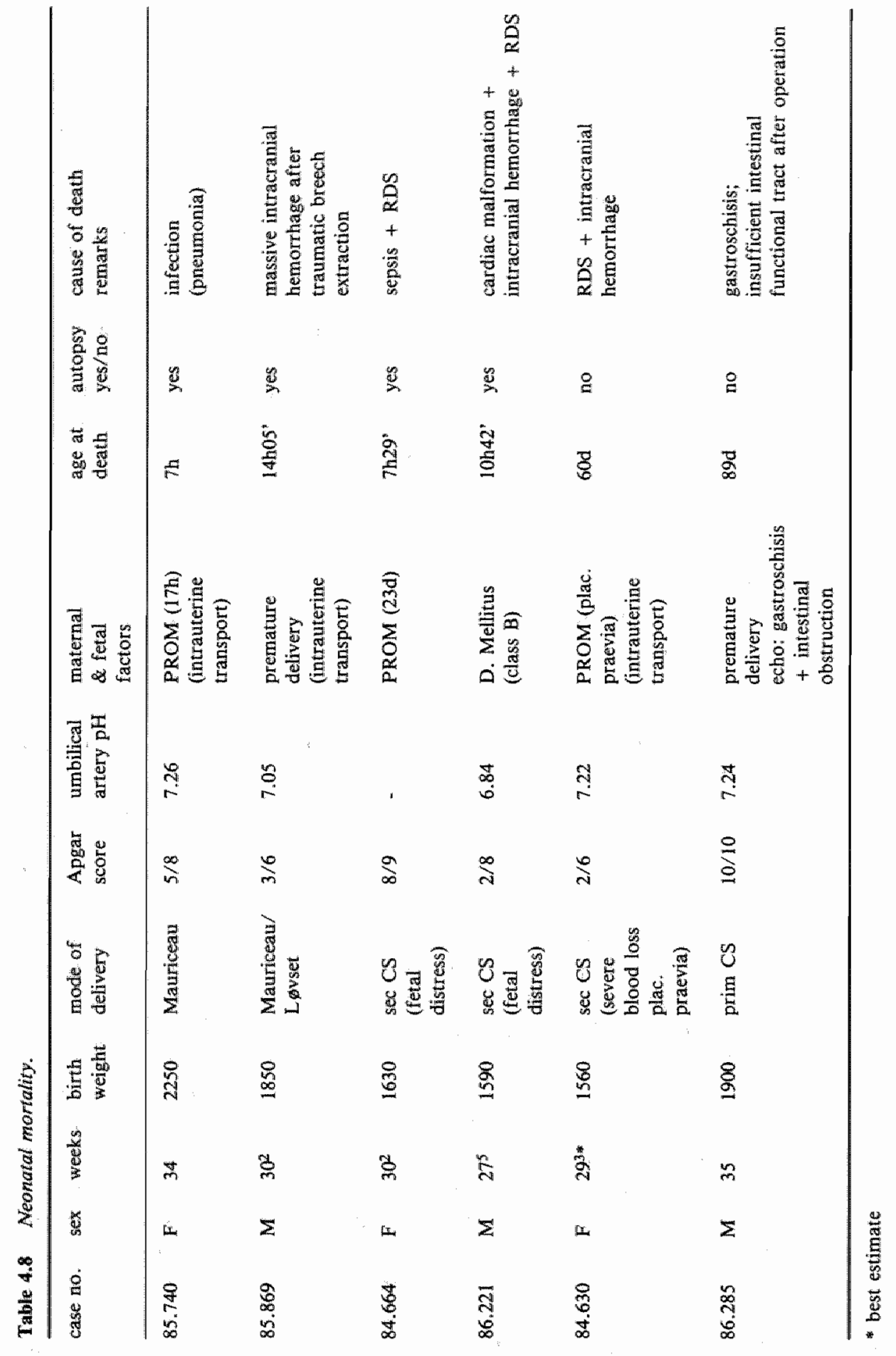




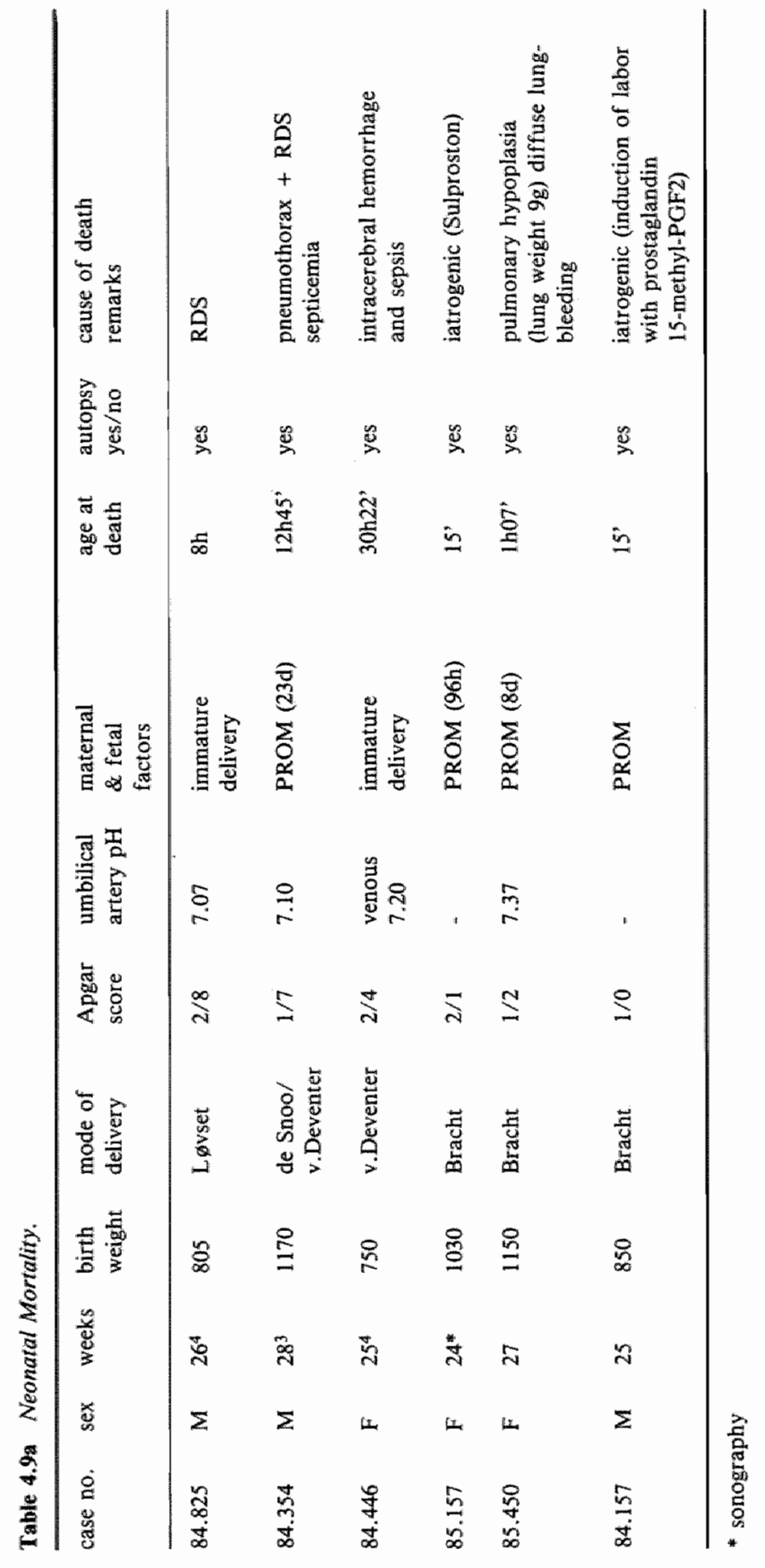




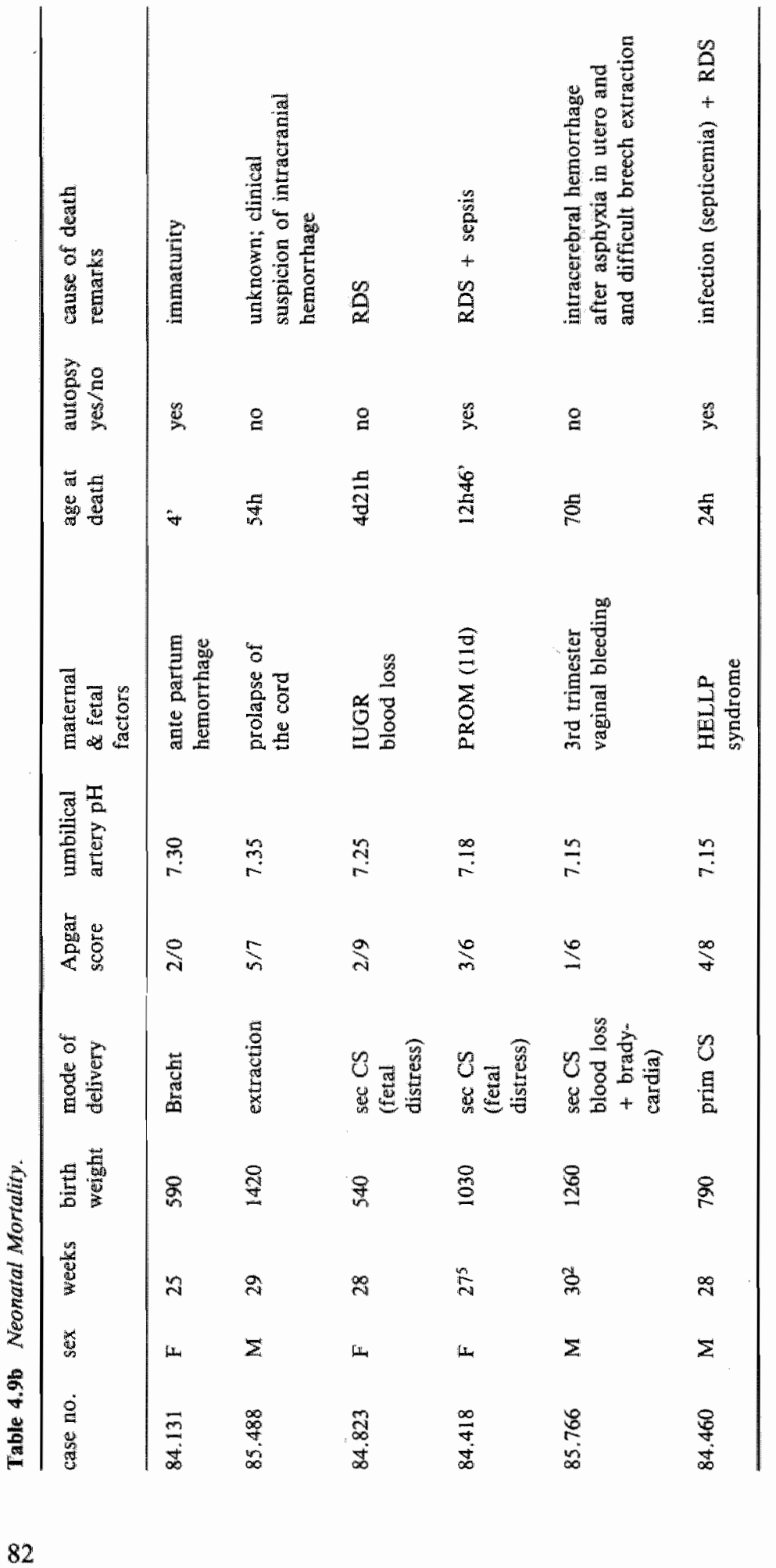




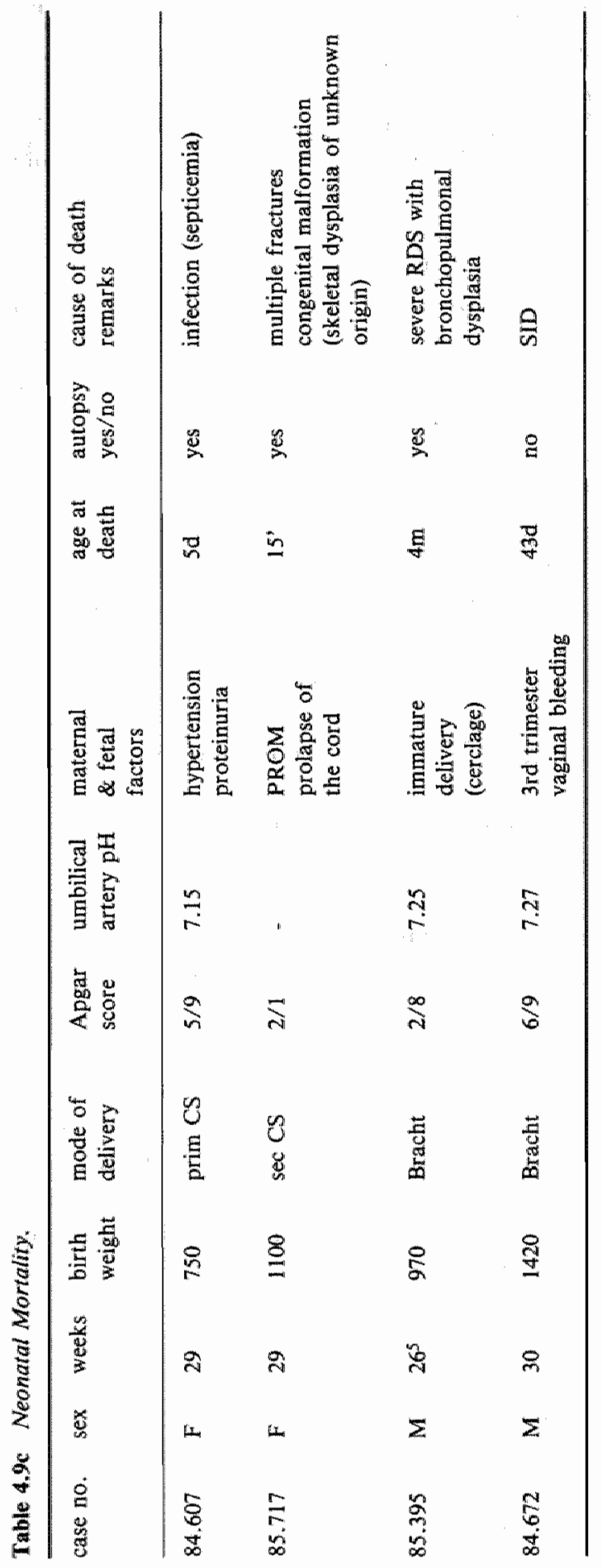


died because the remaining functional intestinal tract was not compatible with life. Post-mortem examination was refused by the parents.

In the very low birth weight group (500-1499 g) 16 deaths occurred: 8 early neonatal deaths occurred in the vaginal group and 6 early neonatal deaths in the abdominal group. There were two post-neonatal deaths in the vaginal group.

One early neonatal death occurred because of respiratory distress syndrome $(84.825$, Table 4.9a). Post-mortem examination confirmed the clinical diagnosis.

The second death in this category was also due to respiratory distress syndrome with clinical signs of sepsis ( 84.354 , table $4.9 \mathrm{a})$. Post-mortem examination revealed RDS but histologically there was no indication for sepsis as a cause of death.

The third death was due to intracerebral hemorrhage and sepsis. At autopsy massive intracranial bleeding and inflammation of lung tissue was diagnosed $(84.446$, Table 4.9a).

The cause of death in the fourth case was possibly a neonatal infection after premature rupture of the membranes (85.157, Table 4.9a). Post-mortem examination revealed no abnormalities except immaturity. Labor was induced by sulproston, since the gestational age estimated by ultrasound was 24 weeks (DBP $6.0 \mathrm{~cm}$ ) in the presence of amnionitis after premature rupture of the membranes.

The true gestational age must have been approximately 30 weeks based on the actual birth weight of $1030 \mathrm{~g}$. Before induction the child was considered to have no chance of survival and the death must be regarded as iatrogenic.

Another death occurred because of abnormal pulmonary function (85.450, Table 4.9a). At obduction pulmonary hypoplasia and diffuse lung bleeding was diagnosed.

The sixth death occurred after induction of labor with prostaglandines (84.157, Table $4.9 \mathrm{a}$ ). The decision of induction was undertaken because the gestational age was 25 weeks in the presence of amnionitis after premature rupture of the membranes. This death must also be regarded as iatrogenic.

Immaturity accounted for the other death $(84.131$, Table $4.9 b)$. In one case no clear cause was detectable ( 85.488 , Table $4.9 \mathrm{~b})$. However, there was a suspicion of intracranial hemorrhage after a difficult breech extraction under general anaesthesia. Autopsy was refused by the parents for religious reasons.

In the abdominally delivered group one death was due to respiratory distress syndrome. Post-mortem examination was not performed (84.823, Table 4.9b).

Another death occurred because of sepsis and respiratory insufficiency (84.418, Table 4.9 b). Post-mortem examination revealed a Streptococcus sepsis and hyaline membrane disease.

One death was due to intracerebral hemorrhage after asphyxia in utero and difficult breech extraction at cesarean section ( 85.766 , Table $4.9 \mathrm{~b}$ ).

In two cases in the cesarean group death was due to sepsis ( 84.460 and 85.607 , Table $4.9 \mathrm{~b}$ and $4.9 \mathrm{c})$. In the last case skeletal dysplasia of unknown origin was diagnosed (85.71.7, Table 4.9c). 
There were two cases of post-neonatal mortality in the vaginal group. One postneonatal mortality in the vaginal group was due to chronic lung disease, following RDS, in which chronic artificial ventilation was required. Post-mortem examination revealed broncho pulmonary dysplasia ( 85.395 , Table $4.9 \mathrm{c}$ ). The other postneonatal mortality occurred unexpectedly and was classified as sudden infant death (84.672, Table 4.9c). Post-mortem examination was not performed.

\subsection{Maternal morbidity and mortality}

Table 4.10 lists figures concerning maternal morbidity.

In the total group one maternal death was recorded, which was due to anaesthetic problems during cesarean section (see case report Table 4.A).

Fever occurred in 18 cases $(20 \%)$ in the cesarean section group and in 2 cases ( $1 \%$ ) in the vaginally delivered group. This was a statistically significant difference.

Seven women $(8 \%)$ in the cesarean section group developed a wound infection, whereas in the vaginally delivered group 2 women $(1 \%)$ experienced this complication. This difference was statistically significant.

As regards the time between the ruptured of membranes and the birth in relation to fever and wound infection there was a relation with fever in two patients in the cesarean section group; these two women $(1 \%$ ) had ruptured membranes more than 24 hours before the birth.

The incidence of positive urine cultures was higher in the cesarean section group $(7 \%)$ than in the vaginally delivered group, where most cultures were sterile. This difference was statistically significant.

The frequency of blood transfusion differed significantly between the cesarean section group and the vaginally delivered group.

The mean hospital stay for the women in the cesarean section group was $9.5 \pm$ 3.4 days, compared with $3.6 \pm 3.2$ days for the women in the vaginally delivered group.

Table 4.10 Maternal morbidity and mortality in relation to mode of delivery in the total group ro\%.

\begin{tabular}{|c|c|c|c|}
\hline Mode of Delivery & $\begin{array}{l}\text { Vaginal } \\
\text { Delivery } \\
(\mathrm{n}=176)\end{array}$ & $\begin{array}{l}\text { Cesarean } \\
\text { Section } \\
(n=92)\end{array}$ & $\begin{array}{l}\text { Chïsquare } \\
\text { tost }\end{array}$ \\
\hline Fever & 2 (I) & $18 \quad(20)$ & $p<0.001$ \\
\hline Wound infection & 2 (1) & $7 \quad(8)$ & $p<0.01$ \\
\hline Urinary tract infection & 2 (I) & 6 (7) & $p<0.05$ \\
\hline Blood transfusion & $18 \quad(10)$ & $34 \quad(37)$ & $p<0.001$ \\
\hline Maternall death & 0 & 1 (1) & $\mathrm{NS}$ \\
\hline $\begin{array}{l}\text { Postpartum hospital days } \\
\text { (mean } \pm \mathrm{SD} \text { ) }\end{array}$ & $3.6 \pm 3.2$ & $9.5 \pm 3.4$ & $p<0.001$ \\
\hline
\end{tabular}


Medical report on patient $L$ d $M$, born 18 june 1957, died 6 February 1985.

Previous medical history included a spontaneous delivery of a girl weighing $3250 \mathrm{~g}$ at birth without complications. At the age of 6-7 months the infant was found to suffer from a highly abnormall neurological development.

Genetic and chromosome studies proved normal.

Present pregnancy was without complications except for the breech presentation. On 2 February 1985 , at agestational age of 38 weeks and 5 days, patient is admitted to hospital at $05.10 \mathrm{am}$, in labor, with $8 \mathrm{~cm}$ dilatation and a non-frank breech presentation.

At 06.03 am dilatation is complete and the patient begins to push. At that time both feet are at the level of the wulva. Because the impression at that time was of good progress of the presenting part, an episiotomy is performed, in the previous scar $(06.10 \mathrm{am})$. There is only diffuse bleeding from the wound area. However, at 06.30 an. there is no further progress at all, as the fetus"right leg is caught behind the symphysis.

It is decided to perform a secondary cesarean section under general anesthesia. Induction of anesthesia starts at 06.50 am. The child is born at 06.53 , weight 3300g, Apgar 5/9, pH A. umb. 7.11 , pH V. umb. 7.20 , pH A. fem. 7.25, pO2 A.fern. $140 \%$. The placenta (weighing $820 \mathrm{~g}$ ) shows mola degeneration (histologically confirmed). From this moment, profylactic blood transfusion is started (blood type $O$ pos.) because of the episiotomy. It is reported to the anesthesist that the blood in the operating area is dark red in colour. He considers everything to be under control.

Hemostasis is unproblematic. Closure of the wound is achieved without further complications. As the fascia is being closed, a progressive bradycardia sets in (down to 40 beats per minute). This occurs at ca. $07.51 \mathrm{am}$. Attempts to treat this bradycardia are unsuccessful. At. 08.15 asystoly is present. External cardiac massage is started at once. After ca. 5 minutes cardiac massage is stopped because there is spontaneous cardiac activity. Heart rate is now $150 / 160$.

At ca. 08.15, the episiotomy is sutured. Blood loss from this episiotomy is found to be moderate. Blood loss during operation is estimated at $1500 \mathrm{ml}$. During operation $1000 \mathrm{c}$ blood was transferred. Total operating time was 2 hours 5 minutes. After operation, the patient is in coma.

The total amount of blood transfused is $3460 \mathrm{ml}$ of blood and $2800 \mathrm{ml}$ packed cells. The patient remains in coma all the time, and electro-encephalograms at 2 February and 4 February show a diffuse, highly abnormal pattern, which is, however, not isoelectric.

On 6 February 1985, progressive bradycardia sets in, with exitus at $0.30 \mathrm{am}$.

At autopsy, macroscopic examination shows a hemoperitoneum of 2-3 litres of liquid blood, a subcapsular hepatic hemorrhage (dorsal and caudal, beside the vena cava), and clear softening of the brain.

The neonatal development of the child is completely normal.

In the birth weight category of $2500 \mathrm{~g}$ or more one maternal death was recorded, due to anaesthetic problems during cesarean section (see case report Table 4.A) In this birth weight category fever occurred in 11 patients (19\%) in the cesarean section group. In the vaginal group no fever occurred.

This difference was signinificant.

Five of the women $(9 \%)$ in the cesarean section group developed wound infections, whereas in the vaginally delivered group 2 women $(2 \%)$ had this complication.

The incidence of positive urine cultures was higher in the cesarean section group $(5 \%)$, while in the vaginally delivered group all cultures were sterile.

Thus significant differences in all these maternal complications (fever, wound infections and urinary tract infections) were found between the two groups.

The need for blood transfusion also differed significantly between the cesarean section group and the vaginally delivered group in this weight category. 
Talble 4.10a Maternal morbidity and mortality in relation to mode of delivery in the three birih weight categories (\%).

\begin{tabular}{|c|c|c|c|c|c|c|}
\hline \multirow{3}{*}{$\begin{array}{l}\text { Birth weight category }(\mathrm{g}) \\
\text { Mode of Delivery } \\
\text { No. of Patients }\end{array}$} & \multicolumn{2}{|l|}{$\geqslant 2500$} & \multicolumn{2}{|c|}{$1500-2499$} & \multicolumn{2}{|c|}{$500-1499$} \\
\hline & VD & $\mathrm{CS}$ & VD & $\operatorname{cs}$ & VD & $\operatorname{cs}$ \\
\hline & 132 & 57 & 26 & 17 & 18 & 18 \\
\hline Fever & $0(0)^{*}$ & $11(19)$ & $1(4)$ & $3(18)$ & $1(6)$ & $4(22)$ \\
\hline Wound infection & $2(2)^{*}$ & $5(9)$ & $0(0)$ & $1(6)$ & $0(0)$ & $1(6)$ \\
\hline Urinary tract infection & $0(0)^{*}$ & $3(5)$ & $1(4)$ & $2(12)$ & $1(6)$ & $1(6)$ \\
\hline Blood transfusion & $14(11)^{* * 4}$ & $21(37)$ & $1(4)^{* *}$ & $8(47)$ & $3(17)$ & $5(28)$ \\
\hline Maternal death & $a(0)$ & $1(2)$ & $0(0)$ & $0(0)$ & $0(0)$ & $0(0)$ \\
\hline $\begin{array}{l}\text { Postpartum hospital days } \\
\text { (mean) }\end{array}$ & $3.54 \mathrm{~A}$ & 9.7 & 4.7 & 9.4 & $3.0 \AA$ & 9.1 \\
\hline SD & 32 & 2.8 & 3.7 & 1.7 & 1.9 & 5.6 \\
\hline
\end{tabular}

Chi-square test $\begin{aligned} * & <0.05 \\ * & <0.01 \\ * * * & <0.001\end{aligned} \quad$ Mann-Whitney U test $\begin{aligned} * p<0.01 \\ \end{aligned}$

The mean hospital stay for the women in the cesarean section group was $9.7 \pm 2.8$ days, compared with $3.5 \pm 3.2$ days for the women in the vaginally delivered group. This difference is statistically significant.

In the $1500-2499 \mathrm{~g}$ birth weight category 3 women (18\%) in the cesarean section group developed fever as previously defined, compared with one woman (4\%) in the vaginally delivered group, a difference which is not significant.

One patient $(6 \%)$ developed wound infection after cesarean section. In the abdominal delivered group there was a higher incidence of positive urine cultures (12\%) than in the vaginally delivered group (4\%). However, this difference was not statistically significant.

Blood transfusion was necessary in 8 patients $(47 \%)$ in the cesarean section group and in only one patient ( $4 \%$ ) in the vaginally delivered group.

The need for blood transfusion was significantly different between the cesarean section group and the vaginally delivered group.

The mean hospital stay for the women in the cesarean section group was $9.4 \pm 1.7$ days, compared with $4.7 \pm 3.7$ days for the women in the vaginally delivered group. This difference is statistically significant.

Finally the figures concerning maternal morbidity in the $500-1499 \mathrm{~g}$ birth weight category are listed. Maternal fever occurred significantly more often after cesarean section $(22 \%)$ compared to vaginal delivery $(6 \%)$.

As regards wound infection, one patient $(6 \%)$ in the abdominal group developed a wound infection. The incidence of positive urine cultures was similar for the two groups.

Five patients $(28 \%)$ in the cesarean section group and 3 patients $(17 \%)$ in the vaginal group received blood transfusion.

The maternal complications (fever, wound infection, urinary tract infection, blood 
transfusion and maternal death) did not differ significantly between the two groups in this birth weight category.

The mean hospital stay for women in the cesarean section group was $9.1 \pm 5.6$ days, compared with $3.0 \pm 1.9$ days for the women in the vaginally delivered group. This difference was significant. 


\section{Chapter 5}

\section{Factors studied in relation to neonatal outcome}

\subsection{Neonatal outcome analyzed by parity and breech type}

In the total study group of 159 primiparous patients $64 \%$ were delivered vaginally and $36 \%$ were delivered by cesarean section.

Of the 109 multiparous patients $69 \%$ delivered vaginally, while $31 \%$ underwent a cesarean section. There were no statistically significant differences with regard to the mode of delivery between the primiparous and the multiparous patients (Table $5.1)$.

Of all 117 primiparous patients delivered in the birth weight category of $2500 \mathrm{~g}$ or more, $32 \%$ underwent a cesarean section, while $68 \%$ delivered vaginally.

Of the 72 multiparous patients in the birth weight category of 2500 grams or more, $26 \%$ underwent a cesarean section and $74 \%$ delivered vaginally. The groups showed no statistical differences with respect to the mode of delivery (Table 5.1).

Table 5.1 Mode of delivery analyzed by parity and breech type.

\begin{tabular}{|c|c|c|c|c|c|}
\hline Total & $\begin{array}{l}\text { vaginal deliwery }(\%) \\
\text { cesarean section }(\%)\end{array}$ & $\begin{array}{l}\text { Primiparous } \\
(n=159) \\
101(64) \\
58(36)\end{array}$ & $\begin{array}{l}\text { Multiparous } \\
(n=109) \\
75(69) \\
34(31)\end{array}$ & $\begin{array}{l}\text { Frank } \\
(\mathrm{n}=193) \\
131(68) \\
62(32)\end{array}$ & $\begin{array}{l}\text { Non-frank } \\
(\mathrm{n}=75) \\
45(60) \\
30(40)\end{array}$ \\
\hline$\geqslant 2500 \mathrm{~g}$ & $\begin{array}{l}\text { vaginal delivery }(\%) \\
\text { cesarean section }(\%)\end{array}$ & $\begin{array}{l}(\mathrm{n}=117) \\
79(68) \\
38(32)\end{array}$ & $\begin{array}{l}(n=72) \\
53(74)) \\
19(26)\end{array}$ & $\begin{array}{c}(n=140) \\
100(71) \\
40(29)\end{array}$ & $\begin{array}{l}(n=49) \\
32(65) \\
17(35)\end{array}$ \\
\hline $\begin{array}{l}1500- \\
2499 \mathrm{~g}\end{array}$ & $\begin{array}{l}\text { vaginal delivery }(\%) \\
\text { cesarean section }(\%)\end{array}$ & $\begin{array}{l}(n=28) \\
18(64) \\
10(36)\end{array}$ & $\begin{array}{l}(n=15) \\
8(53) \\
7(47)\end{array}$ & $\begin{array}{l}(n=27) \\
17(63) \\
10(37)\end{array}$ & $\begin{array}{l}(n=16) \\
9(56) \\
7(4.4)\end{array}$ \\
\hline $\begin{array}{l}500- \\
1.499 \mathrm{~g}\end{array}$ & $\begin{array}{l}\text { vaginal delivery }(\%) \\
\text { cesarean section }(\% \%)\end{array}$ & $\begin{array}{c}(n=14) \\
4(29) \\
10(71)\end{array}$ & $\begin{array}{c}(n=22) \\
14(64) \\
8(36)\end{array}$ & $\begin{array}{l}(n=26) \\
14(54) \\
12(46)\end{array}$ & $\begin{array}{l}(n=10) \\
4(40) \\
6(60)\end{array}$ \\
\hline
\end{tabular}

Chi-square test: NS

In the $1500-2499 \mathrm{~g}$ birth weight group vaginal delivery was achieved in $53 \%$ of multiparous patients, while primiparous women delivered vaginally in $64 \%$ of cases, which represents no significant statistical difference.

Thirty six per cent of the primiparous patients and $47 \%$ of the multiparous patients 
underwent a cesarean section in the $1500-2499 \mathrm{~g}$ birth weight category. This difference was again not significant.

Of all 14 primiparous patients delivered in the very low birth weight category $(500-1499 \mathrm{~g}), 71 \%$ underwent a cesarean section, while $29 \%$ delivered vaginally. Of the 22 multiparous patients in this group $36 \%$ underwent a cesarean section and $640 \%$ delivered vaginally, again representing no statistical difference with respect to the parity.

As for the type of breech presentation, $68 \%$ of all frank breeches delivered vaginally and $32 \%$ underwent cesarean section. Of the non-frank breeches $60 \%$ delivered vaginally and $40 \%$ underwent cesarean section (Table 5.1).

In the birth weight category of $2500 \mathrm{~g}$ or more, $71 \%$ of all frank breeches were delivered waginally, as were $65 \%$ of all non-frank breech infants.

In the $1500-2499 \mathrm{~g}$ birth weight category, $63 \%$ of all frank breeches were delivered vaginally, as were $56 \%$ of all non-frank breech infants.

Of all neonates weighing $500-1499 \mathrm{~g}$ with frank breech presentation, $54 \%$ were delivered vaginally, while $40 \%$ of all non-frank breech infants were delivered vaginally. Neither of the three birth weight groups nor the total group showed statistical differences with respect to the type of breech presentation in relation to the mode of delivery.

Apgar scores, umbilical artery $\mathrm{pH}$ and perinatal mortality analyzed by breech type (frank/non-frank) and related to mode of delivery are described in Tables 5.2-5.5. In the three birth weight categories no statistically significant differences in neonatal outcome were shown between the vaginally delivered group and the abdominally delivered group in neonatal outcome, with respect to mortality and morbidity according to breech type. In the total group of the non-frank breeches, however, there was a statistically significant difference between the vaginal group and the abdominal group as regards one minute Apgar scores below $7(\mathrm{p}<0.02$, Chi-square test; Table 5.2)

Table 5.2 Neonatal outcome analyzed by breech type and related to mode of delivery.

\begin{tabular}{|c|c|c|c|c|}
\hline \multirow[t]{3}{*}{ Total group } & \multicolumn{2}{|c|}{ 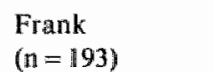 } & \multicolumn{2}{|c|}{$\begin{array}{l}\text { Non-Frank } \\
(n=75)\end{array}$} \\
\hline & VD & $\mathrm{CS}$ & VD & $\mathrm{CS}$ \\
\hline & 131 & 62 & 45 & 30 \\
\hline $\begin{array}{l}\text { 1"Apgar }<7 \\
\text { (number of cases) }\end{array}$ & 42 & 26 & 9 & $15 *$ \\
\hline $5:$ Apgar $<7$ & 12 & 5 & 2 & 4 \\
\hline $\begin{array}{l}\text { Umbilical ari. pH } \\
\text { (mean) }\end{array}$ & 7.22 & 7.24 & 7.22 & 7.22 \\
\hline $\begin{array}{l}\text { Perinatal mortality } \\
\text { (number of cases) }\end{array}$ & 8 & 6 & 3 & 2 \\
\hline
\end{tabular}

$* \mathrm{p}<0.02$ (Chi-square test). 
Table 5.3 Neonatal owtcome analyzed by breech type and related to mode of delivery.

\begin{tabular}{|c|c|c|c|c|}
\hline \multirow[t]{3}{*}{ Birth weight $\geqslant 2500 \mathrm{~g}$} & \multicolumn{2}{|c|}{$\begin{array}{l}\text { Frank } \\
(n=140)\end{array}$} & \multicolumn{2}{|c|}{$\begin{array}{l}\text { Non-Frank } \\
(n=49)\end{array}$} \\
\hline & VD & $\mathrm{CS}$ & VD & $\mathrm{CS}$ \\
\hline & 100 & 40 & 32 & 17 \\
\hline $\begin{array}{l}1 \text { Apgar }<7 \\
\text { (number of cases) }\end{array}$ & 23 & 11 & 4 & 6 \\
\hline $5^{*}$ Apgar $<7$ & 4 & 2 & 1 & 0 \\
\hline $\begin{array}{l}\text { Umbilical art. pH } \\
\text { (mean) }\end{array}$ & 7.22 & 7.26 & 7.22 & 7.24 \\
\hline $\begin{array}{l}\text { Perinatal mortality } \\
\text { (number of cases) }\end{array}$ & 1 & 0 & 0 & 0 \\
\hline
\end{tabular}

Table 5.4 Neonatal outcome analyzed by breech type and related to mode of delivery.

\begin{tabular}{|c|c|c|c|c|}
\hline \multirow[t]{3}{*}{$\begin{array}{l}\text { Birth weight } \\
1500-2499 \mathrm{~g}\end{array}$} & \multicolumn{2}{|c|}{$\begin{array}{l}\text { Frank } \\
(n=27)\end{array}$} & \multicolumn{2}{|c|}{$\begin{array}{l}\text { Non-Frank } \\
(\mathrm{n}=16)\end{array}$} \\
\hline & VD & $\mathrm{CS}$ & VD & $\mathrm{cs}$ \\
\hline & 17 & 10 & 9 & 7 \\
\hline $\begin{array}{l}\text { 1"Apgar < } 7 \\
\text { (number of cases) }\end{array}$ & 5 & 5 & 2 & 5 \\
\hline $5^{\prime}$ Apgar $<7$ & $\mathbb{1}$ & 1 & 0 & 1 \\
\hline $\begin{array}{l}\text { Umbilical art. } \mathrm{pH} \\
\text { (mean) }\end{array}$ & 7.24 & 7.19 & 7.25 & 7.19 \\
\hline $\begin{array}{l}\text { Perinatal mortality } \\
\text { (number of cases) }\end{array}$ & 1 & 2 & 1 & 0 \\
\hline
\end{tabular}

Table 5.5 Neonatal outcome analyzed by breech type and related to mode of delivery.

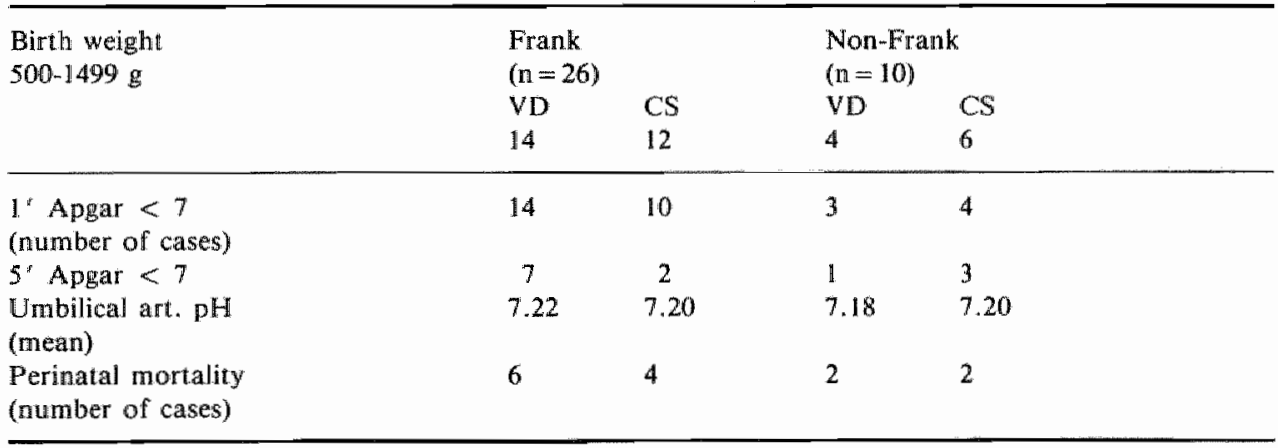

As regards the parity, listed in Tables 5.6-5.9 there were no statistically significant differences in neonatal outcome between the vaginally delivered group and the abdominally delivered group. There was, however one exception: in the total group of primiparous patients the abdominally delivered neonates showed a lower Apgar score after one minute than the vaginally delivered neonates $(p<0.01$, Chi-square test; Table 5.6). 
Table 5.6 Neonatal outcome analyzd by parity and related to mode of deliwery.

\begin{tabular}{|c|c|c|c|c|}
\hline \multirow[t]{3}{*}{ Total group } & \multicolumn{2}{|c|}{ Primiparous } & \multicolumn{2}{|c|}{ Multiparous } \\
\hline & $V D$ & $\mathrm{Cs}$ & VD & $\mathrm{CS}$ \\
\hline & 101 & 58 & 75 & 34 \\
\hline $\begin{array}{l}\text { I'Apgar }<7 \\
\text { (number of calses) }\end{array}$ & 21 & $24 *$ & 30 & 17 \\
\hline $5^{\prime \prime}$ Apgar $<7$ & 4 & 4 & 10 & 5 \\
\hline $\begin{array}{l}\text { Umbilical art. pH } \\
\text { (moan) }\end{array}$ & 7.23 & 7.24 & 7.21 & 7.21 \\
\hline $\begin{array}{l}\text { Perinatal mortality } \\
\text { (rumber of cases) }\end{array}$ & 4 & 5 & 7 & 3 \\
\hline
\end{tabular}

$* 0.01$ (Chi-square test)

Table 5.7 Neonatal outcome analyzed by parity and related to mode of delivery.

\begin{tabular}{lcccc}
\hline Birth weight $\geqslant 2500 \mathrm{~g}$ & \multicolumn{3}{l}{ Primiparous } & \multicolumn{2}{l}{ Multiparous } \\
& VD & CS & VD & CS \\
& 79 & 38 & 53 & 19 \\
\hline $\begin{array}{l}\text { I' Apgar }<7 \\
\text { (number of cases) }\end{array}$ & 14 & 11 & 13 & 6 \\
$5^{r}$ Apgar $<7$ & 2 & 1 & 3 & 1 \\
$\begin{array}{l}\text { Umbilical art. pH } \\
\text { (mean) }\end{array}$ & 7.22 & 7.26 & 7.21 & 7.24 \\
$\begin{array}{l}\text { Perinatal mortality } \\
\text { (number of cases) }\end{array}$ & 1 & 0 & 0 & 0 \\
\hline
\end{tabular}

Table 5.8 Neonatal outcome analyzed' by parity and related to mode of delivery.

\begin{tabular}{|c|c|c|c|c|}
\hline \multirow{3}{*}{$\begin{array}{l}\text { Birth weight } \\
1500-2499 \mathrm{~g}\end{array}$} & \multicolumn{2}{|c|}{ Primiparous } & \multicolumn{2}{|c|}{ Multiparous } \\
\hline & VD & $\mathrm{CS}$ & $\mathrm{VD}$ & $\mathrm{CS}$ \\
\hline & 18 & 10 & 8 & 7 \\
\hline $\begin{array}{l}\text { I' Apgar < } 7 \\
\text { (number of calses) }\end{array}$ & 3 & 5 & 4 & 5 \\
\hline $5^{\prime}$ Apgar $<7$ & 0 & 1 & 1 & 1 \\
\hline $\begin{array}{l}\text { Umbilical art. pH } \\
\text { (nean) }\end{array}$ & 7.25 & 7.19 & 7.23 & 7.17 \\
\hline $\begin{array}{l}\text { Perinatal mortality } \\
\text { (number of cases) }\end{array}$ & 1 & 1 & 1 & 1 \\
\hline
\end{tabular}


Table 5.9 Neonatal outcome analyzed by parity and related to made of delivery.

\begin{tabular}{|c|c|c|c|c|}
\hline \multirow{3}{*}{$\begin{array}{l}\text { Birth weight } \\
500-1499 \mathrm{~g}\end{array}$} & \multicolumn{2}{|c|}{ Primiparous } & \multicolumn{2}{|c|}{ Multiparous } \\
\hline & VD & $\mathrm{CS}$ & VD & $\mathrm{Cs}$ \\
\hline & 4 & 10 & 14 & 8 \\
\hline $\begin{array}{l}\text { 1. Apgar < } 7 \\
\text { (number of cases) }\end{array}$ & 4 & 8 & 13 & 6 \\
\hline 5. Apgar $<7$ & 2 & 2 & 6 & 3 \\
\hline $\begin{array}{l}\text { Umbilical art. pH } \\
\text { (mean) }\end{array}$ & 7.25 & 7.23 & 7.20 & 7.17 \\
\hline $\begin{array}{l}\text { Perinatal mortality } \\
\text { (number of cases) }\end{array}$ & 2 & 4 & 6 & 2 \\
\hline
\end{tabular}

\subsection{Use of oxytocin during labor and its influence on the neonatal outcome.}

Oxytocin by continuous intravenous infusion $(1-30 \mathrm{mU} / \mathrm{min})$ or prostaglandines extra-amniotic or intravenous were administered in 116 of the patients; in 13 patients for induction of labor and in 103 patients to augment insufficient or dysfunctional labor.

Of these 103 patients, 32 were multiparous women and 71 were primiparous women. In the total group of 116 patients to whom oxytocin or prostaglandines were administered, 91 patients achieved a vaginal delivery and 25 were delivered by cesarean section.

Labor was induced in 5 multiparous patients and in 8 primiparous patients.

Table 5.10 Neonatal outcome analyzed by augmentation and no augmentation related to mode of delivery.

\begin{tabular}{|c|c|c|c|c|}
\hline \multirow[t]{3}{*}{ Total study group } & \multicolumn{2}{|c|}{$\begin{array}{l}\text { Augmentation } \\
(\mathrm{n}=103)\end{array}$} & \multicolumn{2}{|c|}{$\begin{array}{l}\text { No A ugmentation } \\
(\mathrm{n}=165)\end{array}$} \\
\hline & VD & $\operatorname{cs}$ & VD. & $\mathrm{Cs}$ \\
\hline & 79 & 24 & 97 & 68 \\
\hline $\begin{array}{l}\text { 1 Apgar }<7 \\
\text { (number of cases) }\end{array}$ & 21 & 6 & 30 & $34 *$ \\
\hline $5^{\prime}$ Apgar $<7$ & 7 & 0 & 7 & 9 \\
\hline $\begin{array}{l}\text { Unbilical art. pH } \\
\text { (mean) }\end{array}$ & 7.23 & 7.26 & 7.21 & 7.22 \\
\hline $\begin{array}{l}\text { Perinatal mortality } \\
\text { (number of cases) }\end{array}$ & 2 & 0 & 9 & 8 \\
\hline
\end{tabular}

$* p<0.02$ (Chi-square test)

- including all 13 newborns, in which labor was induced. 
Table 5.11 Neonatal outcome analyzed by augmentation and no awgmemation related to mode of delivery.

\begin{tabular}{|c|c|c|c|c|}
\hline \multirow[t]{3}{*}{ Birth wreight $\geqslant 2500 \mathrm{~g}$} & \multicolumn{2}{|c|}{$\begin{array}{l}\text { Augmentation } \\
(n=94)\end{array}$} & \multicolumn{2}{|c|}{$\begin{array}{l}\text { No Augmentation } \\
(m=95)\end{array}$} \\
\hline & VD & $\mathrm{CS}$ & VD & $\operatorname{cs}$ \\
\hline & 71 & 23 & 61 & 34 \\
\hline $\begin{array}{l}1^{\prime} \text { Apgar }<7 \\
\text { (number of cases) }\end{array}$ & 17 & 6 & 10 & 11 \\
\hline $5^{\prime}$ Apgar $<7$ & 5 & 0 & 0 & 2 \\
\hline $\begin{array}{l}\text { Umbilical art. pH } \\
\text { (mean) }\end{array}$ & 7.23 & 7.26 & 7.21 & 7.25 \\
\hline Perinatal mortality & 0 & 0 & 1 & 0 \\
\hline
\end{tabular}

- including all 13 neonates, in which labor was induced.

In this group of 13 induced labors, 12 vaginal deliveries occurred, 8 in primiparous patients.

In the 1500-2499 $\mathrm{g}$ birth weight category 3 inductions were performed, against 10 inductions in the birth weight category of $2500 \mathrm{~g}$ or more. In the 500-1499 g birth weight group no inductions were performed. Augmentation was necessary in 3 cases in the very low birth weight category and in 6 cases in the $1500-2499 \mathrm{~g}$ birth weight category. The highest incidence of augmentation occurred in the birth weight category of $2500 \mathrm{~g}$ or more: 94 patients (Table 5.11).

There were no maternal or neonatal complications related to oxytocin administration in the total study group. In the total group a statistically significant difference was shown between the vaginal group and the abdominal group, where no augmentation was used as regards the one minute Apgar score ( $p>0.02$, Chi-square test; Table 5.10). In the group of neonates weighing $2500 \mathrm{~g}$ or more no statistically significant differences were found between the vaginally delivered group and the $a b-$ dominally delivered group as regards neonatal morbidity and augmentation (Table $5.11)$.

Of the 10 neonates in the birth weight category $2500 \mathrm{~g}$ or more who were delivered vaginally after induction by means of oxytocin or prostaglandines, none had a 5-minute Apgar score $<7$ or a birth trauma. The mean umbilical artery $\mathrm{pH}$ was 7.26 .

The number of inductions in the total group and the cases in which augmentation was necessary in the low and very low birth weight categories were too small for valid statistical analysis regarding the neonatal outcome. 


\section{Chapter 6}

Complicating factors during delivery and neonatal outcome

\subsection{Birth weight and mode of delivery in the weight category of $2500 \mathrm{~g}$ or more}

In the birth weight category of $2500 \mathrm{~g}$ or more the mean birth weight of the infants was $3189 \mathrm{~g}$ in the vaginal group and $3378 \mathrm{~g}$ in the abdominal group.

In the vaginal group (176 patients), six patients delivered neonates weighing more than 3750 grams, the largest weighing 4170 grams. In the cesarean section group ( 57 patients), two patients delivered neonates weighing more than 4500 grams, the largest weighing 4780 grams (Fig 6.1).

Fig 6.1 Birth weight $\geqslant 2500 \mathrm{~g}$ Mode of delivery

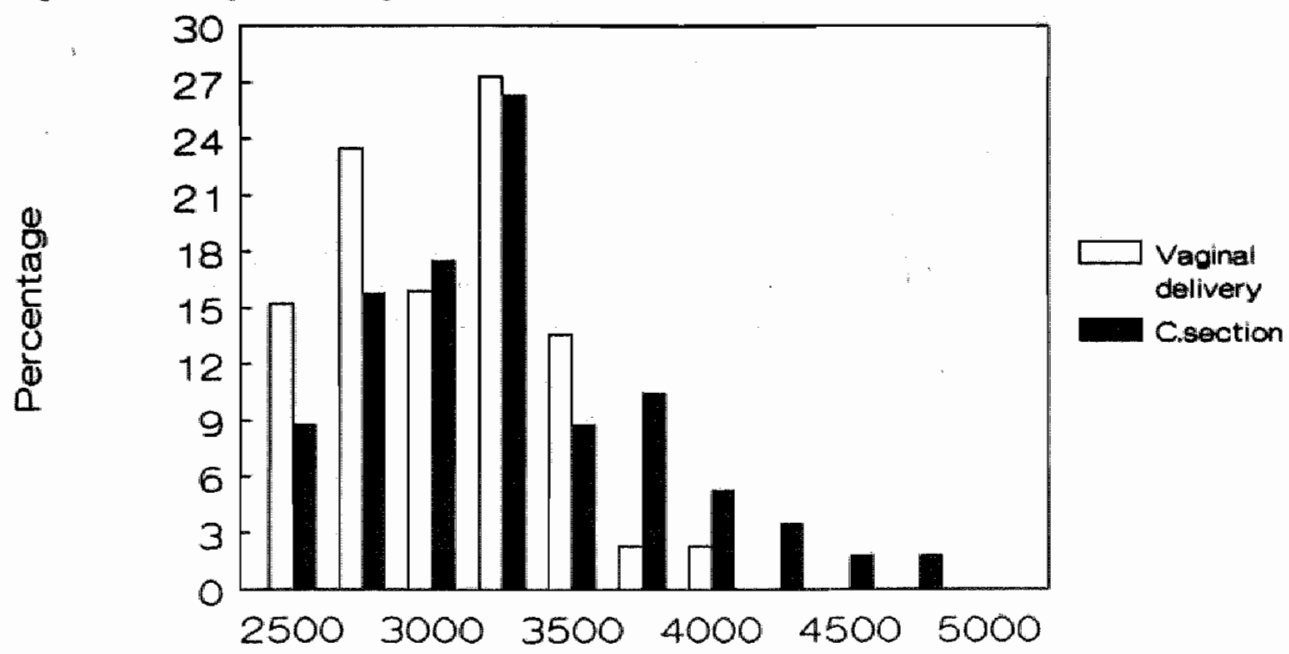

Birth weight (grams)

\subsection{BPD and the mode of delivery}

Fig 6.2 shows the BPD in the range $9.0-10.4 \mathrm{~cm}$ in relation to the mode of delivery. BPD was measured and noted in 226 cases $(84 \%), 77$ cases in the cesarean section group and 149 in the vaginal group.

There was no relation between the BPD measured and the mode of delivery. (Mann-Whitney U test). 


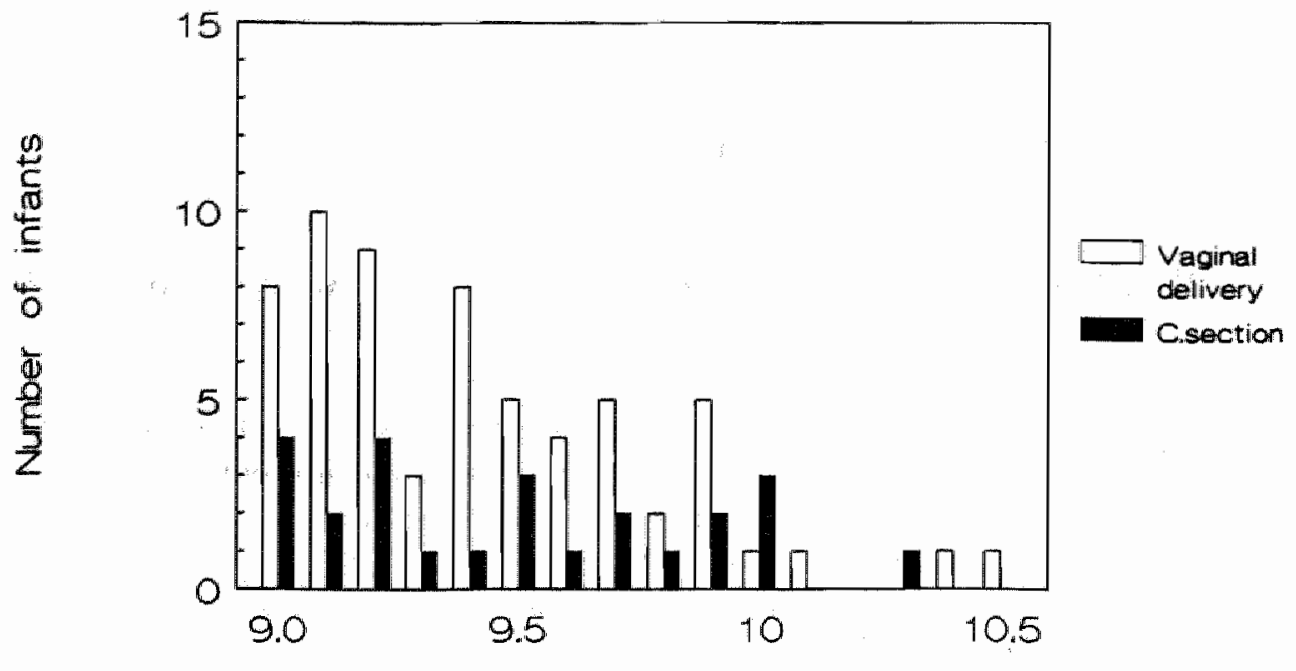

Biparietal diameter $(\mathrm{cm})$

\subsection{Cord prolapse}

Prolapse of the umbilical cord occurred in 5 of the 193 patients (3\%) presenting with a frank breech and in 5 of the 75 patients $(7 \%$ ) presenting with a non-frank breech. In the birth weight category of $2500 \mathrm{~g}$ or more, three patients (all non-frank presentations) with prolapse of the umbilical cord were delivered by cesarean section and three (all frank presentations) delivered vaginally. Five neonates showed a good outcome (Apgar score after 5 minutes over 7, arterial umbilical pH over 7.20).

The infants had no neonatal complications.

One neonate died during labor due to puncture of the prolapsed cord by a scalp electrode after misdiagnosis. There were no statistically significant correlation between the mode of delivery and the neonatal outcome in the cases of umbilical cord prolapse.

In the 1500-2499 $\mathrm{g}$ birth weight category one neonate with prolapse of the umbilical cord was delivered vaginally. The neonate had a 5 min Apgar score of over 7 . The umbilical artery $\mathrm{pH}$ was 7.20 .

In the neonates weighing 500-1499 g, prolapse of the umbilical cord occurred three times. One patient underwent cesarean section and two others delivered vaginally. All three neonates died in the neonatal period (see chapter 4.1.6). 


\subsection{Hyperextension of the fetal head}

Hyperextension of the fetal head occurred in one case and was detected by ultrasound examination and confirmed by $\mathrm{X}$-ray (Fig 6.3 and 6.4).

In this case this was regarded as an indication for cesarean section.

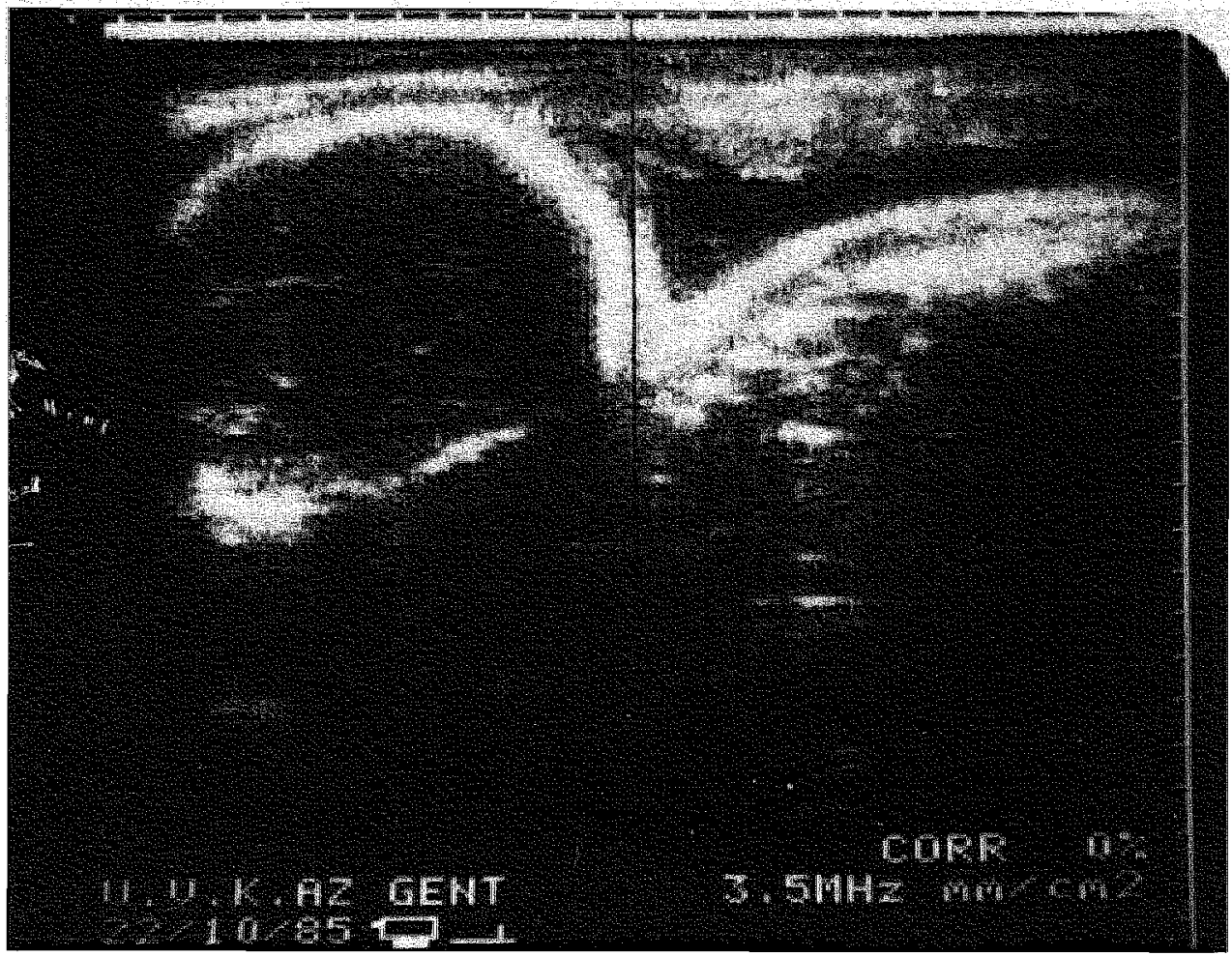

Fig. 6.3 Hyperextension of fetal head (ultrasound examination). 


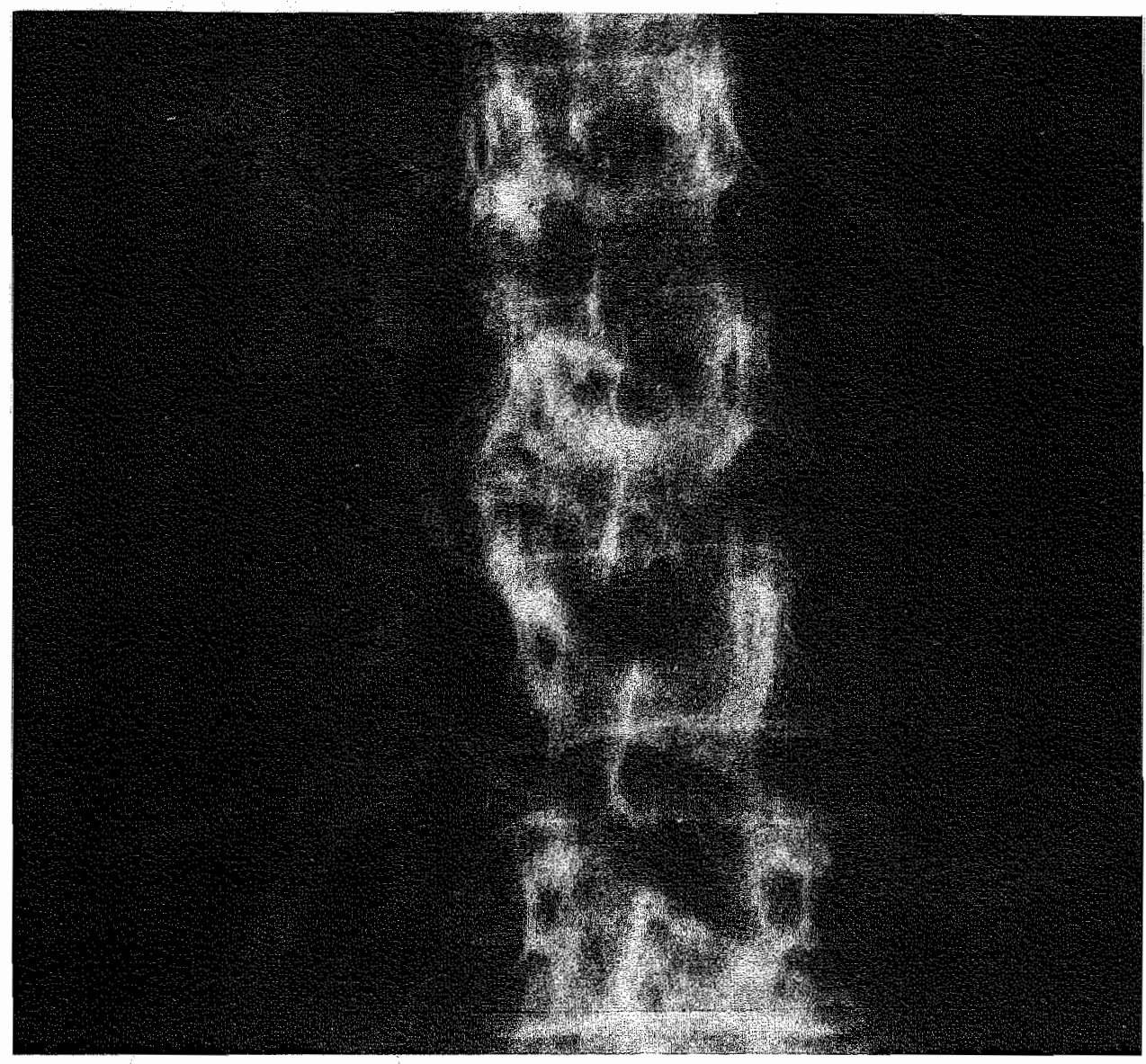

\subsection{Umbilicus to delivery time}

In the total study group umbilicus-to-delivery time was reliably recorded in 167 of the 166 vaginally delivered neonates. There was a negative correlation between umbilicus-to-delivery time and Apgar scores both after one and after five minutes ( $p<0.01$, Spearmann correlation coefficient; Fig. 6.5 and 6.6). No statistically significant correlations were found between the umbilicus-to-delivery time and umbilical arterial or umbilical venous pH values (Fig. 6.7 and 6.8).

Umbilicus-to-delivery time was recorded in 127 of the 132 vaginally delivered infants weighing $2500 \mathrm{~g}$ or more.

Umbilicus-to-delivery time ranged from 2 to 450 seconds, the average being $57 \mathrm{se}$ conds. The four infants with depressed 5 minute Apgar scores had umbilicus-todelivery times of $10,150,180$ and 240 seconds respectively. The 5 patients in whom 
Table 6.5 Umbilicus-tondelivery yime in relation to Apgar after I minute.

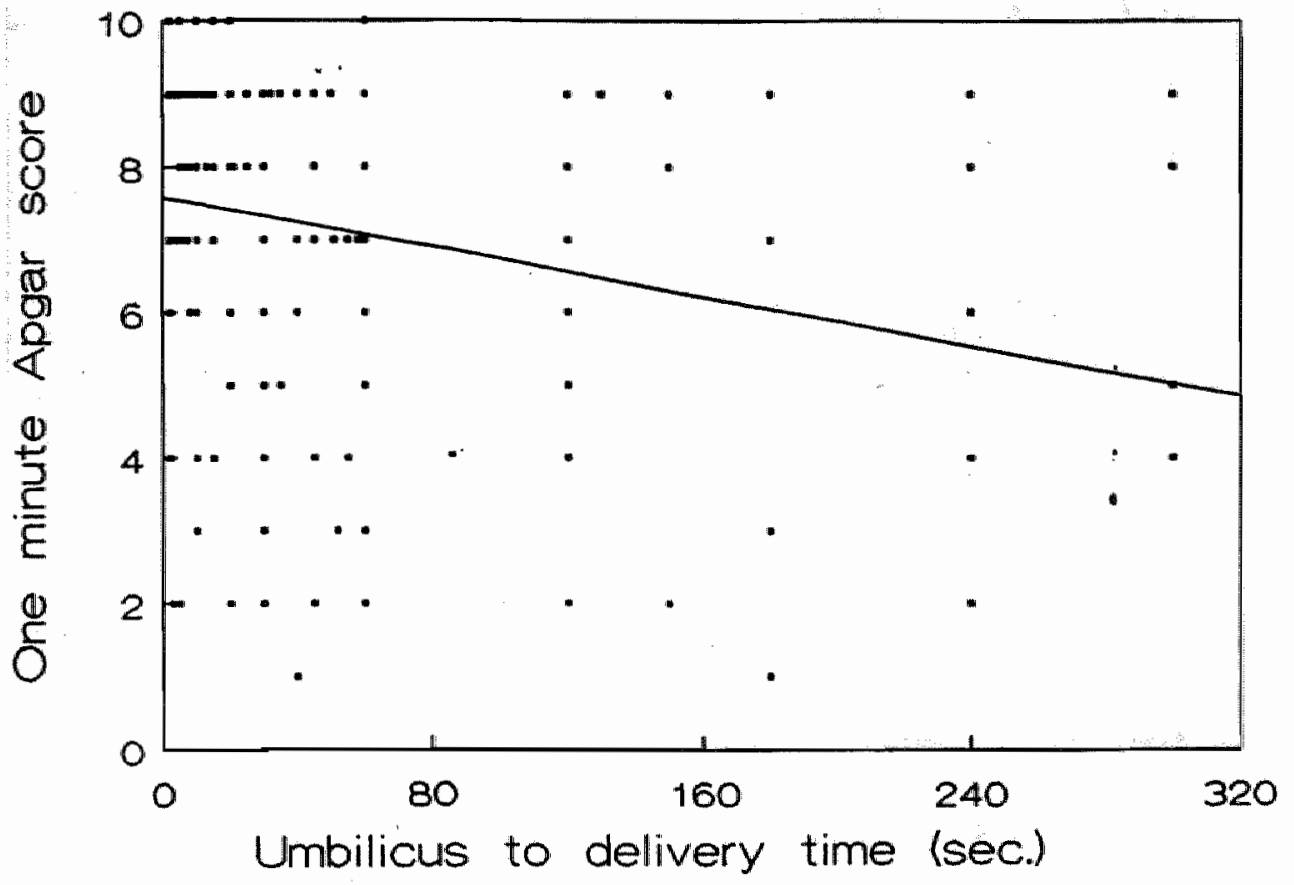

Table 6.6 Umbilicus-to-delivery time in relation lo Apgar after 5 minutes.

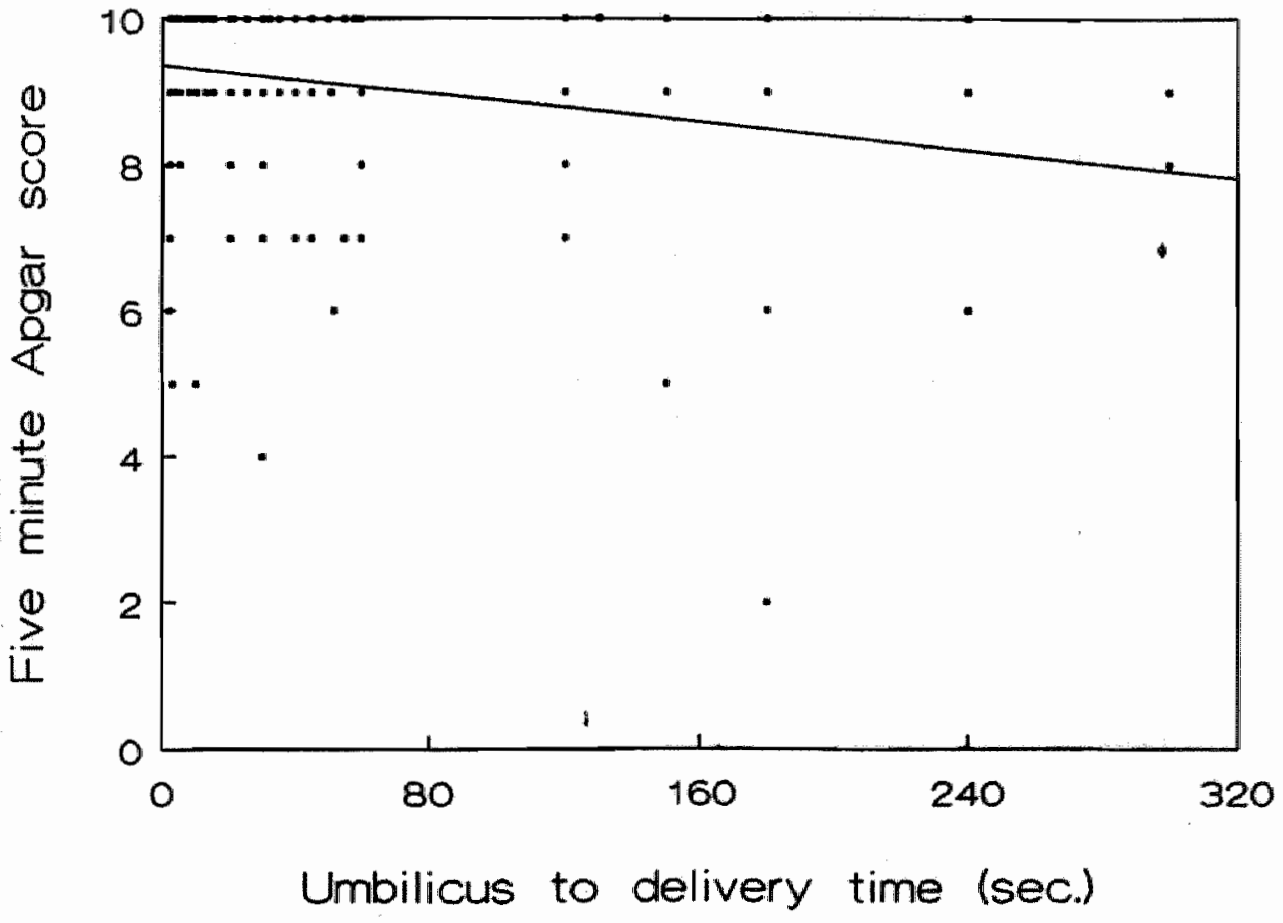


Table 6.7 Umbilicus-to-delivery time in retation to umbillical artery $p H$.

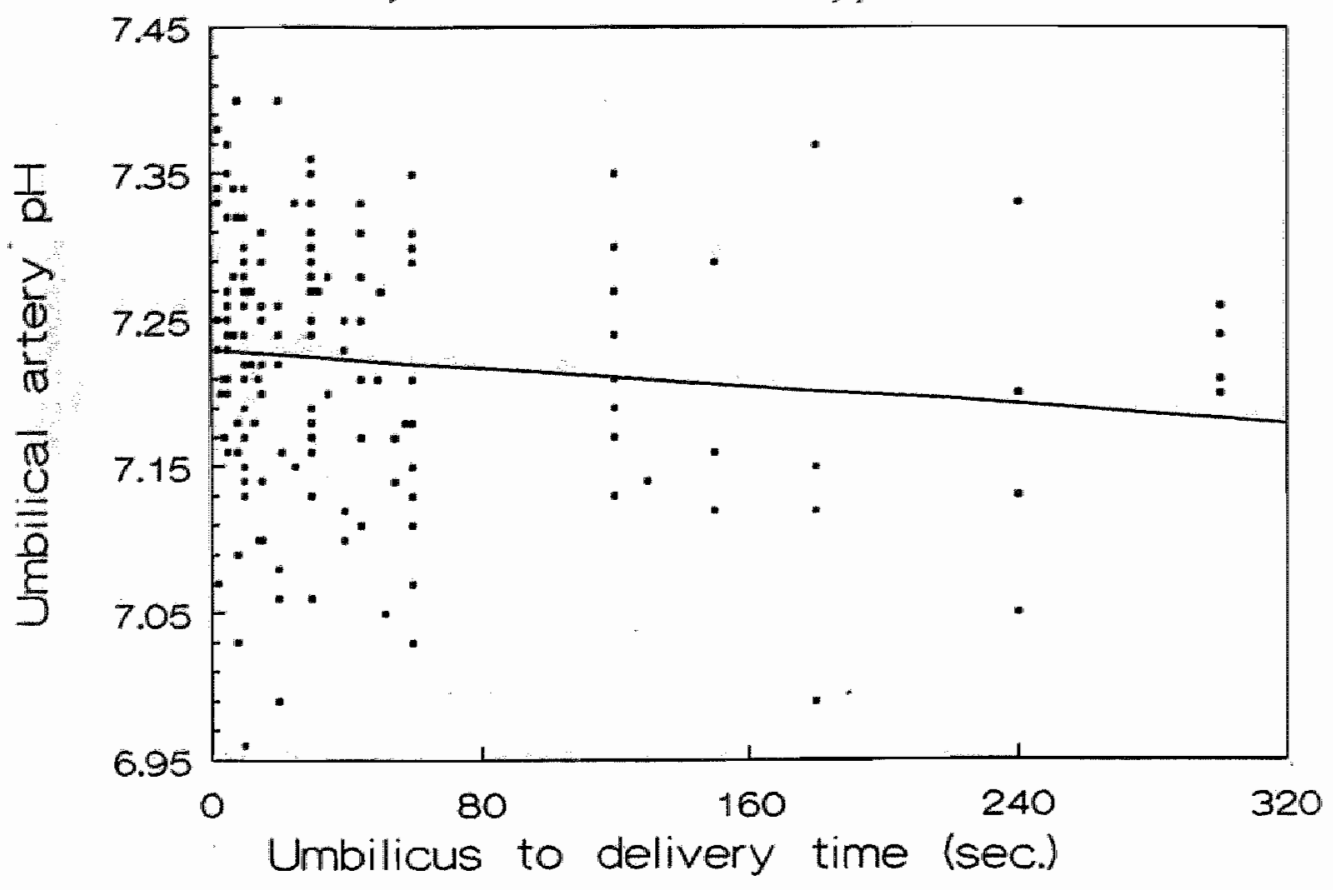

Table 6.8 Umbilicus-to-delivery time in relation to umbilical venous pH.

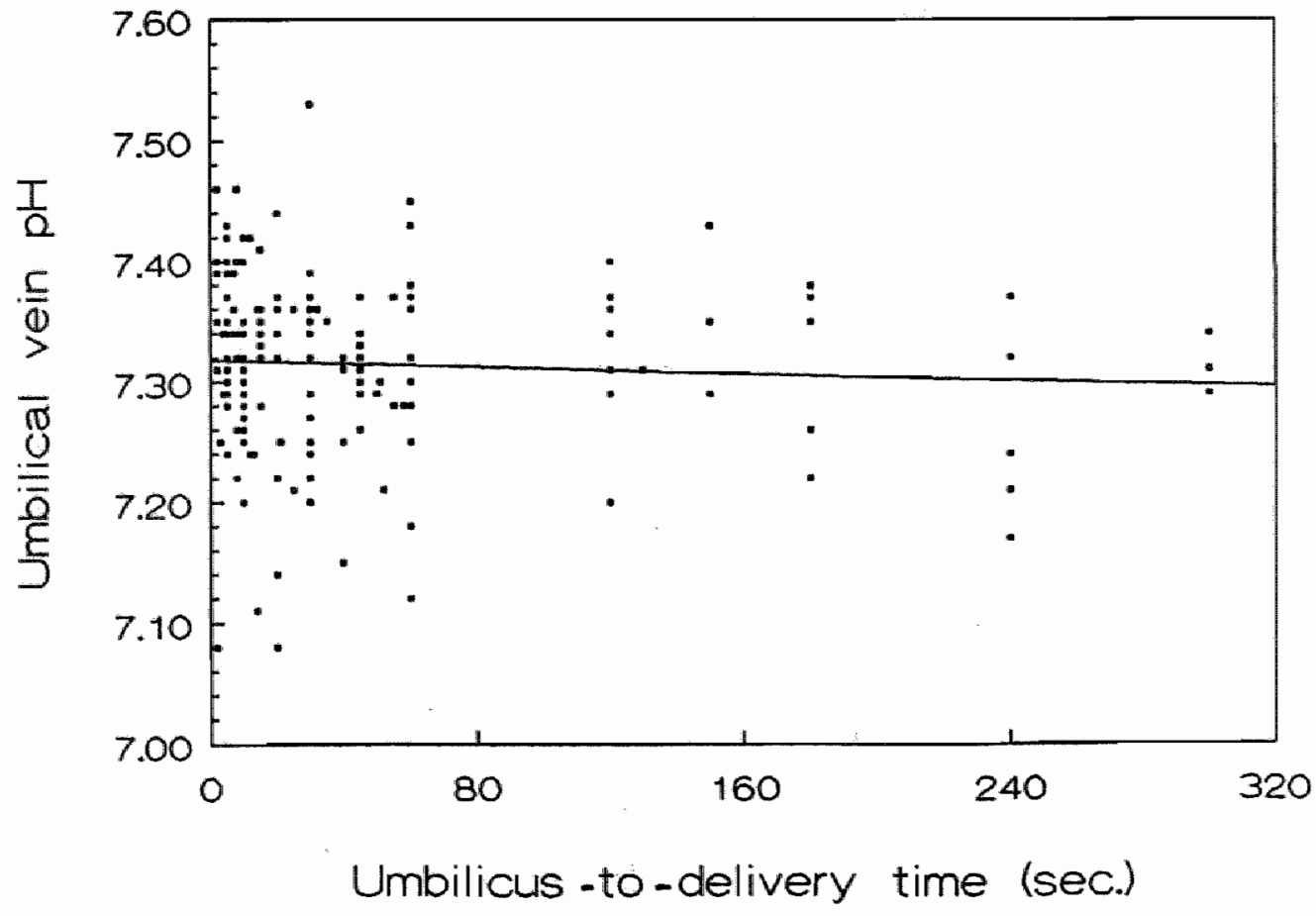


no umbilicus-to-delivery time was recorded all had 5 minute Apgar scores of 7 or more, except one neonate, which was born dead. In this birth weight category there was again a negative correlation between the umbilicus-to-delivery time and 1 and 5 min Apgar scores $(p<0.01$, Spearmann correlation coefficient). No statistically significant correlations were found between the umbilicus-to-delivery time and arterial and venous umbilical $\mathrm{pH}$ values.

In the 1500-2499 $\mathrm{g}$ birth weight category, umbilicus-to-delivery time was recorded in 25 of the 26 infants delivered vaginally. Umbilicus-to-delivery times ranged from 2 to 240 seconds, the average being 40 seconds.

Of the 25 patients, 24 had 5 minute Apgar scores of 7 or more, and the umbilicus-todelivery time for these infants ranged from 2 to 240 seconds.

The one infant with a depressed 5 minute Apgar score had an umbilicus-to- delivery time of 52 seconds. The patient in whom no umbilicus-to-delivery time was recorded had a 5 minute Apgar scores over 7. In this birth weight category no statistically significant correlations were found between the umbillicus-to-delivery time and Apgar scores and arterial and venous umbilical $\mathrm{pH}$ respectively.

In the very low birth weight category $(500-1499 \mathrm{~g})$, umbilicus-to-delivery time was recorded in 14 of the 18 infants delivered vaginally. Umbilicus-to-delivery time ranged from 2 to 180 seconds, the average being 40 seconds. 10 of the 14 patients had 5 minute Apgar scores of 7 or more, and the umbillicus-to-delivery times for these infants ranged from 5 to 120 seconds. Of the eight infants with depressed 5 minute Apgar scores, four had umbilicus-to-delivery times of 2,3,30 and 180 seconds respectively. The four patients in whom no umbilicus-to- delivery time was recorded all had 5 minute Apgar scores lower than 7. There was only a negative correlation between the umbilicus-to-delivery times and 5 min Apgar scores ( $p<0.05$, Spearmann correlation coefficient).

As regards the $1 \mathrm{~min}$ Apgar scores and the arterial and venous $\mathrm{pH}$ values no statistically significant correlation was found.

\subsection{Duration of the second stage of labor}

The duration of the second stage varied from 1 to 37 minutes in the $500-1499 \mathrm{~g}$ birth weight category, from 1 to 38 minutes in the $1500-2499 \mathrm{~g}$ birth weight category and from 2 to 92 minutes in the group with a birth weight of $2500 \mathrm{~g}$ or more. In this birth weight category, 15 patients $(11 \%)$ had a second stage lasting longer than 60 minutes. 


\section{Results of the neurological examinations after birth.}

Neurological examinations were performed in all neonates after birth, except those neonates who were either stillborn or expired shortly after birth, because these were in a critical condition.

In the total vaginal group of 163 surviving neonates, $14(9 \%)$ showed signs of neurological abnormalities at examination.

In the total abdominal group of 82 surviving neonates $6(7 \%)$ showed signs of neurological abnormalities at examination (Table 7.1).

Table 7.1 Neurological outcome after birth in the total study group.

\begin{tabular}{lll}
\hline Total study group & $\begin{array}{l}\text { vaginal delivery } \\
(\mathrm{n}=176)\end{array}$ & $\begin{array}{l}\text { cesarean section } \\
(\mathrm{n}=92)\end{array}$ \\
\hline Number of surviving neonates & 163 & 82 \\
\hline Normal $(\%)$ & $1.49(91)$ & $76(93)$ \\
Abnormal $(\%)$ & $14(9)$ & $6(7)$ \\
\hline
\end{tabular}

Chi-square test:

NS

There was some difference between the numbers of children with neurological dysfunctions in the vaginal and the abdominal group, but the differences were not statistically significant (Table 7.1).

In the birth weight group of $2500 \mathrm{~g}$ or more, 9 neonates in the vaginal group and one in the abdominal group had neurological dysfunctions. The 10 patients with abnormal neurological findings are numbered from 1 to 10 in the Table. In one patient a combined abnormal neurological syndrome was diagnosed.

Four patients had an abnormal spontaneous behaviour; one showed a syndrome of abnormal reactivity and one a hemisyndrome; one patient had an abnormal posture; another patient had signs of abnormal reactivity, abnormal posture and spontaneous behaviour. One patient suffered from Erb's paralysis, but otherwise had a normal neurological examination (Table 7.2).

In the abdominal group one patient with abnormal spontaneous behaviour was diagnosed ('Table 7.2).

In the weight category of $2500 \mathrm{~g}$ or more, the percentage of abnormal neurological outcome was found to be lower in infants born by cesarean section compared to 
Table 7.2 Neonatal neurological outcome according to mode of dellivery in birth weight category $\geqslant 2500 \mathrm{~g}$.

\begin{tabular}{|c|c|c|}
\hline $\begin{array}{l}\text { Birth weight category } \\
\geqslant 2500 \mathrm{~g} \text {. }\end{array}$ & $\begin{array}{l}\text { VD } \\
(n=132)\end{array}$ & $\begin{array}{l}\mathrm{CS} \\
(\mathrm{n}=57)\end{array}$ \\
\hline $\begin{array}{l}\text { Number of surwiving patients } \\
\text { normal }(0 \%) \\
\text { abnormal }(\%)\end{array}$ & $\begin{array}{l}131 \\
122(93) \\
9(7)\end{array}$ & $\begin{array}{l}57 \\
56(98) \\
1(2)\end{array}$ \\
\hline $\begin{array}{l}\text { hemisyndroms } \\
\text { syndrome of abnormal reactivity } \\
\text { abnormal posture } \\
\text { (increased or decreased tonus) } \\
\text { abnormal spontaneous behaviour } \\
\text { Erb's paralysils }\end{array}$ & $\begin{array}{l}1 \\
7,9 \\
3,9 \\
2,4,5,6,9 \\
8\end{array}$ & 10 \\
\hline
\end{tabular}

Chi-square test:

MS

Numbers 1-10: patient identification.

vaginally delivered newborns. However, none of the differences between the two groups were statistically significant.

In the $1500-2499 \mathrm{~g}$ birth weight category 37 neonates were neurologically examined. Six neonates died in the neonatal period and were not examined.

In the vaginally delivered neonates three neurologically abnormal neonates were diagnosed (Table 7.3).

Two neonates in the vaginal group showed abnormal spontaneous behaviour.

One neonate in the vaginal group suffered from Erb's paralysis.

In the neonates born by cesarean section two neurologically abnormal cases were diagnosed.

Table 7.3 Neonatal neurological outcome according to made of detivery in the $1500-2499 \mathrm{~g}$ birth werght category.

\begin{tabular}{|c|c|c|}
\hline $\begin{array}{l}\text { Birth weight category } \\
1500-2499 \mathrm{~g}\end{array}$ & $\begin{array}{l}\text { VD } \\
(n=26)\end{array}$ & $\begin{array}{l}\mathrm{CS} \\
(\mathrm{n}=17)\end{array}$ \\
\hline $\begin{array}{l}\text { Number of surviving patients } \\
\text { normal }(\%) \\
\text { abnormal }(\%)\end{array}$ & $\begin{array}{l}24 \\
21(88) \\
3(12)\end{array}$ & $\begin{array}{l}13 \\
11(85) \\
2(15)\end{array}$ \\
\hline $\begin{array}{l}\text { hemisyndrome } \\
\text { syndrome of abnormal reactivity } \\
\text { abnormal posture } \\
\text { (increased or decreased tonus) } \\
\text { abnormal spontaneous behaviour } \\
\text { Erb's paralysiss }\end{array}$ & $\begin{array}{l}1,2 \\
3\end{array}$ & $\begin{array}{l}4 \\
5\end{array}$ \\
\hline
\end{tabular}

Chi-square test:

Numbers 1-5* patient idertification 
In this group one neonate showed a syndrome of abnormal reactivity in combination with abnormal spontaneous behaviour and another neonate had an abnormal posture. Statistically, using the Chi-square test, these differences were not significant.

In the $500-1499 \mathrm{~g}$ birth weight category 20 surviving neonates were neurologically examined. During the neonatal period 16 neonates expired and were not examined. In the vaginally delivered neonates two abnormal cases were diagnosed. One neonate suffered from a syndrome of abnormal reactivity and another showed abnormal reactivity with abnormal posture.

Table 7.4 Neonatal meurologicat outcame according to mode of delivery in the $500-1499$ girth weight category.

\begin{tabular}{lll}
\hline $\begin{array}{l}\text { Birth weight category } \\
500-1499 \mathrm{~g}\end{array}$ & $\begin{array}{l}\text { VD } \\
(\mathrm{n}=18)\end{array}$ & $\begin{array}{l}\mathrm{CS} \\
(\mathrm{n}=18)\end{array}$ \\
\hline $\begin{array}{l}\text { Number of surviving patients } \\
\text { normal }(\%)\end{array}$ & 8 & 12 \\
abnormal $(\%)$ & $6(75)$ & $3(75)$ \\
\hline hemisyndrome & $2(25)$ & 3 \\
syndrome of abnormal reactivity & 1,2 & 4 \\
abnormal posture & & 5 \\
(increased or decreased tonus) & 1 & \\
abnormal spontaneous behaviour & & \\
Erb"s paralysis & & \\
\hline
\end{tabular}

Chi-square test: NS

Numbers 1-5: patient identification

Table 7.5 Neurological outcome according to mode of delivery after including additional data in low and very low birth weight category.

\begin{tabular}{|c|c|c|c|c|}
\hline \multirow[t]{2}{*}{ Birth weight category } & \multicolumn{2}{|c|}{$1500-2499 \mathrm{~g}$} & \multicolumn{2}{|c|}{$500-1499$} \\
\hline & $\begin{array}{l}\text { VD } \\
n=3 !\end{array}$ & $\begin{array}{l}\mathrm{CS} \\
\mathrm{n}=2 \mathrm{l}\end{array}$ & $\begin{array}{l}\text { VD } \\
n=24\end{array}$ & $\begin{array}{l}\mathrm{CS} \\
\mathrm{n}=21\end{array}$ \\
\hline Number of surviving patients & 29 & 17 & 13 & 14 \\
\hline normal $(\%)$ & $25(86)$ & $15(88)$ & $10(77)$ & $10(71)$ \\
\hline abnormall $(\%)$ & $4(14)$ & $2(12)$ & $3(23)$ & $4(29)$ \\
\hline hemisyndrome & 6 & & 6 & 3 \\
\hline $\begin{array}{l}\text { syndrome of abnormal reactivity } \\
\text { abnormal posture }\end{array}$ & & 4 & 1,2 & 4,7 \\
\hline (increased or decreased tonus) & & 5 & 1 & 5,7 \\
\hline abnormal spontaneaus behaviour & 1,2 & 4 & & \\
\hline Erb"s paralysis & 3 & & & \\
\hline
\end{tabular}

Chi-square test: NS

Numbers 1-7: patient identification in each birth weight category" 
In the abdominally delivered group 3 abnormal neonates were diagnosed. One neonate showed a syndrome of abnormal reactivity and another showed a hemisyndrome. One neonate had signs of hypertonicity of the lower limbs (Table 7.4). No differences were found between the two groups.

Because the sample sizes in the last two birth weight categories were small, the collecting of data was continued for a consecutive period of half a year. After including these data, the difference was again found not to be statistically significant (Table 7.5). 


\section{Chapter 8}

\section{Follow-up}

Of the 245 survivors, $235(96 \%)$ could be examined in the 1-year follow up study: 156 of the $163(96 \%)$ in the vaginal group and 79 of the $82(96 \%)$ in the abdominal group.

Seven children in the vaginal delivery group and three in cesarean delivery group were lost to the study for the following reasons:

Three infants had moved out of the country and could not be reexamined; six could not be reexamined because their parents refused permission; and one child died in an drowning accident eighteen months after hospital discharge.

A few of the patients were examined by the consultant paediatrician at a local hospital instead of at one of the two acadlemic hospitals.

The date of examination varied between 9 and 36 months post partum (Fig 8.1), with a median of 13 months in the vaginal group and 14 months in the abdominal group

Fig 8.1 Time between birth and follow-up examination.

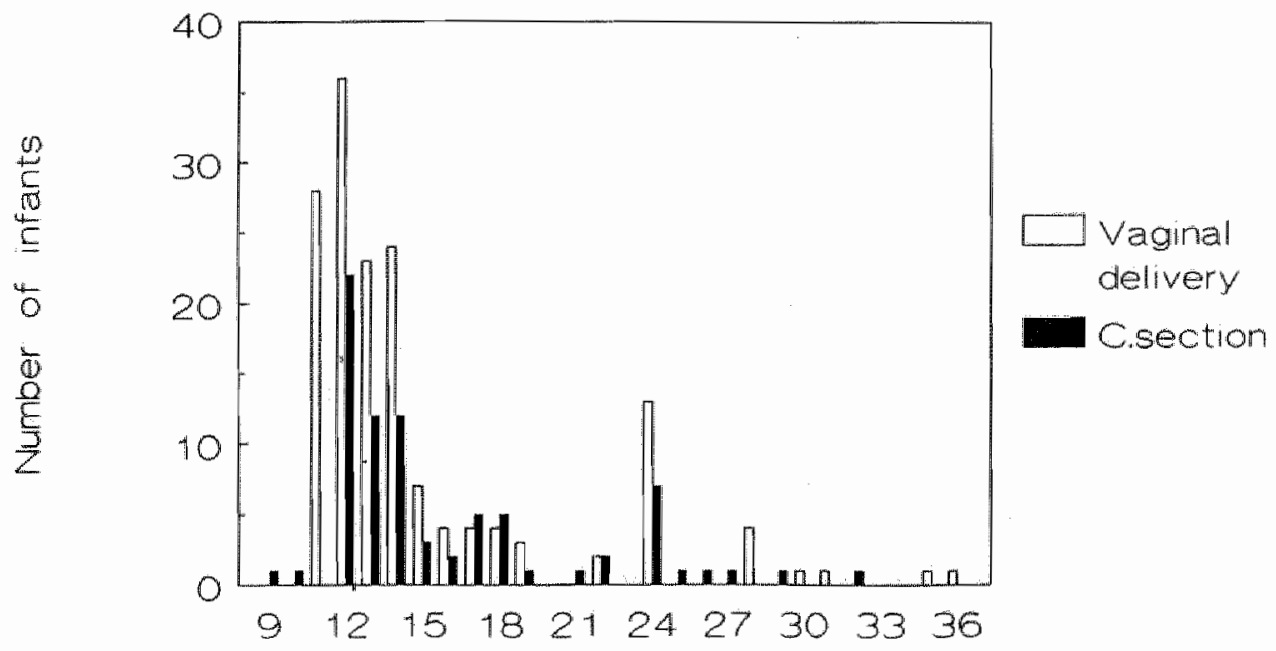


Table 8.2 Neurodevelopmental sequelae ar follow-up examination in 235 breech-born infants.

\begin{tabular}{lll}
\hline Total study group & $\begin{array}{l}\text { waginal } \\
\text { delivery } \\
\mathrm{n}=156\end{array}$ & $\begin{array}{l}\text { cesarean } \\
\text { section } \\
n=79\end{array}$ \\
\hline Normal & 146 & 75 \\
Abnormal & 8 & 4 \\
Suspect & 2 & 4 \\
\hline Total & 10 & 5.0 \\
\hline O\% & 6.4 &
\end{tabular}

The number of children with neurodevelopmental handicaps was 10 in the vaginal and 4 in the abdominal group (Table 8.2).

In the birth weight category of $2500 \mathrm{~g}$ or more, five infants in the vaginal group and two in the abdominal group showed an adverse neurodevelopmental outcome at follow-up examination (Table 8.3).

Table 8.3 Newrodevelopmental sequelae al follow-up examination in 235 breech-barn infants in three birth weight categories.

\begin{tabular}{|c|c|c|c|c|c|c|}
\hline Birth weight category $(\mathrm{g})$ & $\begin{array}{l}\geqslant 2500 \\
V D \\
n=125\end{array}$ & $\begin{array}{l}\mathrm{CS} \\
\mathrm{n}=5.4\end{array}$ & $\begin{array}{l}1500-2 \\
V D \\
n=24\end{array}$ & $\begin{array}{l}\mathrm{CS} \\
\mathrm{n}=13\end{array}$ & $\begin{array}{l}500-1 \\
V D \\
n=7\end{array}$ & $\begin{array}{l}\mathrm{CS} \\
\mathrm{n}=12\end{array}$ \\
\hline Normal & $\mathbb{1 2 0}$ & 52 & 22 & 12 & 4 & 11 \\
\hline Abnormal & 3 & 2 & 2 & 1 & 3 & 1 \\
\hline Suspect & 2 & & & & & \\
\hline Total & 5 & 2 & 2 & 1 & 3 & 1 \\
\hline $\begin{array}{l}\text { O\% } \\
\text { Chi-square test: NS }\end{array}$ & 4.0 & 3.7 & 8.3 & 7.7 & 42.8 & 8.3 \\
\hline
\end{tabular}

Of the five infants with an handicap in the vaginal group, two showed psychomotoric retardation: one after a transient infection of unknown origin at the age of 3 months, followed by hydrocephalus communis; the other was combined with stagnation in growth, hypotonicity, hyperlaxity and macrocephaly. This concerned a case of regression in the development. For this infant no cause of the psychomotoric retardation could be determined. Both children had been spontaneously delivered with Bracht's manoeuvre and had had normal neurological examination after birth. of the three other affected infants, one suffered from achondroplasia and also showed macrocephaly, joint hyperlaxity and a low thoracic kyphosis. Its psychomotoric development was normal. This child had been delivered by a Lovset manoeuvre and had a normal neurological outcome directly after birth. 
Table 8.4 Neurodevelopmental sequalae or impaiments at follow-up examination in the birth weight category $\geqslant 2500 \mathrm{~g}$.

\begin{tabular}{lcc}
\hline Mode of Delivery & vaginal delivery & cesarean section \\
\hline Number of infants & 125 & 54 \\
Normal & 120 & 52 \\
Suspect & 2 & 0 \\
Abnormal & 3 & 2 \\
\hline psychomotoric development & --++- & ++ \\
lone or reflex & ++-+- & - \\
epillepsy & --+-- & - \\
others & - & -
\end{tabular}

In the two remaining cases the outcome at the age of one year was suspect and in both cases a light hypertonicity existed, which had already been present directly after birth in one of them. The other neonate was normal at birth (Table 8.4).

In the cesarean section group there was one infant with a mild psychomotoric retardation with a disturbance in the gross motor behaviour, while the fine motor skills were not affected. At neurological examination after birth this child had shown signs of abnormal spontaneous behavior. In the other infant, wich also showed psychomotoric retardation no cause could be determined, as it was a case of regression in development: it had been found normal at neurological examination directly after birth. In these two cases stimulation by the parents may have been insufficient (Table 8.4).

In the 1500-2499 g birth weight category, three infants showed neurodevelopmental handicaps at the follow-up examination (Table 8.3). All infants in this birth weight category could be examined.

One infant in the vaginal group was a microcephalic with deficient speech development probably caused by environmental factors. The Erb"s paralysis diagnosed after vaginal delivery in this neonate had completely resolved at the follow-up examination.

One infant suffered from Robin's syndrome with psychomotoric retardation. This infant had been spontaneously delivered with a Bracht's manoeuvre. The syndrome had been diagnosed directly after birth, and at neurological examination the neonate was classified as abnormal spontaneous behaviour. The third infant had shown psychomotoric retardation after abdominal delivery. This infant suffered from polycystic renal disease with terminal renal failure managed with peritoneal dialysis. The neurological outcome after birth was completely normal (Table 8.5).

In the 500-1499 $\mathrm{g}$ birth weight category all infants except one were examined after one year. One neonate could not be examined because the parents had moved out of the country.

Three of those in the vaginal group and of one in the cesarean section group were 
Tablle 8.5 Neurodevelopmental sequelat at follow-up examination in the birth weight category $1500-2499 \mathrm{~g}$ and $500-1499 \mathrm{~g}$.

\begin{tabular}{lcccc}
\hline Birth weight category & $\begin{array}{l}1500-2499 \mathrm{~g} \\
\mathrm{VD} \\
\mathrm{n}=24\end{array}$ & $\begin{array}{l}\mathrm{CS} \\
\mathrm{n}=13\end{array}$ & $\begin{array}{l}500-1499 \mathrm{~g} \\
\mathrm{n}=7\end{array}$ & $\begin{array}{l}\mathrm{CS} \\
\mathrm{n}=12\end{array}$ \\
\hline $\begin{array}{l}\text { normal } \\
\text { suspect } \\
\text { abnormal }\end{array}$ & 22 & 12 & 4 & 11 \\
\hline $\begin{array}{l}\text { psychomotoric development } \\
\text { tone of reflex } \\
\begin{array}{l}\text { epilepsy } \\
\text { others }\end{array}\end{array}$ & 2 & 1 & 3 & 1 \\
\hline
\end{tabular}

found to have a mental handicap after one year. In the vaginal group one infant had developed a psychomotoric retardation with hypertonicity; in one there was severe bilateral deafness and signs of cerebral palsy (both children had had a normal neurological examination after birth); the third one had a normal psychomotoric development but was blind due to retrolental fibroplasia after 14 months.

The abnormal infant in the cesarean section group suffered from a moderate hypertonicity of the lower limbs, which had already been diagnosed directly after birth. The child which could not be examined had had directly after vaginal delivery, an abnormal neonatal neurological assesment consisting of a syndrome of abnormal posture and abnormal reactivity. Early ultrasound examination showed a severe grade of intracranial hemorrhage (Table 8.5 ).

In the three birth weight categories there were no any detectable differences in general development or neurologic disorders between the groups of infants born vaginally and those born by cesarean section at follow-up examination.

Because sample sizes in the last two birth weight categories were small, data collection was continued for a consecutive period of half a year. In this way the follow-up results of 15 children could be added to the study group. Two of these 15 showed impairments; one in either weight category (Table 8.6).

The abnormal neonate in the $1500-2499 \mathrm{~g}$ birth weight category was born by cesarean section, and there had been a suspicion of cerebral palsy directly after birth. At follow-up examination a mild hypotony of the lower limbs was diagnosed. The abnormal neonate in the 500-1499 $\mathrm{g}$ birth weight category was born vaginally. After birth this infant had had a normal neurological examination. At followup a delay in development without manifest signs of cerebral palsy was diagnosed (Table 8.7). After including these data in the results the difference between the vaginal and cesarean section group still was not statistically significant (Table 8.6). 
Table 8.6 Neurodevelopmental sequelae at follow-up examination in $7 /$ breech-born infants affer including the 15 neonates added to the siudy group.

\begin{tabular}{lllllll}
\hline Birth weight category $(\mathrm{g})$ & $\begin{array}{l}1500-2499 \\
\mathrm{VD} \\
\mathrm{n}=29\end{array}$ & $\begin{array}{l}\mathrm{CS} \\
\mathrm{n}=17\end{array}$ & $\begin{array}{l}500-1499 \\
\mathrm{VD}\end{array}$ & $\begin{array}{l}\mathrm{CS} \\
\mathrm{n}=14\end{array}$ & $\begin{array}{l}\text { total } \\
\mathrm{nD}=40\end{array}$ & $\begin{array}{l}\mathrm{CS} \\
\mathrm{n}=31\end{array}$ \\
\hline Normal & 27 & 15 & 7 & 13 & 34 & 28 \\
$\begin{array}{l}\text { Abnormal } \\
\text { suspect }\end{array}$ & 2 & 1 & 4 & 1 & 6 & 2 \\
\hline Total & 2 & 2 & 4 & 1 & 6 & 3 \\
\hline$\%$ & 6.8 & 11.7 & 36.4 & 7.1 & 15 & 9.7
\end{tabular}

Chi-square test: $\mathbb{N}$ S

Table 8.7 Neurodevelopmental sequelae at follow-up examination after including the 15 neonates added to the study group.

\begin{tabular}{lllll}
\hline Birth weight category & $\begin{array}{l}1500-2499 \mathrm{~g} \\
\mathrm{VD} \\
\mathrm{n}=29\end{array}$ & $\begin{array}{l}\mathrm{CS} \\
\mathrm{n}=17\end{array}$ & $\begin{array}{l}500-1499 \mathrm{~g} \\
\mathrm{VD} \\
\mathrm{n}=11\end{array}$ & $\begin{array}{l}\mathrm{CS} \\
\mathrm{n}=14\end{array}$ \\
\hline $\begin{array}{l}\text { normal } \\
\text { suspect } \\
\text { abnormal }\end{array}$ & 27 & 15 & 7 & 13 \\
\hline $\begin{array}{l}\text { psychomotoric development } \\
\text { tone of reflex } \\
\text { epilepsy } \\
\text { others }\end{array}$ & 2 & 1 & 4 & 1 \\
\hline
\end{tabular}

As regards to the neurologic outcome after birth, only 5 of the 14 infants with abnormalities after birth showed abnormalities at follow-up examination (Tables 8.8 and 8.9).

The follow-up examinations were analyzed for the extent to which neurological or developmental abnormalities in breech-born infants may be due to the mode of delivery.

Table 8.8. Infants with abnormalities at follow-up examination in the voginal group.

\begin{tabular}{|c|c|c|c|c|c|c|c|c|c|c|}
\hline Patient no. & 1 & 2 & 3 & 4 & 5 & 6 & 7 & 8 & 9 & 10 \\
\hline 1. Apgar & 3 & 9 & 8 & 8 & 3 & 2 & 7 & 4 & 6 & 2 \\
\hline 5 Apgar & 9 & 10 & 10 & 10 & 5 & 9 & 9 & 9 & 6 & 5 \\
\hline Umbil. $\mathrm{pHa}$ & 7.30 & 7.21 & 7.24 & 7.14 & 6.96 & 7.18 & 7.34 & 7.35 & 7.07 & 7.20 \\
\hline Umbil. $\mathrm{pHv}$ & 7.43 & 7.31 & 7.30 & 7.34 & 7.20 & 7.27 & 7.46 & 7.53 & 7.08 & 7.25 \\
\hline $\begin{array}{l}\text { Neuroll abn.* } \\
\text { after birth }\end{array}$ & - & - & - & $+t$ & - & $t+4$ & $+t$ & - & - & 一 \\
\hline
\end{tabular}

* Patient 4: Abnormal spontanious behaviour

Patient 6: Erb's paralysis

Patient 7: Pierre Robin syndrome 
Talile 8.9 Infanis with abnormalites ar follow wp examination in the cesarean section group.

\begin{tabular}{|c|c|c|c|c|}
\hline Patient no. & 1 & 2 & 3 & 4 \\
\hline 1 Apgar & 10 & 9 & 8 & 0 \\
\hline S'Apgar & 10 & 10 & 10 & 4 \\
\hline Umbil. pHa & 7.31 & 7.29 & 7.24 & 7.24 \\
\hline Lnibil. $\mathrm{pH}$ & 7.36 & 7.36 & 7.28 & 7.25 \\
\hline $\begin{array}{l}\text { Meurol.abn } \\
\text { after birth }\end{array}$ & $4+$ & - & - & +4 \\
\hline
\end{tabular}

* Pariemt 1: Abnormal spontaneous behaviour

Patient 4: Abnormal posture (Hypertonia)

For this purpose, some of the most important parameters assessed directly after birth are reviewed (Tables 8.8 and 8.9 ). In no case was a clearly manifest relation with the mode of delivery detected. There was one infant, born vaginally, in which the abnormal findings might have been caused by hypoxaemia. However, the infant was not manifestly abnormal but only suspected to be so.

Another infant showed low Apgar scores after one and five minutes and had $\mathrm{pH}$ values below 7.10. This infant was extremely immature at birth (gestational age 27 weeks and 4 days; birth weight $1000 \mathrm{~g}$ ).

The cesarean section group there also included a case of hypoxaemia, caused by abruptio placentae. 


\section{Chapter 9}

\section{Breech deliveries and CTG patterns}

\subsection{Introduction}

Continuous information concerning the fetal heart frequency is important in high risk pregnancies in order to detect any abnormality as early as possible. Therefore electronic fetal monitoring is nowadays used routinely.

Until now research has almost completely concentrated on phenomena in the CTG and cephalic presentation. But there are a number of potential differences between labor in cephalic and breech presentations.

1. The incidence of prolapsus funiculi is higher in breech presentations (Wheeler and Greene, 1975; White and Cibils, 1984); during labor cord compression frequently happens. Both factors may cause special phenomena in the fetal heart rate pattern such as variable decelerations and accelerations (Wheeler and Greene, 1975; J ames et al., 1976).

2. Cephalic compression may cause changes in the fetal heart rate pattern (early decelerations). In breech presentations cephalic compression probably occurs only at the end of the second stage (Wheeler and Greene, 1975; Teteris et al., 1970) although in the case of ruptured membranes compression of the fetal head may also occur earlier.

Also it is found that the breech fetus deteriorates more rapidly than the vertex fetus (Eilen et al., 1984).

In cephalic presentations more than $50 \%$ of all CTG's show decelerations of all types and almost half of these are variable decelerations (Cibils, 1978; Anyaegbunam et al., 1986).

Variable decelerations are frequently associated with adverse outcomes as related to Apgar scores, neonatal intensive care admission and neonatal death (Anyaegbunam et al., 1986; Cibils, 1976, 1978 and 1988). But when combined with accelerations and good variability, variable decelerations are associated with good fetal outcome (Anyaegbunam et al., 1986). Elsewhere, however, it was stated that accelerations may foretell the presence of cord problems (Cibils, 1976).

Tachycardia alone has the same prognosis as that of normocardia, but when found with any other abnormal pattern the prognosis significantly worsens (Krebs et al., 1979; Cibils, 1976).

The scant literature regarding CTG and breech presentation reveals that the CTG's showing variable and late decelerations, were found to correlate with a significantly higher incidence of depressed newborns and neonatal deaths, in comparison with CTG's showing early and no decelerations (White and Cibils, 1984). 
The presence of accelerations is associated with a normal $\mathrm{pH}$ (Wheeler and Greene, 1975 ) and with a significantly lower rate of depression, morbidity and neonatal mortality (White and Cibils, 1984).

The present study evaluates the relationships between CTG patterns and neonatal outcome (Apgar scores and umbilical arterial and venous $\mathrm{pH}$ values) in breech presentations.

\subsection{Materials and Methods}

Between January 1984 and June 1986, 174 single live breech deliveries occurred at the University Hospital Maastricht. The intrapartum heart rate tracings of these breech fetuses were recorded; externally by means of the ultrasound technique or internally after rupture of the membranes by means of a scalp electrode. The last hour of tracing of the first stage of labor and the whole tracing of the second stage were analysed. In case of a secondary cesarean section (CS) the tracing of the hour before the CS was analysed. All cesarean sections but one took place in the first stage ( 56 cases).

Two mothers received pethidine and 22 CTG's were not available (lost or not made). Analysis of these 22 cases showed that the mean umbilical arterial and venous $\mathrm{pH}$ as well as the Apgar scores did not differ significantly from the study group. All further CTG's were recorded without any other kind of drug being administered to the mother. This left $150 \mathrm{CTG}$ 's for analysis (51 CS , $99 \mathrm{VD}$ ).

However, in case more than $50 \%$ of a CTG in one stage was poorly registered, only the CTG of the remaining stage was used. In the end, 143 CTG's of the first stage could be used (49 CS, $94 \mathrm{VD}$ ) and 86 of the second stage (only vaginal deliveries).

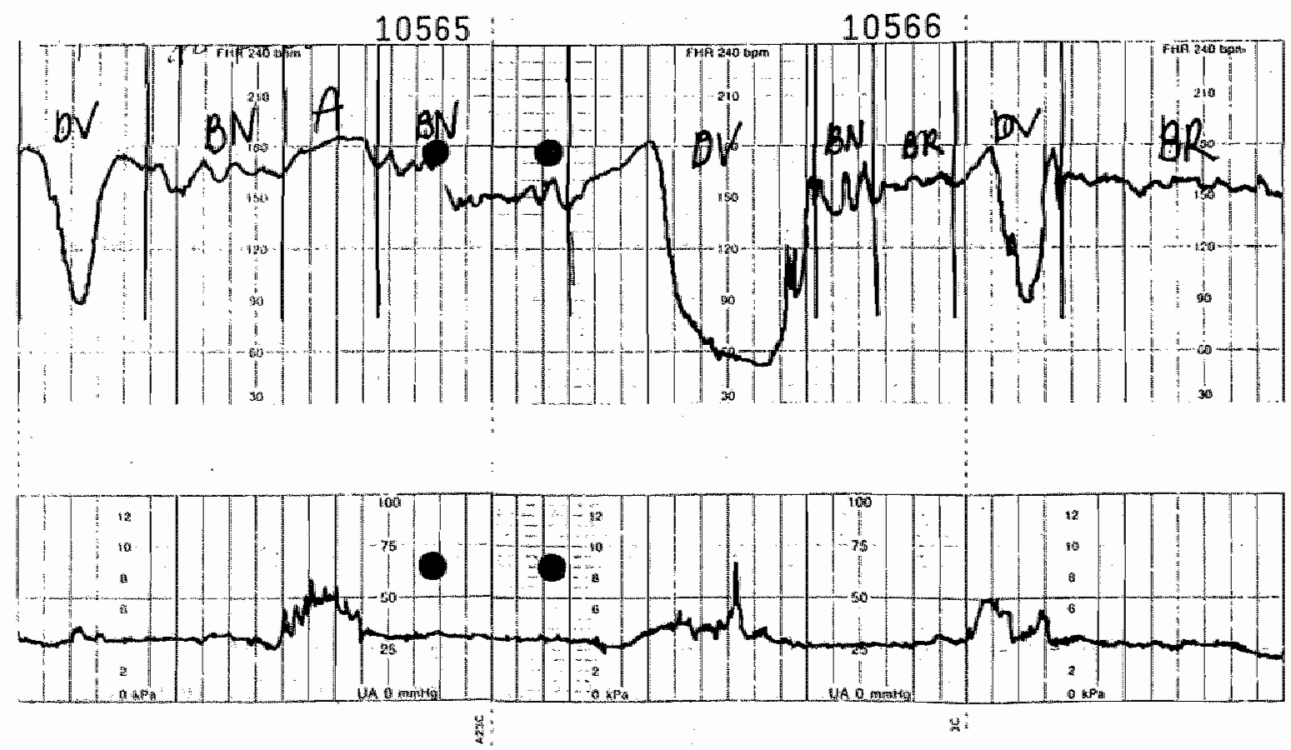

Fig. 9.1 Example of segmented CTG; segments between the dark vertical bars. 
Analysis of CTG's was done by the method described by Donker et al. (1985). Each registration was divided into segments (figure 9.1), which were defined in accordance with the CTG nomenclature by Hon (Hon and Quilligan, 1967) (see Table 9.1). The total time of each feature was calculated for each stage.

Table 9.1

Definitions of CTO features

Tachycardia (T):

Bradycardia (B):

Silent Pattern (BS):

Reduced Pattern (BR):

Normal Pattern (BN):

Increased Pattern (BI):

Acceleration:

Deceleration, early (DE):

Deceleration, late (DL):
160 Beats Per Minute (BPM)

$120 \mathrm{BPM}$

fluctuations of the baseline occurring at a frequency of 3 to 6 per minute, with a range of less then $6 \mathrm{BPM}$

the same as Silent Patterr., with a range of $5-9$ BPM

the same as Silent Pattern, with a range of $10-30$ BPM

the same as Silent Pattern, with a range of more than $30 \mathrm{BPM}$

transcient increase of the Fetal Heart Rate (FHR)

decrease of the FHR of at least 10 BPM coinciding with a uterine contraction; it starts before the contraction reaches its peak and the

"valley" of the deceleration coincides in time very closely with it (type I deceleration)

the beginning of the fall in heartrate starts when the contraction reaches its peak or slightly later (the recovery is marliked by slow rise; the shape of the deceleration reflects the shape of the uterine contracm tion)(type II deceleration)

Deceleration, variable (DV):its pattern differs from contraction to contraction and does not reflect the shape of the uterine contraction

Deceleration, other (DO): all remaining types of decelerations

MRP: badly registrated part, segmentation not possible

In addition to this material, the following information was also recorded: maternal age, parity, gestational age, mode of delivery, (abdominal or vaginal), medication during delivery, birth weight, Apgar scores after 1 and 5 minutes and arterial and venous umbilical $\mathrm{pH}$.

CTG registrations were grouped according to the mode of delivery (abdominal or vaginal) and the stage of registration (first or second).

Every group was subdivided according to birth weight:

$500-1499 \mathrm{~g}, 1500-2499 \mathrm{~g}$ and $\geqslant 2500 \mathrm{~g}$

In each group and subgroup, analysis of frequency of the several features was performed. The relations between CTG features and neonatal outcome parameters were investigated using Spearman Correlation Coefficients. Correlations were significant at a level of $p<0.05$.

Stepwise regression analysis was used to seek for combinations of CTG features that could account for the variance in Apgar scores and $\mathrm{pH}$ values. In addition to this regression analysis a sensitivity analysis was done in which the sensitivity (Se) and specificity (Sp) of the combination were estimated. (Cut-off value for Apgar scores was 7 ( $<7$ or $\geqslant 7$ ), for art.pH 7.15 and for ven.pH 7.20.)

The results are presented for each group and subgroup separately. 


\subsection{Results}

In Table 9.2 the mean birth weight, Apgar scores $<7$ and mean pH values of the total group are listed.

Table 9.2 mean birth weight, Apgar scores and $p H$ walues in the total group in relation to the mode of delivery.

\begin{tabular}{|llll|}
\hline & $\begin{array}{l}\text { total } \\
(\mathrm{n}=150)\end{array}$ & $\begin{array}{l}\text { VD } \\
(\mathrm{n}=99)\end{array}$ & $\begin{array}{l}\text { CS } \\
(\mathrm{n}=51)\end{array}$ \\
\cline { 1 - 2 } birth weight $(\mathrm{g})$ & 2855 & 2900 & 2760 \\
1'Apgar $<7(\%)$ & $30(20)$ & $14(14)$ & $16(31)$ \\
5'Apgar $<7(\%)$ & $4(3)$ & $2(2)$ & $2(4)$ \\
art.pH (mean $\pm \mathrm{SD})$ & $7.22 \pm 0.09$ & $7.21 \pm 0.08$ & $7.23 \pm 0.11$ \\
ven.pH (mean $\pm \mathrm{SD})$ & $7.30 \pm 0.08$ & $7.31 \pm 0.07$ & $7.28 \pm 0,10$ \\
\hline
\end{tabular}

In Table 9.3 the incidence of the most important CTG features in the total group are listed.

Table 9.3: Incidence of the CTG features studied, in the total group in relation to the mode of delivery.

\begin{tabular}{|lccc|}
\hline & $\begin{array}{c}\text { total } \\
(\mathrm{n}=150)\end{array}$ & $\begin{array}{l}\text { VD } \\
(\mathrm{n}=99)\end{array}$ & $\begin{array}{l}\text { CS } \\
(\mathrm{n}=51)\end{array}$ \\
\hline bradycardia & 17 & 14 & 3 \\
tachycardia & 9 & 8 & 1 \\
reduced pattern & 118 & 82 & 36 \\
acceleration & 138 & 94 & 46 \\
late deceleration & 4 & 0 & 4 \\
variable deceleration & 113 & 85 & 28 \\
\hline
\end{tabular}

Distribution in the three birth weight categories showed that late decelerations occur more frequently in the $500-1499 \mathrm{~g}$ and $1500-2499 \mathrm{~g}$. categories (7\% and $13 \%$ ) comm pared to the category of $\geqslant 2500 \mathrm{~g}(0 \%)$. A similar pattern was found for tachycardia (15\% and $9 \%$ versus $4 \%$ ). Accelerations occur most frequently in the birth weight category $\geqslant 2500 \mathrm{~g}$. (96\% vs. $69 \%$ and $82 \%$ ). The incidence of variable decelerations is nearly the same for all three birth weight categories $(77 \%, 78 \%$ and $750 \%$ )

First stage, vaginal deliveries and cesarean sections, all birth weight categories ( $\mathrm{n}=$ 143)

The CTG features showed the following relations with the neonatal outcome parameters.

bradycardia: neg.correlation with $5^{\prime}$ Apgar, art.pH and ven.pH 
reduced pattern:

acceleration:

late deceleration: variable deceleration: neg.correlation with art.pH pos.correlation with $1^{\prime}$ Apgar, $5^{\prime}$ Apgar and art.pH pos.correlation with $1^{\prime}$ Apgar, 5'Apgar and art.pH neg.correlation with $1^{\prime}$ Apgar, 5'Apgar and ven.pH

(see Table 9.4)

Table 9.4 Relations* between CTG features and neonatal outcome parameters for the first stage, $V D$ and $C S$, all birth weight caregories $(n=143)$.

\begin{tabular}{|c|c|c|c|c|}
\hline & \multicolumn{2}{|c|}{ Apgar } & \multicolumn{2}{|c|}{$\mathrm{pH}$} \\
\hline & 1 & 5 & art. & ven. \\
\hline bradycardia & & - & -- & -- \\
\hline reduced pattern & + & ++ & + & \\
\hline acceleration & + & + & & $+t$ \\
\hline $\begin{array}{l}\text { late dec. } \\
\text { variable dec. }\end{array}$ & - & - & - & -- \\
\hline
\end{tabular}

* Levels of significance (in all tables): + or $-0.01<p<0.05$

$$
+ \text { tor }-\mathrm{p}<0.01 \text {. }
$$

All other features had no significant correlation with any of the parameters.

Stepwise regression analysis revealed that

- the combination of reduced pattern and late deceleration accounted for $10 \%$ of the variance in $1^{\prime}$ Apgar $(\mathrm{Se}=1.00, \mathrm{Sp}=0.84)$;

- the combination of bradycardia, reduced pattern and late deceleration accounted for $14 \%$ of the variance in $5^{\prime}$ Apgar $(\mathrm{Se}=0.13, \mathrm{Sp}=0.98)$;

- the combination of tachycardia, bradycardia, late deceleration and variable deceleration accounted for $18 \%$ of the variance in art.pH ( $\mathrm{Se}=0.24, \mathrm{Sp}=0.87$ );

- there was no combination of variables found at a significant level to account for the variance in ven.pH but late deceleration alone accounted for $15 \%$ of the variance $(\mathrm{Se}=0.75, \mathrm{Sp}=0.83)$.

First stage, vaginal deliveries and cesarean sections, birth weight category 500-1499 g. $(n=13)$

The CTG features showed the following relations with the neonatal outcome parameters.

reduced pattern: variable deceleration: other deceleration: (see Table 9.5) pos.correlation with 5' Apgar

neg.correlation with 5' Apgar and art.pH

neg.correlation with 1' Apgar

All other features had no significant correlation with any of the parameters. 
Table 9.5: Relutions between CTG fearures and neonatal outcome paraneters for the first stage, VD. and $\mathrm{CS}_{\mathrm{n}}$ birth weigh category $500-1499 \mathrm{~g}(n=13)$.

\begin{tabular}{|c|c|c|c|c|}
\hline & \multicolumn{2}{|c|}{ Apgar } & \multicolumn{2}{|c|}{$\mathrm{pH}$} \\
\hline & 1 & 5 & art. & wen. \\
\hline reduced pattern & & + & & \\
\hline $\begin{array}{l}\text { variable dec. } \\
\text { other dec. }\end{array}$ & - & - & -- & \\
\hline
\end{tabular}

Due to the small number of CTG's, it was unjustified to carry out regression analysis in this group.

First stage, vaginal deliveries and cesarean sections, birth weight category 1500-2499 g. $(n=22)$

The CTG features showed the following relations with the neonatal outcome parameters.

tachycardia:

bradycardie:

silent pattern:

reduced pattern:

normal pattern:

late deceleration:

variable deceleration:

(see Table 9.6) pos.correlation with ven.pH neg.correlation with art.pH neg.correlation with ven.pH pos.correlation with 1'Apgar and 5'Apgar pos.correlation with ven.pH neg.correlation with art.pH and ven.pH neg.correlation with $1^{\prime}$ Apgar, 5' Apgar and art.pH

Table 9.6: Relations between CTG features and neonatal outcome parameters for the first stage, $V D$ and CS, birth weight category 1500-2499 $g(n=22$ ).

\begin{tabular}{|c|c|c|c|c|}
\hline & \multicolumn{2}{|c|}{ Apgar } & \multicolumn{2}{|c|}{$\mathrm{pH}$} \\
\hline & 1 & 5 & art. & ven. \\
\hline tachycardia & & & & the \\
\hline bradycardia & & & - & \\
\hline sillent pattern & & & & - \\
\hline reduced pattern & + & + & & \\
\hline normal pattern & & & & + \\
\hline late dec. & & & - & -- \\
\hline variable dlec. & $-\ldots$ & -- & - & \\
\hline
\end{tabular}

All other features had no significant correlation with any of the parameters.

Due to the small number of CTG's, it was unjustified to carry out regression analysis in this group. 
First stage, vaginal deliveries and cesarean sections, birth weight category $\geqslant 2500$ g. $(n=108)$

The CTG features showed the following relations with the neonatal outcome parameters.

bradycardia: neg.correlation with art.pH

acceleration: pos.correlation with ven. $\mathrm{pH}$

variable dec.: neg.correlation with ven.pH

(see Table 9.7)

Table 9.7: Relations between CTG features and neonatal outcome parameters for the first stage, VD and $C S$, birth weight category $\geqslant 2500 \mathrm{~g}(\mathrm{n}=108)$.

\begin{tabular}{|lllll|}
\hline & \multicolumn{3}{c}{ Apgar } & \multicolumn{2}{c|}{ pH } \\
\hline $\begin{array}{l}\text { bradycardia } \\
\text { acceleration. } \\
\text { variable dec. }\end{array}$ & 1 & 5 & art. & ven. \\
\hline
\end{tabular}

All other features had no significant correlation with any of the parameters.

Regression analysis was not performed for this group because it could be compared with the results in the other birth weight categories, and because this group consisted almost completely of the whole first stage group (108 out of 143 recordings).

First stage, vaginal deliveries, all birth weight categories $(n=94)$

The CTG features showed the following relations with the neonatal outcome parameters.

bradycardia:

neg.correlations with $5^{\prime}$ Apgar

(see Table 9.8)

Table 9.8: Relations between CTG features and neonatal outcome parameters for the first stage, waginal deliveries, all birth weight categories $(n=94)$.

\begin{tabular}{|c|c|c|c|c|}
\hline \multirow{3}{*}{ bradycardia } & \multirow{2}{*}{\multicolumn{2}{|c|}{${ }^{\text {Apgar }}$}} & \multicolumn{2}{|c|}{$\mathrm{pH}$} \\
\hline & 1 & & art. & ven. \\
\hline & & - & & \\
\hline
\end{tabular}

All other features had no significant correlation with any of the parameters. 
Stepwise regression analysis revealed that

- there was no combination of variables found at a significant level to explain the variance in Apgar scores but bradycardia alone accounted for $6 \%$ of the variance in $1^{\prime} \mathrm{Apgar}(\mathrm{Se}=0.67, \mathrm{Sp}=0.89)$ and for $10 \%$ of the variance in $5^{\prime} \mathrm{Apgar}(\mathrm{Se}=$ $0.33, \mathrm{Sp}=0.99$ );

- the combination of tachycardia, bradycardia and variable deceleration accounted for $14 \%$ of the variance in art.pH $(\mathrm{Se}=0.24, \mathrm{Sp}=0.83)$;

- there was no variable or combination of variables found at a significant level to explain the variance in ven.pH.

First stage, vaginal deliweries, birth weight category $500-1499 \mathrm{~g}$ and $1500-2499 \mathrm{~g}$ $(n=18)$.

None of the features had a significant correlation with any of the parameters.

Due to the small number of CTG's, it was unjustified to carry out regression analysis in this group.

First stage, vaginal deliveries, birth weight category $\geqslant 2500$ g. $(n=76)$

The CTG features showed the following relations with the neonatal outcome parameters.

acceleration:

pos.correlation with ven.pH

(see Table 9.9)

Table 9.9 Relations between CTO features and neonatal autcame paramerers for the first stage, vaginal deliveries, birth weigth category $\geqslant 2500 \mathrm{~g} .(\mathrm{n}=76)$.

\begin{tabular}{|c|c|c|c|c|}
\hline & \multicolumn{2}{|c|}{ Apgar } & \multicolumn{2}{|c|}{$\mathrm{pH}$} \\
\hline & 1 & 5 & art. & ven. \\
\hline acceleration & & & & +4 \\
\hline
\end{tabular}

All other features had no significant correlation with any of the parameters.

Regression analysis was not performed for this group because it could be compared with the results in the other birth weight categories and because this group consisted allmost completely of the whole first stage group ( 76 out of 94 recordings).

First stage, cesarean sections, all birth weight categories $(n=49)$

The CTG features showed the following relations with the neonatal outcome parameters. 
bradycardia:

reduced pattern:

normal pattern:

acceleration:

late dec.:

variable dec.:

(see Table 9.10) neg.correlation with art.pH and ven.pH values pos.correlation with 1'Apgar, 5'Apgar, art.pH, wen.pH pos.correlation with ven.pH pos.correlation with 1'Apgar, 5'Apgar, art.pH, ven.pH neg.correlation with 1 'Apgar and ven.pH neg.correlation with art.pH and ven.pH

Table 9.10: Relations between CTG features and neonatal outcome parameters for the first stage, $C S$, all birth weight categories $(n=49)$.

\begin{tabular}{|c|c|c|c|c|}
\hline & \multicolumn{2}{|c|}{ Apgar } & \multicolumn{2}{|c|}{$\mathrm{pH}$} \\
\hline & 1 & 5 & art. & ven. \\
\hline bradycardia & & & -- & - \\
\hline reduced pattern & + & ++ & + & + \\
\hline normal pattern & & & & + \\
\hline acceleration & $+t$ & + & ++ & + \\
\hline late dec. & - & & & -- \\
\hline variable dec. & & & $-\ldots$ & $\ldots$ \\
\hline
\end{tabular}

All other features had no significant correlation with any of the parameters.

Stepwise regression analysis revealed that

- the combination of reduced pattern and late deceleration accounted for $21 \%$ of the variance in 1 'Apgar $(\mathrm{Se}=0.83, \mathrm{Sp}=0.79)$;

- the combination of increased pattern, late deceleration, variable deceleration and reduced pattern accounted for $34 \%$ of the variance in $5^{\prime}$ Apgar $(\mathrm{Se}=0.12$, $\mathrm{Sp}=1.00)$;

- the combination of bradycardia, late deceleration, variable deceleration and reduced pattern accounted for $49 \%$ of the variance in art. $\mathrm{pH}(\mathrm{Se}=0.43, \mathrm{Sp}=$ $0.94)$;

- the combination of bradycardia and late deceleration - accounted for $45 \%$ of the variance in ven. $\mathrm{pH}(\mathrm{Se}=0.86, \mathrm{Sp}=0.86)$.

First stage, cesarean sections, birth weight category 500-1499 $\mathrm{g}$ and $1500-2499 \mathrm{~g}$ $(\mathrm{n}=17)$.

The CTG features showed the following relations with the neonatal outcome parameters.

reduced pattern: pos.correlation with 1'Apgar and 5'Apgar

increased pattern: neg.correlation with 1 'Apgar

(see Table 9.11)

All other features had no significant correlation with any of the parameters. 
Table 9.11: Relations between CTG features and neonatal outcome parameters for the first stage, C.S., birth weight category $500-1499 \mathrm{~g}$ and $1500-2499 \mathrm{~g}(\mathrm{n}=1 \mathrm{1})$.

\begin{tabular}{|c|c|c|c|c|}
\hline & \multicolumn{2}{|c|}{ Apgar } & \multicolumn{2}{|c|}{$\mathrm{pH}$} \\
\hline & 1 & 5 & art. & ven. \\
\hline $\begin{array}{l}\text { reduced pattern } \\
\text { increased paittern }\end{array}$ & +4 & $t+$ & & \\
\hline
\end{tabular}

Due to the small number of CTG's, it was unjustified to carry out regression analysis in this group.

First stage, cesarean sections, birth weight category $\geqslant 2500 \mathrm{~g}(\mathrm{n}=32)$

The CTG features showed the following relations with the neonatal outcome parameters.

increased pattern: pos.correlation with art.pH

variable deceleration: neg.correlation with art.pH and ven.pH

(see Table 9.12)

Table 9.12: Relations between CTG features and meonatal outcome parameters for the first stage, CS, birth weight category $\geqslant 2500 \mathrm{~g} .(\mathrm{n}=32)$.

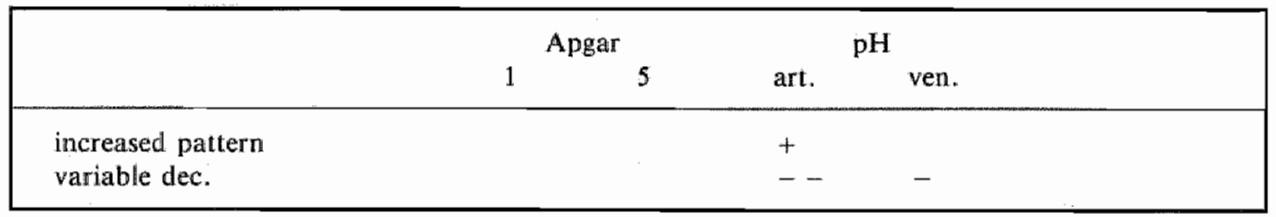

All other features had no significant correlation with any of the parameters.

Regression analysis was not performed in this group because it could not be compared with the results of the other birth weight categories and because this group consisted almost completely of the whole first stage group (32 out of 49 recordings).

Second stage, only vaginal deliveries $(n=86)$

The CTG features in this group showed the following relations with the neonatal outcome parameters.

bradycardia:

silent pattern:

early deceleration:

(see Table 9.13) neg.correlation with 1 'Apgar and art.pH

neg.correlation with ven.pH

neg.correlation with $\mathbb{1}^{\prime}$ Apgar 
Table 9.13: Retations between CTG features and neonatal autcome parameters for the second stage $(n=86)$.

\begin{tabular}{|c|c|c|c|c|}
\hline & \multicolumn{2}{|c|}{ Apgar } & \multicolumn{2}{|c|}{$\mathrm{pH}$} \\
\hline & 1 & 5 & art. & ven. \\
\hline $\begin{array}{l}\text { bradycardia } \\
\text { silent pattern } \\
\text { early dec. }\end{array}$ & - & & - & - \\
\hline
\end{tabular}

All other features had no significant correlation with any of the parameters.

Stepwise regression analysis revealed that

- the combination of bradycardia and early deceleration accounted for $11 \%$ of the variance in $1^{\prime}$ Apgar $(\mathrm{Se}=0.23, \mathrm{Sp}=0.92)$;

- the combination of bradycardia and acceleration accounted for $12 \%$ of the variance in $5^{\prime}$ Apgar $(\mathrm{Se}=0.06, \mathrm{Sp}=1.00)$;

- there was no combination of variables found at a significant level to explain the variance in art.pH but bradycardia alone accounted for $5 \%$ of the variance $(\mathrm{Se}=$ $0.38, \mathrm{Sp}=0.79$ );

- there was no variable or combination of variables found at a significant level to explain the variance in ven.pH.

Second stage, birth weight category 500-1499 $\mathrm{g}$ and $1500-2499 \mathrm{~g}(\mathrm{n}=13)$.

The CTG features showed the following relations with the neonatal outcome parameters.

bradycardia:

neg.correlation with $1^{\prime}$ Apgar and $5^{\prime}$ Apgar

(see Table 9.14)

Table 9.14: Relations between CTG features and neonatal ourcome parameters for the second stage, birth weight category $500-1499 \mathrm{~g}$ and $1500-2499 \mathrm{~g}(n=13)$.

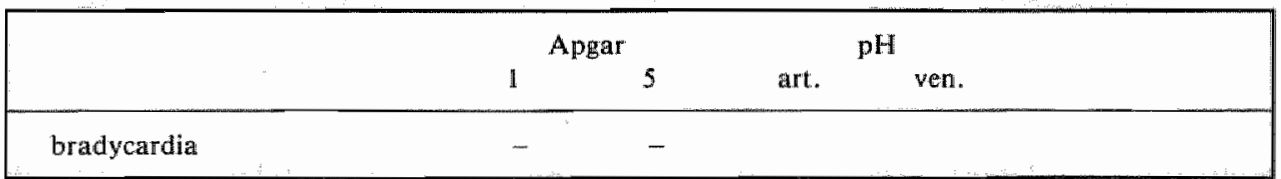

All other features had no significant correlation with any of the parameters.

Due to the small number of CTG's, it was unjustified to carry out regression analysis in this group. 
Second stage, birth weight category $\geqslant 2500 \mathrm{~g} .(\mathrm{n}=73)$

The CTG features showed the following relations with the neonatal outcome parameters.

bradycardia: neg.correlation with art.pH

sillent pattern: neg.correlation with wen.pH

increased pattern: neg.correlation with ven.pH

variable deceleration: neg.correlation with art.pH

(see Table 9.15)

Table 9.15: Relations bewteen CTG features and neonatal outcome parameters for the second stage. birth weight category $\geqslant 2500 \mathrm{~g}(\mathrm{n}=73)$.

\begin{tabular}{|c|c|c|c|c|}
\hline & \multicolumn{2}{|c|}{ Apgar } & \multicolumn{2}{|c|}{$\mathrm{pH}$} \\
\hline & 1 & 5 & art. & ven. \\
\hline bradycardia & & & - & \\
\hline silent pattern & & & & $-\cdots$ \\
\hline increased pattern & & & & - \\
\hline variable dec. & & & - & \\
\hline
\end{tabular}

All other features had no significant correlation with any of the parameters.

Regression analysis was not performed in this group because it could not be compared with the results of the other birth weight categories and because this group consisted almost completely of the whole first stage group (73 out of 86 recordings).

\subsection{Conclusions}

In our study many CTG's showed variable decelerations in the total CTG (75\%), as was also reported by White and Cibils (1984). However, late decelerations were rare in this study and occured only in the low birth weight categories $(<2500 \mathrm{~g}$.). White and Cibils used a different classification, consisting of wariable decelerations, variable decelerations with a late character and late decelerations, whereas in this study the classification according to Hon (Hon and Quilligan, 1967) has been strictly used.

Bradycardia and late decelerations generally showed a negative correlation with all the neonatal outcome parameters, especially with the $\mathrm{pH}$ values, and of course in such cases delivery should then be terminated as soon as possible.

Variable decellerations in the total group (vaginal deliveries and cesarean sections in all birth weight categories) showed a negative correlation with art.pH ( $\mathrm{p}<0.05$ ). This finding is in accordance with the findings of White and Cibils (1984), who 
found that the group with variable or variable-late decelerations had a significantly higher incidence of depressed neonates and neonatal deaths. However, when the total group is divided into a cesarean section group and a vaginally delivered group it is found that variable decelerations in the vaginally delivered group did not have any specific correlation with the neonatal outcome parameters. It was only when a variable deceleration occured in combination with bradycardia that it could worsen the negative effect of the bradycardia. However in the cesarean section group a negative correlation was found with both art. and ven. $\mathrm{pH}(\mathrm{p}<0.01)$.

This difference might be caused by the effects of the narcotic agents, as well as by the fact that for the period of transport from the delivery floor to the operating theatre no recording was available. These two facts probably limit the validity of the findings in the cesarean section group. Moreover, the possibility exists that the severity of the variable decelerations during the period directly preceding the decision to perform a cesarean section influenced the results. It should be mentioned that no other study devided the total group into a cesarean section group and a vaginally delivered group. Also no report mentioned the effect of epidural anaesthesia. The results also showed that the negative effect of variable decelerations on neonatal outcome were more severe in the birth weight categories 500-1499 $\mathrm{g}$ and 1500-2499 $\mathrm{g}$ than in the $2500 \mathrm{~g}$ or more birth weight category.

Tachycardia did not negatively effect the neonatal outcome parameters. This is in accordance with the result of Ron et al. (1985), who found that tachycardia in breech presentations did not represent any degree of fetal hypoxia. However, in contrast with the results which Krebs et al. (1979) and Cibils (1976) found in cephalic presentations, we found that tachycardia in breech presentations combined with other abnormal features, did not negatively effect neonatal outcome.

The occurence of accelerations in this study is very frequent (92\%), as also reported by Cibils (1988). The presence of accelerations in our study generally had a positive correlation with all neonatal parameters. This is in accordance with the findings of Wheeler and Greene (1975) and White and Cibils (1984). It was only in combination with bradycardia in the cesarean section group that it contributed to the negative correlation of the bradycardia.

The results show the sensistivity of the CTG with regard to the neonatal parameters to be low. Hence, the predictive value of the CTG for neonatal outcome is also low. The CTG may, however, still be useful as a monitoring tool for the intrauterine behavior of the fetus. 



\section{Chapter 10}

\section{Discussion}

The incidence of breech presentation in this study $(7.2 \%)$ was higher than commonly reported by other authors, in whose studies this frequency varies between 3.3 and 4.3\%. (Brenner, 1978; Lewis and Seneviratne, 1979; DeCrespigny and Pepperell, 1979; Hochuli et al., 1981; Döring and de Sousa Gerbert, 1988; Mecke et al., 1988). This high incidence is mainly caused by the fact that in the Netherlands women with pathologic pregnancies deliver in the hospitals. Approximately $35 \%$ of all babies in the Maastricht area are delivered at home. This selection results in a higher incidence of breech presentation in the hospital population in Maastricht.

Comparisons of results between hospitals in different countries are frequently not justified since the populations are often not comparable (Leveno et al., 1985). However, in the present study, maternal and neonatal characteristics were comparable, as there were hardly any significant differences.

As could be expected, some differences were found in prenatal care: In Maastricht prenatal care was primarily provided by midwifes in 48 per cent of the cases. In Gent prenatal care was in no case provided by midwifes. This difference can be completely explained by the differences between both countries in the organisation of prenatal care.

An important difference between the two centers regarded obstetrical history: significantly more women in Gent had prior cesarean sections, resulting in a larger proportion of infants being delivered by repeat operation. Overall, the primary cesarean section rate was significantly higher in Gent than in Maastricht. This means that cesarean section was performed more frequently for maternal indications in Gent.

Epidural anesthesia was used substantially more often in Gent, resulting in lower percentages of general and local anesthesia.

In this prospective non-randomized study, the policy was to allow a vaginal delivery as the management of choice. This policy resulted in a trial of labor in $94 \%$ of the cases in Maastricht, against $80 \%$ in Gent. In the total study group, the percentage was 89 per cent of all breech deliveries. This percentage is consistent with the rates given by Jaffa et al. (1981), and is much higher than reported in other studies (Watson and Benson, 1984; Bingham et al., 1987). In Gent twenty three percent of the cases in which a trial of labor was performed failed, against $28 \%$ in Maastricht. In the total group, 176 mothers $(74 \%)$ were delivered vaginally and the trial failed in $63(26 \%)$. This percentage was lower than that in the study by Bingham et al. (1987), where the trial failed in $40 \%$. 
In agreement with the statement." The higher the rate of failed trial of labor, the less desirable a policy of allowing a trial of vaginal delivery becomes " (Bingham and Lilford 1987), it can be concluded that it is justified to allow a trial of vaginal delivery in a great number of patients, in view of the low rate of failed trial of labor in our study.

The cesarean section rate was $34 \%$ in our study, which is higher than that reported by Faber-Nijholt (1981) (20\%), but lower than in most other studies, where this percentage varies between $57.7 \%$ and $74 \%$ (Gimovsky et Paul, 1982; Tatum et al., 1985; Dorring and de Sousa Gerbert, 1988). In our study the cesarean section rate was highest $(50 \%)$ in the lowest birth weight category (500-1499 g).

As reported by Döring and de Sousa Gerbert (1988), poor progress is the most common indication for cesarean section. This was also the most frequent indication in the present study, directly followed by fetal indications. The indication for cesarean section is certainlly also determined by complications in pregnancy besides breech presentation in itself, in view of the higher incidence in the cesarean section group of diabetes mellitus, gestational hypertension, prolonged rupture of the membranes, third trimester vaginal bleeding and admission to hospital before labor. For the last two items, the differences were statistically significant.

Because birth weight, rather than gestational age, was used as an index of maturity, neonates in this study were divided into three birth weight categories: $500-1499 \mathrm{~g}$, $1500-2499 \mathrm{~g}$ and $2500 \mathrm{~g}$ or more at birth.

There are certainly possible drawbacks of dividing up and comparing breech deliveries by method of delivery and not by the primarily intended method of management (Bingham and Lilford, 1987; Bingham et al., 1987).

The main reason for making a comparison between abdominally and vaginally delivered breeches was to analyse the neonatal condition of the infants in these two groups of deliveries.

Randomisation was not used in the study, since the purpose was to analyse our policy with regard to the management of breech presentation, which has for years resulted in a cesarean section rate substantially below 50\%. Randomisation would have forced us to increase the cesarean section rate to at least $50 \%$.

This examination is an example of an observational study in which the management was accurattely described, the data were collected prospectively, and the measurement of outcome was standardized and almost complete ( $96 \%$ follow-up), in contrast with most observational approaches to treatment comparisons (Grant,1985). The selection of treatment was mainly based on clinical opinion, which offers disadvantages regarding possible confounding factors. These can, however, not be completely circumvented, even in randomized clinical trialls (Greenland and Neutra, 1980). Our interest was primarily focused on the results of a management policy in breech presentation in which vaginal delivery was the primary goal. Due to the potential risks of a cesarean section, which were also shown in this study, a ran- 
domized clinical study would have met with substantial ethical objections. On the other hand, patients' acceptance of randomisation can seriously influence the composition of the groups (vaginal versus abdominal) and even hamper the comparison. Another possibility would have been a prospective matched-pair study which compares cephalic presentations with breech presentations. However the conditions before and during labor are completely different, especially regarding typical obstetrical factors such as engagement, uterine activity, birth mechanisme etc. Moreover there is some evidence in the literature (Braun et al, 1975; Hytten, 1982), which indicates that the very fact that the fetus is presenting in breech could be a sign of neurological abnormalities which make a comparison with cephalic presentation invalid.

As for the risk of mortality in relation to the method of delivery in breech presentation, there was no difference in mortality between breech infants delivered vaginally and those delivered by cesarean section in the total study group. Excluding for cases of multiple pregnancies, fetal death before labor and lethal malformations, the mortality rate (500 g or more) in our study was $9 \%$, or $0.5 \%, 14 \%$ and $44 \%$ respectively for the different weight categories. In the $2500 \mathrm{~g}$ or more birth weight group, one infant died during labor as a result of an iatrogenic trauma which was preventable (puncture of umbilical cord by scalp electrode; see page 78 ).

For the 1500-2499 g birth weight category, no statistically significant differences in mortality were found with respect to the mode of delivery, which is in accordance with most other studies, as reported by Crowley and Hawkins (1980). In one infant in the vaginal group, in the $1500-2499 \mathrm{~g}$ weight category, a relation between the mode of delivery and the cause of death was probably present, although the intrauterine transfer from another hospital over a distance of 45 kilometers contributed considerable to the deterioration of the fetal condition and consequently to the bad outcome. So in this case the organization of the obstetrical care played an important role.

In the 500-1499 $\mathrm{g}$ birth weight category, vaginal delivery was not associated with a higher mortality in this group, a finding which contradicts those of other studies (Bowes et al., 1979; Main et al., 1983; Verloove-Vanhorick and Verwey, 1987). Moreover, the mortality in this weight category in the present study must be considered against the fact that two deaths occurred iatrogenically after prostaglandine induction because of underestimation of the maturity and weight of the fetus. The problem of erroneous underestimation of fetal size has recently also been emphasized in the literature (Mecke et al., 1988; Socol et al., 1988); according to Paul et al. (1979), this was the most important factor contributing to meonatal death. In one patient in the vaginal group, but also in one in the cesarean section group, a relation between the neonatal death and the mode of delivery was demonstrable. Results of other studies of the same subject in the 500-1499 $\mathrm{g}$ weight category underline our findings that no difference in mortality is found between the vaginally delivered group and the abdominally delivered group (Olshan et al., 1984; Westgren et al., 1985; Effer et al, 1983; Von Weisbach et al., 1986). 
Our results generally allow the conclusion that a further increase of the cesarean section rate does not reduce mortality in breech presentation in any of the three birth weight categories.

Neonatal morbidity was assessed in this study by Apgar scores, umbilical arterial and venous $\mathrm{pH}$, neurological and general examination after birth, and follow-up examination.

In the total study group there was a smaller proportion of Apgar scores $<7$ at one minute in the vaginal group compared to the cesarean section group. However, analysis of 5 minute Apgar scores demonstrated no significant differences between infants delivered vaginally or by cesarean section.

In the weight category of $2500 \mathrm{~g}$ or more, no significant difference in Apgar score was found between the two modes of delivery. These results are in disagreement with data recently published by Socol et al. (1988), who found higher Apgar scores for cesarean section deliveries of neonates weighing $2500 \mathrm{~g}$ or more.

In the low birth weight category (1500-2499 g), the frequency of low Apgar scores was also found to be independent of the mode of delivery, as was recently also reported by some authors ( Karp et al., 1979; Ladehoff et al., 1986). But other studies showed a higher incidence of one-minute Apgar scores below 7 after cesarean section in this weight category (Frenzel et al., 1984; Mecke et al., 1988). In the study by Frenzel et al. (1984) the difference after 5-minute was even statistically significant, in favor of the cesarean section.

Only in the very low birth weight category was the incidence of low Apgar scores higher in the vaginal group, but the differences were not statistically significant, which is consistent with other studies (Main et al., 1983; Westgren et al., 1985; Ladehoff et al., 1986; Von Weisbach et al., 1986).

In the study by Doyle et al. (1985), however, there was a trend of higher Apgar scores after cesarean section.

Although these differences were formerly considered of importance for the choice of the mode of delivery and for the final outcome, recent publications show no relation between Apgar scores and neurological handicaps, nor between Apgar scores and umbilical artery pH (Silverman et al., 1985; Dijxhoorn, 1986).

In the total study group there were no statistically significant differences in the mean arterial and venous umbilical $\mathrm{pH}$ values between the two delivery methods. The mean values in both groups were within the range which is generally considered normal. Regarding acidosis $(\mathrm{pH}<7.10)$ there were no differences, but a higher frequency of values in the 7.10-7.19 pH range occurred in the vaginal group.

In term breech neonates (birth weight $2500 \mathrm{~g}$ or more) the arterial $\mathrm{pH}$ of vaginally born infants was significantly lower $(p<0.01)$, than that of infants delivered by cesarean section. In both groups, however, the mean umbilical artery $\mathrm{pH}$ was within normal limits and in the same range. Moreover the mean values were in a range which is generally considered normal in obstetrics; the difference probably has no clinical impact. 
There were more $\mathrm{pH}$ values between $7.10-7.19$ in the vaginal group, while the frequency of $\mathrm{pH}$ values lower than 7.10 was not significantly different for the two groups. Similar results have recently been reported by others (Hochuli and Kaech, 1981; Mecke et al.,1988; Luterkort and Marsáll, 1987; Socol et al., 1988).

In the low birth weight category $(1500-2499 \mathrm{~g})$, there was a statistically significant difference regarding the umbilical venous $\mathrm{pH}$ between the vaginally delivered neonates and the abdominally delivered neonates in the $1500-2500 \mathrm{~g}$ birth weight category, in favor of the vaginally delivered group. This is in contrast with other studies, in which less acidosis (Frenzel et al,1984; Mecke et al., 1988) was found in the cesarean section group for this weight category. However, the differences in these studies were not statistically significant.

In the very low birth weight category there were no statistically significant differences in umbilical arterial and venous $\mathrm{pH}$ values between the vaginal and cesarean section group. The results regarding the umbilical $\mathrm{pH}$ values in this weight category are similar to the ones reported by Frenzel et al.(1984) and Von Weisbach et al.(1986).

Although the low $\mathrm{pH}$ values found in infants delivered vaginally after breech presentation used to be considered an important argument for performing cesarean section in every breech presentation, the indicative value of blood $\mathrm{pH}$ is highly doubtful, as it is a poor predictor of perinatal brain damage, especially regarding the neurological outcome after one year (Ruth and Raivio, 1988).

In the total study group there was a trend towards an increased frequency of intubation and correction of acidosis with sodium bicarbonate in infants born by cesarean section; 25 cesarean births (27\%) needed intubation, compared with $18(10 \%)$ of those born vaginally. Twelve cesarean births (13\%) received sodium bicarbonate compared with $10(6 \%)$ of those delivered vaginally. However, the differences were not statistically significant.

In the 1500-2499 g birth weight category, the frequency of ventilation with intubation was higher after cesarean section. This may perhaps be explained by a transient effect of anaesthesia and the absence of the stimuli which are normally present during a vaginal birth.

Our findings in this respect are in contrast with those of Frenzel et al., (1984), who found that there was less need for ventilation after cesarean section in this birth weight category. However, the differences in this study were not statistically significant.

In agreement with the study by Doyle et al. (1985), there was no association between the mode of delivery and the proportion of infants requiring endotracheal intubation or intravenous sodium bicarbonate in the very low birth weight category.

As far as transfer to the neonatal unit was concerned, we found a statistically significant difference between the two modes of delivery over the total study group. But after division of the data into the three birth weight categories, this difference only 
remained significant in the highest birth weight category. This higher incidence of transfers to the neonatal unit in the cesarean section group is probably determined mainly by the influence of anesthetic procedures.

A study by Mecke et al.(1988) showed more transfers to the neonatal unit in the vaginal group, but after reviewing the indication, he found no relationship with the mode of delivery. The percentages of infants requiring admission to the intensive care unit in the study by Tatum et al., (1985) were not statistically different for the two groups, but vaginal delivery was only accomplished in $30 \%$ of the patients.

In the low and very low birth weight categories, the transport rate to the pediatric unit was less than 100 per cent, because some neonates were in such a bad condition that they died before transfer could take place.

Furthermore, transfer to the pediatric unit was considered unnecessary in two of the Gent cases, as these were cases of dysmaturity and no prematurity.

In the total study group, cesarean delivery was significantly more often associated with neonatal infections, RDS and sepsis than vaginal delivery. After distribution of the data over the three weight categories, this difference only remained significant for the incidence of infections and sepsis in the 1500-2500 g birth weight category. RDS did not occur significantly more often after vaginal delivery in this birth weight category, as was also reported by others (Duenhoelter et al. 1979).

Frenzel et al., (1984), however, found more prolonged ventilation (CPAP treatment for more than 12 hours) in the vaginal group. However, the definition of RDS in our studly was different from that used Frenzel et al. (1984) with regard to prolonged ventilation.

In the very low birth weight category we found no statistically significant differences between the vaginal and abdominal group as regards RDS.

Doyle et al. (1988) reported a higher incidence of ongoing respiratory support in the cesarean section group, while Frenzel et al.(1984) found that CPAP treatment for more than 12 hours was more common after cesarean section.

However, the differences in these two studies were not statistically significant.

Just as was reported by Flanagan et al. (1987) we found a statistically significant difference between the vaginal group and the cesarean section group in the average duration of stay in the neonatal unit in the birth weight category of $2500 \mathrm{~g}$ or more, which is in disagreement with the results reported by Tatum et al.(1985)., in which the average duration in the intensive care unit per infant was 3.9 days, with no difference between the vaginal and abdominal groups.

Because sample sizes in the low and very low birth weight categories was small, the collection of data was contimued for a period of half a year for this weight category. After including these extra data, the differences were still not statistically significant (Table 10.1). 
Table 10.1 Neanatal mortality and morbidity after including the 18 neonates added to the study group $<2500 \mathrm{~g}(\%)$.

\begin{tabular}{lcccc}
\hline Birth weight (g) & $1500-2499$ & & 500.1499 & \\
Mode of delivery & VD & CS & VD & CS \\
No. of Breeches & 31 & 21 & 24 & 21 \\
\hline $1^{\prime}$ Apgar $<7$ & $11(35)$ & $13(62)$ & $22(92)$ & $17(81)$ \\
5. Apgar $<7$ & $1(3)$ & $1(5)$ & $10(42)$ & $6(29)$ \\
Mean umbilical artery pH & 7.24 & 7.20 & 7.23 & 7.20 \\
SD & 0.08 & 0.14 & 0.12 & 0.09 \\
Mean umbilical venous pH & 7.33 & $7.24^{* *}$ & 7.28 & 7.25 \\
SD & 0.07 & 0.13 & 0.12 & 0.10 \\
Ventilation without intubation & $6(19)$ & $4(19)$ & $2(8)$ & $1(5)$ \\
Ventlation with intubation & $5(16)$ & $10(48)^{*}$ & $16(67)$ & $17(81)$ \\
Correction of acid base balance & $3(10)$ & $5(24)$ & $8(33)$ & $7(33)$ \\
Transfer to pediatric unit & $29(97)$ & $20(95)$ & $20(83)$ & $20(95)$ \\
Birth trauma & $2(6)$ & $0(0)$ & $0(0)$ & $1(5)$ \\
Intracranial hemorrhage & $3(10)$ & $3(14)$ & $8(33)$ & $4(19)$ \\
Seizures & $1(3)$ & $2(10)$ & $1(4)$ & $1(5)$ \\
Malformations & $1(3)$ & $4(19)$ & $2(8)$ & $0(0)$ \\
Neonatal infection & $3(10)$ & $7(33)$ & $9(38)$ & $12(57)$ \\
Sepsis & $1(3)$ & $5(24)^{*}$ & $8(33)$ & $8(38)$ \\
RDS & $3(10)$ & $7(33)$ & $13(54)$ & $10(48)$ \\
Post partum hospital days & 19.1 & 26.2 & 79.5 & 75.1 \\
SD & 11.7 & 15.2 & 40.5 & 24.0 \\
Intrapartum fetal death & $0(0)$ & $0(0)$ & $0(0)$ & $0(0)$ \\
Early neonatal mortality & $2(6)$ & $2(10)$ & $10(42)$ & $7(33)$ \\
Late neonatal mortality & $0(0)$ & $0(0)$ & $0(0)$ & $0(0)$ \\
Post neonatal mortality & $0(0)$ & $2(10)$ & $2(10)$ & $0(0)$ \\
\hline
\end{tabular}

Chi-square test: * $\mathrm{p}<0.05$

Mann-Whitney $U$ test: ** $\mathrm{p}<0.01$

Intracranial hemorrhage did not occur significantly more frequently in the vaginally delivered group than in the abdominally delivered group.

In the birth weight category of $2500 \mathrm{~g}$ or more, one infant suffered from an intracranial hemorrhage, which was classified as a subarachnoidal bleeding.

Although it is possible to diagnose this type of hemorrhage by means of ultrasound (Ennis et al., 1985), it was only seen on CT scans during our study.

As regards the occurrence of intracranial haemorrhage in the 1500-2499 $\mathrm{g}$ birth weight category, the rate in the vaginally delivered group was the same as that in the cesarean section group $(12 \%)$.

In the very low birth weight category neonates delivered by cesarean section showed a lower incidence of intracranial hemorrhage than those delivered by the vaginal route: $17 \%$ versus $28 \%$. This difference was not statistically significant, which is in agreement with some other studies (Main et al., 1983; Doyle et al., 1986). However, Tejani et al. (1987) reported significantly more intracranial hemorrhage after vaginal delivery in neonates weighing up to $2000 \mathrm{~g}$. In their study, however, neonates who were considered by the author to be "unsalvageable" (not further defined) were 
excluded from the study. Moreover, no well-defined protocol was used in the management of breech presentation.

Birth trauma has been suggested as a major factor in vaginally delivered breeches (Anonymous 1978; Painter and Bergman 1982; Hytten, 1982). However, in our study birth trauma was not observed to occur significantly more often in the vaginally delivered group than in the abdominally delivered group. Similar findings were reported by Tatum et al. (1985).

One infant delivered vaginally in the birth weight category of $2500 \mathrm{~g}$ or more sustained an lethal birth trauma during vaginal delivery; this case of birth injury occurred after prolapse of the cord and puncture of the cord by a scalp electrode (see page 78 ).

In the low and very low birth weight categories three cases of serious birth trauma resulted in mortality; one of these occurred during cesarean section.

Trauma resulting in brachial plexus injury did not occur more frequently during vaginal delivery than during cesarean section. The incidence of such traumata in our study was lower $(0.8 \%)$ than that usually reported in breech delivery management (Fisher-Rasmussen and Trolle, 1967; Camus et al., 1986). Other traumatic morbidity was not observed to occur more often during vaginal delivery, and again its incidence was lower than in most other reports (Brenner, 1978; Cefalo and Seeds, 1982). However, this kind of morbidity can not be completely avoided, not even with cesarean delivery, as was demonstrated by one case in the very low birthweight category in our study. In our study, where a high percentage of vaginal delivery was achieved, traumatic morbidity was low, and occurred with roughly the same frequency in the vaginal and cesarean section groups.

Cord prolapse is another potential problem in breech presentation and a possible source of morbidity and mortality. The incidence of cord prolapse in non-frank breech presentation was $7 \%$, which was higher than in frank breech presentation (3\%), as also reported by others (Gimovsky and Paul, 1982; Seeds and Cefalo, 1982). In the birth weight category of $2500 \mathrm{~g}$ or more, neonatal outcome in nonfrank breech presentation was not different from that in frank breech presentation. One infant died as an indirect result of this complication (puncture of the umbilical cord; see page 78), but in the other cases this complication never led to manifest problems.

In non-frank presentation the cord is frequently prolapsed between the fetal legs, and is often not markedly compressed during contractions.

Cord prolapse is supposed to be more hazardous especially in the lower weight categories. Our results indeed seem to confirm that this complication carries an additional hazard especially in the very low birth weight category. Prolapse of the cord was associated with mortality in all three cases in this weight category. A similar fatal outcome in the $\rrbracket$ owest weight category was also reported by Gimovsky and Paul (1982) and by Nisell et al.(1981).

Awareness of this potential problem and continuous surveillance by fetal monitor- 
ing may lead to prompt recognition and intervention. Although cord prolapse occurs rather frequently (in our study in $3 \%$ of frank and $7 \%$ of non-frank breeches), manifest problems could be avoided, except in the very low birth weight category.

Hyperextension of the fetal head was identified in one out of 268 fetuses evaluated by ultrasound. It was confirmed in this case by abdominal $\mathrm{X}$-ray. This incidence is lower than that commonly reported by others (Ballas et al.,1978; Tatum et al., 1985). Because of this low incidence, conclusions about the potential problems resulting from this position of the fetus would be is unjustified. Moreover, the reported frequency of this diagnosis in the literature is heavily influenced by the lack of opportunities to examine the fetus in such a way that this diagnosis can be uniformly defined.

While some investigators used the biparietal diameter as a criterium to exclude patients from a trial of labor (O' Leary, 1979; Mecke et al., 1988), this measurement was not used at all in our study. Moreover, there was no correlation between BPD and mode of delivery (Fig 6.2).

Parity has been a major consideration in the management of breech delivery. There were no statistically significant differences in outcome, in terms of morbidity and mortality, between the vaginal and abdominal breech deliveries among both primiparous and multiparous women, or among the various types of breech presentation. This finding apparently conflicts with those of several other reports, which have consistently shown the benefit of cesarean section to be greater for primiparae (Fortney et al., 1986). It was for this reason that Ryan (1986) regarded cesarean section as probably the safest route of delivery for a breech in this category.

After vaginal delivery the mean arterial cord $\mathrm{pH}$ was not lower in neonates born out of primiparae (7.23) than in those born out of multiparae (7.21).

The $\mathrm{pH}$ values found in the primiparae group were comparable to those of neonates born from multiparae, as was also reported from other studies (Luterkort and Marsál, 1985; Mecke et al.,1988). Neither were statistically significant differences found between the two types of breech presentation as regards the neonatal mortality and morbidity, which is inconsistent with other recent studies (Karp et al., 1979; Fortney et al., 1986). Hochuli (1981) found a correlation between umbilical artery $\mathrm{pH}$ and the type of breech presentation, to the disadvantage of the non-frank presentation. However, a recent study by Gimovsky et al.(1983) failed to show any beneficial effect of cesarean section, which is in agreement with our results. So parity or type of breech alone should not exclude a woman from a trial of labor and vaginal breech delivery.

In contrast to results reported in the literature (Karp et al., 1979),i.e. that prolapse of the umbilical cord in non-frank breeches yields a high frequency of fatal complications, we found no such high frequencies except in the very low birth weight category. 
Until now, cesarean section continues to be recommended for non-frank breech presentation (Myers and Gleicher, 1986).

Earlier, mostly retrospective studies comparing children born in breech presentation vaginally with those born by cesarean section do not use the neurological findings in the early neonatal period or the neurological and general condition at a follow-up examination after one or two years as measures of outcome.

All 245 surviving neonates in this study were neurologically examined. In the total study group there were no differences in neurological condition after birth between the breech-born infants delivered vaginally and those born by cesarean section. Although in the birth weight category of $2500 \mathrm{~g}$ or more there was some difference between the number of children with neurological dysfunctions in the vaginal and in the abdominal group, the differences were not statistically significant. Neither were there significant differences in the incidence of neurological sequelae directly after birth in the low and very low birth weight categories.

Just as in the report by Rosen et al. (1985), no increase in neurologic damage was found in the present study for the vaginally delivered breech population compared to the cesarean section population.

On the other hand Bingham and Lilford (1987) in a review of several papers regarding breech presentation concluded that the probability of serious cerebral dysfunction was $2-4$ cases per 1000 , which was attributed to vaginal delivery. Although the original papers give a good deal of attention to the degree of handicap as well as to the etiology of the sequelae, Bingham and Lilford arrived at this general statement, which in our opinion is questionable, because it is still uncertain whether there is a relation between the birth route and the morbidity.

Because of the possibility that the chances of discovering minor neurological dysfunctions are smaller for younger children (Faber-Nijholt, 1981), it is possible that some minor neurological deviations were not detected at follow-up examination in our study. But manifestly abnormal neurological or developmental disturbances were certainly all detected at the time of the follow-up examination.

At follow-up examination, 235 of the 245 survivors $(96 \%)$ could be examined.

The total study group showed no statistically significant differences between the vaginally delivered neonates and the abdominally delivered neonates at follow-up examination.

The follow-up examinations in the birth weight category of $2500 \mathrm{~g}$ or more were analyzed with regard to the extent to which neurological or mental abnormalities in breech-born infants may be due to the mode of delivery itself. In none of the cases was a clearly manifest relation with the mode of delivery detected. There was one case in which the abnormal finding consisted of a light hypertonicity, which may have been caused by hypoxaemia. However, the infant was not manifestly abnormal, but only suspected to be so. In contrast to the study of Svenningsen et al. (1985), obstetrical complications in our study did not account for the abnormal sequelae in our study. As also reported by Rosen et al. (1986), the birth route played 
only a minor role in the etiology of neurological abnormalities at follow-up. In the prospective matched-pair controlled studies with a cesarean section rate comparable to that in our study (Faber-Nijholt,1983; Mantzke 1988) minimal neurological dysfunction were more frequent in the vaginally born breeches than in the vaginally delivered counterparts.

Mantzke (1988) even concluded, that the prognosis of vaginally breech-born children was marginally less favourable than for breech-born infants delivered by cesarean section, as was also reported by Krause et al. (1984).

Unlike these researchers we found results which are more consistent with the studies of Hochuli and Kaech (1981) and Huchcroft et al.(1981), who found no statistically significant difference in late morbidity rates in breech-born infants delivered vaginally or by cesarean section.

There was no significantly higher frequency of neurologic abnormalities in the vaginally breech-born infants than in those born by cesarean section in the low birth weight category (1500-2499 g), which is in agreement with the results obtained by Nisell et al.(1981). This finding contrasts with the results reported by Ingemarsson et al. (1978).

After cesarean section neonates weighing 500-1499 g showed fewer developmental or neurologic abnormalities; however, the difference was not statistically significant. This finding contradicts the results in the study by Doyle et al. (1985), but is similar to those published by Effer et al. (1983) and Yu et al. (1984), who found no significant difference between cesarean and vaginal birth in the occurrence of disability in survivors presenting by breech in the very low birth weight category. Signs of hypoxaemia were observed in one case in the vaginal group and in one in the cesarean section group. This could have been an aetiologic factor in the abnormalities found at follow-up examination.

All handicaps of the children in the lowest birth weight category were probably attributable to complications associated to their very low birth weight in itself, rather than to the mode of delivery. The mode of delivery was very unlikely to be the prime cause of handicap in the vaginally delivered group, because all neonates in this birth weight category developing handicaps later on, had normal neurological examination after birth. In conclusion, we have found no statistically significant associations between cesarean section and reduced handicap at one year of corrected age in singleton infants born after breech presentation in the very low birth weight category. Although in this category the number of neonates is low, it seems that cesarean section can improve the prognosis only because of the fatal complications of cord prolapse in this weight category, as has also been reported by others (Gimovsky and Paul, 1982; Nisell et al. (1981).

From our results we conclude that the prognosis for vaginally breech-born children after one year is in general as good as that for breech-borns delivered by cesarean section, if our policy in breech presentations is used.

We agree with Mantzke et al.(1988) that characteristic cerebral damages formerly supposed to be caused by the pathology which is inherent to the mechanisme of the vaginal breech delivery appear to have become rare. 
Most authors agree, that the risk of maternal mortality and morbidity is increased in abdominal compared to vaginal delivery ( Survey, 1986). Although maternal mortality associated with cesarean birth has become rare (Bottoms et al.,1980), one maternal death occurred during our study of 92 cesarean sections. This case of maternal mortality is regarded as an anaesthetic death. It is unlikely that this death could have been prevented by a primary cesarean section. Maternal death after cesarean section occurs 3-10 times more often than after vaginal delivery (Moldin, 1984). Our study revealed significantly more non-fatal maternal complications in the cesarean compared with the vaginal deliveries, which is in agreement with the results of other studies (Lyons and Papsin, 1978; Bowes et al., 1979; Collea et al., 1980; Tatum et al., 1985; Fortney et al., 1986; Boulanger et al., 1986).

Just as in the survey by Petitti (1985), infection and transfusion were the most common cause of maternal morbidity.

We found that maternal morbidity related to cesarean sections also involved an increase in the duration of hospital stay, as was also reported by others (Sachs et al, 1983 ; Duenhoelter et al., 1979; Tatum et al., 1985; Flanagan et al., 1987).

Various attempts have been made to reduce the incidence and severity of cesarean birth-associated complications (Hirsch und Niehues, 1988). A change in the obstetrical mangement in favor of the vaginal delivery would also appear to be a possible way of reducing these complications.

Although X-ray pelvimetry is frequently used in the selection of patients allowed for a trial of labor, this technique was not used before labor in either of the two hospitals in the present study; assessment of the pelvis was only performed by vaginal examination. In our policy progress of labor was considered to be an important criterion for the choice to deliver vaginally. Fetal abnormalities, final fetal presentation and type of breech would have been evident on radiologic examination, but these can nowadays also, and in many cases better, be detected by ultrasound examination. The use of X-ray pelvimetry is still controversial, but the disadvantages are known: a higher fetal risk of the fetus developing a malignancy, a lack of uniform indications, and arbitrary and variable interpretations of the bony dimensions (Chassin and McCue, 1986).

Trial of labor is probably the most reliable test of pelvic capacity, but this requires extensive experience in the management of breech deliveries. During this proces the fetal condition has to be monitored very closely in order to enable the obstetrician to detect any abnormality as early as possible.

The obvious implication of the dramatically decreased experience and training opportunities in vaginal breech deliveries is that the procedural danger to the infant will rise and lack of appropriate skills will become an indication for abdominal delivery ( Seeds and Cefalo 1982). This restrictive policy may prevent young obstetricians from mastering the technique of breech presentation, with the inevitable consequence of fetal injury on the rare occasions when the vaginal route is selected. 
Experience and skill are required to minimize the risk of birth asphyxia and trauma in vaginal breech delivery but also during cesarean section.

The conservative approach of our policy, without early amniotomy and using oxytocin or prostaglandines if necessary, results in good obstetrical outcome at a low cesarean section rate. A more aggressive approach in conducting labor, as suggested by Confino et al. (1985), is not necessary according to our results.

The Bracht manoeuvre was the most frequently used manoeuvre in vaginal breech delivery in the present study. However, this manoeuvre has been criticized because of the supposed uncontrolled delivery of the head. In addition the traction on the fetal musculature, with possible damage to the cervical spinal cord, has been regarded as a danger (Confino et al., 1985). However, in our study there were no signs of neonatal trauma due to the Bracht manoeuvre.

The use of oxytocin in cases of breech presentation is controversial. Induction has been deemed safe by some investigators (Gimovsky et al., 1980; Collea et al., 1980; Tatum et al., 1985), whereas more concern has been expressed about augmentation of labor in breech presentation (Brenner et al., 1974; O'Leary, 1979).

In view of our results the use of oxytocin in dysfunctional labor seems to offer no problems, and the underlying belief that dysfunctional labor as a negative symptom may be masked, is not supported by our study.

Neither does our study appear to support the opinion that a higher morbidity occurs in those patients who are delivered vaginally than in those delivered by cesarean section.

With a conservative approach, as used in this study, and as described by Thiery et al., (1981), vaginal delivery is possible in more than 50 per cent of the patients with a breech presentation, as was also reported by Kasule et al.(1985). Hence breech presentation alone is not a sufficient indication for elective cesarean section.

In summary, our results suggest that the contention, made by the editor of the Survey (1981), that even the best obstetrician will deliver a damaged child in 2 to 3 per cent of all cases, is not necessarily true if our policy is followed.

In spite of extreme safeguards and careful selection, entrapment of the aftercoming head by the pelvis or the cervix has remained a much-feared risk of vaginal breech delivery. Maintaining flexion of the head and avoiding traction is essential and recently a new technique for this has been described (Myers, 1986). If unexpected difficulties arise in the delivery of the upper body during breech delivery, abdominal rescue is possible after pushing the body back into the pelvis (Iffy et al, 1986). Alternatively symphysiotomy can performed, as was recently desribed by Spencer (1987).

In view of the data presented here, there is no reason to suggest that the liberal use of cesarean section which is approaching $100 \%$ in several hospitals will improve neonatal and late outcome. Rather, it will increase maternal morbidity directly after 
birth and in the long run. In particular, we found no obvious arguments to advise routine cesarean section in preterm breech as has been proposed by others (Standardkommission Beckenendlage, 1984). The abdominal route in preterm birth does not, however guarantee an easy delivery, as was recently reported (Pinion and Mowat, 1988).

Contrary to the opinion expressed by Lomas (1988), we think that studies like this, can hold back the tide of cesareans and contributed to a change in doctor's behaviour. 


\section{Summary}

Chapter 1 discusses the motivation for this investigation and the purpose of the study.

Concern about the degree of variation in treatment policy, in combination with the still increasing cesarean section rate for breech presentation, as well as doubt concerning the assumed improvement in neonatal and maternal morbidity and mortality obtained by increasing the cesarean section rate in breeches led to this study. Therefore 268 consecutive breech presentations in two university hospitals were studied prospectively. Breech presentations are generally regarded as a select group of high risk cases. Perinatal and maternal mortality/morbidity rates are major criteria in the evaluation of the quality of care in obstetrics and neonatology especially in high risk cases. Therefore breech presentations are especially suitable for such an evaluation.

In chapter 2 a review of the literature on this subject is given. There are many differences and controversies in decision protocols for the management of breech presentation, resulting in widely different percentages of cesarean sections. The studies are mostly retrospective and the outcome variables are often incomplete documented.

Chapter 3 outlines the study and describes its most important characteristics.

From January 1984 to June 1986 all 268 consecutive breech deliveries resulting in a birth weight over or equal to 500 grams were studied in two university hospitals ( University of Gent, Belgium and University of Limburg, Maastricht, The Netherlands). Cases of multiple pregnancies, fetal death before labor and lethal malformations were excluded from the study.

Recorded data were analysed for three birth weight categories: $500-1499 \mathrm{~g}$, $1500-2499 \mathrm{~g}$ and equal to or over $2500 \mathrm{~g}$.

Because the sample size in the category of low and very low birth weight was small, the study was continued from July 1986 until January 1987 for preterm breech deliveries.

The policy for breech delivery was similar in the two hospitals:

In principle vaginal delivery was attempted in all cases, under expert supervision and electronic monitoring, except in the presence of clear-cut contraindications. X-ray pelvimetry was not used. Hyperextension of the fetal head was excluded by ultrasound examination.

Similarities and differences between the two hospitals, as well as between the vaginally and abdominally delivered patients, were studied. For most of the neonatal 
and maternal characteristics, no statistically significant differences were found either between the two hospitals or between the vaginally and abdominally delivered patients in the total group. The trial of vaginal delivery failed in 63 patients $(26 \%)$. The incidence of cesarean section was $34 \%$. More cesarean sections were performed in Gent than in Maastricht (38\% and 32\% respectively) and the divergence is even greater for elective operations (20\% in Gent as against $6 \%$ in Maastricht). The hilghest percentage of cesarean sections occurred in the 500-1499 g category.

The results concerning neonatal and maternal mortality and morbidity are presented in chapters 4,7 and 8 .

Neonatal condition was determined by Apgar scores, umbilical cord blood values, ventilation after birth, correction of the acid-base balance with sodium bicarbonate, transfer to neonatal unit, congenital malformations, birth trauma, intracranial hemorrhage, seizures, neonatal infections, RDS, duration of hospital stay, general and neurological examination after birth and follow-up examination. Neonatal mortality was defined as all deaths during labor plus neonatal deaths before discharge from the hospital. Maternal morbidity was judged by duration of hospitalisation, fever, need for blood transfusion and other puerperal complications. Special attention was devoted to the influence of the mode of delivery on the fetal and neonatal condition in the total group as well as in the three birth weight categories separately.

For most of the examined parameters no statistically significant differences were found in neonatal mortality and morbidity between the vaginally delivered group and the cesarean section group in the three birth weight categories. As regards the mortality: a relation with the mode of delivery was demonstrable in two cases in the vaginal group and one case in the cesarean section group, in the low and very low birth weight category. Moreover, in the 500-1499 $\mathrm{g}$ birth weight category, underestimation of the birth weight during pregnancy lead to iatrogenic neonatal death in two cases.

Maternal morbidity was significantly higher in patients delivered abdominally. Moreover, one maternal death occurred because of anaesthetic problems during cesarean section.

Of the 245 survivors after one year, 235 were examined in the follow-up study $(96 \%)$.

No statistically significant differences were found between the vaginal group and the abdominal group. The follow-up examinations were analyzed with regard to the extent to which neurological or developmental abnormalities in breech-born infants may be due to the mode of delivery. In no case was a clearly manifest relation with the mode of delivery detected. After including the data of the preterm neonates who were added to the study group, the difference between the vaginal and cesarean section groups was not statistically significant for most of the examined neonatal parameters. 
In chapters 5 and 6 the relative importance of a number of factors in the increase in cesarean section rate for breech presentation , and the influence of obstetrical factors which can affect the outcome in breech presentation are examined.

Of all 159 primiparous patients in the two hospitals $36 \%$ underwent a cesarean section, while $64 \%$ were delivered vaginally. Sixty eight percent of all frank breech infants were delivered vaginally, as were $60 \%$ of all non- frank breech infants. The cesarean section rate was $32 \%$ in the frank group, against $40 \%$ in the non-frank group. Indeed, the trial of vaginal delivery succeeded in $64 \%$ of the nulliparas and in $60 \%$ of the non-frank breeches, without statistically significant differences in outcome parameters compared with the multiparous women and the frank group respectively.

As far as augmentation was concerned no statistically significant differences were found between the two groups either.

Hyperextension of the fetal head rarely occurred.

In chapter 9 CTG patterns during breech delivery of 150 patients are analysed. Variable decelerations were recorded in $75 \%$ of all cases, but were rarely the sole indication for cesarean section. Although variable decelerations in the total group generally showed a negative correlation with the umbilical artery $\mathrm{pH}$, there was no negative influence on the examined outcome parameters in the vaginal group of the birth weight category of $2500 \mathrm{~g}$ or more.

Finally the results are discussed in relation to the literature in chapter 10 .

These results show that most of the patients with a living singleton fetus in breech presentation who had been admitted to a trial of labor, were delivered by the natural route without a significant increase in neonatal mortality/morbidity, and with a conspicuously low maternall morbidity.

Progress of labor was a more important sign in deciding on a cesarean section than birth weight or pelvic capacity separately.

Selection of candidates for vaginal delivery trial continues to be the crux of the problem. In this respect, an important finding of our study is the suggestion that several 'classic' obstetric factors (e.g. parity, type of breech, and fetal weight) have a lower discriminating value than is currently assumed.

Nor does this study support the contention that all tiny neonates should systematically be delivered by elective cesarean section. The abdominal route does not guarantee an easy delivery, especially in preterm birth.

Our analysis shows that the management of breech presentation can be adjusted in order to stop the increase in cesarean section rate and diminish the degree of variation in operative delivery rate without endangering the perinatal outcome. 


\section{Samenvatting}

In het eerste hoodstuk worden de overwegingen die tot het onderzoek hebben geleid en het doel van de studie besproken. Bezorgdheid over de verschillen in beleid bij de geboorte in stuitligging en het nog steeds stijgende aantal keizersneden voor deze indlicatie was aanleiding tot deze studie. Daartoe werden 268 opeenvolgende stuitliggingen prospectief bestudeerd in twee universiteitsklinieken. De stuitligging wordt over het algemeen beschouwd als een ligging met een verhoogd risico. Getallen met betrekking tot de perinatale en maternale mortaliteit respectievelijk morbiditeit nemen een belangrijke plaats in bij het toetsen van de kwaliteit van de zorg zowel in de verloskunde als de neonatologie, zeker bij zwangerschappen met een verhoogd risico.

In hoofdstuk 2 wordt een overzicht gegeven van de recente literatuur, met betrekking tot dit onderwerp. Er blijken vele verschillen en tegenstellingen te bestaan als het om de behandeling van de stuitligging gaat, welke resulteren in uiteenlopende aantallen keizersneden. De meeste studies zijn retrospectief en de uitkomsten zijn vaak onvolledig gedocumenteerd.

Hoofdstuk 3 beschrijft de belangrijkste kenmerken van de studie alsmede de opzet. Van januari 1984 tot juni 1986 werden alle 268 kinderen geboren in stuitligging met een geboortegewicht van 500 gram of meer bestudeerd in de twee universiteitsklinieken: Academisch ziekenhuis Gent (België) en Academisch ziekenhuis Maastricht (Nederland). Tweeling zwangerschap, intra-uteriene vruchtdood voor het begin van de baring en lethale aangeboren afwijkingen werden van de studie uitgesloten. De gegevens werden bestudeerd met betrekking tot drie gewichtscategoriën: 500-1499 gram, 1500-1499 gram en 2500 gram of meer. Omdat het aantal kinderen in de laatste gewichtscategoriën klein in aantal was, werd de studie voor deze groep voortgezet van juli 1986 tot januari 1987 . In beide klinieken werd hetzelfde beleid gevoerd: onder optimale foetale bewaking werd in principe een vaginale baring nagestreefd, tenzij er absolute contra-indicaties aanwezig waren. Radiologische pelvimetrie werd niet uitgevoerd. Hyperextensie van het foetale hoofd, het zogenaamde "stargazer" fenomeen werd door middel van echografie onderzocht. Overeenkomsten en verschillen in de patiënten populatie van beide ziekenhuizen alsmede van patiënten die vaginaal bevielen en die uiteindelijk door middel van een keizersnede bevielen werden bestudeerd. In de meeste gevallen werden geen essentiële verschillen gevonden tussen de bestudeerde populaties.

Een keizersnede vond plaats in $34 \%$ van de gevallen; in $26 \%$ werd een keizersnede 
verricht nadat aanvankelijk een vaginale baring was nagestreefd. Er werden meer keizersneden uitgevoerd in Gent dan in Maastricht (38\% respectievelijk $32 \%$ ), dit was met name het gevolg van een groter aantal electieve keizersneden ( $20 \%$ in Gent in vergelijking met $6 \%$ in Maastricht). In de gewichtscategorie $500-1499 \mathrm{~g}$ werden de meeste keizersneden verricht.

De neonatale en maternale mortaliteit en morbiditeit wordt besproken in de hoofdstukken 4,7 en 8 .

De toestand van de neonatus werd bepaald door de Apgar scores, de arteriële en veneuze navelstreng $\mathrm{pH}$, de noodzaak tot beademing na de geboorte of het corrigeren van het zurr-base evenwicht, opname op de afdeling neonatologie, de anwezigheid van aangeboren afwijkingen, geboorte traumata, intracraniële bloedingen, convulsies, infecties, sepsis, RDS, de lengte van de opnameduur, algemeen en neurologisch onderzoek na de geboorte en tenslotte een follow-up onderzoek. De neonatale mortaliteit was in deze studie gedefinieerd als alle sterfte tijdens de baring en daarna tot aan de dag van ontslag.

De maternale morbiditeit werd bepaald aan de hand van opnameduur, temperatuur, aantal bloedtransfusies en andere complicaties in het kraambed. Speciale aandacht werd besteed aan de invloed van de wijze van bevallen op de foetale en de neonatale conditie in zowel de gehele groep als in de drie gewichtscategoriën afzonderlijk. Voor de meeste van de onderzochte parameters werden geen verschillen gevonden tussen de vaginaal geboren kinderen en de door middel van een keizersnede geboren kinderen in de 3 gewichtscategoriën. Wat betreft de neonatale mortaliteit bleek er in twee gevallen in de vaginalle groep en in één geval in de groep van de keizersneden in de twee laagste gewichtscategoriën een verband met de wijze van bevalling aanwezig te zijn. Bovendien waren in de laatste gewichtscategorie (500-1499 g) twee gevallen van neonatale sterfte terug te voeren op onderschatting van het geboortegewicht voor de bevalling hetgeen dientengevolge leidde tot iatrogene sterfte t.g.v. op onjuiste indicatie voortijdig inleiden van de baring.

De maternale morbiditeit was significant hoger bij patiënten met een keizersnede. Bovendien was er één moederlijke sterfte ten gevolge van anaesthesie problemen tijdens de keizersnede.

Van de 245 kinderen, die na een jaar nog in leven waren, werden er $235(96 \%)$ in een follow-up studie opnieuw onderzocht. Er werden geen verschillen gevonden tussen de kinderen, die vaginaal en die uiteindelijk door middel van een keizersnede geboren waren.

De kinderen, die bij het follow-up onderzoek afwijkende bevindingen vertoonden, werden nader geanalyseerd om te beoordelen in hoeverre de gevonden afwijkingen in relatie zouden kunnen staan tot de aard van de bevalling. In geen enkel geval kon een duidelijke relatie met de wijze van bevallen worden aangetoond. Ook na het toevoegen van de gegevens van de kinderen uit de twee laagste gewichtscategoriën uit de periode juli 1986 tot januari 1987, waren er in de meeste van de onderzochte parameters geen verschillen. 
In hoofdstuk 5 en 6 worden een aantal factoren bestudeerd, die mogelijk van inwloed kunnen zijn op de stijging van het percentage keizersneden bij stuitliggingen en de de invloed van obstetrische factoren, die het uiteindelijk resultaat van de geboorte in stuitligging beinvloeden.

Van de 159 primiparae in de twee ziekenhuizen onderging $36 \%$ een keizersnede, terwijl $64 \%$ vaginaal beviel. Acht en zestig procent van de patiënten met een onvolkomen stuitligging beviel spontaan; bij de overige typen stuitligging bedroeg dit percentage zestig.

Bijstimulering met oxytocine of proslaglandines had in geen van beide groepen (vaginaal en abdominaal) een nadelig effect. Hyperextensie van de foetale schedel kwam zelden voor.

In hoofdstuk 9 worden CTG patronen bij stuitliggingen geanalyseerd.

Variabele deceleraties komen frequent voor bij de stuitligging en vormen op zich zelden een indicatie voor een keizersnede. Hoewel er in de totale groep een duidelijke negatieve correlatie wordt aangetoond tussen de variabele deceleraties en de arteriële navelstreng $\mathrm{pH}_{\text {, was }}$ er in de vaginale groep met een geboortegewicht van 2500 gram of meer, geen negatieve invloed waarneembaar op de onderzochte neonatale parameters.

Tenslotte worden in hoofdstuk 10 de resultaten uit deze studie besproken tegen de achtergrond van de recente literatuur.

De resultaten tonen aan dat de meeste patiënten met een kind in stuitligging, vaginaal kunnen bevallen zonder dat er een toename is van de neonatale mortaliteit respectievelijk morbiditeit en met een aanzienlijk lagere mortaliteit en morbiditeit voor de moeder dan bij een keizersnede het geval was geweest.

Een belangrijk probleem blijft de selectie van patiënten voor een vaginale baring. In dit opzicht is een opmerkelijke bevinding in deze studie het feit dat verschillende obstetrische factoren zoals pariteit, type stuitligging en geboortegewicht van minder waarde blijken te zijn voor het stellen van de indicatie keizersnede dan algemeen wordt aangenomen.

Evenmin verleent deze studie steun aan argumenten voor een primaire keizersnede bij alle vroeggeboren kinderen in stuitligging.

Deze studie toont aan dat het bijstellen van de behandeling van de stuitligging mede ertoe kan bijdragen dat er een halt wordt toegeroepen aan de stijging van het aantal keizersneden. Tevens kan dan het sterk uiteenlopende percentage keizersneden in de verschillende klinieken verminderd worden zonder dat het resultaat negatief wordt beïnvloed. 


\section{References}

Abrams IF, Bresnan MJ ,Zuckerman JE: Cervical cord injuries secondary to hyperextension of the head in breech presentation.

Obstat Gynecol $41: 369,1973$

Ahram I: High cesarean section rate"

Obstet Gynecol 66: 858,1985

Alder Ch, Aebi S, Bernhard M: Der Stellenwert der radiologischen Beckenmessung.

Geburth u Frawenheilk $47: 483,1987$

Alexander J, Gregg JEM, Quim MW: Femoral fractures at caesarean section. Case reports. Br J Obstet Gynaecol 94: 273, 1987

Anderman S, Ellewbogen A, Jaschevataky OE, Grunstein S: Is term breech presentation in primigravida an absolute indication for caesarean section?

Eur J Obstet Gynecol Reprod Biol 18: 11,1984

Anderson $\mathbf{G}$, Strong $\mathrm{C}$ : The premature breech: caesarean section or trial of labour?

J Med Ethics 14: 18, 1988

Anonymous: Premature breech: vaginal delivery or caesarean section?

Br Med J I: 1747,1979

Anonymous: Birth trauma in vaginaldelivery.

Br Med J II: 320,1978

Anonymous: Delivery of small breech babies.

Lancet i: 336,1983

Anyagbunam A, Brustman L, Divon M, Langer O: The significance of antepartum variable decelerchtions.

Am J Obstet Gynecol 155: 707, 1986

Apgar : A proposal for new method of ewaluation of the newborn infant.

Anesth Analg (Cleve) 32: 260, 1953

Apgar $\mathbf{V}$, James LS: Further observations on the newborn scoring system.

Am J Dis Child 104: 419, 1962

Bada HS, Korones SB, Anderson GD, Magill HL, Wong SP: Obstetric factors and relative risk of neondm tal germinal layer/intraventricular hemorrhage.

Am I Obstet Gynecol 148: 798, 1984

Baerts W: Echo-encefalografie bij prematuur geborenen: resultaten van onderzoek bij 244 patienten. Ultrasonoor bulletin $1: 1,1986$ 
Ballas $\mathbf{S}$, Toaffi $\mathbf{R}_{1}$ Jaffa AJ: Deflexion of the fetal head in breech presertation. Incidence, management, and outcome.

Obstet Gynecol 52:653, 1978

Barlöv K, Larsson G: Results of a five-year prospective study using a feto-pelvic scoring system for term singleton breech delivery after uncomplicated pregnancy.

Acta Obstet Gynecol Scand 65: 315, 1986

Hejar R, Coen RW, Gluck L: Hypoxic-ischemic and hemorrhagic brain injury in the newborn. Perinatol Neonatol 6: 69, 1982

Berendes $H W_{\text {, Weliss }}$, Deutschberger $\mathbf{J}_{*}$ Jackson $\mathbf{E}$ : Factors associated with breech delivery. Am J Public Health 55: 708, 1965

Bilodeau $\mathbf{R}$, Marier R: Breech presentation at term.

Am I Obstet Gynecoll 130: 555, 1978

Bingham P, Bird V, Lilford RJ: Management of the mature selected breech presentation: an analysils based on the intended method of delivery.

Br. J Obstet Gynaecol 94: 746, 1987

Bingham $\mathbf{P}_{\mathrm{t}}$ Lilford RJ: Management of the selected term breech presentation: Assessment of the risks of selected. vaginal clelivery versus cesarean section for all cases.

Obstet Gynecol 69: 965, 1987

Bistolletti P, Nisell H, Palme C, Lagercrantz H: Term breech delivery; early and late complications. Acta Obstet Gynecol Scand 60: 165, 1981

Bodmer B, Benjamin A, McLean FH, Usher RH: Has use of cesarean section reduced the risks of delivery in the preterm breech presentation?

Am J Obstet Gynecol 154: 244, 1986

Bottoms SF, Rosen MG, Sokol RJ: The increase in the cesarean birth rate.

N Engl J Med 302: 559, 1980

Boulanger JC, Vitse M, Verhoest P, Camier B, Caron C, Firmin JM: Les complications maternelles des césariennes. Resultats d'une étude multicentrique.

J Gynecol Obstet Biol Reprod 15: 327, 1986

Bowes WA, Taylor RS, O'Brien M, Bowes C: Breech delivery: Evaluation of the method of delivery on perinatal results and maternal morbidity.

Am J Obstet Gynecol 135: 965, 1979

BPA Report: International classification of diseases (ICD 9th rewision), Weatherall JAC, ed, The Britisch Paediatric Association, London, 1979

Brucht E: Zur Behandlung der Steislage. In: Brill EJ, ed. Handelingen van het Internat. Congres voor Verlosk. en Gynaec. , Amsterdam: 93-94, 1938

Braun FHT, Jones KL, Smith DW: Breech presentation as an indicator of fetal abnormality. J Pediatr 86: 419, 1975

Brenner WE: Breecli presentation. Clin Obstet Gynaecol 21: 511,1978

Brenner WE, Bruce RD, Hendricks CH: The characteristics and perils of breech presentation. Am J Obstet Gynecol 118: 700, 1974 
Camus $\mathbf{M}$, Lefebvre $\mathbf{G}$, Darbois $\mathbf{Y}_{\text {: }} \mathbf{L}$ a paralysie obstétricale du plexus brachial dans fa presentation du siège.

J Gynecol Otstet Biol Reprod 15: 1104, 1986

Caterini H, Langer A, Sama JC: Fetal risk in hyperextension of the fetal head in breech presentation. Am J Obstet Gynecol 123: 632, 1975

Chassin MR, McCue SM: A randomized trial of medical quality assurance improving physicians" use of pelvimetry,

JAMA 256: 1012, 1986

Chiswick ML: Commentary on current World Health Organisation definitions used in perinatal statistics.

Arch Dis Child 61: 708, 1986

Cibils LA: Clinical significance of fetal heart rate patterns during labor. I Baseline patterns.

Am J Obstet Gynecol 125: 290, 1976

Cibils LA: Clinical significance of fetal heart rate patterns during labor. V Variable decelerations.

Am J Obstet Gynecol 132: 791, 1978

Cibils LA: Fetal heart rate patterns during labor in breech presentations.

Seminar on 12th World Congress, Rio de Janeiro (Brasil), 23-27 october 1988 (Proceedings in press).

Clinch J, Matthews T: The obstetric management of the mature breech

In: Clinch J, Matthews T eds. Proceedings of the IX European Congress of Perinatal Medicine, Dublin, Ireland, 1984, MTP Press Limited, Lancaster: 213-217, 1984

Collea JV, Chein C, Quilligan EJ: The randomized management of term frank breech presentation: A study of 208 cases.

Am J Obstet Gynecol 137: 235, 1980

Collea JV, Rabin SC $\mathrm{S}_{y}$ Weghorst GR, Quilligan EJ: The randomized management of term frank breech presentation: Vaginal delivery vs. cesarean section.

Am J Obstet Gynecol 131: 186, 1978

Confino E, Gleicher N, Elrad H, Ismajovich B, David MP: The breech dilemma. A Review.

Obstet Gynecol Surv 40: 330,1985

Confino E, Ismajovich B, Sherzer A, Peyser RM, David P: Vaginal versus cesarean section oriented approaches in the management of breech delivery.

Int $J$ Gynaecol Obstet 23: 1, 1985

Cox C, Kendall AC, Hommers M: Changed prognosis of breech-presenting low bith weight infants. Br J Obstet Gynaecol 89: 881, 1982

Crowley P, Hawkins DF: Premature breech delivery - the caesarean section debate (Review).

J Obstet Gynaecol 1: 2, 1980

Cruikshank DP: Breech Presentation.

Clin Obstet Gynecol 29: 255, 1986

Cruikshank DP, Pitkin RM: Delivery of the premature breech.

Obstet Gynecol 50: 367,1977 
Davey DA, MacGillwray 1: The classification and definition of the hypertensive disorders of pregnancy. Recommendations submitted on behalf of the international society for the study of hypertension in pregnutucy at the 11 th World Congress of Gynecology and Obstetrics: West Berlin, 1985

Clin. and Exper. Hyper B5(1): 97,1986

DeCrespigny LJC, Pepperell RJ: Perinatal mortality and morbidity in breech presentation.

Obstet Gynecol $53: 141,1979$

Derom R: Het chemisch geboortetrauma.

Tijdschr Geneeskd: 4: 234, 1978

Derom R: The collection of basic perimatal data in a uniform way. A concerted action in the EEC.

Eur J Obstet Gynecol Reprod Biol 15: 303, 1983

Derom R, de Leeuw JPh, van Geijn HP, Thiery M, de Haan J, Odekerken D, van den Broecke R, MarIens $\mathbf{G}$, van Maele $\mathbf{G}$ : Breech presentation: comparative description of populations, obstetrical care and outcome in three university hospitals of Belgium and The Netherlands.

In: van Geijn HP, ed. Perinatal Monitoring. 3rd Progress Report. European Communities, Medical and Public Health Research, Spinhex BV, Amsterdan: 91-96, 1984

Deventer van, H: Manuale Operatien 1701, s'Gravenhage

Dijxhoorn MJ: Asphyxia at birth and neonatal neurological morbidity.

Thesis, University of Groningen, The Netherlands, 1986

Döring GK, de Sousa Gerbert Al: Zum Wandel der Beckenendlagenentbindung.

Geburtsh u Frauenheillk 48: 150, 1988

Donker DK, van Geijn HP, Derom R: Study of intervention strategies based upon cardiotocographic recordings.

In: wan Geijn HP, ed. Perinatal Monitoring. 4th Progress Report. European cormmunities, Medical and Public Health Research, Spinhex BV, Amsterdam: 51-53, 1985

Doyle LW, Rikards LA, Ford GW, Pepperell RJ, Kitchen W: Outcome for the very low birth-weight $(500-1499 \mathrm{~g})$ singleton breech: Benefit of cesarean section.

Aust NZ J Obstet Gynaecol 25: 259, 1985.

Duenhoelter JH, Wells CE, Reisch JS, Santo-Ramos R, Jiminez JM: A paired controlled study of waginal and abdominal delivery of the low birth weight breech fetus.

Obstet Gynecol 54: 310, 1979

Duisterhout JS, van Geijn HP, wan der Kool R: Data processing results from the first try-outs of collecting basic perinatal datia.

In: van Geijn $\mathrm{HP}_{\mathrm{P}}$ ed. Perinatal Monitoring 2rd Progress Report. European communities, Medical and Public Healith Research, Spinhex BV, Amsterdam: 38-47, 1983

Editorial comment Obstet Gynaecol Survey 36:244, 1981

Editorial comment Obstet Gynaecol Survey 38:608, 1984

Editorial comment Obstet Gynaecol Survey 41:633, 1986

Effer SB, Saigal S, Rand C, Hunter DJS, Stoskopf B, Harper AC, Mimrad C, Milner R: Effect of delivery method on outcomes in the very low birthweight breech infant: Is the improved survival related to cesarean section or other perinatal care manoeuvres?

Am J Obstet Gynecol 145: 123, 1983 
Eilen B, Fleischer A, Schulman H, Jagani N: Fetal acidosis and the abnormal fetal heart rate tracing: The term breech fetus.

Obstet Gynecal 63: 233, 1984

Ekker W: Presentatie in stuitligging: wijze wan verlossing en perinatale sterfte, 19691976.

Ned Tijdschr Geneeskd 123:235, 1979

Ennis MG, Kaude JV, Williams JL: Sonographic diagnosis of subarachnoid hemorrhage in premature newborn infants; a retrospective study with histopathologic and CT correlation.

J Ultrasound Med 4: 183, 1985

Eyk v. EA, Huisjes HJ: Neonatal mortality and morbidity associated with pretern breech presentation. Eur J Obstet Gynecol Reprod Biol 15: 17, 1983

Faber-Nijholt R: Breech presentation and neurological morbidity. A comparative study. Thesis, University of Groningen, The Netherlands, 1981

Faber-Nijholt R, Huisjes HJ, Touwen BCL, Fidler VJ: Neurological follow-up of 281 children born in breech presentation: a controlled study.

Br Med J 286: 9, 1983

Federle MP, Cohen HA, Rosenwein MF, Brant-Zawadxki MN ${ }_{4}$ Cann CE:

Pelvimetry by Digital Radiography: A low-dose examination.

Radiology 143: 733, 1982

Filanu S, Joelsson I: Minimal brain dysfunction in children born in breech presentation.

Acta Obstet Gynecol Scand 58: 295, 1979

Figo: List of gynecologic and obstetrical terms and definitions.

Int J Gynaecol Obstet $14: 570,1976$

Figo: Report of the FIGO committee on perinatal mortality and morbidity following a workshop on monitoring and reporting perinatal mortality and morbidity, Geneva, 1982

Fischer-Rasmussen W, Trolle D: Abdominal versus vaginal delivery in breech presentation.

Acta Obstet Gynecol Scand 46: 69, 1967

Flanagan TA, Mulchahey KM, Korenbrot CC, Green JR, Russell KL, Jr: Management of term breech presentation.

Am J Obstet Gynecol 156: 1492, 1987

Fortney JA, Higgins JE, Kennedy KI, Laufe LE, Wilkens L: Delivery type and neonatal mortality among 10,749 breeches.

An I Public Health 76: 980, 1986

Frenzel $\mathfrak{J}_{4}$ Krause $\mathbf{W}$, Sander 1 , Michels $\mathbf{W}$ : Zur Frühn und Spätmorbidität mindergewichtiger Neugeborener (LBWI) nach Beckenendlagen in Abhängigkeit vom Entbindungsmodus.

Z Geburtsh u Perinat 188: 261, 1984

Geirsson RT, Namunkangula R, Calder AA, Lunan CB: Preterm singleton breech presentation: the impact of traumatic intracranial haemorrhage on neonatal mortality.

J Obstet Gynaecol 2:219, 1982

Gimovsky ML, Paul RH: Singleton breech in labor: Experience in 1980.

Am J Obstet Gynecol 143: 733, 1982 
Gimowiky ML, Petrie RH, Todd WD: Neonatal performance of the selected term vaginal breech deliwery.

Obstet Gynecol $56 ; 687,1980$

Gimowsky ML, Wallace RL, Schifrin BS, Paul RH: Randomized management of the non frank breech presentation at term: a preliminary report.

Am I Obstet Cynecol 146: 34, 1983

Granati B, Rondinelli M, Capoti C, Carnielli V, Bottos M, Rubaltelli FF: The premature breech presentation: Outcome of newborn infants born by vaginal or abdominal delivery.

Am J Perinatol 1:145, 1984

Grant A: Do computers help or hinder the clincal evaluation of alternative treatments in perinatal medicine?

Am J Perinatol 2: 242,1985

Grant A: Randomised trial of preterm breech delivery.

Br Med J 293: 562, 1986

Green JE, MclLean F, Smith LP, Usher R: Has an increased caesarean section rate for term breech deliwery reduced incidence of birth asphyxia, trauma and death?

Am J Obstet Gynecol 142: 643, 1982

Greenland S, Neutra R: Control of confounding in the assessment of medical technology. Int J Epidemiol 9: 361, 1980

Haan de J: Cesarean delivery for breech presentation in The Netherlands.

Eur J Obstet Gynecol Reprod Biol 24: 96, 1987

Hall MH: When a woman asks for a caesarean section.

Br Med J 294: 201, 1987

Hill JG, Eliot BW, Campbell AJ, Pickett-Heaps AA: Intensive care of the fetus in breech labour. Br J Obstet Gynaecol 83: 271, 1976

Firsch HA, Nilehues U: Mütterliche Morbidität nach sectio: Einfluss von Infektionskontrolle und Antibiotikaprophylaxe.

Geburtsh u Frauenheilk 48: 1, 1988

Hochuli E, Dubler E, Bornhauser E, Schoop E: Die kindliche Entwicklung nach vaginaler und abdominaler Entbindung bei Beckenendlagen.

Geburtsh u Frauenheilk 37: 4, 1977

Hochuli E, Käch O: Die Beckenendlage.

Geburtsh u Frauenheilk 41: 23, 1981

Holland E: Cranial stress in the foetus during labour and on the effects of excessive stress on the intracranial conterts; with an analysis of eighty-one cases of torn tentorium cerebelli and subdural cerebral haemorrhage.

J Obstet Gynaecol Br Empire 29: 549, 1922

Hon EH, Quilligan EJ: The classification of fetal heart rate.

Connecticut Medicine 31: 779, 1967

Hoogeveen AJA: Breech presentations with special reference to their management with Bracht"s manoeuvre. Thesis, University of Utrecht, The Netherlands, 1956 
Huchcroft SA, Wearing MP, Buck CW: Late results of cesarean and vaginal delivery in cases of breech presentation.

Can Med Assoc J 125: 726, 1981

Hytten F: Breech presentation: is it a bad omen?

Br Ibstet Gynaecol 89: 879, 1982

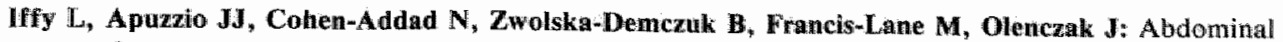
rescue affer entrapment of the aftercoming head.

Am J Obstet Gynecol 154:623, 1986

Ilagan NB, Liang KC, Piligian J, Poland R: Thoracic spinal cord (T3-T4) transection in breechpresenting, cesarean-section-delivered preterm infant.

Am J Perinatol 4: 233, 1987

Ingemarsson I, Westgren M, Svenningsen NW: Long-term follow-up of pteterm infants in breech presentation delivered by caesarean section; A prospective study.

Lancet if: 172,1978

Jaffa AL, Peyser MR, Ballas $\mathbf{S}$, Toaff $R$ : Managenent of term breech presentation in primigravidae. Br J Obstet Gynecol 88: 721, 1981

James LS, Yeh MN, Morishima HO, Daniel SS, Caritis NN, Niemann WH, Indyk L: Umbilical vein occlusion and transient acceleration of the fetal heart rate.

Am J Obstet Gynecol 126:276, 1976

Karp LE, Doney JR, McCarthy T, Meis PJ, Hall M: The premature breech: Trial of labor or cesarean section?

Obstet Gynecol 53:88, 1979

Kasule J, Chimbira THK, Brown IMcL: Controlled trial of external cephalic version.

Br: Obstet Gynaecol 92: 14, 1985

Kauppila O, Groenroos M, Aro P, Aittoniemi P, Kuoppala M:

Management of low birth weight breech delivery: Should cesarean section be routine?

Obstet Gynecol 57: 289, 1981

Kian IS: A study of breech presentation. Thesis, Airlangga University, Surabaya, 1962

Klopsterman GJ: On intrauterine growth.

Int J Gyn Obstet 8:895, 1970

Kopelman JN, Duff P, Karl RT, Schipul AH, Read JA: Computed tomographíc pelvimetry in the evalu. ation off breech presentation.

Obstet Gynecol 68: 455,1986

Kouam L, Werner-Spangenberg 1, Saling $\mathbb{E}_{\text {: Die }}$ kindliche Frihmorbiditat und clie Spattentwicklung nach primärer abdominaler Schnittentbindung bei Beckenendlage in Terminnähe.

Geburtsh u Frauenheilk 46: 609, 1986

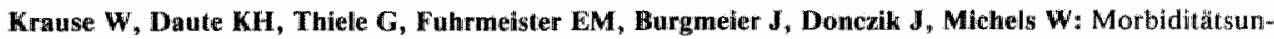
tersuchungen bei Beckenendlagenkindern nach vaginaler und abdominaler Geburt, bezogen aul reife und untergewichtige Kinder.

2. Geburtsh u Perinat 188: 80,1984

Krebs HB, Petres RC, Dunn LJ, Jordaan HVF, Segreti A: Intrapartum fetal heart rate monitoring. 1 Classification and prognosis of fetal heart rate patterns.

Am J Obstet Gynecol 133: 762, 1979 
Kubli F, Ruittgers H, Meyer-Menk M: Die fetale Acidosegefärdutig bei vaginaler Geburt aus Beckenendlage.

Geburtsh u Perinatol 179: 1, 1975

Kubli F: Indication of caesarean section: situation in the German Federal Republic.

In: Clinch J, Matthews T eds. Perinatal Medicine, MTP Press, Lancaster: 161, 1985

Kubli F, Boos W, Rütgers H: Caesarean section in the management of singleton breech presentation. In: Rooth G, Bratteby LE eds. Perinatal Medicine, Proceedings of the 5 th European congress of Perinatal medicine, Stockholm, Sweden, Almqvist and Wiksell: pp 69-75, 1976

Ladehoff P, Pedersen GT, Sorensen T: Apgar scores in low birth weight infants deliwered vaginally and by cesarean section.

Acta Obstei Gynecol Scand 65: 3, 1986

Leveno KJ, Cunningham FG, Pritchard JA:

Cerarean Section: An Answer to the House of Horne.

Am J Obstet Gynecol 153: 838, 1985

Lewis BV, Seneviratne HR: Waginal breech delivery or cesarean section.

Am J Obstet Gynecol 134: 615, 1979

Lieberman BA, Chiswick ML: Breech: vaginal delivery ar caesarean section?

Br Med J 285: 1657, 1982

Lomas $\mathbb{J}$ : Holding back the tide of caesareans.

Br Med J 298: 569,1988

Lowset J: Schulterentwicklung ohne Armlsung bei natürlichen und kunstlicher Beckenendlage.

Arch Gynaekol 161; 397, 1936

Low JA, Galbraith RS, Sauerbrei EE, Muir DW, Killen HL, Pater EA, Karchmar EJ: Maternal, fetal and newborn complications associated with newborn intracranial hemorrhage.

An J Obstet Gynecol 154: 345, 1986

Luterkort M, Marsăl K: Umbilical cord acid-base state and apgar score in term breech neonates.

Acta Obstet Gynecol Scand 66: 57, 1987

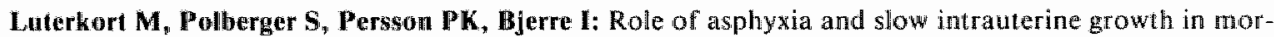
bidity among breech delivered infants.

Early Hum Dev 14: 19, 1986

LVR rapport: 5 jaar landelijke verloskunde registratie $1982-1986$

sig/ informatiecentrum voor de gezondheidszorg. Lunodruk. Houten, The Netherlands, december, 1987

Lyons ER, Papsin FR: Cesarean section in the management of breech presentation.

Am J Obstet Gynecol 130: 558, 1978

Main DM, Main EK, Maurer MM: Cesarean section wersus, vaginal delivery for the breech fetus weighing less than 1500 grams.

An J Obstet Gynecol 146: 580, 1983

Mann LI, Gallani JM: Modern management of the breech delivery.

Am J Obstet Gynecol 134: 611, 1979

Manzke H: Morbidity among infants born in breech presentation.

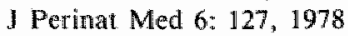


Manzke H: Breech delivery in the term fetus-relation to neuromotor dysfunction and mental handicap. In:Kubli P, Patel N, Schmidt W, Linderkamp O eds. Perinatal events and brain danage in surviving children.

Springer-Verllag Berlin: 192-201, 1988

Mauriceau, F: Traite des maladies des femmes grosses, et de celles qui sont accouchées, Paris 1668

MCDonald MM, Koops BL, Johnson ML, Guggenheim MA, Rumack CM, Mitchell SA, Hathaway WE: Timing and antecedents of intracranial hemorrhage in the newborn.

Pediatrics 74: 32, 1984

Mecke $\mathrm{H}$, Weismer D, Riedel H: Perinatale morbidität bei Beckenendlage-Kindern in Abhängitgkeit wom Geburtsmodus. Eine retrospektive Untersuchung.

Geburtsh u Frauemheilk $48: 41,1988$

Meuwissen JHJM, Reijnders FJL: Landelijke Verloskundige Registratie: bevalling in stuitligging.

Ned Tijdschr Geneeskd 129: 693, 1985

Moldin P, Hoekegard KH, Nielsen TF: Cesarean section and maternal mortality in Sweden 1973-1979. Acta Obstet Gynecol Scand 63: 7, 1984

Morales WJ, Koerten $\mathfrak{J}$ : Obstetric management and intraventricular hemorrhage in very-low-birtllweight infants

Obstet Gynecol 68: 35,1986

Müller A: Die extraktion der Schulitern.

Zbl f Gynaek 16: 550, 1921

Muth $\mathbf{H}_{n}$ Hannemann $\mathbf{H}$, Kropshofer H: Zur Frage der optimalen Entbindungsmethode bei der Beck. enendlage.

Geburtsh u Frauenheilk 36: 163, 1976

Myers SA: A new technique for flexion of the aftercoming head during breech delivery.

Am J Obstet Gynecol 155: 33, 1986

Myers SA, Gleicher N: Breech delivery: Why the dilemma?

Am J Obstet Gynecol 155: 6, 1987

Neilson DR: Management of the large breech infants.

Am J Obstet Gynecol 107: 345, 1970

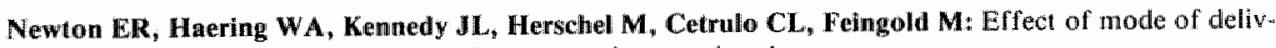
ery on morbidity and mortaiity of infants at early gestational age.

Obstet Gynecol 67: 507, 1986

NIH Consensus Development Task Force Statement on cesarean childbirth. National Institutes of Health. Published by United States Department of Health and Human Services. Public Health Serwice, National Institutes of Health, NIH Publication No. 82-2067, Oktober, 1981

Nilsen ST, Bergsjo P: Males born in breech presentation 18 years after birth. Acta Obstet Gynecol Scand 64: 323, 1985

Nisell H, Bistoletti $\mathbf{P}$, Palme $\mathbf{C}$ : Preterm breech delivery; early and late complications..

Acta Obstet Gynecol Scand 60: 363,1981

Notzon FC, Placek PJ, Taffel SM

Comparisons of national cesarean-section rates.

N Engl J Med 316: 386, 1987 
O'Connell P, Keane A: The term breech: subsequent growth and development.If: Clinch $J$ and Matthews T eds.Perinatal Medicine Section 8: Mankgement of breech delivery. Proceedings of the X European congress of Perinatal Medicine held in Dublin, Ireland, september $3 \mathrm{rd}-5 \mathrm{th}, 1984$. MTP press limited, Läncaster $34: 219,1984$

O'Leary JO: Vaginal delivery of the term breech.

Obstet Gynecol 53: 341, 1979

Olshan AF, Kirkwood KS, Lutthy DA, Hickok D, Weiss NS, Daling JR: Cesarean birth and neonatal mortality in very low birth weight infants.

Obstet Gynecol 64: 267, 1984

Painter MJ, Bergman I: Obstetrical trauma to the neonatal central and peripheral nerwous system.

Semin Perinatol 6: 89, 1982

Papille LA, Burstein J, Burstein R, Koffer $\mathbf{M}$ : Incidence and evolution of subependymal and intraventricular haemorrhage: A study of infants with birthweight less than $1500 \mathrm{~g}$.

J Pediatr 92: 529,1978

Patel N: Management of breech presentation.

Eur J Obstet Gynecol Reprod Biol 24:98, 1987

Paul RH, Koh KS, Monfared AH: Obstetric factors influencing outcome in infants weighing from 1001 to 1500 grans.

Am J Obstet Gynecol 133: 503, 1979

Perkins RP: Fetal Dystocia.

Clin Obstet Gynecoll 30: 58,1987

Pethti DB, Golditch IM: Mortality in relation to method of delivery in breech infants.

Int J Gynaecol Obstet 22: 189,1984

Petitti DB: Maternal mortality and morbidity in cesarean section.

Clin Obstet Gynecol 28: 763, 1985

Philipson EH, Rosen MG: Trends in the frequency of cesarean birthis.

Clin Obstet Gynecol 28: 691, 1985

Pinion SH, Mowat J: Preterm caesarean section.

Br J Obstet Gynaecol 95: 277, 1988

Polsson-Salomon AS, Breart G, Mallard F, Rabarison Y, Chavigny C, Sureau C, Rumeau-Rouquette

C: Can the number of cesarean sections be reduced without risk? An analysis of rates and indications in at university clinic.

Eur J Obstet Gynecol Reprod Biol 22: 297, 1986

Porreco RP: High cesarean section rate: $A$ new perspective.

Obstet Gynecol 65: 307,1985

Precht HFR: The neurological examination of the full term newborn infant. In: Clinics in Developmental Medicine, No. 63, 2nd, Heinemann Medical Books, London:1-65, 1977

Ridley WJ, Jackson P. Stewart JH, Boyle P: Role of antenatal radiography in the management of breech deliveries.

Br.J Obstet Gynaecol 89; 342, 1982 
Rosen MG, Bilenker MR, Thompson $\mathbf{K}$ : Assessment of developmental time periods of brain damage in the fetus and neonate.

J Reprod Med 31: 297, 1986

Rosen MG, Chik L: The effect of delivery route on outcome in breech presentation. Am J Obstet Gynecol $\Vdash 48: 909,1984$

Rosen MG, Debanne S, Thompson K, Bilenker RM: Long-term neurological morbidity in breech and wertex births.

Am J Obstet Gynecol 151: 718, 1985

Rovinsky JJ, Miller JA, Kaplan S: Management of breech presentation at term.

Am IObstet Gynecol 115: 497, 1973

Russell JK: Breech: vaginal or caesarean section?

Br Med J 285: 830, 1982

Ruth VJ, Raivio KO: Perinatal brain damage: predictive value of metabolic acidosis and the Apgar score. Br Med J 297: 24, 1988

Ryan GM: Cesarean section and breech presentations.

Am J Public Health 76: 962, 1986

Sachs BP, McCarthy BJ, Rubin G, Burton A, Terry J, Tyler CW.

Cesarean section risk and benefits for mother and fetus.

JAMA 250: 2157, 1983

Sadowski R, Staemmler HJ: Zum Einfluss der Beckenendlagengeburt auf die geistige und körperliche Entwicklung der Kinder.

Z Geburtsh u Perinat 178: 104, 1974

Schutte MF, van Hemel OJS, van de Berg C, van de Pol A: Perinatal mortality in breech presentations as compared to vertex presentations in singleton pregnancies: an analysis based upon 57819 computerregistrated pregnancies in The Netherlands.

Eur J Obstet Gynecol Reprod Biol 19: 391, 1985

Seeds JW, Cefalo RC: Breech presentation.

Clin Obstet Gynecol 25: 150, 1982

Serreyn R, Thiery M, Lybeer F, Derom R: Fetal hypoxia and breech delivery.

Int J Gynaec Obstet 11: 11,1973

Shiono PH, MeNellis D, Rhoads GG.

Reasons for the rising cesarean delivery rates:1978-1984.

Obstet Gynecol 69: 696, 1987

Silber TJ: Ethical and legal issues in perinatology.

Clin Perinatol 14: 318,1987

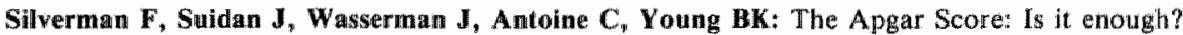
Obstet Gynecol 66: 331, 1985.

Smale LE, Guico MF, Ensminger CL: Difficulties in breech delivery.

Clin Obstet Gynecol 19: 587, 1976

Smellie WA: Treatise on the theory and practice of Midwifery, London, 1752 


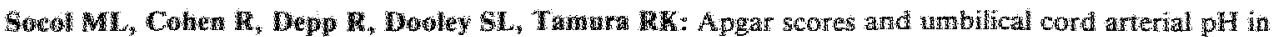
the brect reontate.

Int I Gynecol Obsted 27: 37, 988

Spencer IAD: Symphysurotony for waginal brech delivery: wo case reports.

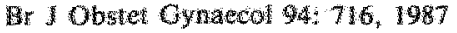

Standwithown mässion: Heckenerdilage.

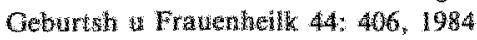

Stephenson MA: Changes in obstetric care in breech births.

J R Coll Gen Pract $36: 385,1986$

Swensingsen NW, Westgren M, Ingemarson I: Modern strategy for the term breech delivery; A study with a 4-yer follow-le of the infants.

2 Perinat Med 13: 117, 1985

Tatum $\mathrm{RK}$, Orr JW, Soong $\mathbf{S}$, Ifuddleston $\mathrm{JF}$ : Vaginal breech delivery of selected infants weighing more than 2000 grams.

An J Obstet Gynecol 152: 145, 1985

Tejani N, Verma $U_{\text {, ShIfman }}$, Chayen B: Effect of route of delivery on periventricular/intraventricular hemorrlwage in the low-birth-weight fetus with a breech presentation.

I Reprod Med 32: 911, 1987

Terry $\mathbf{B}$, Loyd DI: Randomised triats and intormed consent in neonatal medicine.

Am Med I 20:439, 1986

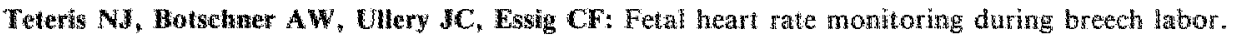
Am I Obstet Gynecol 107: 762, 1970

Thery M, Egmond van H, Deron R, Schryver de D, Kets van $\mathbf{H}$ : De geboorte in stuitligging. Tijdschr Geneeskd 4: 239-252, 1978

Treffers PE: The European collaborative trial on the early preterm breech delivery.

Eur J Obstet Gynecol Reprod Biol 24: 101, 1987

Varner WD: Management of labor in the primigravida with breech presentation.

Am J Obstet Oymecol 84: 876,1962

Varner MW, Cruikshank DP, Laube DW: Xwray pelvimetry in clinical obstetrics.

Obstet Giynecol 56: 296,1980

Verloove-Vanhorick SP, Verwey RA: Project on preterm and small for gestational age infants in the Netherlands 1983, at collaborative surwey. Thesis, University of Leiden, The Netherlands, 1987

Volpe JJ: Current concepts in neonatal medicine: Neonatal intraventricular hemorrhage.

N Eng J Med 304: 886, 1981

Waes van-van de Velde E, Waes van A: Ontwikkeling van de schouders bij gezonde stuitligging volgens the methode van Loviset.

Ned Tijdschr Geneeskd 54: 81, 1954 
Warenski JC: Management of breech presentation.

In: Rathi $M$ and Kumar $S$ eds. Perinatal Medicine: clinical and biochemical aspects, vol.1. Mc Grawhill, London: pp.61-68,1980

Watson WJ, Benson WL: Vaginal deliwery for the selected frank breech infant at term.

Obstet Gynecol 64: 638, 1984

Weinstein D, Margalioth EJ, Navot D, Mor-Yosef S, Eyal F: Neonatal fetal death following cesarean section secondary to hyperextended head in breech presentation.

Acta Obstet Gynecol Sicand 62:629, 1983

Weisbach von $\mathbf{W}$, Menzel $\mathbf{K}$, Wagner $\mathbf{F}$, Bratanoff $\mathbf{E}$, Jäger $\mathbf{K H}:$ Zur Morbdităt und Mortalität in den Jahren 1984-1985 aus Beckenendlage geborener Prämaturer mit einem Geburtsgewicht $\leqslant 1500 \mathrm{~g}$.

Eine prospektive Studie zur Fragestellung vaginaler oder abdominaler entbindungsweg.

Zbl f Gynack 108: 424,1986

Westgren M, Grundsell H, Ingemarsson I, Muehlow A, Svenningsen NW:

Hyperextension of the fetal head in breech presentation. A study with long-term follow-up.

Br J Obstet Gynaecol 88: 101, 1981

Westgren M, Paul RH: Delivery of the low birth weight infant by cesarean section.

Clin Obstet Gynecol 28: 752, 1985.

Westgren LMR, Songster G, Paul RH: Preterm breech delivery: Another retrospective study.

Obstet Gynecol 66: 481, 1985

Westin B: Evaluation of a feto-pelvic scoring system in the management of breech presentations.

Acta Obstet Gynecol Scand 56: 505, 1977.

Wheeler T, Greene K: Fetal heart rate monitoring during breech labor.

Br J Obstet Gynaecol 82: 208, 1975

White P: diabetes mellitus in pregnancy.

Clin Perinatol 1: 331, 1974

White PC, Cibils LA: Clinical significance of fetal heart rate patterns during labor. VII Breech presentations.

J Reprod Med 29: 45, 1984

WHO: Recommended definitions, termirology and found for statistical tables related to the perinatat period and use of a new certificate for cause of perinatal deaths.

Acta Obstet Gynaecol Scand 56: 247,1977

Wiegand JH: De Geboorte van de mers. vertaald door C. van Eldik, 1822 Amsterdam.

Wigglesworth JS, Husemeyer RP: Intracranial birth trauma in vaginal breech delivery: the continued inyportance of injury to the accipital bone.

Br J Obstet Gynecol 84: 684, 1977

William's Obstetrics 16th ed., edited by JA Pritchard and PC MacDonald, New York: AppletonCentury-Crofts, 1980.

William's Obstetrics 17th ed., edited by Prichard JA, MCDonald PC and Gant NF Norwalk, Conn,CT Appleton-Century-Crofts, 1985. 
Woods JR: Effects of low-birth-weight breech delivery on neonatal mortality.

Obstet Gynecol 53: 735,1979

Wright RC: Reduction of perinatal mortality and morbidity in breech deliwery through routine use of cesarean section.

Obstet Gynecol 14: 758, 1959

Yu VYH, Bajuk B, Culting D, Orgill AA, Asthury J: Effect of mode of delivery on outcome of very-lowbirthweight infants.

Aus Br J Obstet Gynecol 91: 633, 1984

Zatuchni GI, Andros GJ: Prognostic index for vaginal delivery in breech presentation at term. Am IObstet Oynecol 93: 237, 1965 


\section{Addendum 3.1}

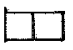

YEAR

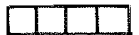

DEL.TVERY NUMBER

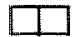

HOSPITAL NUMBER
Mother"s date of birth

Beight (cm)

Pregnanoy

Parity

Diabetes melytus

Chronic sypertension

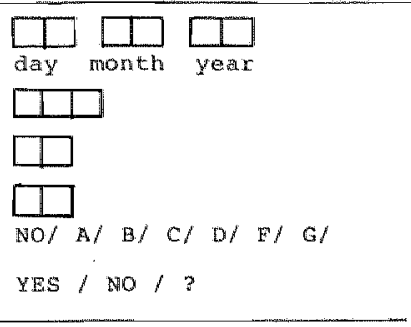

Date first prenatal vistit in oux hospital (weeks)

prenatial care

Wumber of prenatail visits

Diast blood pressure first 20 weeks ater 20 weeks

Protein excretion

i. fyes, max. value

Smoking habjts $(0 i g \cdot / d a y)$

Third trimester wgingl bleeding

Antopartum hosplal admiteance

if yes, totel number of days

Duration of pregnancy at time of delivery (werks)

Duration of pregnancy at lat echography (woeks)

$$
\text { B D D }
$$

comgenital mal tormationg unknowni

(g/1)

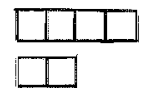

$\mathrm{Y} \mathrm{g}_{\mathrm{w}} / \mathrm{NO} /$ ?

HES $1 \mathrm{MO} / ?$
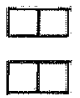

"CERTAIN"/BEST ESTIMATL
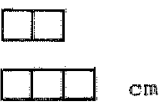

YES / NO 
Induetion

Adgramtation

Gemeral anaeshesi

Eplidura 1 andesthesia

Regional anát thesia

Analgetics-sedatives

Fupture of membranes

Method of rupture of membranes

Hyperextension of the fetal head

pesentation

Fetal 1 micro blood sampling

wectonic fetal monitoring

3

ar:

[as

$\rightarrow$

$H$

$\rightarrow$

[a]

D

Prolapse of umbilical cora

Meconium

Second stage

Umbilicug-to-delivery the

Fundal expression

YES / MO

YES / NO

YES / SBO

HES / MO

YES / NO

YES/ NO

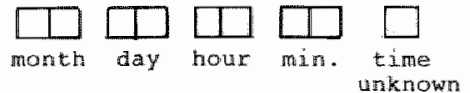
SPONTANEOUSLY / ARTIFICIALLY / DURTNG SECTIO CAESAREA

YES / NO F UNKWOWN

FRAKK $\square$ HON-FRANK

WES / No

YES / NO

YES / MO

YES / No

प min.

I sec.

YES / NO

Delivery

Q Spantaneous

$\square$ Primary cesarean section

D Secondary Cosarman Slection

$\square$ Mssisted bxeech

De snoo

Mauriceau / Veit-Smellie

7 Loviset

$\square$ Wan Deventer (mullex)

$\square$ corceps

$\square$ other

describe

Total breech extraction 
Moment of delivery

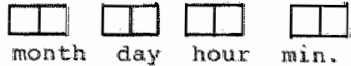

Cesarean section indication

$\begin{array}{ll}\text { Fetal } & \square \text { Dystocia } \\ \square \text { macental } & \square \text { Maternal }\end{array}$

Birth

Birth weight (gram)

Apgar-score 1. / $5^{\prime}$

pili a $/ v$

Transferred to neonital unit

if yes a date

Sex

Artificial ventilation

Buffexing with sodium bicarbonate

Intracrand l hemorrhage

Seizures

RDS

Menatal infection

it yes, which

Congenital mal formation

coae $1 \square T \square$

Birth tranga

if res, aescribe

Weurollogical examination

oltrasound of the brain

Discharge newborn

if newbon was transferred

Eariy reonatal death

$\{=\langle 7 \mathrm{~d}$. post partum $)$ born alive / born dead

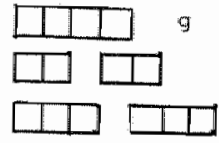

XES/ NO

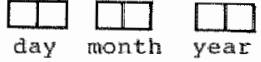

male / Female

none / with intubation /

without fintubation

YES / NO

YES / NO

YES / NO

YES / No

YES / NO

sepsis / meningitis / transplacental / others
Code 3

YES / NO
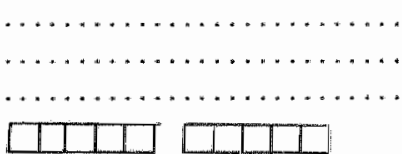

$Y E S / N O$

Abnornaliticg $\ldots \ldots \ldots \ldots \ldots$

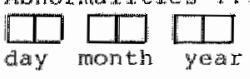

YES / NO 
4.

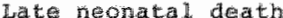
$(8-28$ d. post partint)

Date and hour of reonatal death

74TOSY

Catrse of death

a.s

$\sigma_{n}^{\prime \prime}$

a.

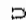

a.:
Matrinal mosbiaity

Ditacharge mother

Maternal. death
YES I 110

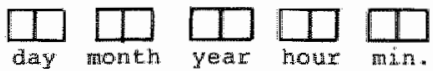

YEIS 19
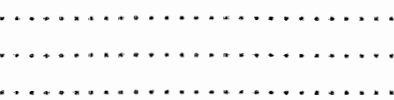

fener YES / ro duration in days $\square$ wound infection YES / NO localisation $\ldots$ urinary tract infection $\mathrm{XES}_{\mathrm{S}} / \mathrm{HO}$

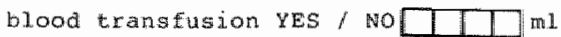

$\frac{\square}{\text { day }} \underset{\text { month }}{\square} \underset{\text { Year }}{\square}$

XES / nO

Varia (antibiotjcs given, ....... serious complications) 


\section{Addendum 3.2}

BREECA DELIVERY PROJECT

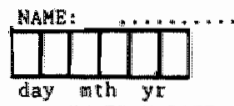

EXMAINATION DATE

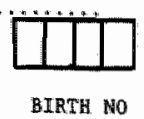

BIRTE NO
BIRTH DATE:

HOSPITAL CODE

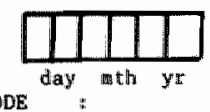

EXAK * MODE: ULTRASOURD:

CT SCAN :

\section{CLAASSIFICATTON OF NEONATAL INTRACRANIAL HABMORRHAGE}

INTRACEREBRAL

0 Grade 0 : Normal

- Grade I: Isolated Subependyat Haemor rhage (b)

0 Grade II : Subependyma $1 \mathrm{H}$. or choroid Plexus H.

- With inrraventricular $\mathrm{H}$.

- No ventrlcular dilatation

0 Grade III : Subependymal H. or choroid plexus $H_{\text {. }}$

- With incraventricular $H$.

- With ventricular dilatation

O Grade IV * Subependyal H. or choroid plexus $H$.

- Mith intraventricular $R$.

- Wth incraparenchymal $H$.

o Eortical

0. DIf Eusie

o Cerebellar

0. Brainstem

\section{EXTRACEREBRAL}

a Epidural

- Subdural

- Subarachnoid

* N.B. Ith consecutive examinations please note ouly the wost serious grade

REMARKS: 


\section{Addendum 3.3}

NEUROLOGICAI EXAMIMATION OF NEWEORIN INPANTS

$(1 / 2-6)$ case nimber Natane:

(7) $\operatorname{sex}$

Bith-date :

Date and time of exalnation :

(10-11) Bitth-weight:

(12-13) Lat feeding : lareast

bottlie:

mixed

nagial tube

intravenous $\mathbb{1 n f u s i o n :}$

(14) Body temperature:

(64) Environmental temperature:

(15) Drugis administered :

(16) Information from the nurse:

(17) Bdi.i rubin:

(18) Defaecation :

(19) Vomiting :

(20) Respiration afficulties :

(2i) Incubator :
Place of examination:

Name of examiner:

Term-date

(63)

gram, at $0^{\prime}$ clock

gram, at o'clock

gram, at $0^{\circ}$ clock

(65) Other laboratory data :

\section{SUMMARY}

Posture: (22) normal and symmetrioal

(2.) asymmetrical

(23) opisthotonus

(24) frog position

(25) arms predominantly :

flextion semiflexion extension

legs predominantly:

flexion

semif lexion

extension

\section{Mot1lity : normokinetic:}

(26) hyperktnetic: : +*

(27) hypokinette: $+*+$

Pathologleal movements:

(21) overshoot1ng movernents

(29) convulatons

(30) twitching face

Tremor: (31) intenste $y$ :

(32-33) frequancy:

(34-35) amplitude :

Clonus:
$(66-67)$ generalized :
isolated :
$(68-69)$ frequency :
$(70-71)$ amplitude : 


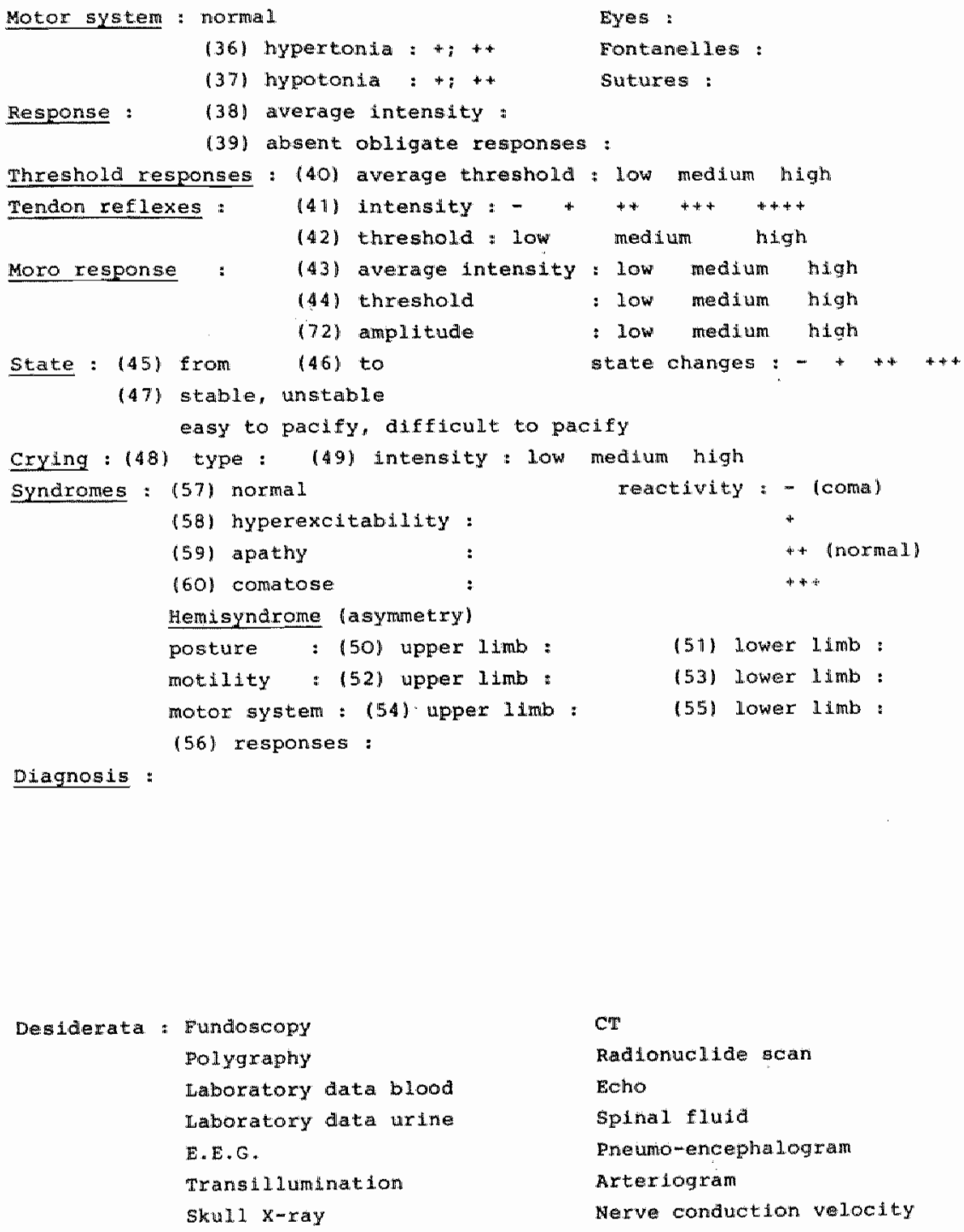

Diagnosis * 
Name of examinex:

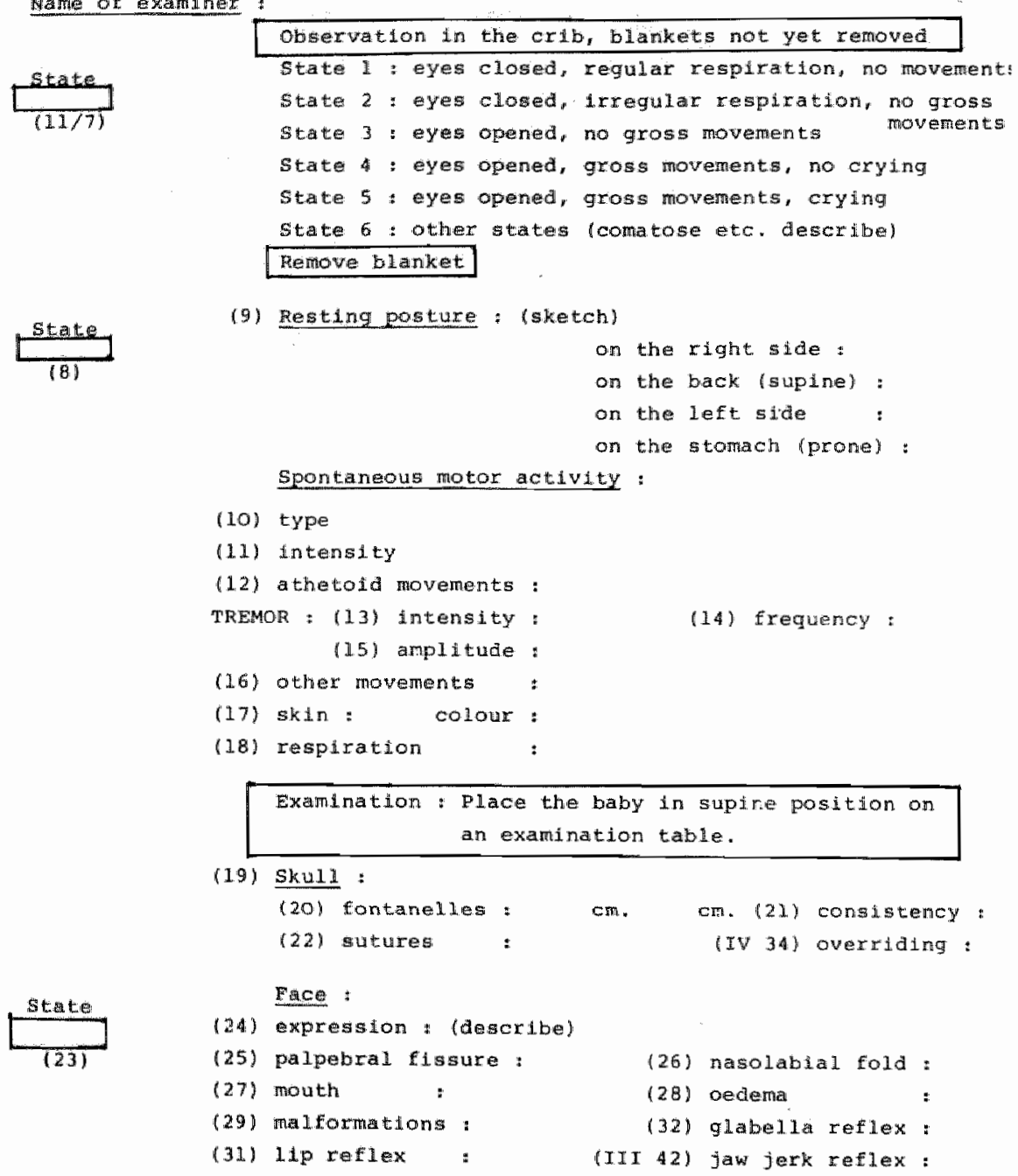


Undress the baby, placed in supine position on the examination

table, the head upright centered in the midine.

(34) Posture : (sketch ana describe)

Weck/trunk :

Arms :

Legs :

skin

(47) colour :

(48) turgor:

(49) abnoxmalities :

(50) temperature:

(51) respiration :

skin reflexes

State (53) abdominal reflexes :

symotry :

(52)

(54) cremater reflex:

(55) aral reflex:

Spontaneous motor ectivity :

State

(35)

136) type:

(37) speed

(38) intensity :

(39) amount :

(40) symetry : (41) athetodd movements

sticothness:

TREMOR (42) intensity :

(53) frequency :

(44) amplitudie:

State

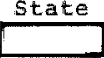

Eyes :

(56) position :

(5.7) sunset sign:

movements:

(59) nystagmus-horizont. :

(58) strabism :

-vertical :

State

PUPILS : $(60)$ shape :

(6.1) $520=$

(62) reaction to 1 ilght : airect:

Indirect :

(63) optical blink reflex :

$165)$ cornea reflex:

(64) acoustigal blink reflex : 
$-5-$

Keep the baby suspended in supine position, the head higher than the legs. Wait until he is quieted.

(69) Doll'g eye test:

put the baby back on the examination table.

\begin{tabular}{|c|c|c|c|c|c|c|c|c|}
\hline Torito & neck & reflex, & ispontaneous & to & the & riglet & * & arms \\
\hline *1" & *1 & , , & $n$ & $n$ & " & * & * & leg: \\
\hline * & :" & a & dmposed & $"$ & " & " & $:$ & artis \\
\hline$" n$ & a & $n$ & $n$ & $"$ & $n$ & $n$ & $:$ & legs \\
\hline Tonic & necik & reflex, & spontaneous & to & the & left & $:$ & axms \\
\hline t. & :i: & of & $a$ & $1 \dot{8}$ & " & " & $:$ & $\operatorname{legs}$ \\
\hline$n$ & it. & $: 1$ & Imposed & $"$ & "r & at & : & arms \\
\hline$"$ & " & 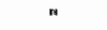 & "* & 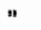 & ต & " & : & legs \\
\hline
\end{tabular}

Examination of the motox system :

\begin{tabular}{l|l|l|l} 
& $\begin{array}{l}\text { resigtance to passive } \\
\text { movements }\end{array}$ & $\begin{array}{l}\text { active } \\
\text { power }\end{array}$ & range of movenents \\
\hline Neck & 72 & III/7 & 15 \\
\hline Trunk & 73 & 8 & 16 \\
\hline Shoulders & 74 & 9 & 17 \\
\hline Elbows & 75 & 10 & 18 \\
\hline Hands & 76 & 11 & 19 \\
\hline Hilpg & 77 & 12 & 20 \\
\hline Knees & 78 & 13 & 24 \\
\hline Ankles & 79 & 14 & \\
\hline
\end{tabular}

(23) Limitation of passive movements in the hips:

(24) Recoil of the elbow:

(25) Musclle consisteney : 


\section{$-7-$}

Lay the baby down on his stomach

(65) Spontaneous movements of the hea :

State

163) Inspection and palpation of the vertebral columm:

(64)

(66) Crawing

1671 Baver's response:

168) Ankle jerk : threshold:

169) Incuryat lon of the trunk: threshold:

Keep the baby suspended in prone position

State

T70T

171) Posture of head and $\mathbb{l}$ imbs in suspension : (sketch)

\section{$-$}

$+*+$

Keep the baby upright, support mim with both hands under the shoulders and support the head with the thumbs.

Posture in vertical sugpension:

(73) Placing :

Standing :

174) stepping movements :

Rotation test : toward the right $(75)$ head free:

(76) head fixated :

(IV 39) nystagmoid movements:

toward the left 177 head free:

(78) head fixated :

(Tw bo) mystagmold moviemerats :

Put the baby in supine position on the examiration table

place the head centered in the midline

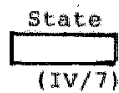

(8) Spantaneous motor activity :

(8) type

(9) speed

(10) intensity

(11) amount

(12) symuetiry"

(15) Erequency :

(13) athetolid movements :

"TREMOR : (14) intensity :

(16) amplitude : 
state

Postute when held in the examiner's arm:

$\begin{array}{lll}\text { Elexed } & \text { extended } & \text { hyperextended } \\ \text { Eloppy } & \text { smootin } & \text { stiff }\end{array}$

Crying:

(26) type :

(27) intensity :

(28) duration (each cry) :

(29) amount :

132) Head circumiference :

(33) Body length (crown - toe) :

Remarks. :

Edition 1979

Dept. of Dew "Neur 


\section{Addendum 3.4}

PROUECT MRERCA DFA.TVERTES

\section{Hewrologite examination of the mentorn}

Partus number:
Name
sex
Date of blrth:
Age

Date and time of examimation:

Place of examination:

Name of examiner:

\section{Infant dxessed}

posture
spontaneous motor activity:
athetoid - tremors - convulsiong - asymul/abnomal-describe.........

athetoid - tremors - convulsions - asyrmetric

\section{Suppine position}

obserwation skul 1 and face

lip reflex

jaw reflex

glabelila reflex

\section{Infant undressed}

- Supine position (on the back) poesture

spontaneous motor activity

abdoninal raflex (skin)

cremster reflex

and reflex

- Eyras

obaervation

puplins

light responste:

blink reflex

mooustic blink reflex nonnal/abnamal-describe........ yes/no/abnommalities

yes/no/abnommilities

yes/no/abnormalities

nomal/abnomal-ciescribe . . . . . . . . . . . yes/no/abnomalities

yes/no/abnomal ities

yes/mo/abnomal lt les

yes/no/abnomal lties

nomal/abnormal-desacribe. . . . . . . . .

nomal/abnomal-describe..........

yes/no

yes/no

yes/no 
- Supine suspension.

asymetries

Hoppy ans

Doll.'s eye test

tonic neck reflex no/yes-describe. .......... *

no/yes

positive/negative

yes/no-describe. . . . . . . . . .

- Tonus

resistanoe to passive movenents nomal/abnomal-describe . . ........

range of movenments

normal/abnomal-degcribe + . . . . . . . . . . .

neck

hips

nomal/abnormal-desscribe n . . .........

nomna 1 /abnomal-describe . . . ........

knees:

nomal/abnomai-describe...........

recoil of the fore-arm at the elbow normal/abromail-aescribe..........

muscular consisitency

nomal/abnonnal-deseribe..........

- Reflexes and responises

biceps jerk

yes/ro/annomalities

knee jerk

yes/no/abnomalities

ankle clionus

yes/no/abnomalities

palinar grasp

yes/no/abnomalities:

plantar grasp

Babinski

magnet reflex

withdrawal reflex

sucking reflex

yes/no/abnomalities

yes/no/abnomalities

yes/no/abnomalities

yes/no/abnomalities

yes/no/abnommalities

traction test (head lag)

control of head movements

during sitting posture

present/absent-describe.

Mroo (dnop)

describe..........

yes/no

- Prone position (on the stomach)

head movenents

nonmal/abnormal-dederibe . . . . . . . .

crawling

Bater' 's response

yeas/no

yes/no

Galant' response

yos/no

posture of head and limbs

nomal /abnomv1-desscr ibe . . . . . . . 
- Upright position placing teeponse

(exige remponse)

stefping

yes/no/abnomelitises

rotation kest - head tree yes/no/ahnomalities

mear hell

yes/no/abromalities

$\mathrm{cry}_{\mathrm{Y}}$

yes/no/dinomalities

yes/no/abromalities

Hexd circunference

Diagnosif:

Reminx: 


\section{Addendum 3.5}

\section{CLASSIFICATION NEUROLOGTCAL MBWORHALITIES AFTER BIRTH}

pasture: ahnorma1: opist hotonus (3)

frog posture (3)

asymetry (3)

predominant extension of armis (3)

legs (3)

flexion of ant (3)

forced tum of the head (3)

Notility:

hypokinetic (4)

hyperkinetio (4)

Pathological Movernent:

rapid (4)

overshooting (4)

tremors (4)

contulstions (4)

Tonus:

hypertonia (3)

hypotonila (3)

Responses:

absent (2)

treshold: low (2)

hinght (2)

medilum (2)

Tendon Reflexes: low (2)

mexilu (2)

high (2)

MORO: $\quad$ IOW (2)

high (2)

medium (2)

Crying: high pitaned (4)

Hemi-gyndrame: present (1)

Abnomal Reactivity:

hyperexcitable (2)

apathetic (2)

comatose (2)

1) Henisynarcme

2) Syndrames of abnomal reactivity

3) Abnomal posture (incremed or decreased tomis?

4) Abnonnal spontanoous behavior 


\section{Addendum 3.6}

Follow-up examination aftex one year

Historin taling

Development

Rolls from suptre to prone (5-6 months) :

Sits without aupport (6-7 monthe) :

Pulls self to stand (10 monthss) :

Walks with support (1.2 months) :

Walks wilthoul support (no help) (18 months) :

Initateg apeech sounds (B months) :

Responds to sounds at home :

Comprehends what people say :

carries out instructions :

Histon of diseagey:

Cenera 1 examination

Feacling state :

Hydration state:

colcurr.

Consciousness :

Welight: :

:It:

length: $\quad$ head circumference:

cor

:

Pullmones :

Abolamen :

hepar :

1.jen :

Genitals : 
Nanologicai exantination

Posture and spontameous

mentment:

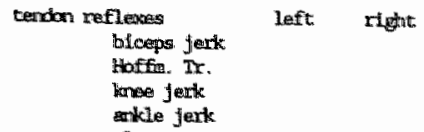

plantar response

cone:

imuxing

doll's aype response

fixating. following

blisk reflex

rooting reflex

sucking reflew

saut reflex

pabmontal raflex

comeo-mindibular red Lex

slavering

palmat grasp neflex

intenked grasping

bringyng ajoct to rorutt

transferring object from

thand to hand

throwing asy an object

firner then appositallax

toorer buildiry

coptes

Moro reflex

herad lag.

head balince

asyminetricul contic nock refelx

rolls frum prone to stplese

twetile plesement reflex

of the hand

optinical placement: reflex

of the hand

parachate reaction

sittiting

Landas reflex

plantur grasp refletix.

tacclle placenent fillex

of the foot

cotelcal placenent of the foot

lieg istrialightentures rester

wallotog reflex

stardisg hold on to boo

wiking

bellance on 1 foot / standile

cin one foot

hasplitit

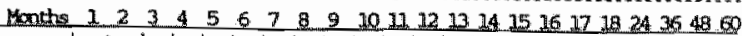

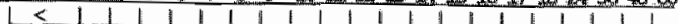

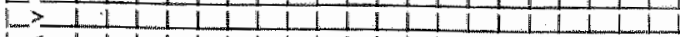

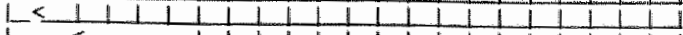

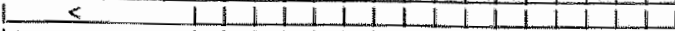

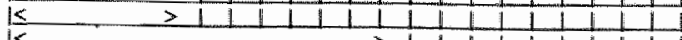

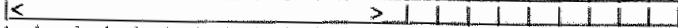

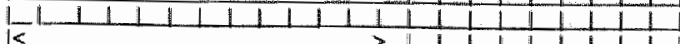

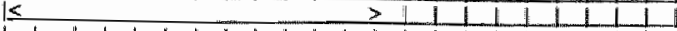

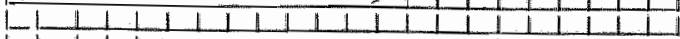

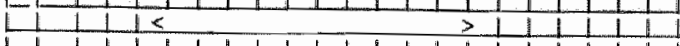

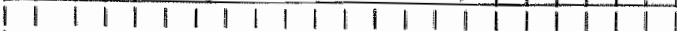

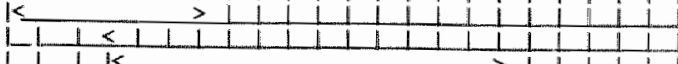
$1-1 / 1<>11$

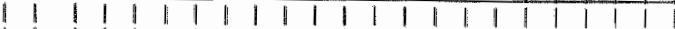

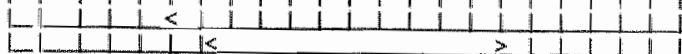

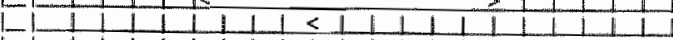

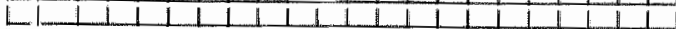

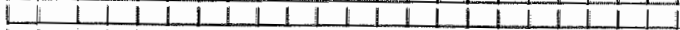

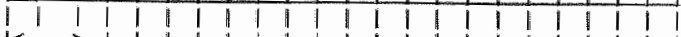

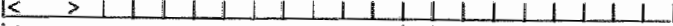

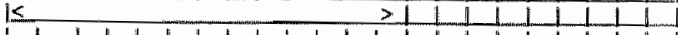

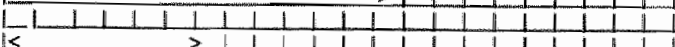

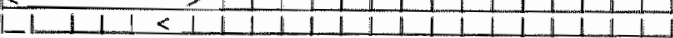

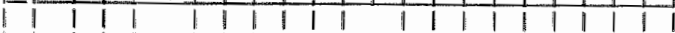

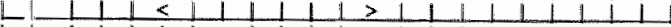

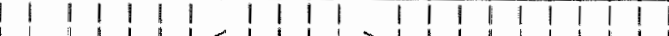

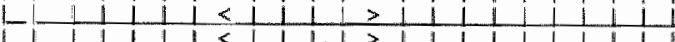

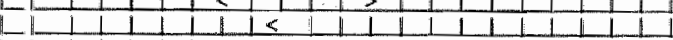

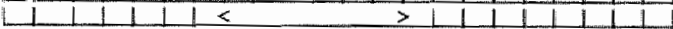
$1|1| 1|1| 1|1| 1 \mid 11111$ $1<$

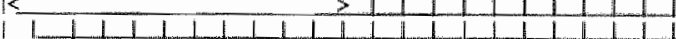

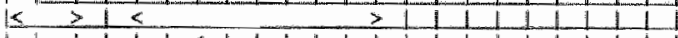

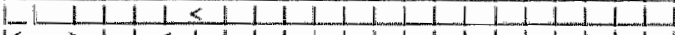

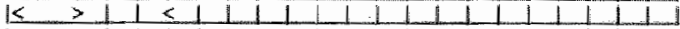

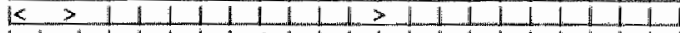

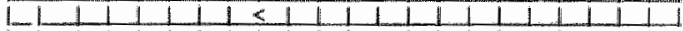

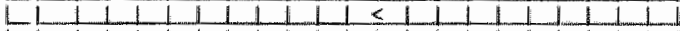

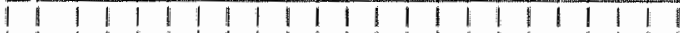

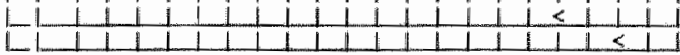


Met dank aan:

Schering BV

Cilag NV

Roussel BV

Pie Data Medical

Organon Nederland BV

Hewlett Packard Nederland BV

Wellcome Nederland BV

Sarva Syntex Nederland BV 


\section{Curriculum}

The author of this thesis was born on August 28, 1951, in Amsterdam, The Netherlands. He attended secondary school (Gymnasium B) at the 'Boschveld College' in Venray, where he graduated in 1971. In that year, he went to Medical school at the University of Leyden and graduated in 1979. In 1980 he started his general practioner training at the University of Leyden, where he graduated in 1981 . In 1982 he worked as a resident in the department of Obstetrics and Gynaecology at the 'Bronovo hospital' in the Hague.

In December 1982 he started his obstetrical and gynaecological training at the University of Limburg in Maastricht and at the 'De Wever' hospital in Heerlen. In 1988 he was registered as a gynaecologist. At this moment he is working as a gynaecologist at the 'Merwede' hospital in Dordrecht. 